\title{
Incremental Strategies for Achieving Suburban Densification
}

\section{Tegan Wardle}

A 120-point thesis submitted to the Victoria University of Wellington in partial fulfilment of the requirements for the degree of Master of Architecture (Professional)

Victoria University of Wellington

School of Architecture 
I would like to thank my supervisor Guy Marriage, my friends and my family for your continuous support and encouragement throughout this process.

Guy, thank you for all the stream meetings, your experience and expertise has been invaluable to my work.

Georgi, Joelle and Philippa, thank you for all the welcome distractions, smiles and laughter this year.

Mum and Dad, thank you for always believing in me and making sure I have everything I need to do well. 


\section{CONTENTS}

ABSTRACT AND INTRODUCTION

CHAPTER 1: Incremental Architecture

5

CHAPTER 2: Modular Architecture

27

CHAPTER 3: Site Selection and Analysis

55

CHAPTER 4: Site Responsive Massing

67

CHAPTER 5: Design Development

101

CHAPTER 6: Final Design Proposal

123

CHAPTER 7: Conclusion

143 



\section{ABSTRACT}

\section{Background}

Sprawling, car related development dominates and destroys natural landscapes and productive farm land at the edges of urban centres. Yet, suburbs continue to grow outwards to meet New Zealanders' preferences for stand-alone housing and keep up with increasing housing demand, while existing dwellings are demolished to make way for new developments.

\section{Research objectives}

This research aims to investigate the implications of building dwellings incrementally to achieve gradual densification within New Zealand suburbs, reducing the need for green field development, and slowing urban sprawl. The objective of this research is to determine how incremental housing strategies could enable suburbs to continue to grow, however in density rather than sprawl, through the design of accessory dwelling units that can be added to existing sites and developed over time.

\section{Research method}

Built and proposed incremental housing projects are reviewed to determine existing strategies and their suitability for creating buildings that are able to grow over time. Literature is reviewed to identify current preferences and priorities for suburban living, strategies for sustainable suburban development and current provisions within district plans for achieving denser suburbs. Siteless and site responsive architectural strategies for incremental accessory dwelling units are developed through iterative massing and plan studies to generate a wide range of potential solutions at each stage of development, continually reflecting on and progressing with the most successful options.

\section{Potential Implications}

The development of spatial strategies for incrementally built accessory dwelling units that could facilitate long term densification in the New Zealand suburban context while reducing the need for the demolition and redevelopment of existing residential sites. 


\section{INTRODUCTION}

\section{THE IDENTIFIED PROBLEM}

Sprawling development dominates and destroys natural landscapes and productive farm land at the edges of urban centres, as well as increasing reliance on private vehicle transport and vehicle miles travelled (Dedek, 2014). Yet, in New Zealand, suburbs continue to grow outwards requiring the development of green field sites to keep up with population growth and the overwhelming demand for stand-alone housing compared to higher density alternatives (Bryson, 2017).

Historically, and still prevalent today, New Zealanders have aspired to the 'quarter-acre dream', desiring stand-alone housing on private land (Bryson, 2017). A 2017 survey found respondents to perceive higher density settlements as less safe, less visually appealing, less value for money, less able to provide a good sense of community and less able to provide an enjoyable lifestyle (Bryson, 2017). In addition to this, the study found NIMBYism as a challenge for higher density housing, with participants reporting objections to having new housing with increased density built on their street (Bryson, 2017).

Despite these attitudes, housing pressure has caused a surge in construction of medium density housing (Bryson, 2017), often achieved through the demolition and redevelopment of lower density sites (Gray Partners Ltd, 2014). The increased density of these sites must be weighed against the energy, resource and waste cost of demolition and redevelopment, contributing to an industry that is estimated to be responsible for $40 \%$ of energy use, $30 \%$ of greenhouse gas emissions and 136 million tonnes of waste annually (Yung \& Chan, 2012). In New Zealand this issue may be more significant, with evidence suggesting construction and demolition waste represents up to $50 \%$ of waste sent to landfills and almost all waste sent to cleanfills, totalling to approximately 1.7 million tonnes annually (REBRI, 2014).

\section{THE PROPOSED SOLUTION}

The sustainable development of cities must aim to meet present and immediate needs, without compromising the ability to meet changing and uncertain needs in the future (Coyle, 2011). Such needs are inclusive of environmental, economic, social and cultural aspects, requiring development strategies to consider the natural environments, resource use, economic vitality, community self-reliance, generational equity and individual wellbeing (Yung \& Chan, 2012).

The usefulness of buildings within urban centres contributes to the amenity of public and reduces the need for peripheral, car related development (Dedek, 2014). Therefore, by redirecting growth inward, through densification rather than sprawl, centrally located neighbourhoods can be made more useful and desirable places to live (Dunham-Jones \& Williamson, 2008). This can be achieved most successfully in underperforming areas where infrastructure is already in place, most significantly depending on proximity to public transport (Dunham-Jones \& Williamson, 2008). Densification of such areas not only ensures accommodation of population growth, but also access to a desirable public realm, with a mix of uses within walking distance (Dunham-Jones \& Williamson, 2008).

To address the issue of resistance to increased density, research into urban design has identified the importance of time as a dimension in design. Despite the inevitability of change in the urban environment, fast paced change can be distressing (Carmona, Heath, Oc, \& Tiesdell, 2010). Alternatively, slow paced, incremental change is seen as comfortable and acceptable (Carmona et al., 2010). Change in the urban environment is therefore recommended to be moderated, avoiding comprehensive redevelopment, to prevent dislocation and preserve continuity with the past (Carmona et al., 2010).

Strategies to increase density should therefore fit around existing dwellings and be designed in a manner that allows for incremental increases in density over time. One way this may be achieved, which will be further explored by this research, is through the implementation of accessory dwelling units (ADUs) within existing residential sites. This will not only contribute to the coherence and familiarity of the suburb, but will also ensure minimal demolition waste is created to achieve higher density on already occupied sites within existing suburbs. 


\section{RESEARCH QUESTION \\ How can incremental strategies be used to densify our existing suburbs?}

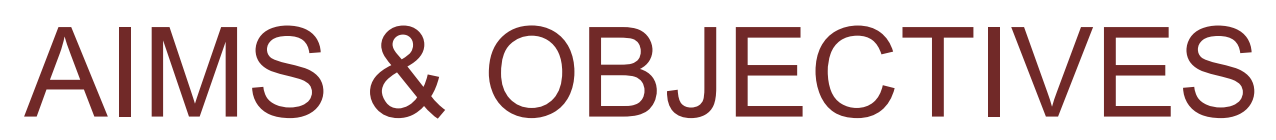

This research aims to address the issues of housing shortages and suburban sprawl in New Zealand by proposing a strategy for increasing the utilisation of land within existing suburbs by adding accessory dwelling units (ADUs) to existing residential sites, without the need for the demolition of existing buildings. The research aims to determine how incremental housing strategies could enable Wellington suburbs to increase in density gradually by adding and expanding accessory dwelling units incrementally over time. To achieve these aims, the following objectives should be met:

1. To determine appropriate incremental growth strategies for ADUs within the Wellington suburban context

2. To identify suitable sites in Wellington for sustainable densification through the implementation of ADUs

3. To develop ADU designs that meet current preferences and priorities for housing in New Zealand

4. To develop spatial strategies for the ADUs to be incrementally built and expanded to densify Wellington suburbs gradually

\section{METHODOLOGY}

Key precedents are identified through the review of incremental housing projects that have been built or proposed internationally to determine possible spatial strategies that allow dwellings to grow over time.

This is used to inform initial design explorations for accessory dwelling units that could be built incrementally.

Literature is then reviewed to identify current needs and constraints for denser suburban living. This is analysed in terms of people's preferences and expectations, sustainable suburban development and the current provisions for densification within New Zealand planning rules. This literature review is used to inform priorities, restrictions and criteria for site selection and further design development.

Based on initial precedent and literature review, siteless and site responsive architectural strategies for incremental accessory dwelling units are iteratively developed. This has been done primarily through iterative massing and plan studies, focussing on the systematic generation and analysis of a wide range of potential solutions at each stage of development. The most successful options are selected at each stage, to be progressed and developed further in the design process. A final scheme for an accessory dwelling unit is then developed and detailed based on the integration of the successful design strategies identified. 


\section{WORKS CITED}

Bryson, K. (2017). The New Zealand Housing Preferences Survey: Attitudes towards medium-density housing (SR378). Retrieved from Judgeford: https://www.branz.co.nz/cms show download. php?id=9aa2011337f7e6cebc169d4ac4c711d721b7e938

Carmona, M., Heath, T., Oc, T., \& Tiesdell, S. (2010). Public Places - Urban Spaces : The Dimensions of Urban Design. Retrieved from Boston:

Coyle, S. J. (2011). Sustainable and resilient communities: A comprehensive action plan for towns, cities, and regions (Vol. 15): John Wiley \& Sons.

Dedek, P. B. (2014). Historic Preservation for Designers. New York: Bloomsbury Publishing Inc.

Dunham-Jones, E., \& Williamson, J. (2008). Retrofitting suburbia: urban design solutions for redesigning suburbs: John Wiley \& Sons.

Gray Partners Ltd. (2014). Commercial Drivers for Medium-Density Residential Development in Selected Wellington Suburbs Retrieved from Wellington: https://wellington.govt.nz/ /media/your-council/projects/files/housing-choice-supply/medium-density-housing/commerical-drivers-mdra-development. pdf?la=en

REBRI. (2014). Waste Reduction - CONSTRUCTION. Retrieved from https://www.branz.co.nz/cms_show download.php?id=5e8633f5234594b316612f186e49687aff5475dd

Yung, E. H. K., \& Chan, E. H. W. (2012). Implementation challenges to the adaptive reuse of heritage buildings: Towards the goals of sustainable, low carbon cities. Habitat International Volume 36, Issue 3 , 352-361. 


\section{CHAPTER 1: INCREMENTAL ARCHITECTURE}




\section{INTRODUCTION}

This chapter explores how incremental building processes can be used to create dwellings that grow over time, identifying key spatial strategies employed in precedent projects internationally. Learnings from a review of these precedents are then applied to initial concept design explorations of small scale infill dwellings that are able to grow over time within common pieces of underutilised land in Wellington suburbs. 
KEY PRECEDENTS 


\section{BOUNDED EXPANSION}

\section{Housing that allows expansion within fixed spatial boundaries}

\section{ELEMENTAL - HALF A GOOD HOUSE}

Elemental's social housing projects utilise incremental construction, through which the architect delivers part of the finished house that the inhabitants are able to complete and expand over time as resources allow (fig. 1-2) (Aravena \& lacobelli, 2012). This allows the settlements to densify over time while also allowing for the customisation of each dwelling to suit individual family needs and preferences (Aravena \& lacobelli, 2012). Elemental aim to design and provide the most difficult and most essential parts of the house, ensuring the initial house meets all basic needs of inhabitation and that the remaining expansions can be achieved by the occupants without further architectural advice (Aravena \& lacobelli, 2012). The initial form of each building typically consists of half a house encased in a "porous structure that works like a support", separating and framing space for future expansions to fill (Aravena \& lacobelli, 2012, p. 492).
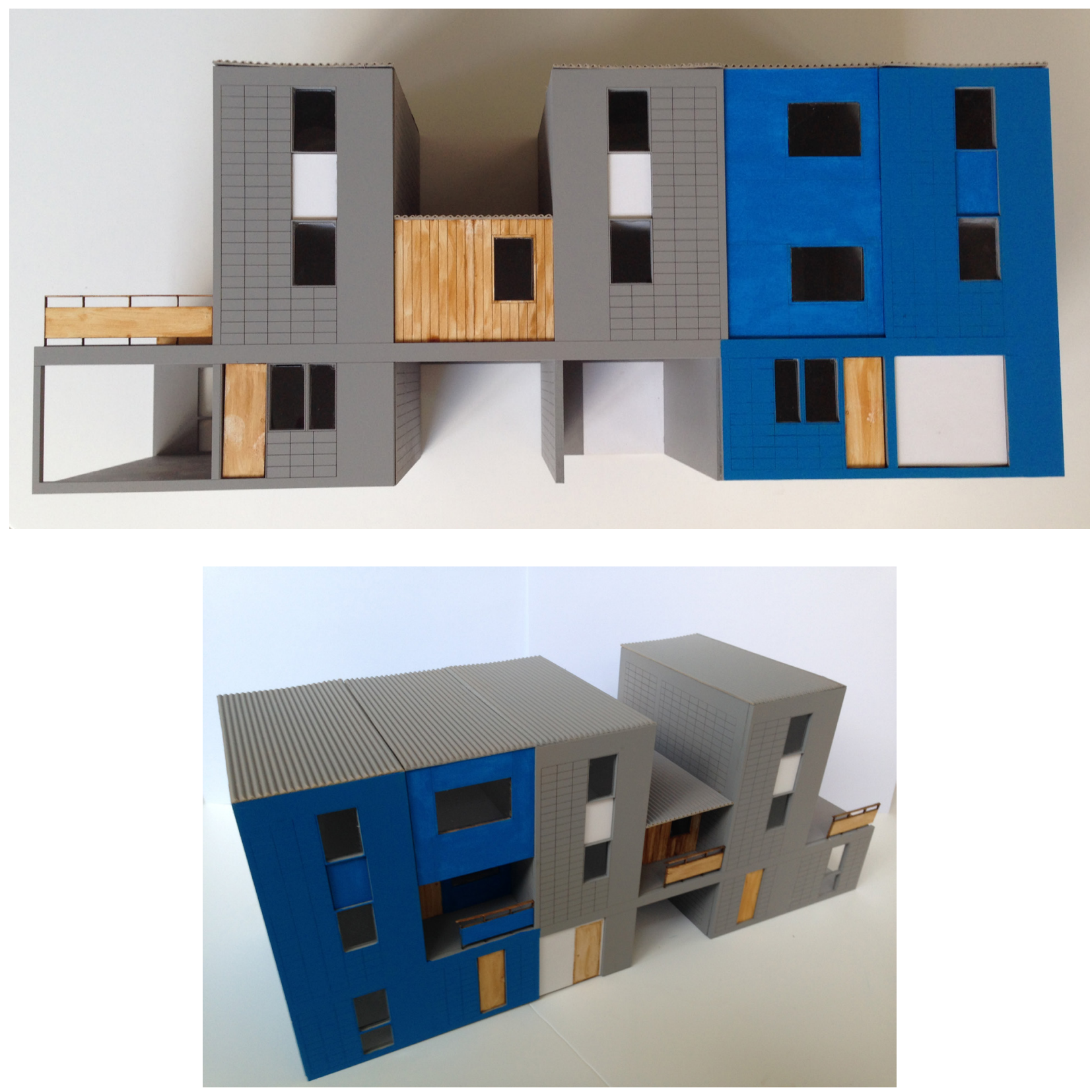

Figure 1. Author's model of Elemental's first incremental social housing project in lquique, Chile. Shown at various stages of inhabitant expansions. 


\section{ASSEMBLE - INTERIOR DEVELOPMENT}

A key incremental project produced by Assemble is a proposal for flexible and affordable housing, developed in collaboration with elderly activists Stille Strasse and exhibited at the Wohnungsfrage exhibition in 2015 (fig. 3) (Assemble, 2015). The scheme proposes 20 empty apartment shells, sitting above a shared space featuring a workshop, shared kitchen, shower block and storage (Assemble, 2015). Each apartment is made up of two distinct spaces separated by a soundproofed wall (fig. 3), allowing one side to be owned by the occupant (the 'house' half) and the other to be rented from the building co-op (the 'garage' half) (Assemble, 2015). The 'house' half is completed by the occupant first, using the workshop facility within the building, and the 'garage' half becomes slack space to be used by the occupant as storage, or to be later completed to extend the apartment (Assemble, 2015). The 'garage' half is able to be returned back to the co-op, as children leave home or downsizing is necessary, to be offered as extra space to neighbours or to be rented to new occupants as another one bedroom apartment (Assemble, 2015).
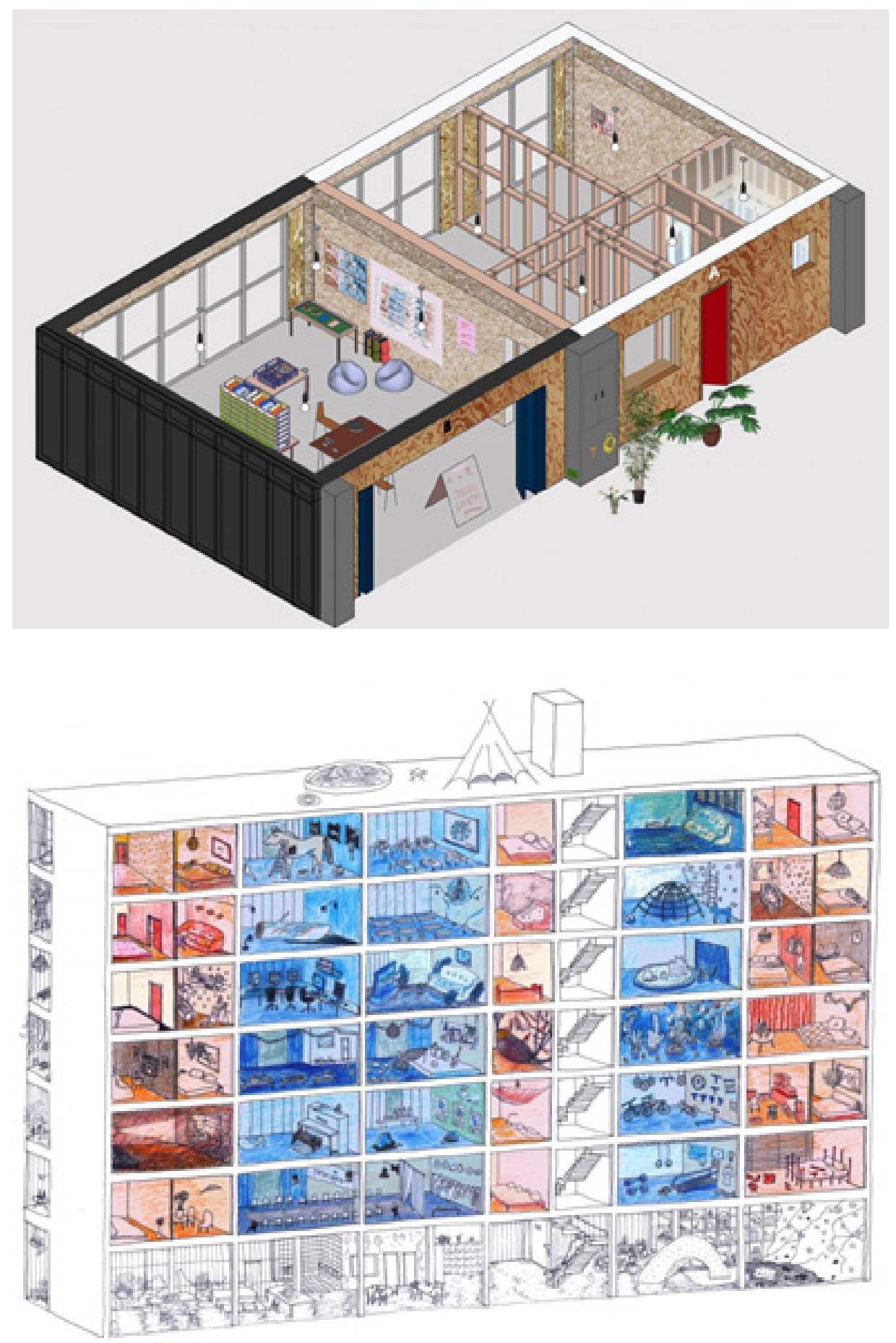

Figure 2. Stille Strasse incremental apartment concept (Assemble, 2015). Image courtey of Assemble. 
Assemble have also designed and built a prototype coworking space in London that offers affordable and adaptable work spaces for artists and designers engaged in practical work (Assemble, 2014). Incremental processes are seen within the interior of the building, as individual workspaces are merely demarcated through the structural columns, allowing occupants to add their own partitions (Assemble, 2014).

Occupants are able to enclose their units to achieve desired levels of privacy and also have the opportunity to expand into adjacent units (Assemble, 2014).
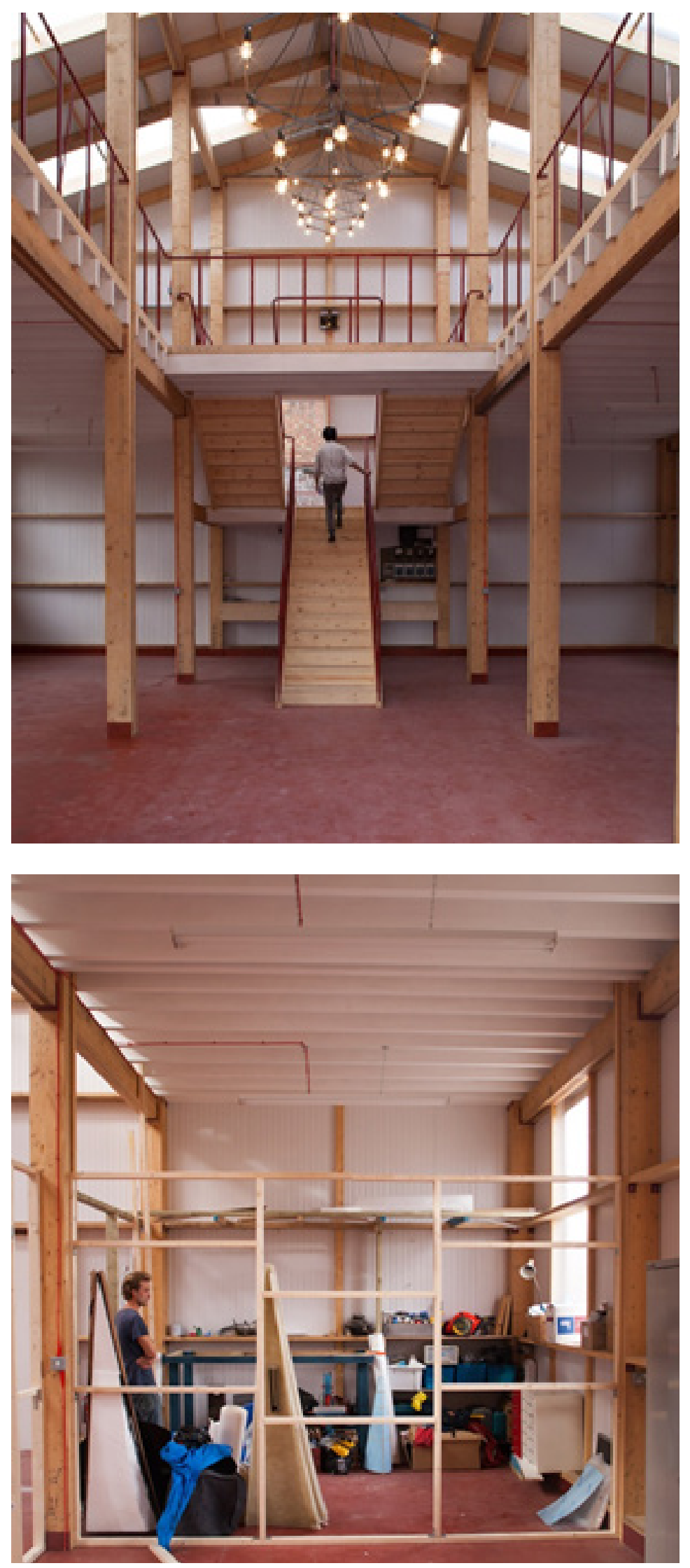

Figure 3. Yardhouse coworking maker space in London (Assemble, 2014). Image courtesy of Assemble. 
The winner of the 2017 "Build to Grow" social housing competition proposed to locate 120 incremental homes on the 3.7 hectare plot of land in lquitos, Peru (Bayona, 2018). The incremental homes consist of a central 'nucleus' that contains the kitchen and bathroom, accommodating all water and drainage and the main electrical network (Bayona, 2018). Surrounding the nucleus, the house can expand in all directions, limited by the overall footprint of the floor and roof (Bayona, 2018). The expansion phases are proposed to be modular, permitting occupant choice of material and finish (Bayona, 2018).

\section{BALESTRA \& GÖRANSSON - HALF A GOOD HOUSE}

Filipe Balestra and Sara Göransson were invited by SPARC, an NGO in India focused on the urban poor and the development of the city, to develop an Incremental Housing Strategy that could be implemented in Indian slums (Basulto, 2009). This required the architects to develop strategies with communities that could be extended over time without further input from architects (Basulto, 2009). The existing urban forms and organic patterns of development are respected in these schemes, forming a starting point and a basis for conserving existing social networks (Basulto, 2009).

Three housing typologies are proposed, able to be implemented together in various configurations, allowing houses to share walls and columns (Basulto, 2009):

- $\quad$ House A: a 2 story house with sufficient structure to be extended vertically to a 3 story house

- House B: a 2 story house on an open ground floor that allows for parking or to be later developed as a shop or extra bedroom

- House C: a 3 story house with a void in the middle to be used as an outdoor space or to be later enclosed for an extra bedroom

\section{OMMX NAKED HOUSE - GARDEN AND INTERIOR EXPANSION}

OMMX won a competition to design affordable houses for non-profit organisation Naked House to address London's housing crisis (Mairs, 2017). The homes are laid out as row housing, providing a 50m2 open plan, double height exterior shell which is designed to accommodate future adaptations and expansions (Mairs, 2017). Concrete foundations and single storey height garden walls provide the opportunity for extensions into the back yard, while footings for a second floor level within the initial volume provide the opportunity for an internal loft extension (Mairs, 2017).

\section{WESTON WILLIAMSON - BALCONY EXPANSION}

British Firm Weston Williamson has proposed an incremental multi-storey housing project to address the lack of affordable housing in Palestine (Mairs, 2017b). Basic apartments are located around a central circulation core, each with a large balcony formed by an extension of the floor slab (Mairs, 2017b). The apartments can be expanded into the balcony spaces using prefabricated panels that allow for a range of variations in layout (Mairs, 2017b). 


\section{ADDITIVE EXPANSION}

Housing that allows expansion through unconstrained additions

\section{MALKA ARCHITECTURE - PARASITIC ADDITIONS}

Malka Architecture have designed an extension project that addresses the low energy performance and size constraints of a 1970s apartment building in Paris (Malka, 2017). The co-owners of the building each dictated their individual spatial development needs to the architect (Malka, 2017).

The extensions consist of modular timber boxes, prefabricated in a workshop and directly 'plugged' into the existing façade of the building (Malka, 2017). The box shaped extensions on the ground floor and protruding out of the upper floors create bow-windows, loggias and covered balconies within the box, as well as uncovered balconies on top of the box (Malka, 2017). These extensions also work to improve thermal efficiency by reducing thermal bridging and replacing inefficient windows, reducing the energy consumption of the building by a factor of four (Malka, 2017).

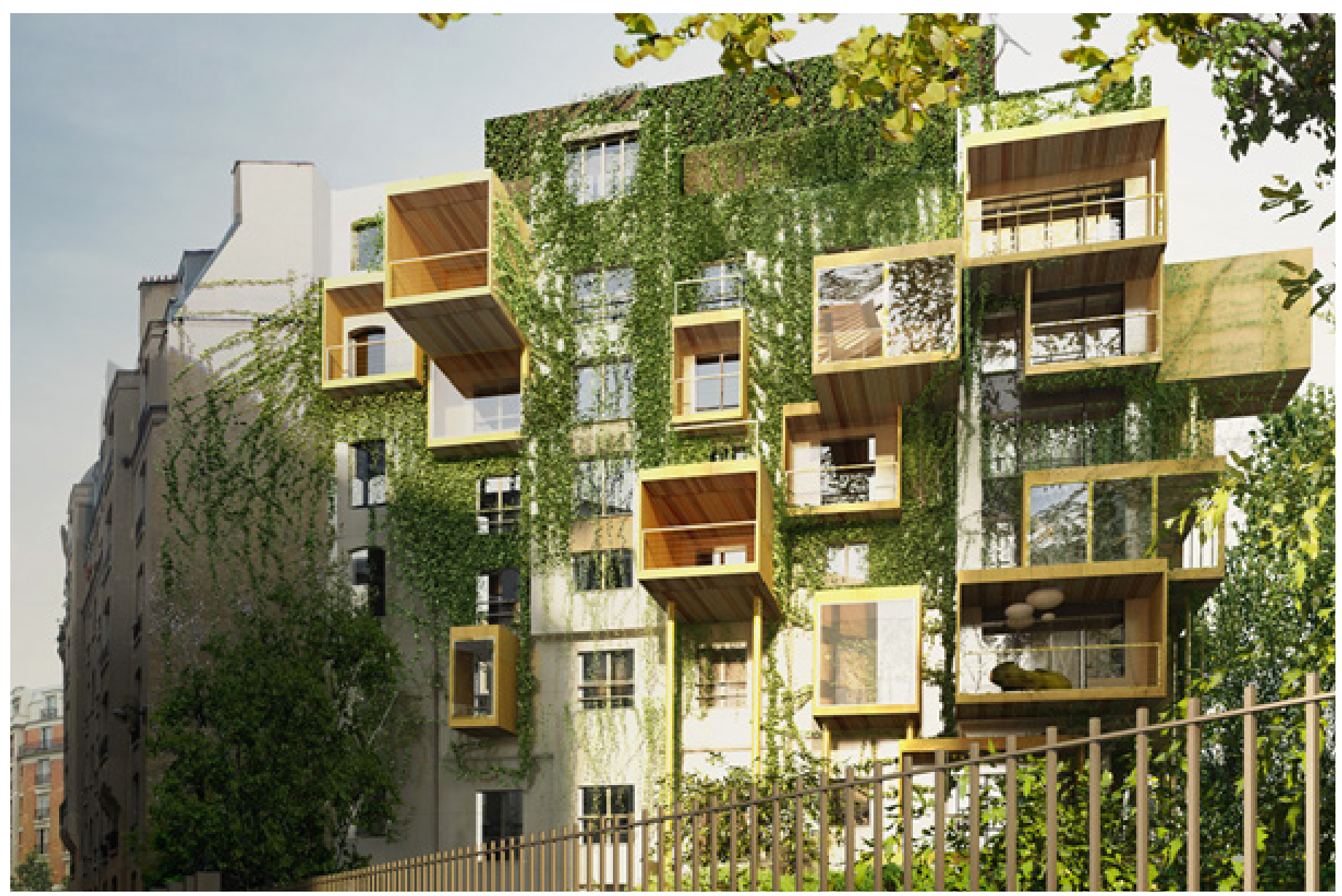

Figure 4. Exterior render of parasitic additions to an apartment building in Paris (Malka, 2017).

\section{SYTEM 3 - MODULAR ADDITIONS}

Oskar Leo Kaufmann and Albert Rüf exhibited a prototype of System 3 at the Museum of Modern Art "Home Delivery" exhibition that aimed to address the issues around fabricating the modern dwelling (Viladas, 2008). The $52.5 \mathrm{~m}^{2}$ modular home is made up of two parts, one containing the services for the house, including kitchen, bathroom, heating, electricity and stairs, and the other as a 'naked', empty space (Viladas, 2008). Each half fits within the dimensions of a shipping container, with the services half transported as a volume and the naked half transported in flat panels (Viladas, 2008). 


\section{TATIANA BILBAO - MODULAR ADDITIONS}

Tatiana Bilbao produced a full scale prototype of an expandable, flexible solution to the Mexican housing crisis for the Chicago Architecture Biennial (Cruz, 2015). The core of the house is constructed from concrete blocks and can be expanded by adding modules made from cheaper and lighter materials such as wood pallets (Cruz, 2015). The $43 \mathrm{~m} 2$ first phase of the house can be constructed for as little as US $\$ 8,000$ and consists of two bedrooms, one bathroom, a kitchen and a $5 \mathrm{~m}$ height dining and living space (Cruz, 2015).
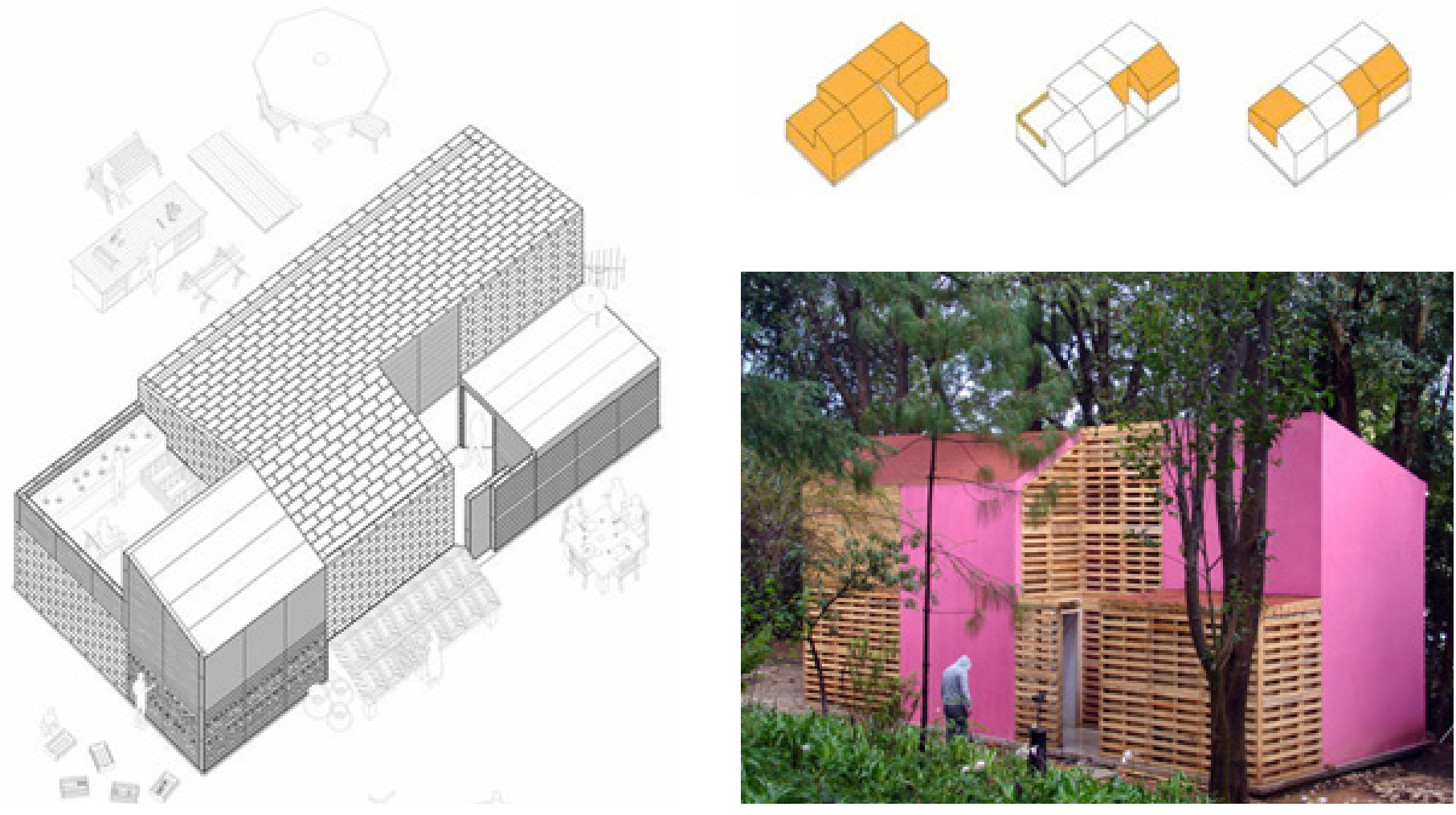

Figure 5. Concept drawings for modular, expandable housing in Mexico (Cruz, 2015).

\section{C2C HOUSING COMPETITION - MODULAR PLUG-INS}

Sean Wheeler and Jason Zawitkowski were the student winners of the Cradle to Cradle housing design competition that aimed to inspire the design of residential dwellings that go beyond sustainability towards being waste free (Marshall-Baker, 2012). Their design proposes modules that can stand alone or be stacked, grouped or 'plugged' into each other in similar ways to the peripherals of digital devices (MarshallBaker, 2012). Home owners would have the opportunity to add modules to expand their existing home, or alternatively switch out modules for different or upgraded models (Marshall-Baker, 2012).

\section{FAVELA CONSTRUCTION - FLOOR BY FLOOR ADDITIONS}

Houses in Rio de Janeiro's favelas demonstrate an informal process of incremental construction as houses are built and expanded over several generations, typically upward, floor by floor (Veysseyre, 2014). Families may rent out upper floors of their houses to other families or extended relatives, while ground floors may be rented for commercial purposes (Veysseyre, 2014).

Floors are laid as a starting point and columns are erected with protruding rebar, finished with a thin tin roof to mark where the next builder should continue the construction (Veysseyre, 2014). More permanent tile roofs are not seen as a sign of wealth, but rather a sign the building will not be expanded further (Veysseyre, 2014). Materials used in the construction must be low cost, light enough to be carried and small enough to fit through the narrow streets, resulting in a trend of brick houses with concrete structures (Veysseyre, 2014). Craftsmen may be hired for more technical tasks, such as casting slabs or constructing roofs, however much of the construction is self-built with the help of friends (Veysseyre, 2014). 


\section{STRATEGY SUMMARY}

\section{BOUNDED EXPANSION}

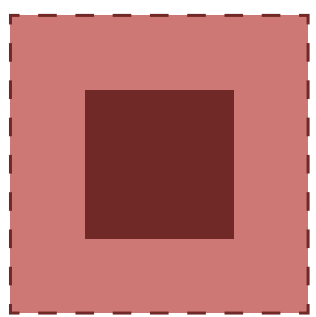

Expansion around a nucleus

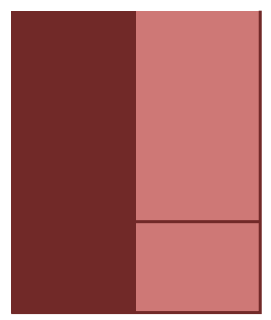

Filling voids between dwellings

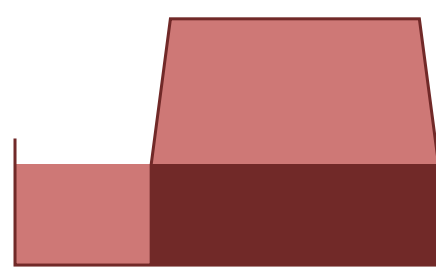

Loft and yard expansion

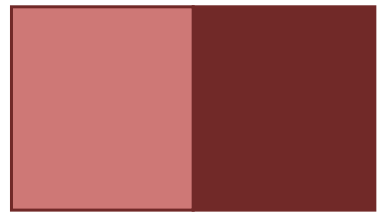

Internal expansion through fitout

\section{ADDITIVE EXPANSION}

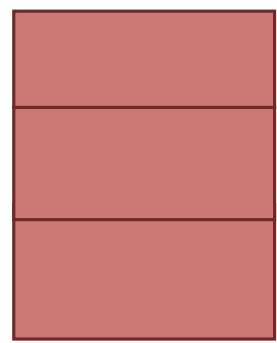

Vertical growth storey by storey

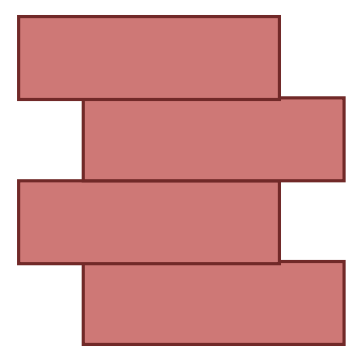

Stacking a standard module

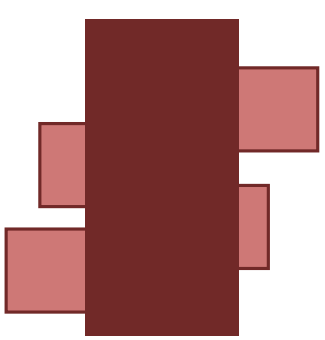

Parasitic additions to existing buildings

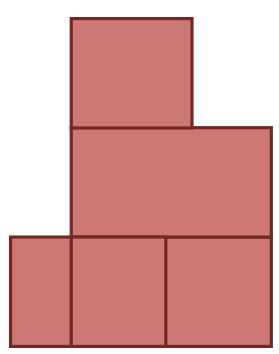

Combining a range of different modules 


\section{PRECEDENT DISCUSSION}

\section{Bounded expansion}

By designing and constructing the physical limitations for the final expanded dwelling, the designer has more control over the final outcome of the dwelling. For Assemble's work this means the external façade and enclosure of the building is determined by the designer and constructed fully in the first phase, giving control over the visual impact of the building as well as the quality of weathertightness. Alternatively, the other precedents allow expansion and addition to the dwelling within a predefined footprint, giving occupants more control and therefore creating more variation and less predictable final outcomes both visually and in terms of construction quality. While the quality of expansions may vary within the precedents seen for social housing, within the New Zealand context these expansions would need to conform to the building code and would therefore not risk being of a poor or insufficient quality.

Bounded expansion requires a lot of the final construction infrastructure to be built up front to facilitate further growth. This may make the first phase less affordable and therefore less accessible for homeowners. This may also waste resources if the dwelling is not expanded later, meaning the space left for expansion should have some useful purpose at phase one, such as sheltered outdoor space as seen in the Build to Grow precedent.

These precedents may also have the largest visual impact at stage one, often starting with the maximum footprint clearly defined. This would reduce the aim of creating gradual, comfortable change through expansion over time. The Assemble and OMMX precedents would be the least successful in achieving this aim, creating large building volumes at the initial phase to be developed internally later. The Elemental precedents are most successful at creating visual growth over time, starting with minimal building volume that is expanded later by filling in the large voids between the initial structures.

\section{Additive expansion}

Vertical growth is ideal within the small sites that are available within Wellington suburbs, allowing initial dwellings with small footprints to gain essential extra floor space by expanding upwards, rather than outwards. This would reduce site impact, consuming less land and allowing more green space to be maintained while density increases. In the New Zealand context the dwelling must be completed fully at each stage, so the method for achieving this growth seen in the favela precedent would not be suitable. However, construction methods suitable to the New Zealand context could be used to add additional storeys to dwellings later making this a useful growth strategy to pursue further.

The modular construction methods seen in the precedents allow fully completed prefabricated units to be added to existing modules allowing growth with minimal disruption to the initial dwelling and minimal work onsite. The small scale of each module would allow for easy transportation and craning onto existing sites which may have limited access around existing buildings. Modular construction may create a very standardised appearance if the building is made entirely from identical modules, as is done with System 3, however other precedents, such as Tatiana Bilbao's and the C2C competition's systems, show how variation in module size, function or materials may create variation within a standardised system.

Parasitic growth conserves resources by making the most of existing buildings, however this may be less suitable for additional dwellings, and more suitable for the expansion of existing dwellings which would not increase density. However, building additional units attached to existing structures would save space on small suburban sites. A similar strategy to the multi-storey Malka Architecture precedent is not feasible within Wellington suburbs which have predominantly low-rise, timber framed buildings. If additional volumes for separate dwelling units were to be added to typical Wellington suburban houses, consideration of fire resistance and acoustic separation would be essential and unlikely to be achieved using the existing wall construction of the dwellings.

\section{Conclusion}

Bounded expansion has clear benefits in the control over the final outcome it offers the designer, but may reduce the affordability and increase the visual impact of the initial stage. Alternatively, additive construction potentially allows for a more minimal initial phase but risks uncertainty of the final outcome. Both methods are worth pursuing at this stage to evaluate how well they could be applied to a Wellington ADU context. 
CONCEPTS 


\section{WELLINGTON SITE TYPES}
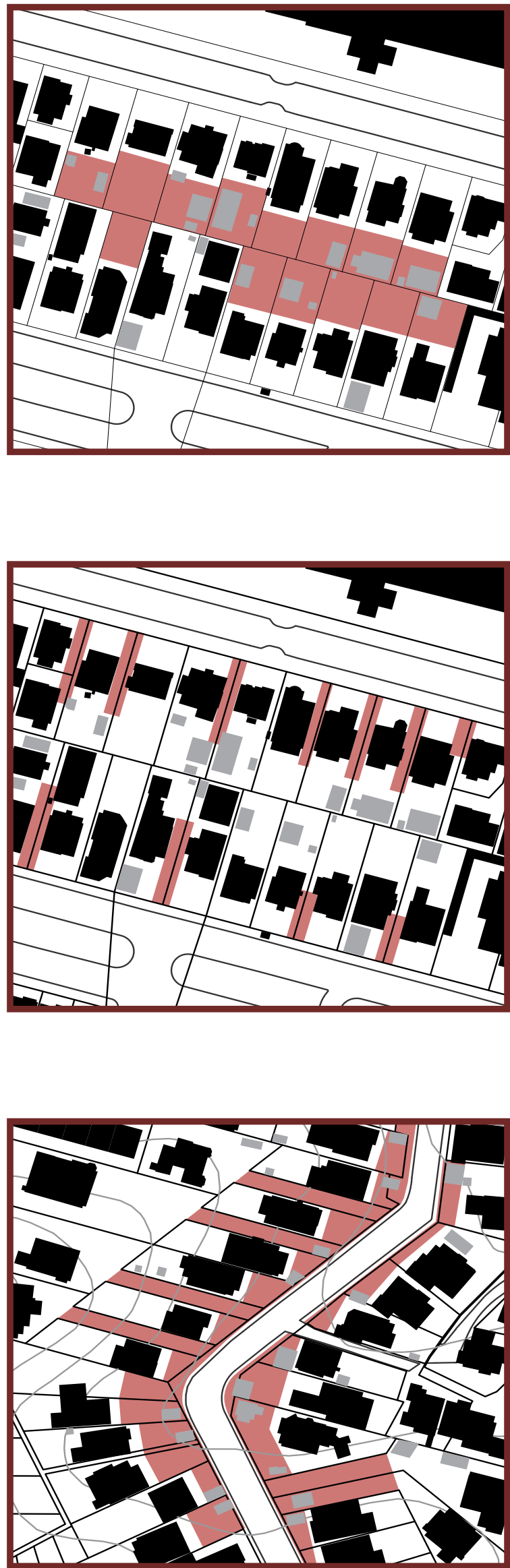

\section{BACK YARDS}

Underutilised land within large back yards, behind existing dwellings.

\section{SIDE YARDS}

Underutilised land between neighbouring dwellings within low density areas.

\section{FRONT YARDS}

Underutilised land in front of existing dwellings, often used for small garages. 


\section{Additive Modular Frames - back yards}

Standard sized frames are added incrementally to the house in a number of horizontal and vertical configurations. Standard sized cladding panels enclose frames and standard sized service pods fit within frames.
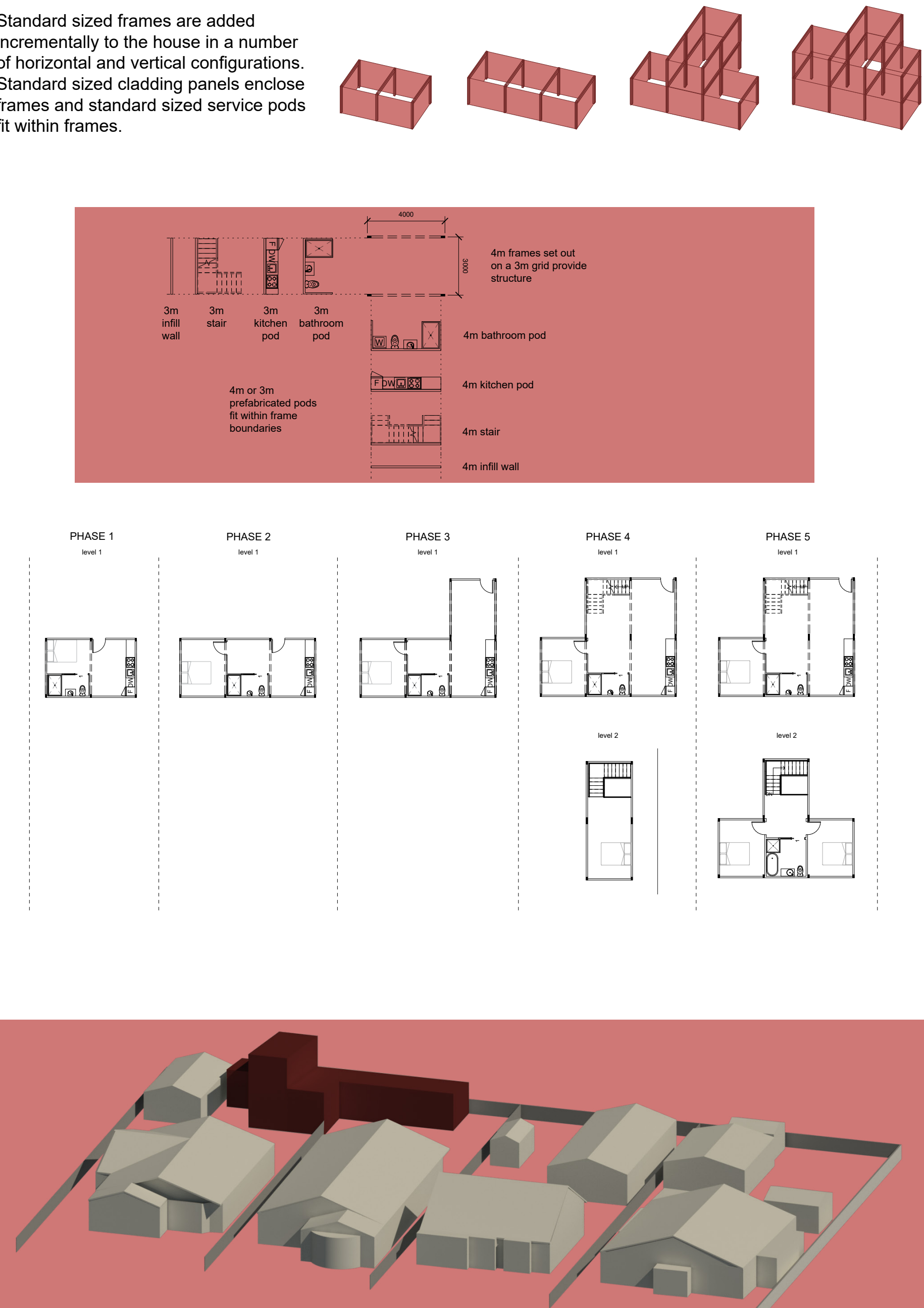


\section{Bounded Expansion - back yards}

The floor and roof are constructed to the maximum size desired on the site, bounding construction within this area. Frames set out at a regular grid support the roof and are gradually infilled with walls, cladding panels and service pods
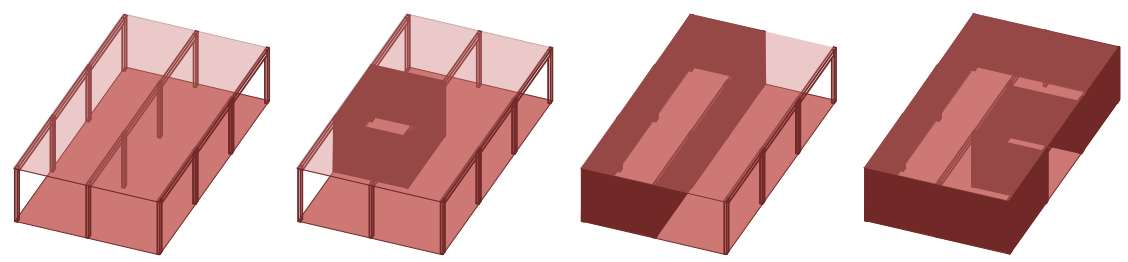

to expand the internal space.

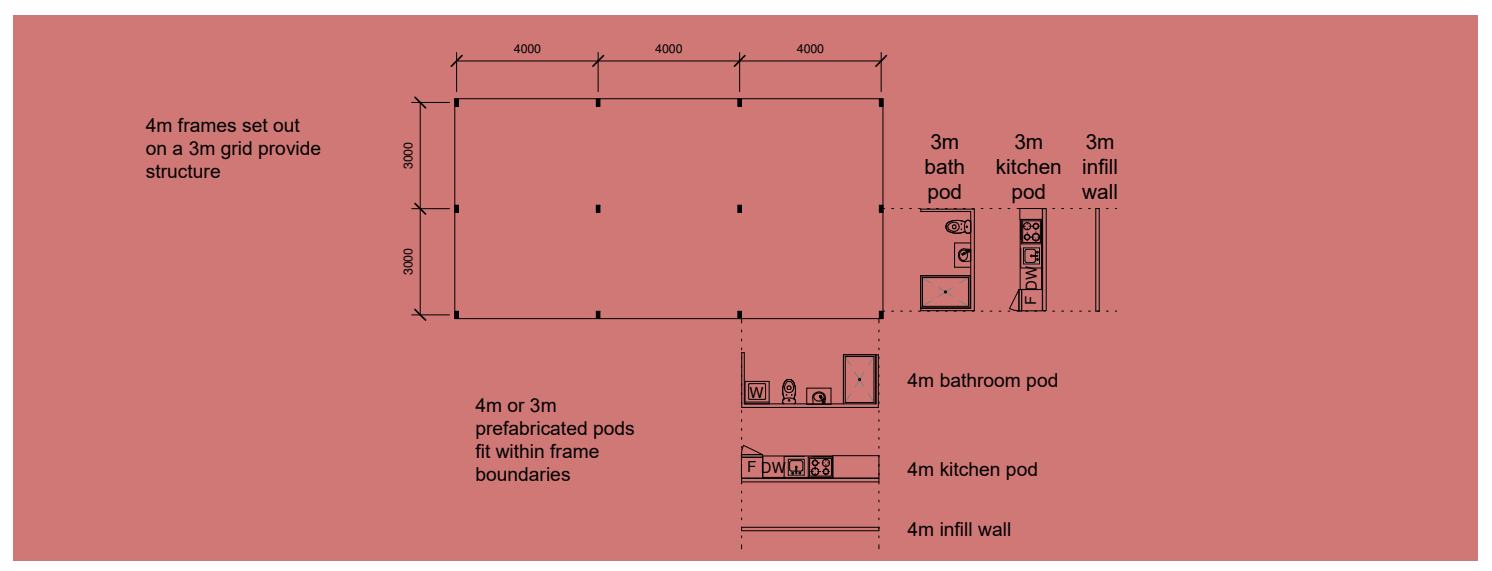

PHASE 1

level 1

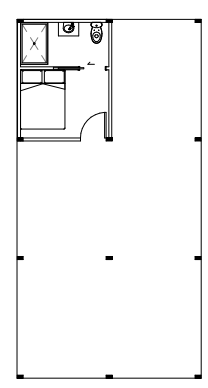

PHASE 2

level 1

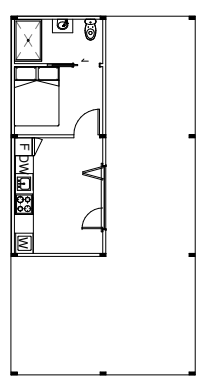

PHASE 3

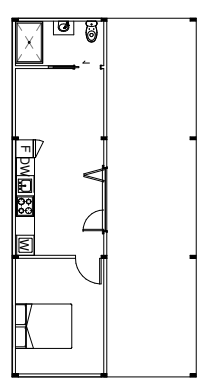

PHASE 4

evel 1

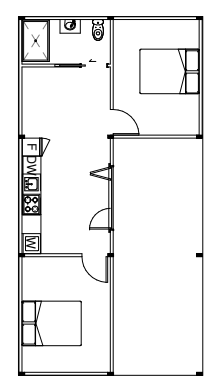

PHASE 5

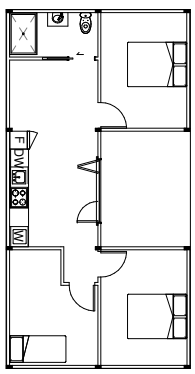




\section{Additive Modular Volumes - side yards}

\section{Standard sized pods with varying}

functions can be combined in a number of horizontal and vertical configurations are added incrementally to the house.

Ends are open and capped with a reusable facade.
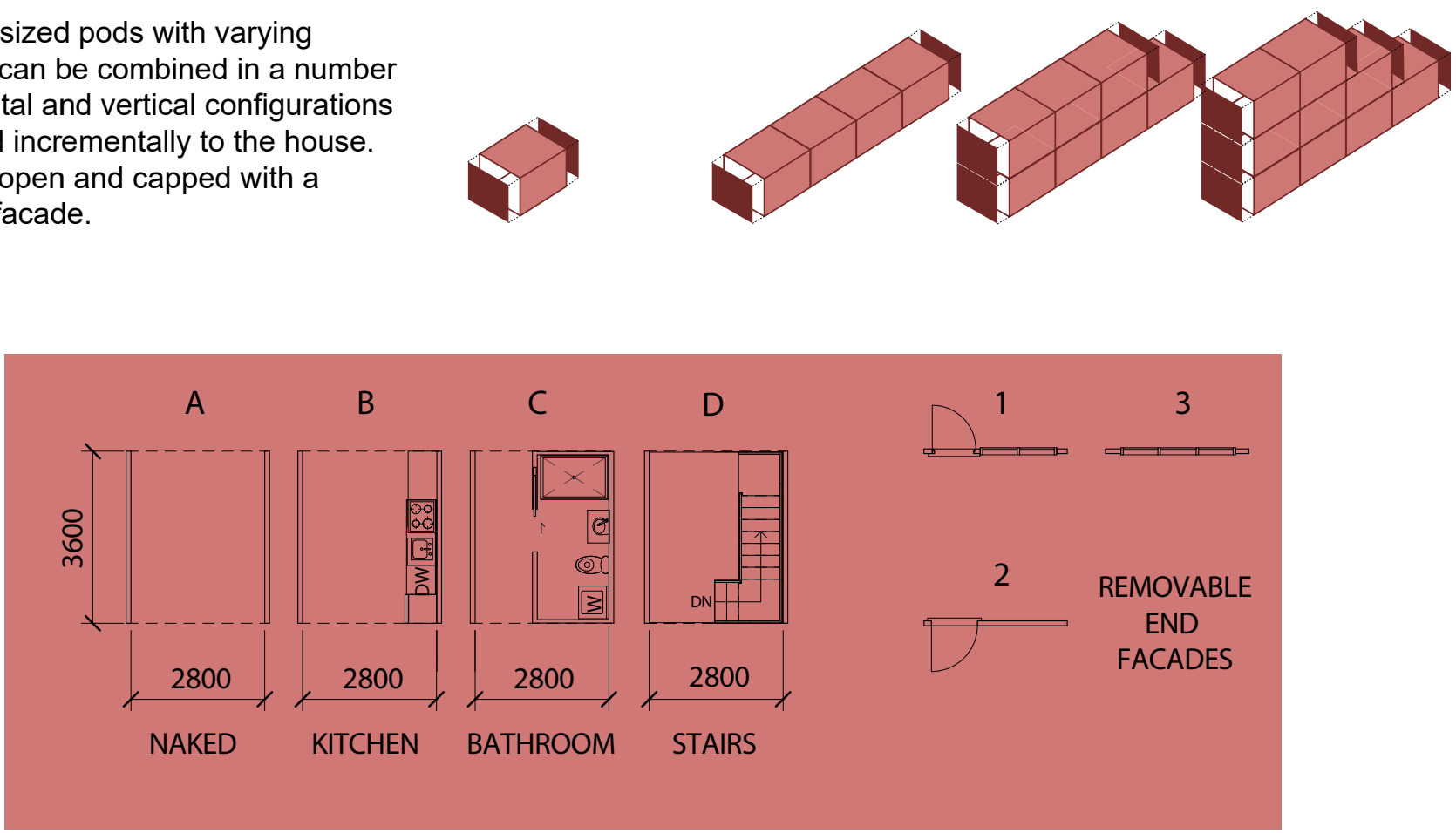

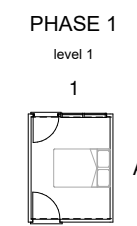

2
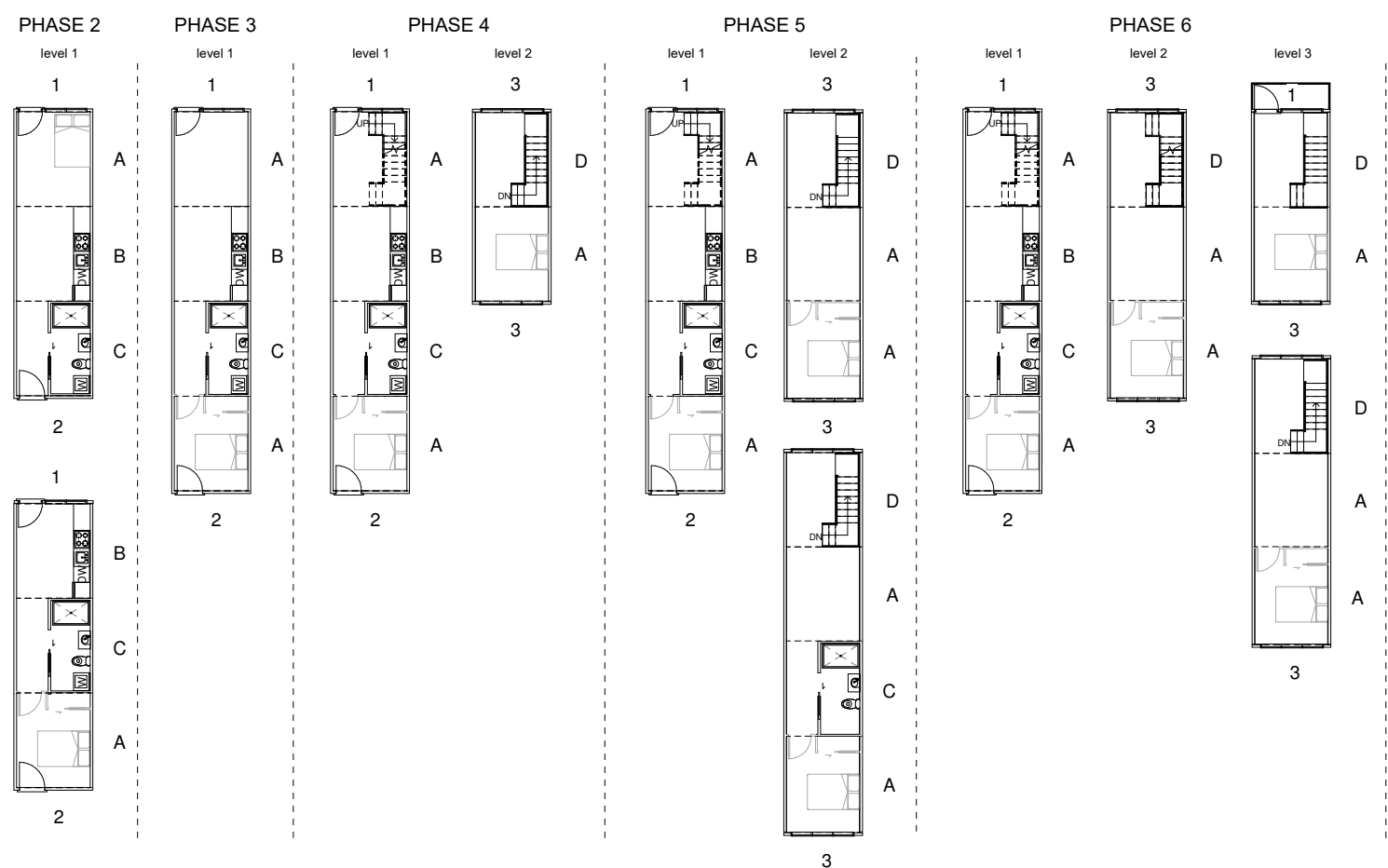


\section{Bounded Expansion - side yards}

Edge walls are constructed to the maximum length possible on the site, able to be gradually infilled with roofing and flooring. End facades are demountable to be moved for each expansion. Width may vary depending on site constraints.
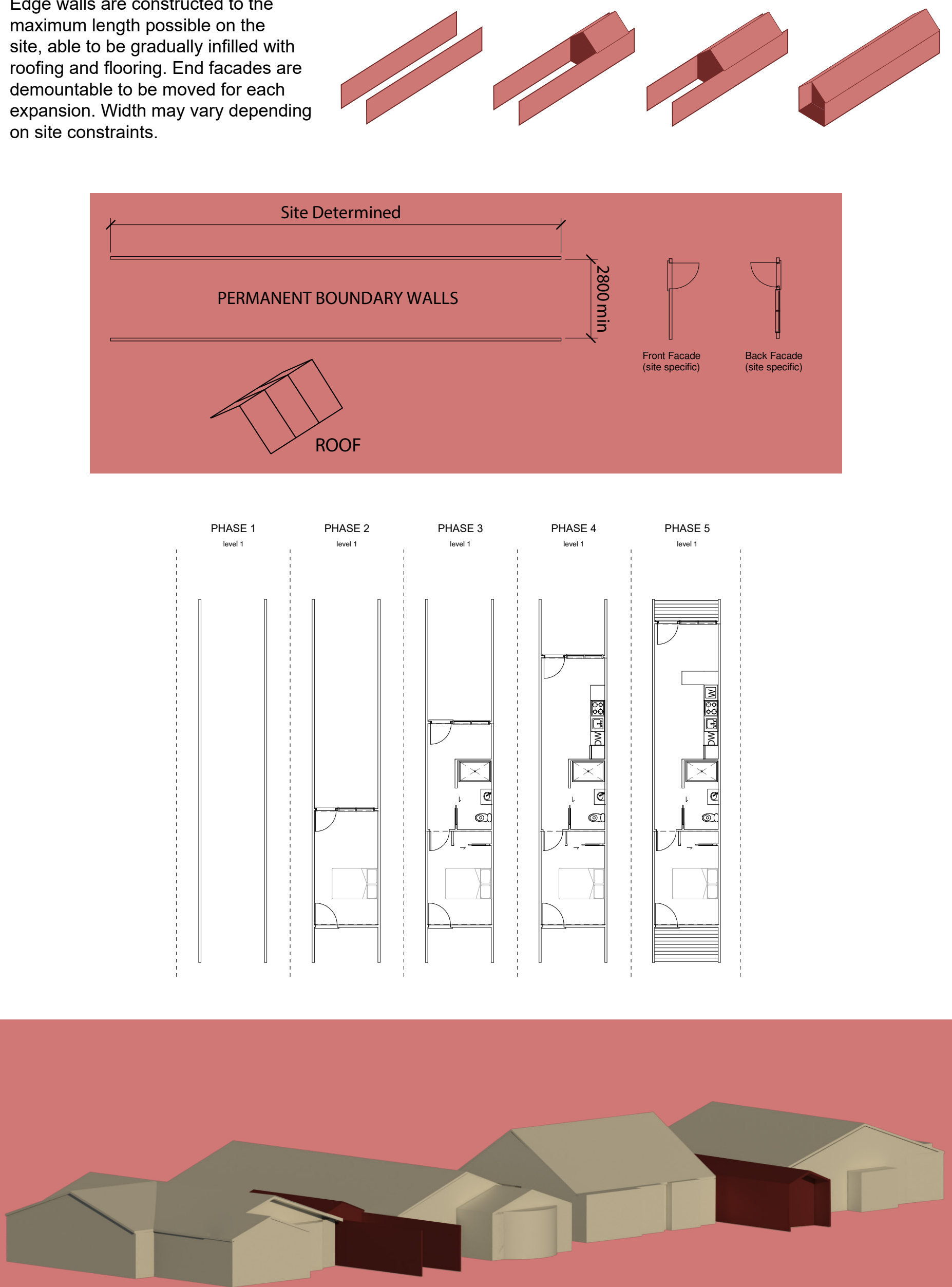


\section{Additive Modular Volumes - front yards}

Full and half sized volumes are added incrementally to the house/garage in a number of horizontal and vertical configurations. Standard sized removable panels allow for circulation and connection between volumes.
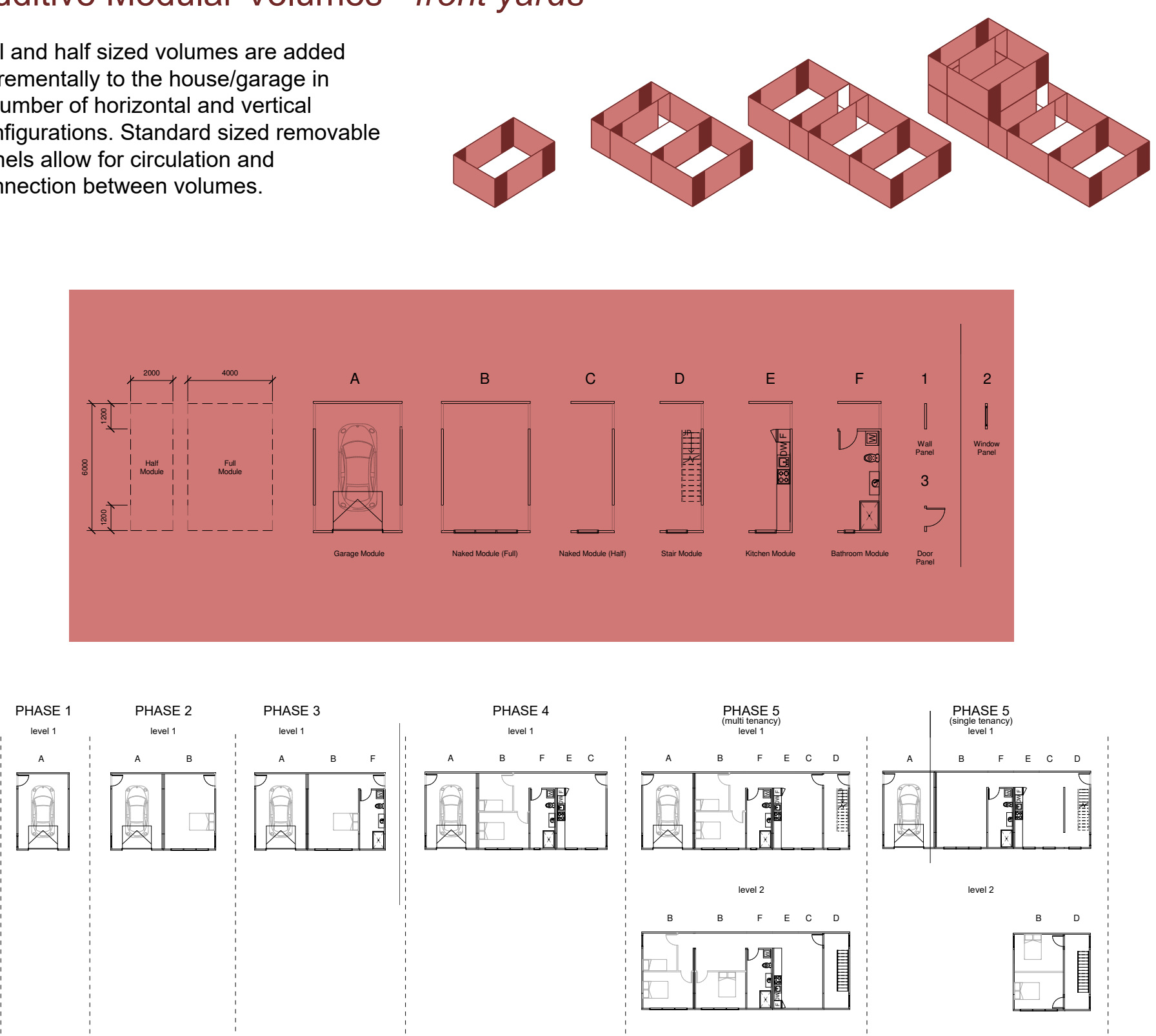
Internal Expansion - front yards

Flats attached to garages in various ways are able to incrementally expand into the garage space through internal rennovation. Demountable interior fitouts allow for the changes in building function over time.
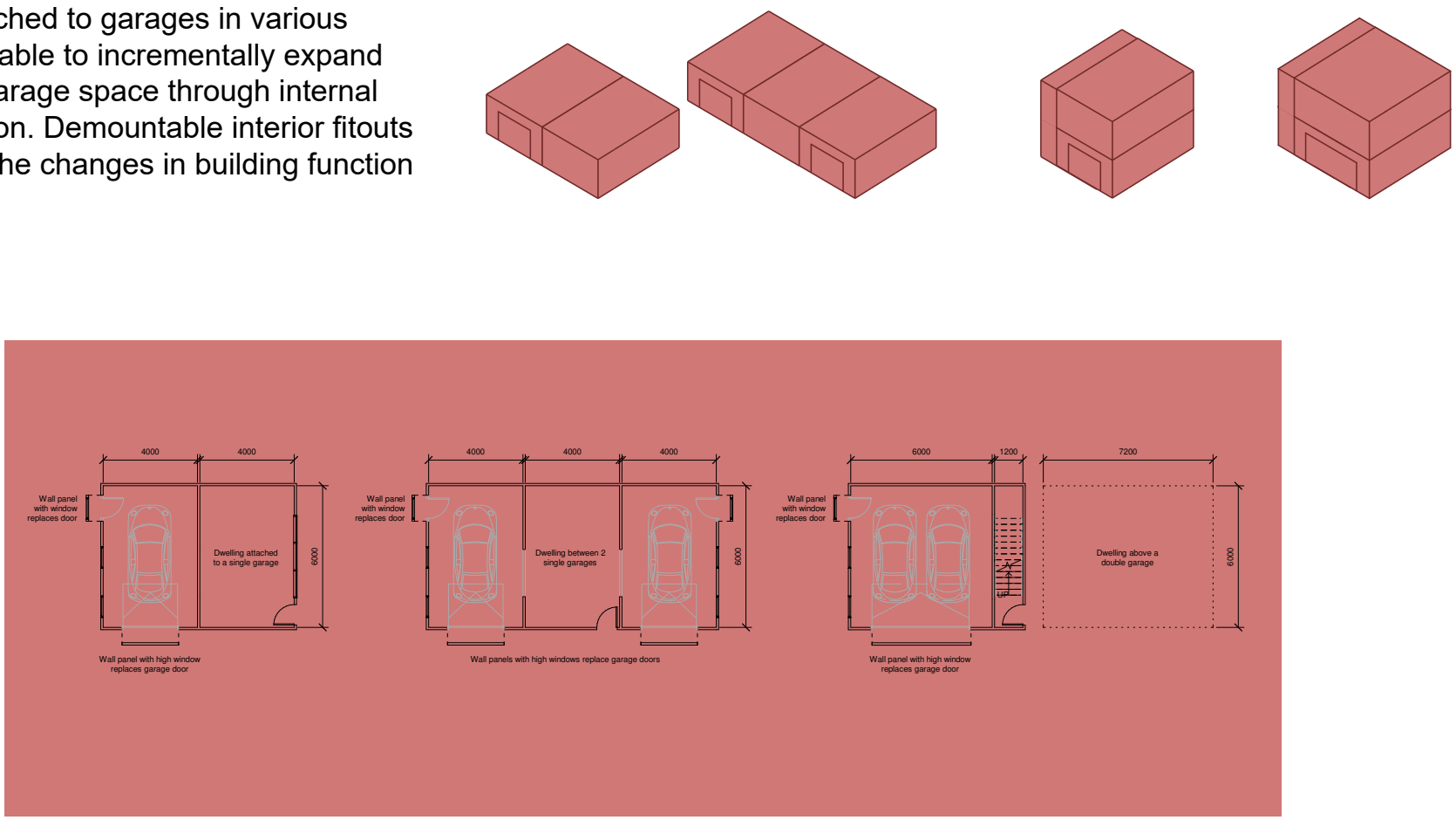

SINGLE

TRIPLE

DOUBLE
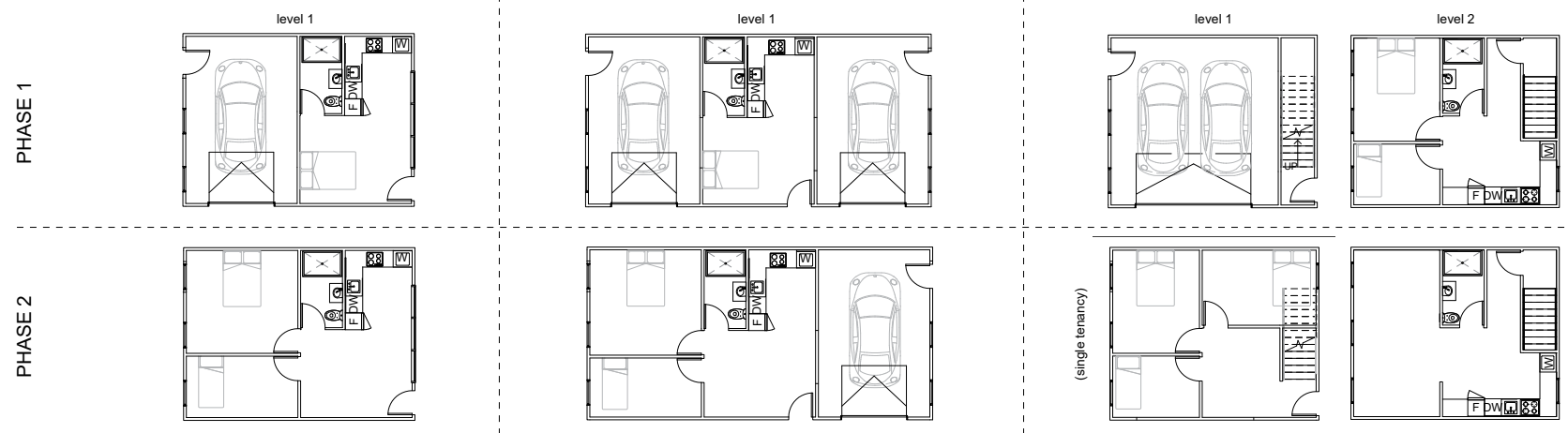

章
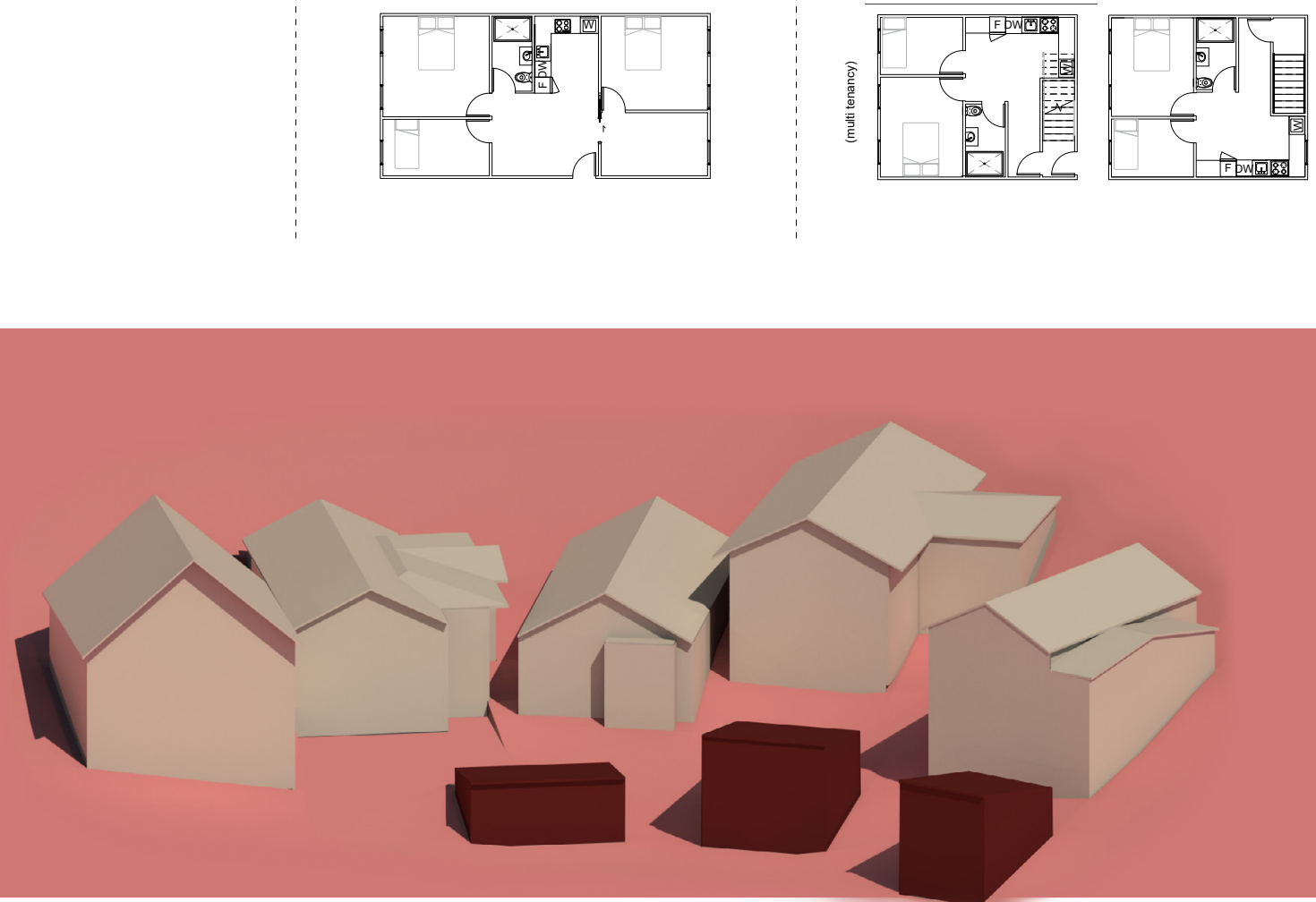


\section{CONCEPT EVALUATION}

The incremental building processes identified through the precedent analysis have been used to create concepts for ADUs on common sites within Wellington suburbs. This has allowed the different strategies to be tested to determine what might be most appropriate for a Wellington suburban context.

\section{Bounded expansion}

The bounded strategies work well to clearly define the spatial boundaries of the new ADU on the existing sites. For back and side yard sites, this has created defined outdoor space for the ADU at initial stages which can be expanded into later. The downside of this strategy is the larger initial impact on the site and the larger initial cost that would result from this. The concepts explored also do not manage to incorporate a second storey, relying only on horizontal expansion due to the boundaries of the initial construction.

\section{Additive expansion}

The additive strategies rely on modular construction to allow volumes to be added to the ADU over time, creating less restriction on the growth of the dwelling over time. This allows for a smaller initial impact and cost than the bounded concepts, enabling the building to start very small without limiting future growth. The downside of this strategy is the sprawling expansion of the ADU which has resulted in the concepts becoming quite large at later stages. This however could be controlled through adherence to WCC district plan and the limitations of site boundaries.

\section{Conclusion}

All concepts have taken very gridded approaches with little consideration for site, aside from overall shape. The impact on existing dwellings and neighbouring sites has not been considered and outdoor space has overall not been incorporated thoroughly into the dwelling designs, especially for the additive concepts.

Overall, for the aims of this research, additive construction has been the most successful in allowing dwellings that start with a small initial impact that may grow over time. This should promote affordability, allowing better access for homeowners to build an ADU on their site, as well as create slower paced, comfortable change to the character of suburbs. 


\section{CONCLUSION}

This initial exploration of incremental building processes has found two main themes for expansion; bounded and additive. Analysis of the potential benefits and limitations of these strategies, as well as the application of these strategies to common Wellington sites has found that overall, a modular, additive approach is the most promising strategy to pursue further. 


\section{WORKS CITED}

Aravena, A., \& lacobelli, A. (2012). Elemental: incremental housing and participatory design manual. Germany: Hatje Cantz Verlag.

Assemble. (2015). Stille Strasse. Retrieved from https://assemblestudio.co.uk/projects/stille-strasse

Assemble. (2014). Yardhouse. Retrieved from https://assemblestudio.co.uk/projects/yardhouse

Basulto, D. (2009). Incremental Housing Strategy in India / Filipe Balestra \& Sara Göransson. Arch Daily.

Bayona, D. (2018). Architects Propose 120 Incremental Social Houses for lquitos, Peru. Arch Daily

Cruz, D. (2015). Tatiana Bilbao's $\$ 8,000$ House Could Solve Mexico's Social Housing Shortage. Arch Daily.

Elemental. (2017). Projects. Retrieved from http://www.elementalchile.cl/en/proyectos/

Kaufmann, O. L. (2008). System3 | New York. Retrieved from http://www.olkaufmann.com/work/08-system3-new-york/

Mairs, J. (2017a). Naked House and OMMX offer bare-bones affordable housing for London. Dezeen.

Mairs, J. (2017b). Weston Williamson proposes incremental building to combat Palestinian housing shortage. Dezeen.

Malka, S. (2017). Plug-in City 75 inhabit the facades. Retrieved from https://www.stephanemalka.com/ portfolio/plug-in-city-75-i-inhabit-the-facades-i-paris-2017/

Marshall-Baker, A. (2012). Cradle to cradle home design : process and experience / Anna Marshall-Baker, Lisa M. Tucker. New York : London: New York : Fairchild books ; London : Bloomsbury distributor.

Veysseyre, S. (2014). Case Study: The Unspoken Rules of Favela Construction. Arch Daily

Viladas, P. (2008). Here Comes the Neighborhood. The New York Times Magazine. 


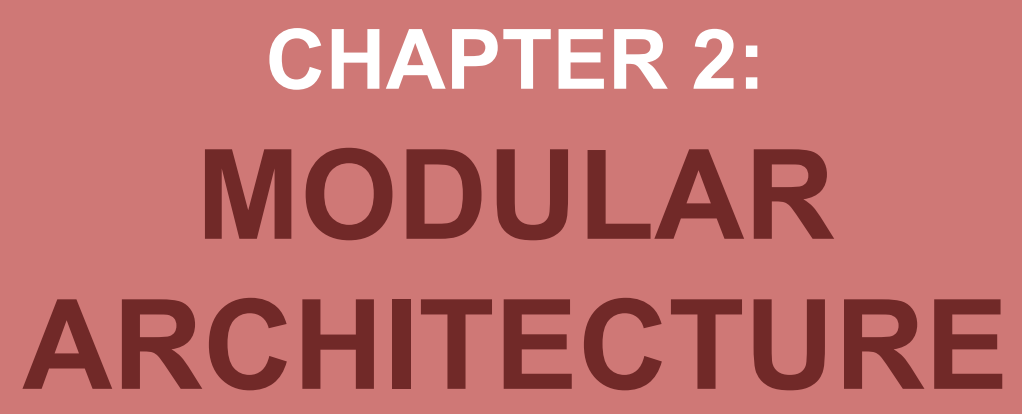




\section{INTRODUCTION}

Following the identification of a modular additive strategy as the most promising incremental building process, modular architecture is explored further in this chapter. Due to the restricted, gridded layout of the initial concepts, design explorations in this chapter aim to explore how standard modules be used in varying arrangements to allow customisation and choice. Literature is also reviewed to investigate how prefabricated, modular architecture is able to address the identified issue of building waste, as well as promote the uptake of infill housing by ensuring affordability. 


\section{BENEFITS OF MODULAR CONSTRUCTION}




\section{PREFABRICATION}

\section{OVERVIEW}

Prefabrication can be defined as the "off-site production of standard or customised components or complete structures" (Page \& Norman, 2014, p. 1). Systems of prefabrication are typically categorised into 5 types; component, panel, module, hybrid and complete buildings (PrefabNZ, 2014). The prefabrication of buildings can therefore vary considerably depending on the systems used (PrefabNZ, 2014).

\section{WASTE REDUCTION}

Greenhouse gas emissions from the building and construction sector account for $33 \%$ of total human emissions, with $30 \%$ of this attributed to construction and demolition (Burgess, Buckett, \& Page, 2013). Research conducted by BRANZ, using a $120 \mathrm{~m} 2$ case study house shows significant reduction in material and component transport emissions for all prefab types studied when compared to traditional onsite building (Burgess et al., 2013). This is due to reduced supply trips, bulk purchasing of materials and better coordination and efficiency of delivery trucks (Burgess et al., 2013). US studies also report transport reduction in terms of labour, finding prefabrication construction employees often live close to the factory in which they work (Kaufmann \& Remick, 2009). One study reported transportation energy used by employees of a modular home was $6 \%$ of that used by employees involved in onsite construction (Kim, 2008). Transport emissions are likely to vary greatly between regions depending on the location of the site, prefabrication factory and material suppliers, so this should be taken into account when determining the construction method for each project (Burgess et al., 2013).

The BRANZ study showed a significant reduction in timber waste for all prefabrication types, resulting largely from the ability of factory type locations to stockpile and warehouse excess timber supply (Burgess et al., 2013). US industry research also reports the potential for onsite waste reduction with $76 \%$ of prefabrication users reporting a decrease in construction site waste (McGraw-Hill Construction, 2011). Research from PrefabNZ also discusses the ability of factory settings to better allow for recycling of waste materials, diverting waste from landfills, as well as the reuse of offcuts in future projects, minimising material requirements (PrefabNZ, 2014). Further, factory conditions also reduce material wastage from imprecise measurements, over ordering and poor site storage conditions (Bell \& Southcombe, 2009; McGraw-Hill Construction, 2011), as well as better control of the disposal of hazardous materials such as treated timber sawdust (Burgess et al., 2013).

Defects and rework are a costly part of construction, causing material wastage and unnecessary repetition of construction work, or the need for the premature maintenance or replacement of materials (Burgess et al., 2013). The manufacturing style of prefab construction allows for early detection of material faults and better quality control throughout the production line and before it is delivered onsite (Fawcett, Allison, \& Corner, 2005). Human error is also a major cause of defects and rework (Atkinson, 2002), which can be significantly reduced within prefabricated construction due to the specialised training of factory based staff, the automation of processes and improved coordination through strongly developed processes (Burgess et al., 2013). The higher quality construction also allows prefabricated buildings to achieve tighter envelopes and higher thermal efficiency (McGraw-Hill Construction, 2011).

\section{COST EFFICIENCY}

The BRANZ study also found that hybrid construction provided the greatest cost efficiencies, effectively combining prefabricated and onsite construction (Burgess et al., 2013). Panelised construction also provided significant cost efficiencies compared to transportable and onsite construction which resulted in the lowest cost efficiencies (Burgess et al., 2013).

The prefabrication of modular or repeated buildings has been found to be more cost effective than one-off, onsite construction largely due to the efficiency of constructing large quantities of similar products within purpose built facilities (Burgess et al., 2013). Benefits may also be found in the consenting process, through the development of 'Multiproof' consents in New Zealand which allow an approved house design to be built multiple times without having to go through the entire consenting process (Burgess et al., 2013). However, 
these savings rely on economies of scale through sufficient demand for the repetition of the building (Burgess et al., 2013).

Research also suggests cost benefits from prefabricated construction in general could result from fewer call backs, a higher performing and longer lasting end product, more efficient labour and shorter production time (Burgess et al., 2013). Exposed sites may further benefit due to the avoidance of adverse weather conditions that cause delays or reduced productivity onsite (Burgess et al., 2013). 


\section{MODULAR CONCEPT}

This construction focused exploration investigates a concept for an LVL framed modular prefabricated system aiming to minimise construction cost and space use. The concept is based around a $2.4 \times 3.6 \mathrm{~m}$ module to utilise the standard dimensions of a plywood sheet to minimise waste and improve construction efficiency. The modules consist of an LVL column and beam structure to take gravity and horizontal loads, allowing freedom of layout and openings. Standard sized wall cassettes will then be added to the frame to enclose the structure, allowing choice in the layout of exterior windows and doors within a $1.2 \mathrm{~m}$ grid layout. The overall concept development follows guidelines set out by the Prefab NZ Snug Competition for accessory dwelling units. 
A
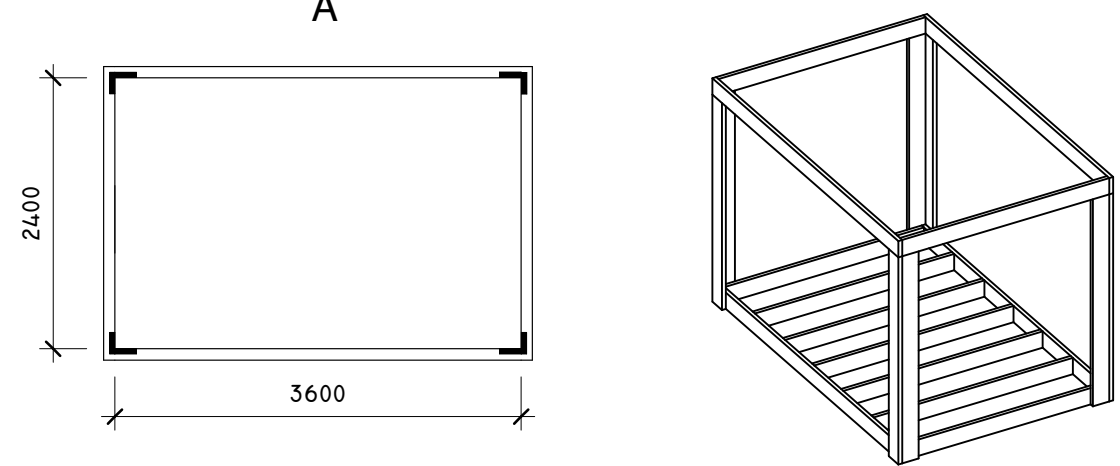

\section{Naked Modules}

The naked module $(A)$ contains no services and therefore carries no specific function. This module type will be added to the service module to create living, dining and bedroom spaces within the dwelling.
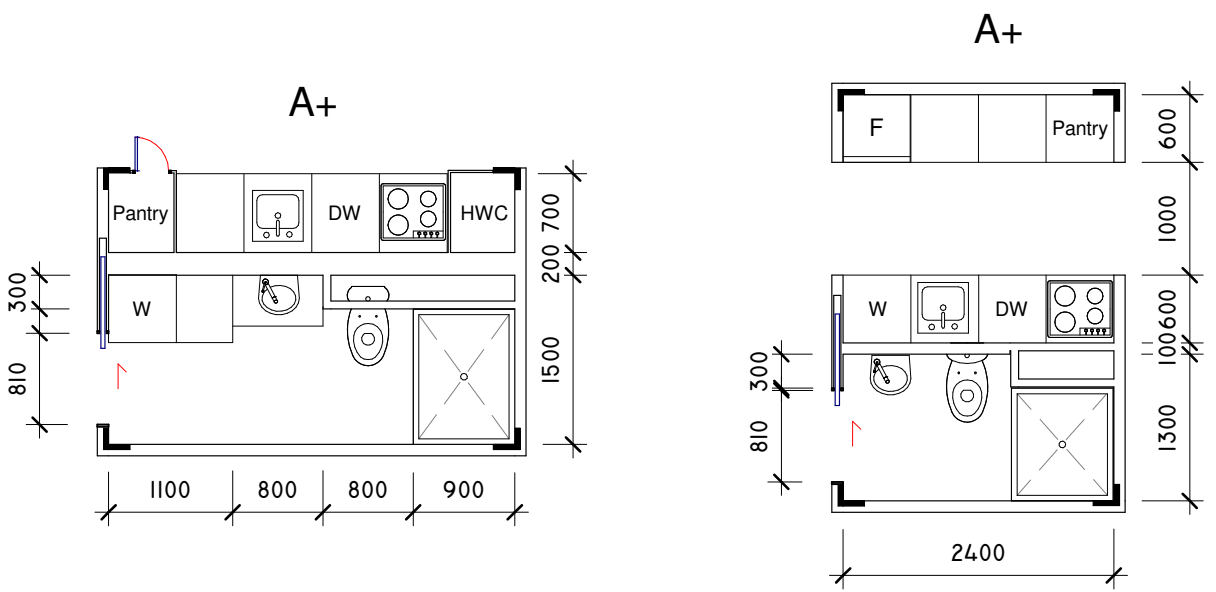

\section{Service Modules}

The service module $(A+)$ includes all services for the bathroom and kitchen, compactly arranged along a central service core. This aims to improve construction and cost efficiency by grouping all building services together. Two possible arrangements have been investigated, placing the core length and cross wise to determine which kitchen/bathroom layout would be most effective.

B1

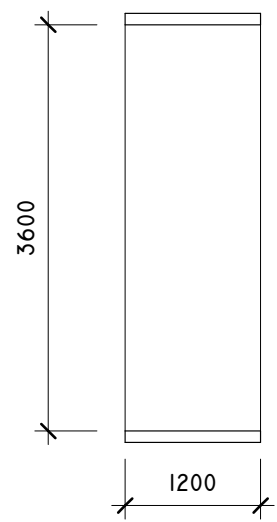

B2
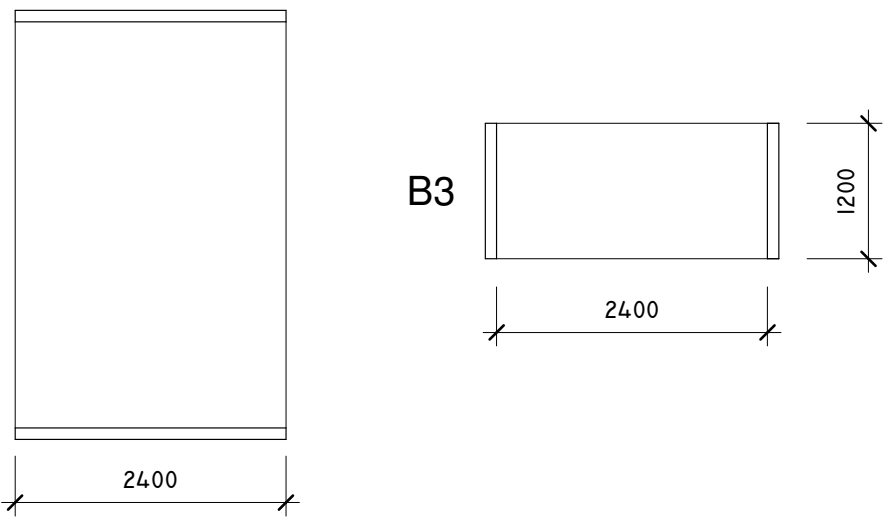

\section{Connection Modules}

The connection elements $(B)$ create less standard connections between or extensions to the modules. These would be non-structural, flat pack elements, spanning between or attached to the structural modules. 
Module arrangements - compact option Possible modular spatial arrangements using a compact service module to minimise dwelling size.
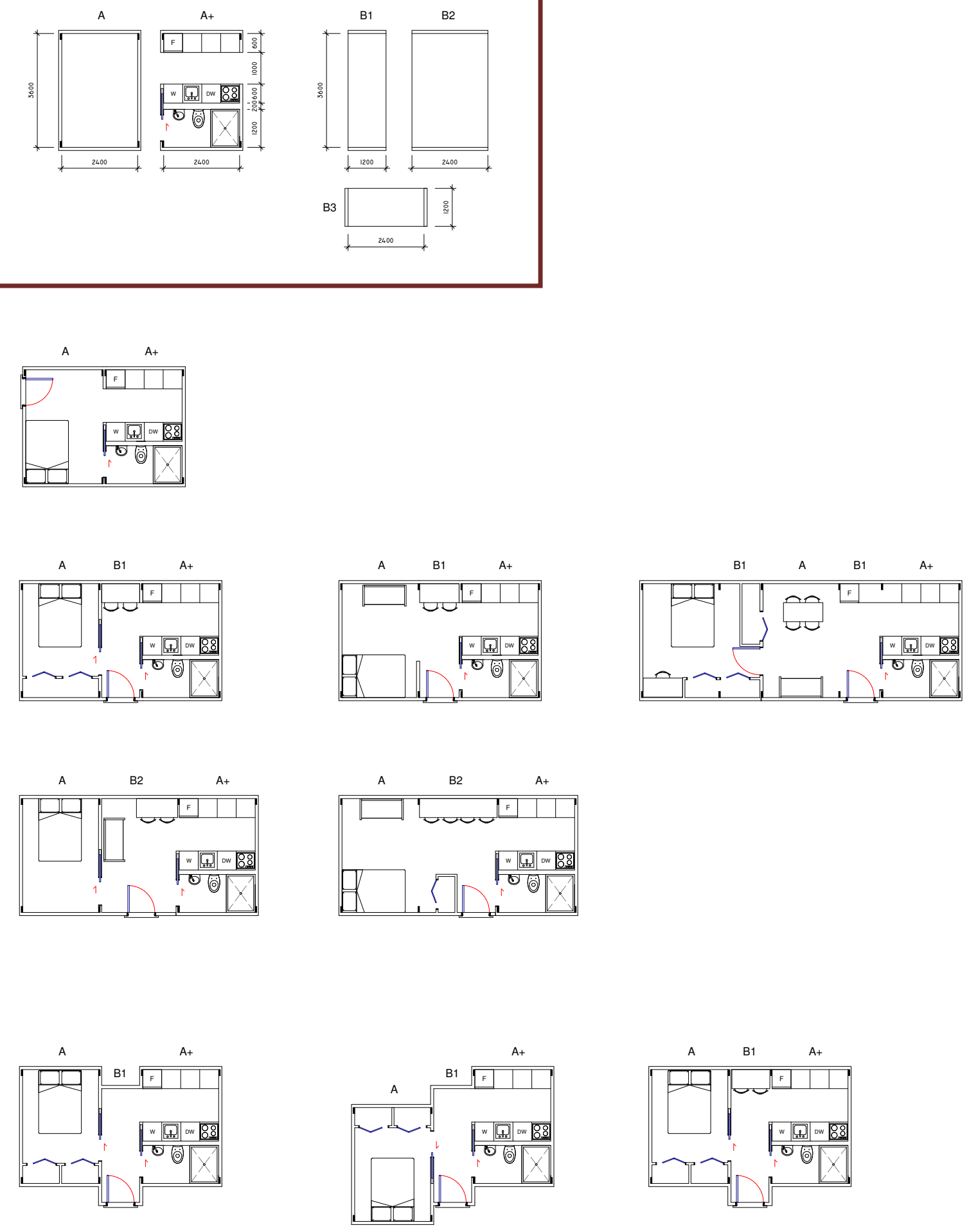

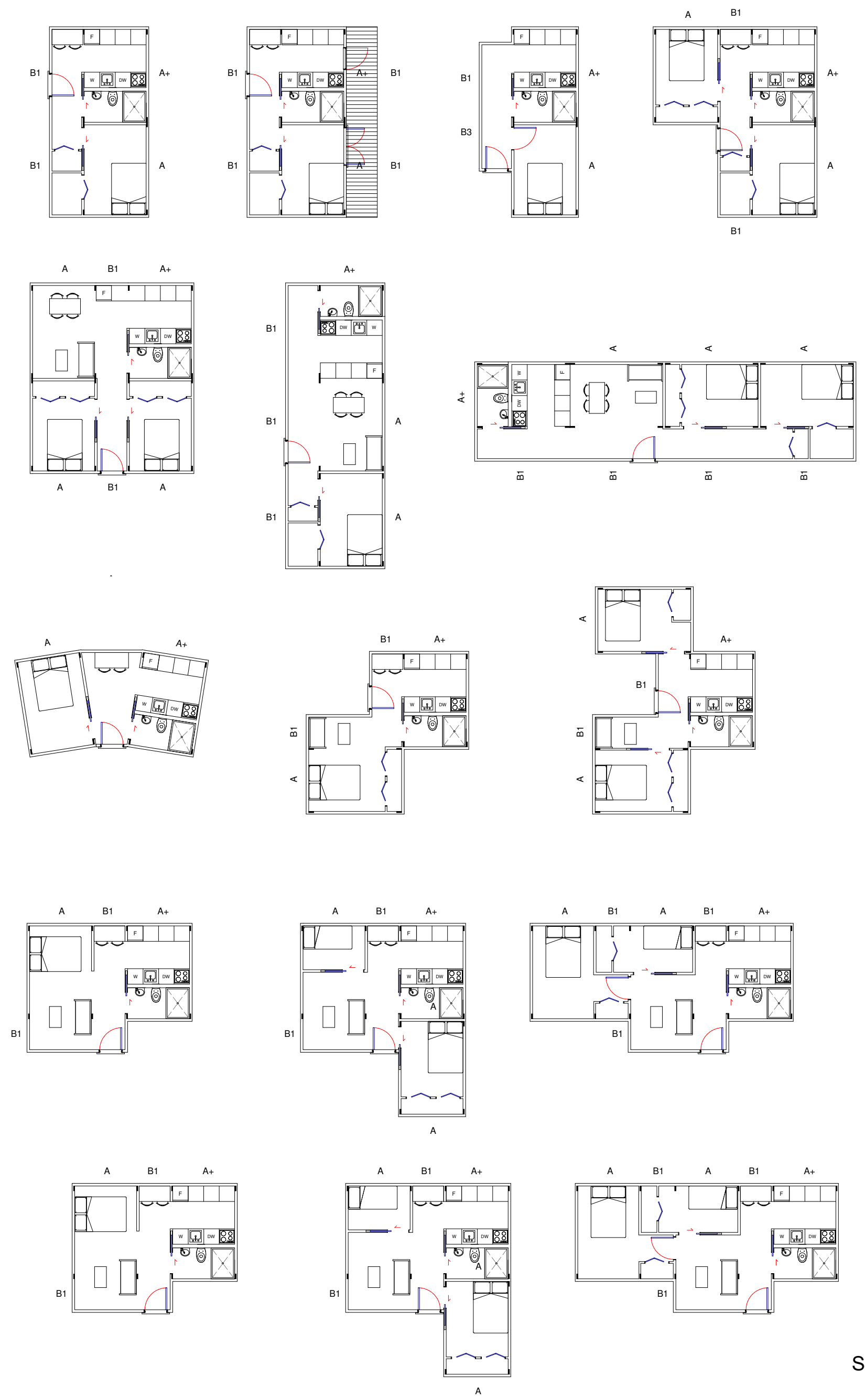
Module arrangements - spacious option

Possible modular spatial arrangements using a larger service module to maximise service amenity.
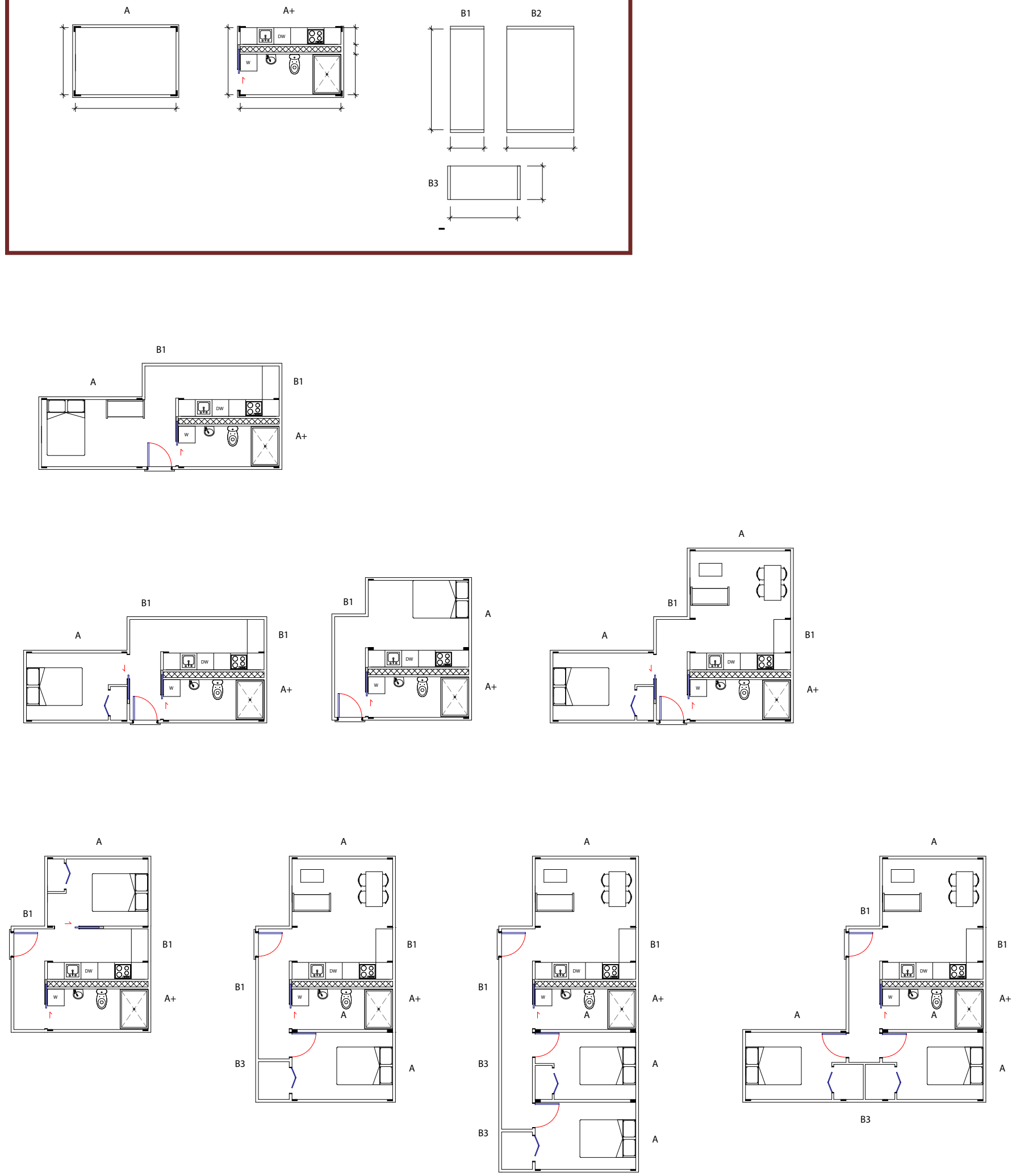

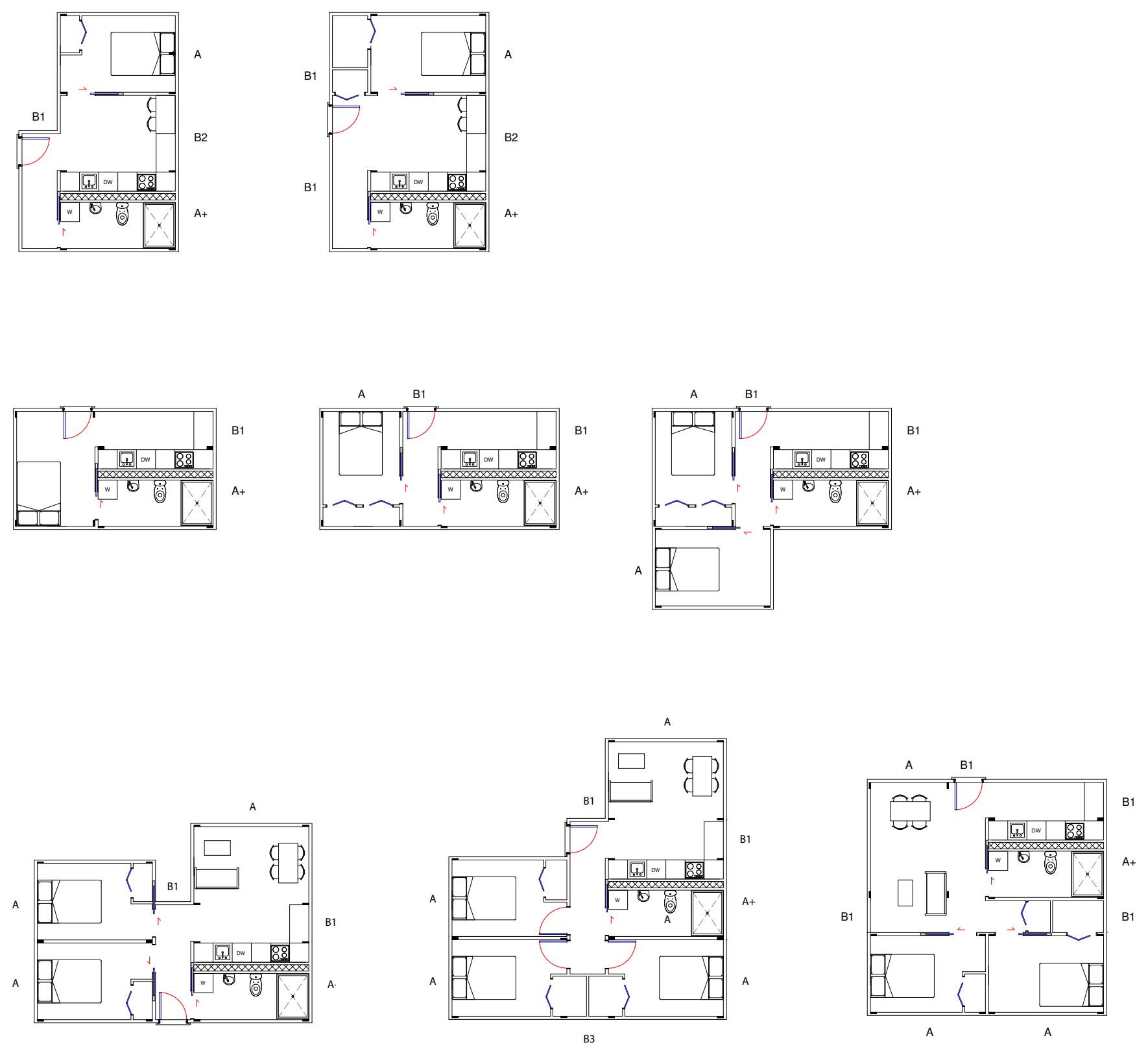
Most successful arrangements - compact option
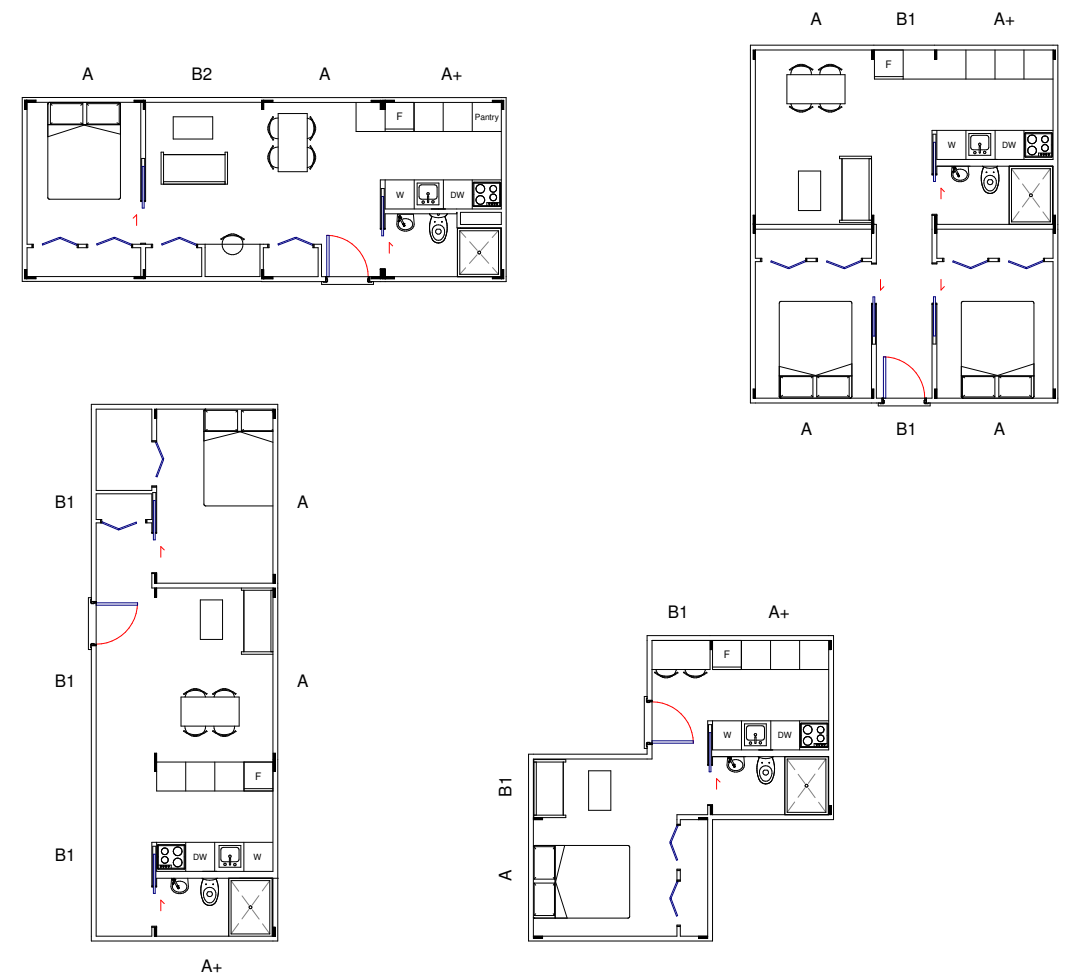

Most successful arrangements - spacious option
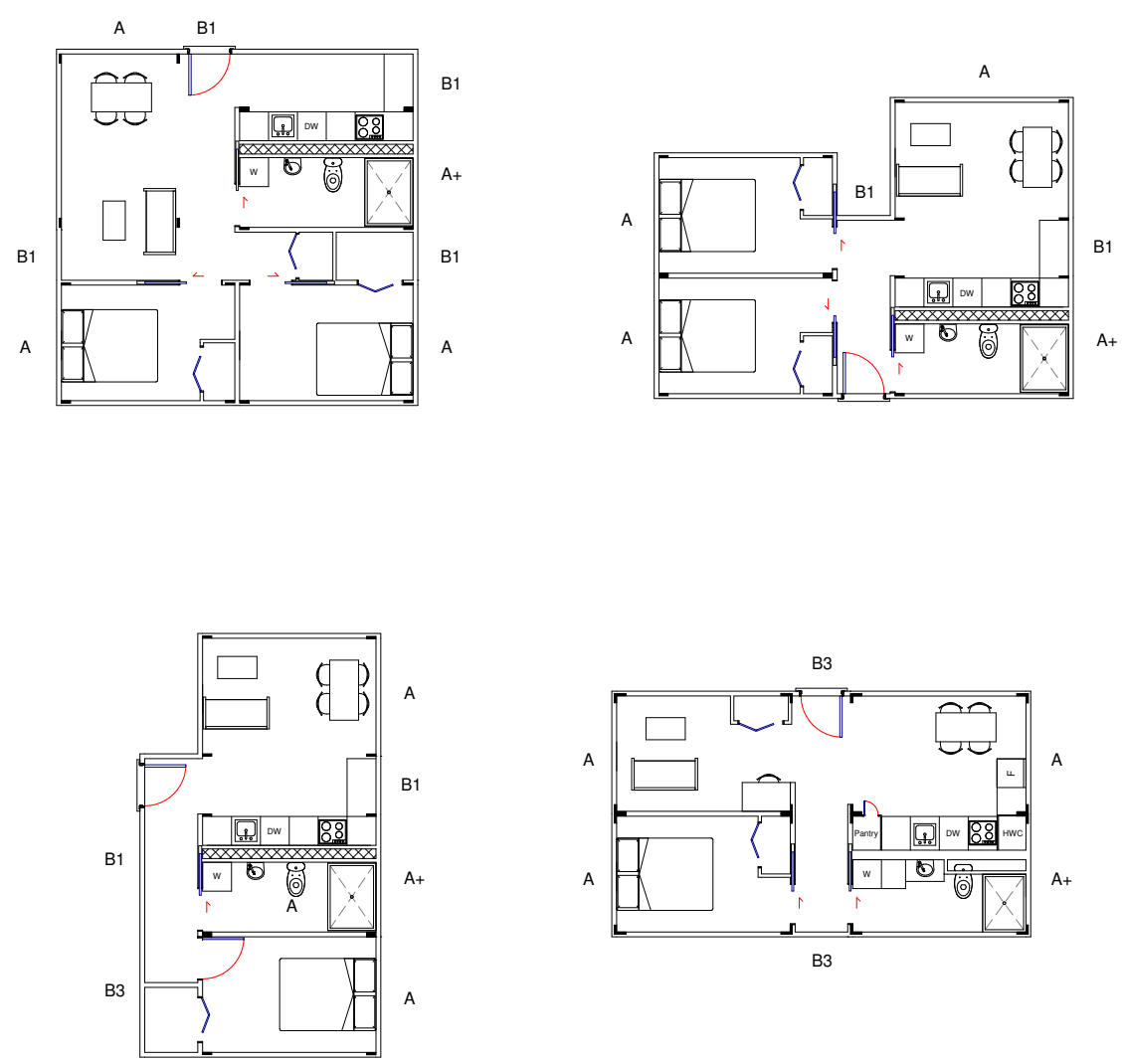
Using the modular construction concept, different spatial arrangements have been investigated to determine the feasibility of this concept for creating liveable dwellings.

\section{Compact option}

The compact service module has resulted in the possibility of smaller dwellings which include the same amenity of services as the spacious option. However, the tight spaces may not be suitable or desirable for all users.

\section{Spacious option}

As the spacious service module does not include circulation space, additional connection modules must be added, reducing spatial efficiency. Therefore, although the spacious service module provides the best accessibility, this benefit must be weighed against the overall larger footprint of the dwelling, requiring a larger site.

\section{Conclusion}

Overall, the 3.6x2.4 module size makes for very tight interior spaces which may not be appropriate for all people or lifestyles. Using a more open plan approach to the dwelling does reduce accessibility issues, especially for the bedroom space, however this may lower comfortability and privacy within dwellings with multiple occupants or when entertaining guests.

The use of standard modules within differing arrangements has allowed for spatial variation, although the number of connection elements required may reduce the desired construction efficiencies. The layouts have also remained fairly constrained to a gridded, rectangular shape with little consideration of site, similarly to the criticism of the initial incremental concepts. 


\section{Frame Connections}

Connections of the beams to the columns within the LVL frame.

\section{Joint Possibilities}

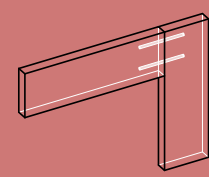

Steel Rods

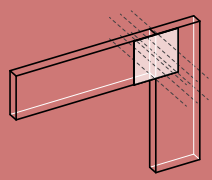

Steel Plate

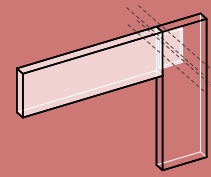

Mortise and Tenon

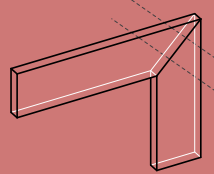

Mitre

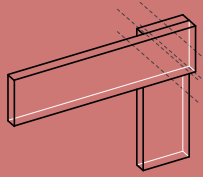

Overlap
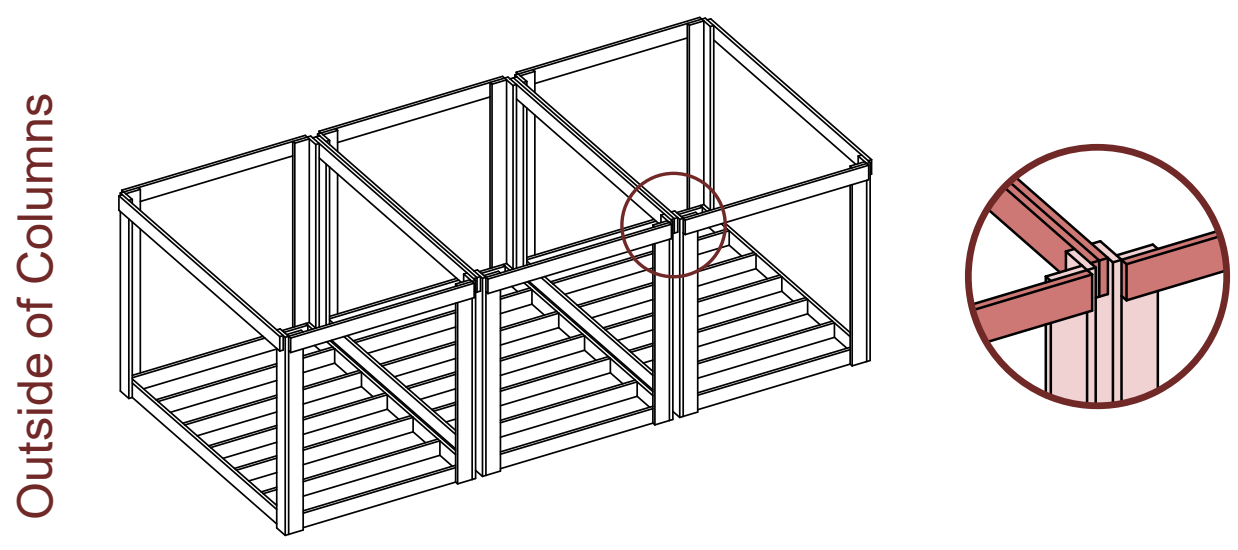

Overlapping the members would allow for the simplest joints, however this would create a gap between the modules, affecting the $2.4 \times 3.6$ grid, potentially making cladding and linings more complex.
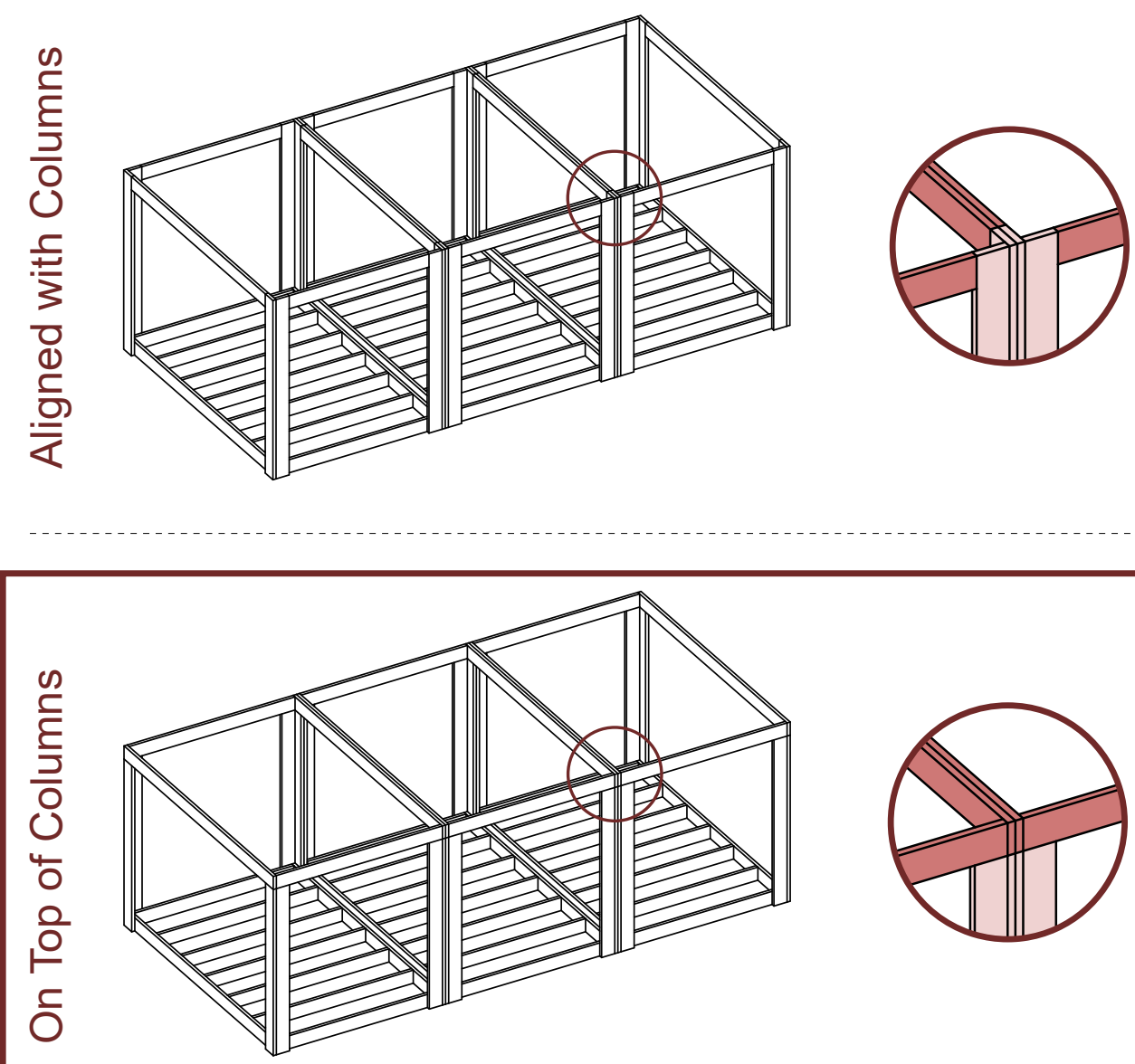

Connecting the members within the same plane, either placing the beams on top or aligned with the columns, would allow the modules to sit flush against each other. This would simplify the cladding and linings and allow more freedom of module layout by maintaining the $2.4 \times 3.6$ grid across connections. This does however make joints between the members more complex, but still achievable. 


\section{Wall Cassettes}

Composition of the wall cassettes and frame.

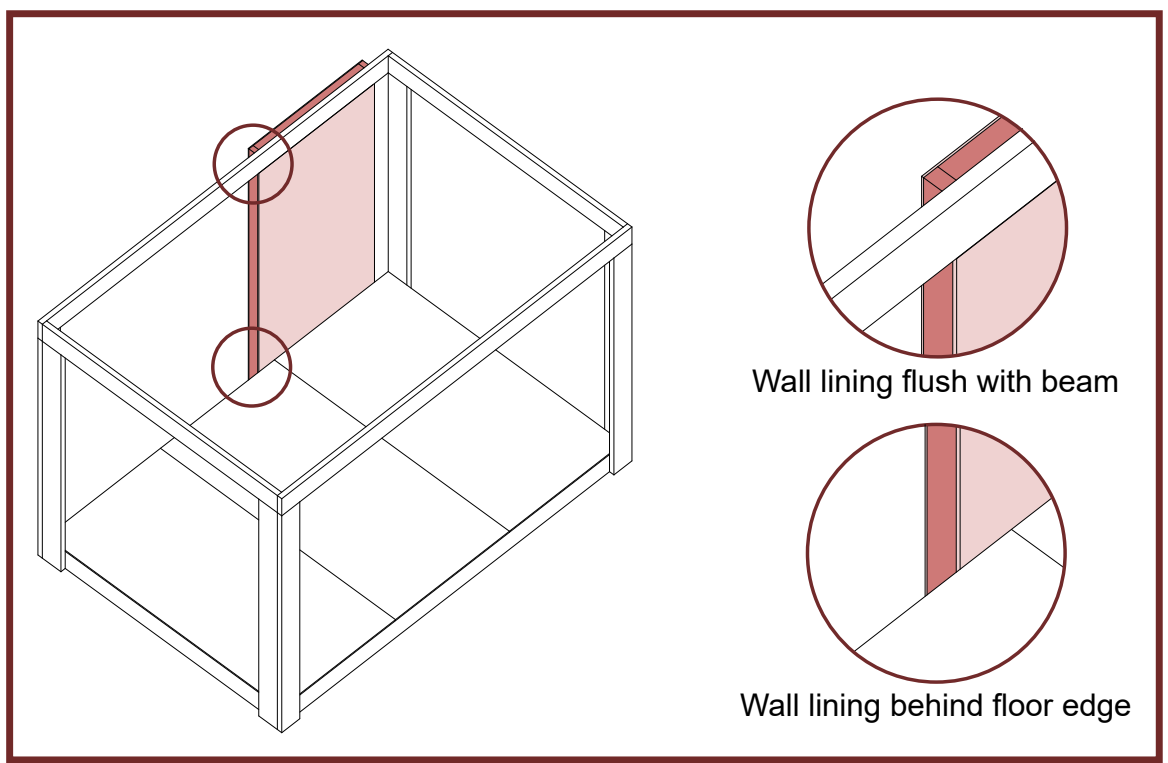

This would expose the structural beam elements, expressing the timber construction. This would also allow the wall cassette to include the interior linings before it is attached to the structure.
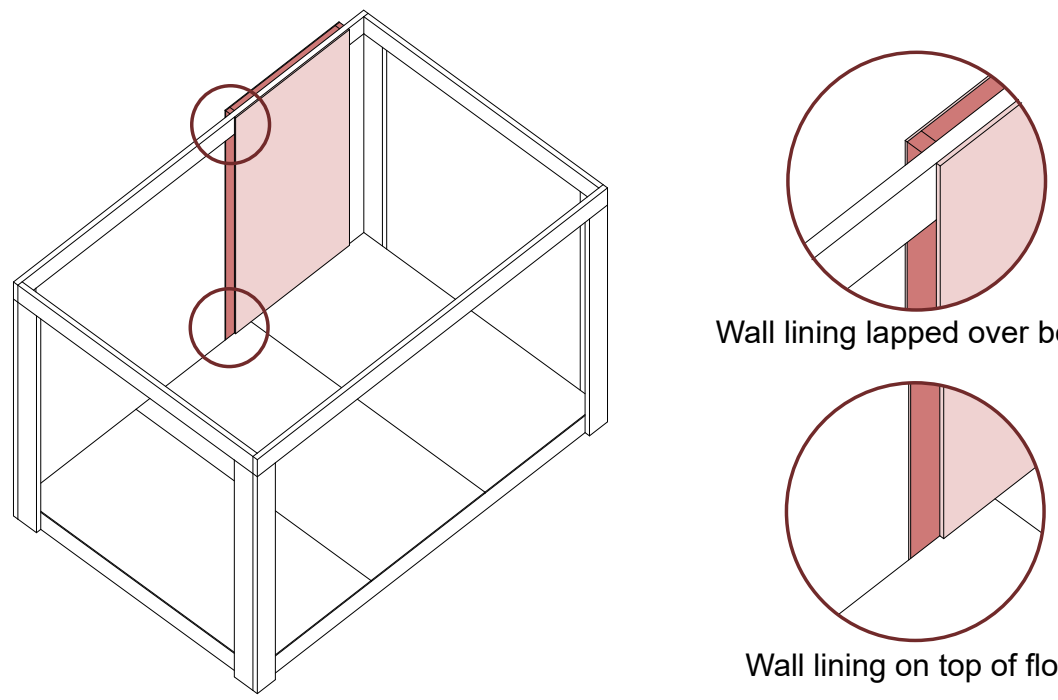

Wall lining lapped over beam

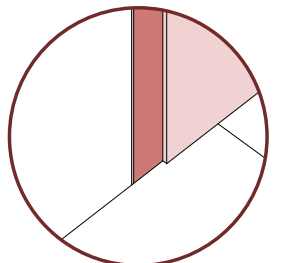

Wall lining on top of floor
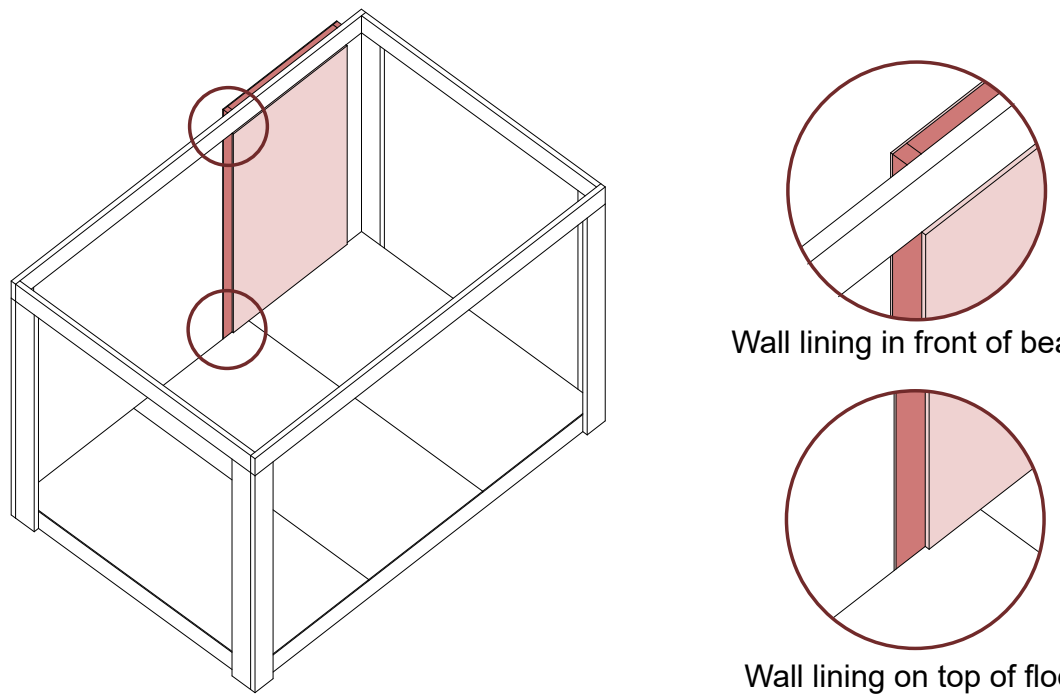

Wall lining in front of beam

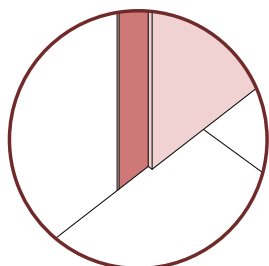

Wall lining on top of floor

This would conceal the structure, creating a clean and simple interior. Due to the overlap, interior linings would be attached separately to the wall cassette, reducing prefabrication time efficiencies on site.
This would expose the beams, however does not create a flush wall plane, sitting in front of the beam which may create a rough, unfinished aesthetic in the interior. 
Sizing of wall cassettes to fit within a standard $2.4 \times 3.6 \mathrm{~m}$ frame with $190 \times 45 \mathrm{~mm}$ members.
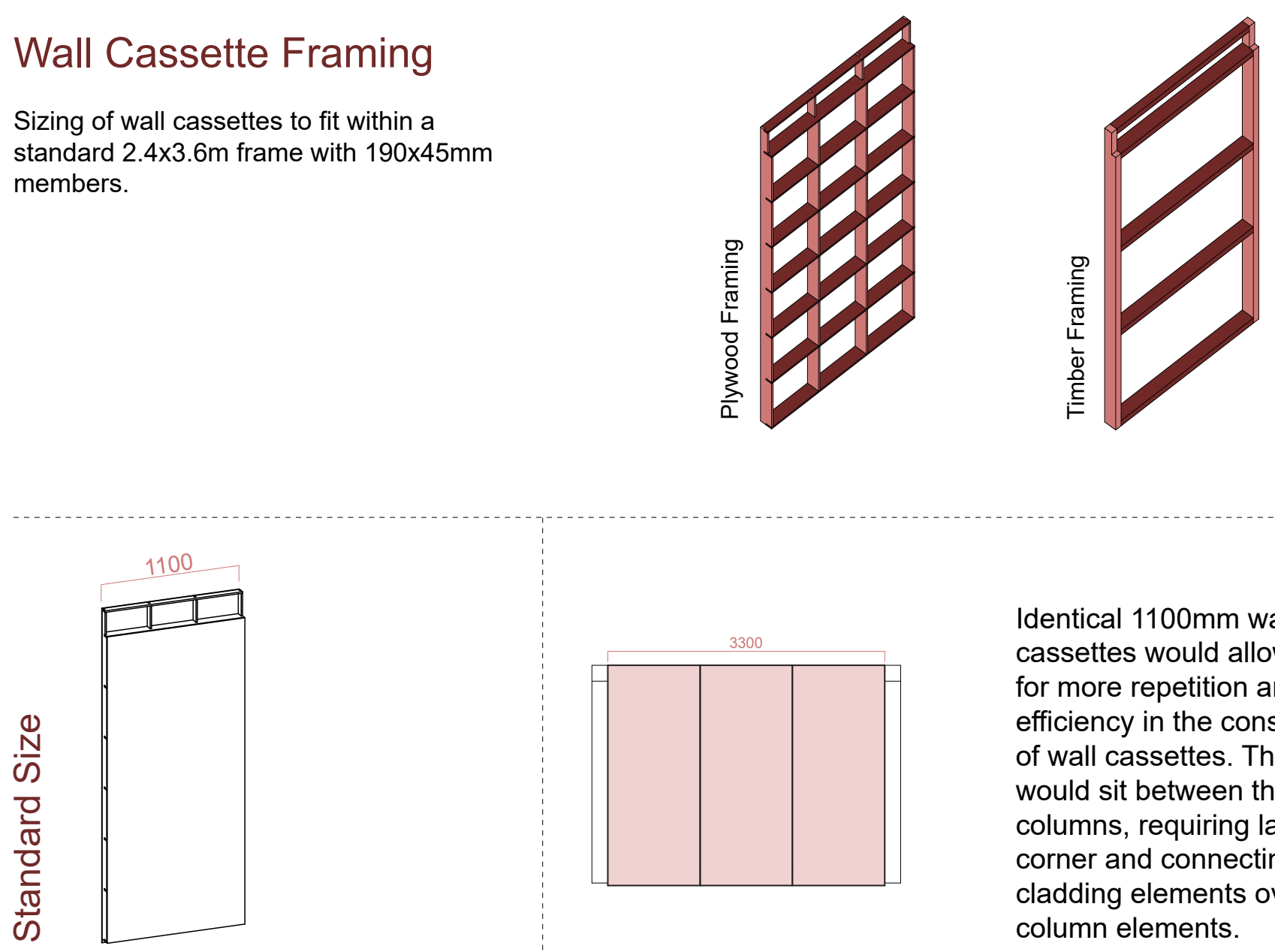

Identical $1100 \mathrm{~mm}$ wall cassettes would allow for more repetition and efficiency in the construction of wall cassettes. These would sit between the columns, requiring larger corner and connecting cladding elements over the column elements.

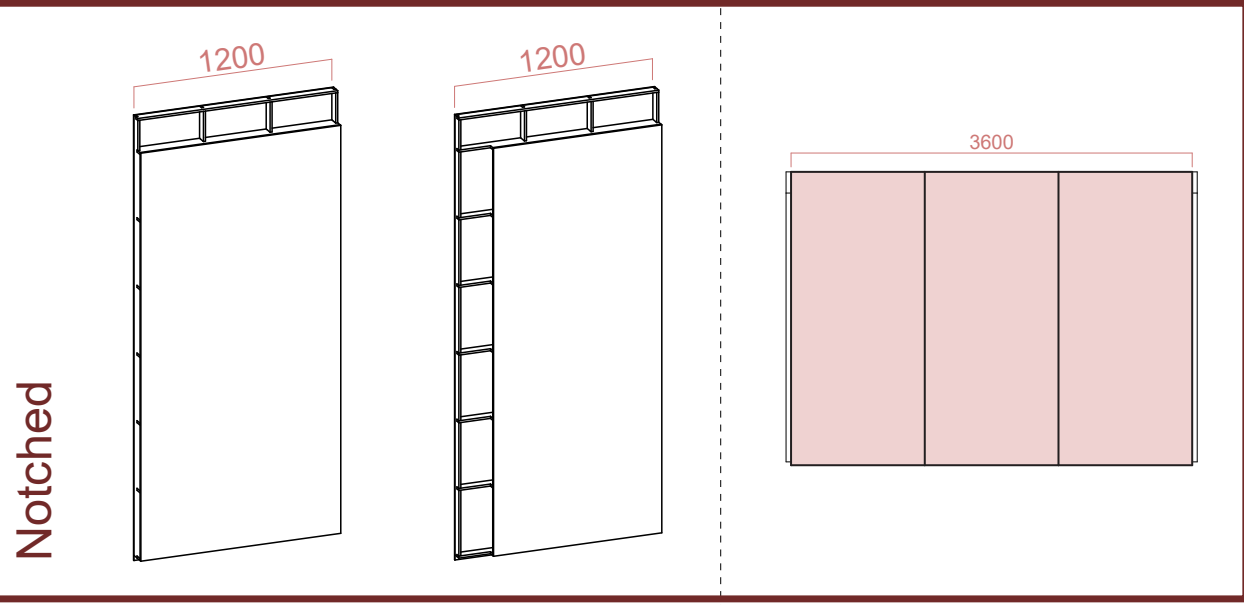

$1200 \mathrm{~mm}$ wall cassettes of two different types reinforce the $1200 \mathrm{~mm}$ grid of the concept, allowing full sheets of linings to be used. This utilises notched and unnotched cassettes to fit over and between the columns, reducing the visual impact of connection pieces.
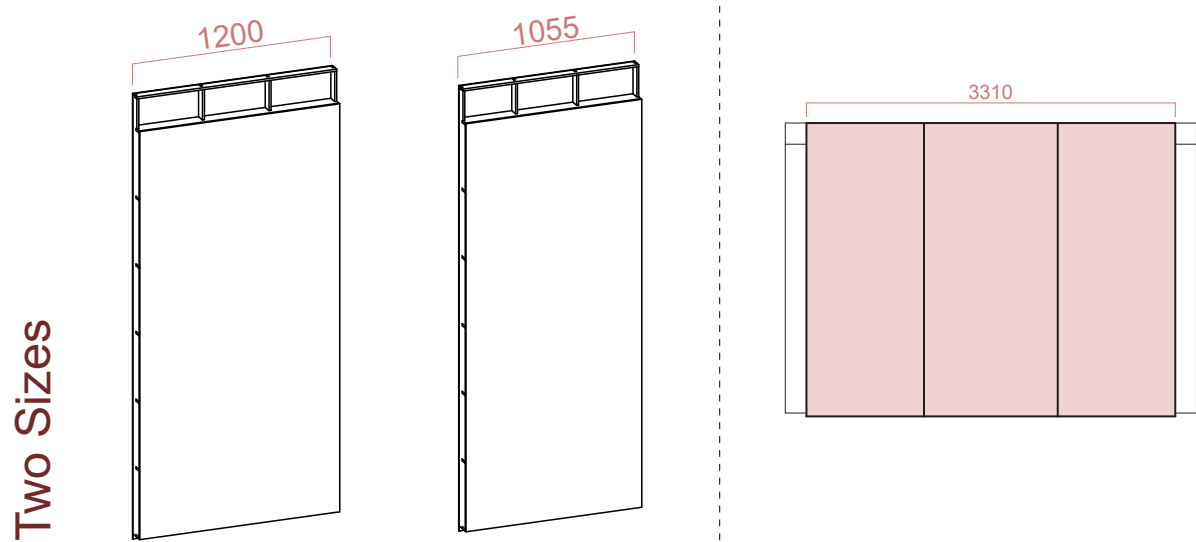

Two different sized wall cassettes allow the $1200 \mathrm{~mm}$ grid to be maintained without the need to notch the wall cassettes. This would again require larger connecting elements over the columns, and may create irregular pattern in the cladding of the façade. 


\section{Modular Roof Form}

Possible roof forms created by combining 3 module types.
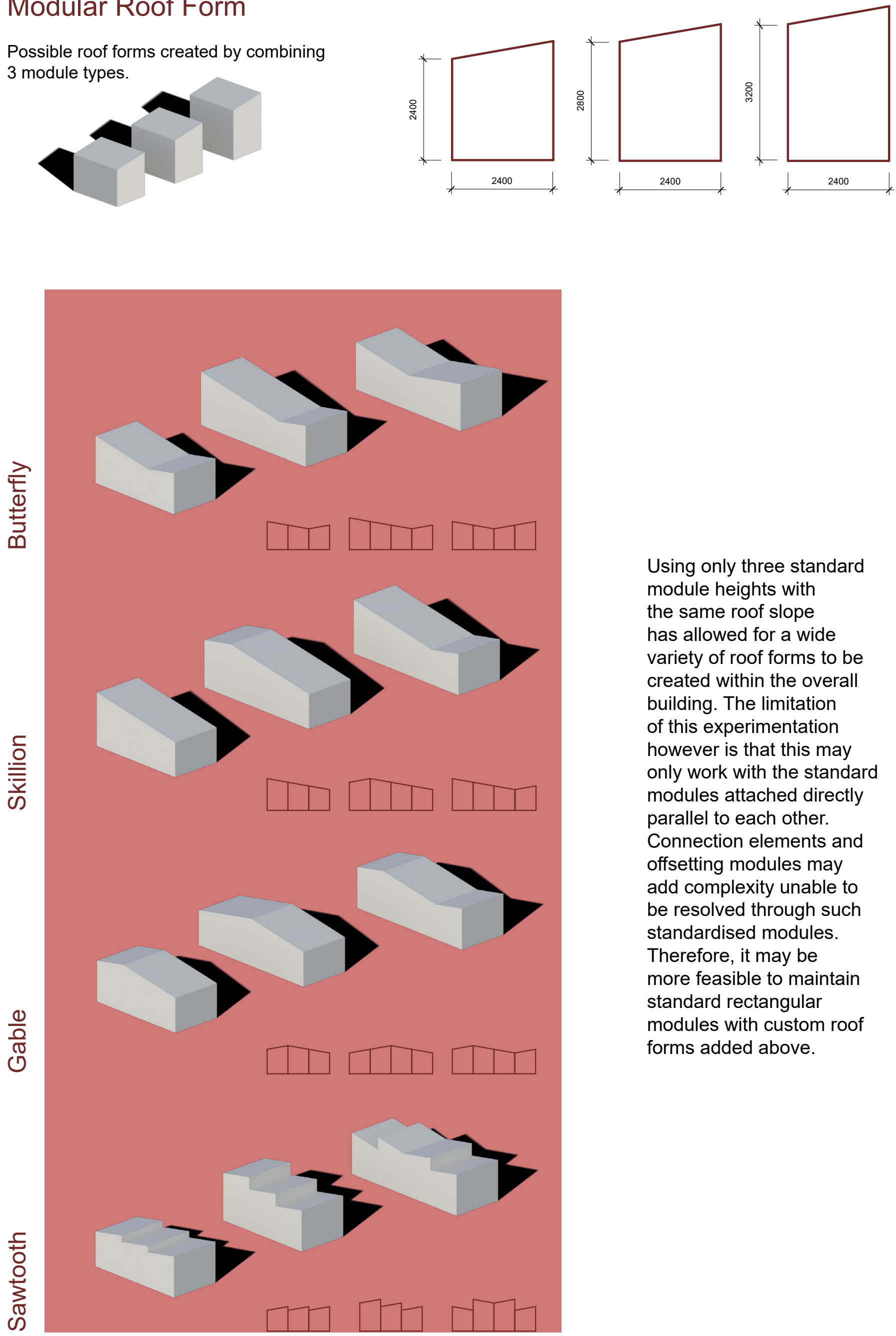

Using only three standard module heights with the same roof slope has allowed for a wide variety of roof forms to be created within the overall building. The limitation of this experimentation however is that this may only work with the standard modules attached directly parallel to each other. Connection elements and offsetting modules may add complexity unable to be resolved through such standardised modules. Therefore, it may be more feasible to maintain standard rectangular modules with custom roof forms added above. 


\section{Exposed Frame}

Frame sits outside of the wall, in front of the wall lining. Plywood floor sheets must be cut to accomodate frame. Allows simpler wall construction but reduces usable interior space, especially an issue for door openings.
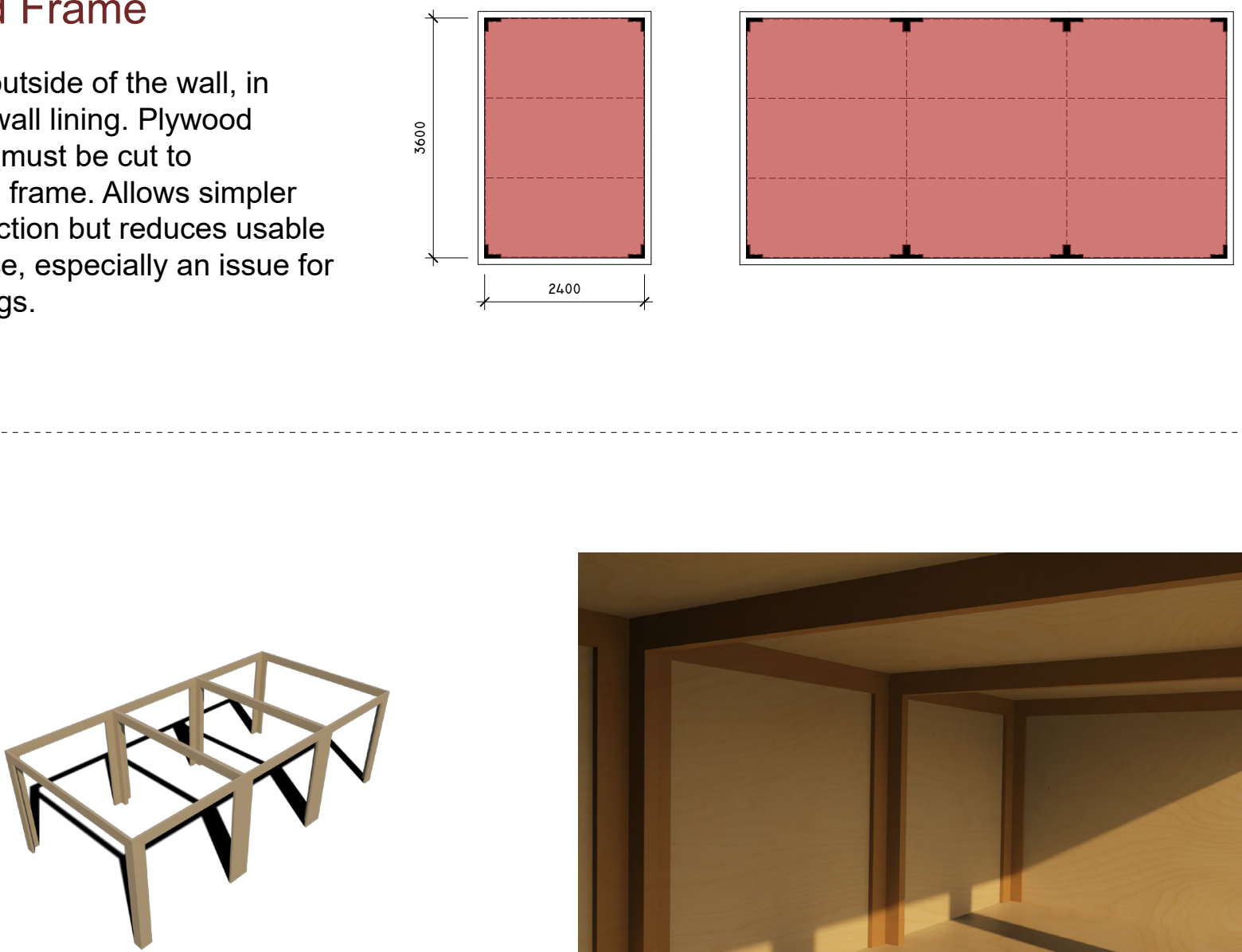

Identical frames, roof formed seperately.
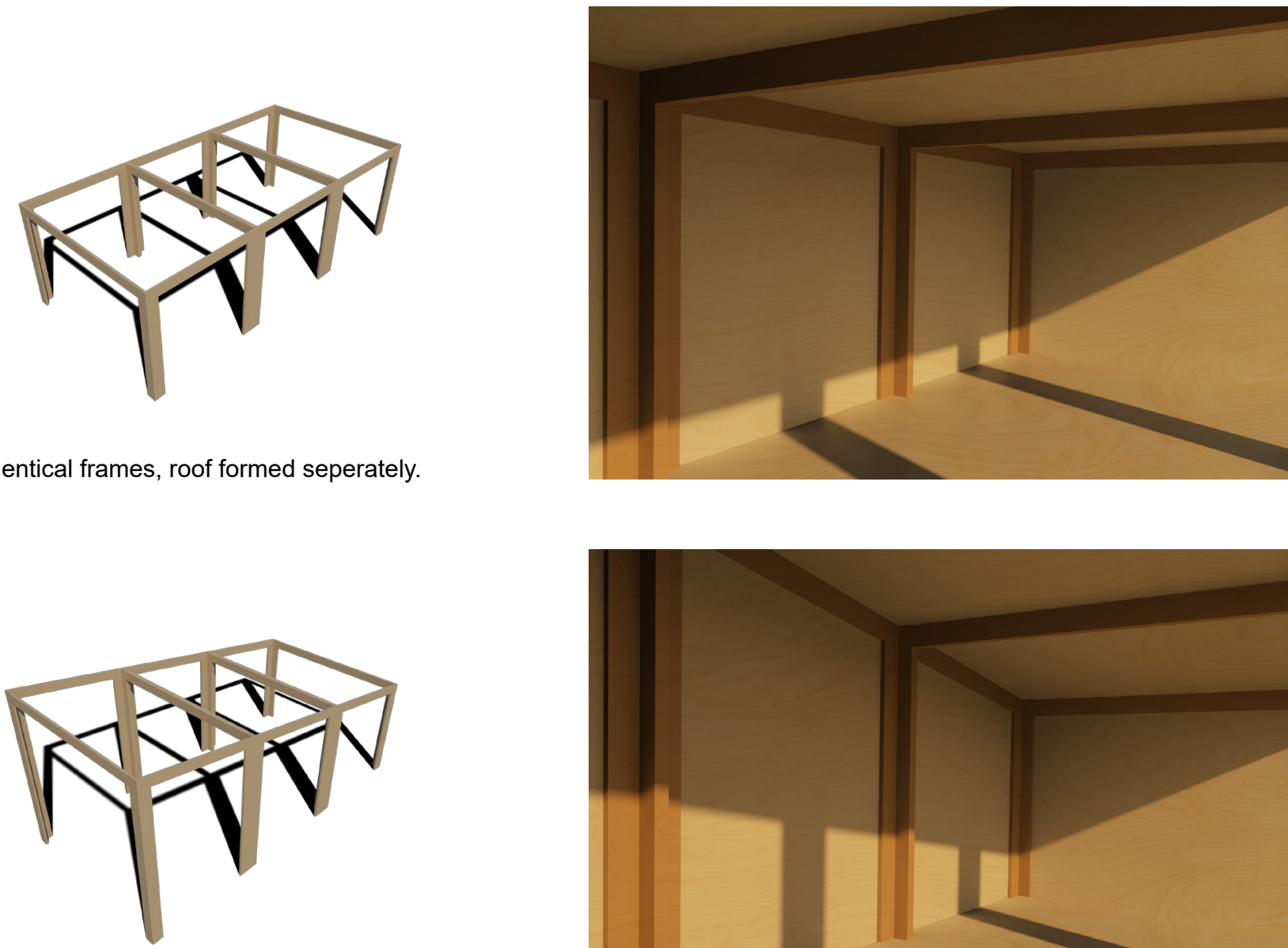

Roof slope formed by varying angled frames.
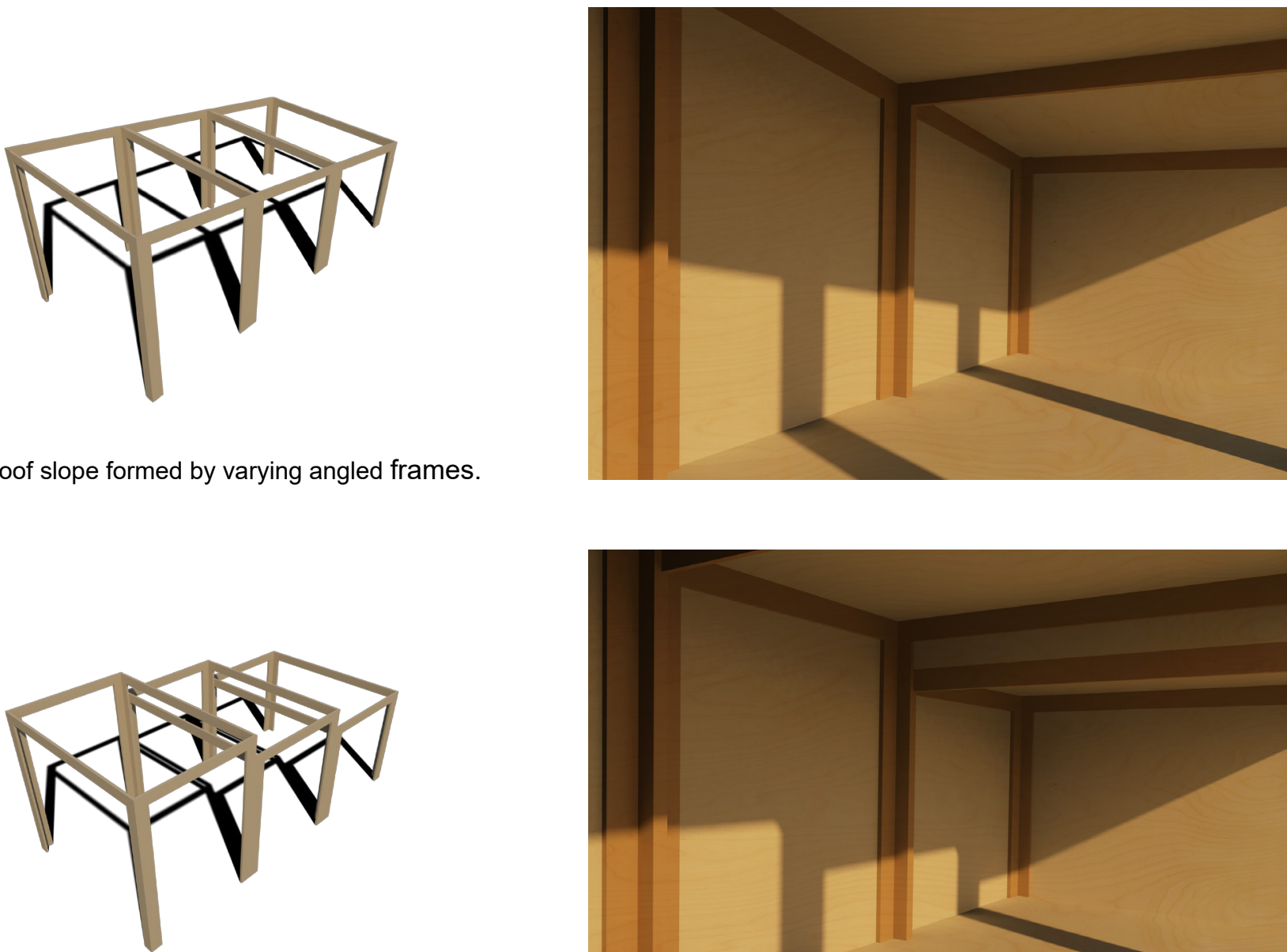

Roof slope formed by varying square frames.

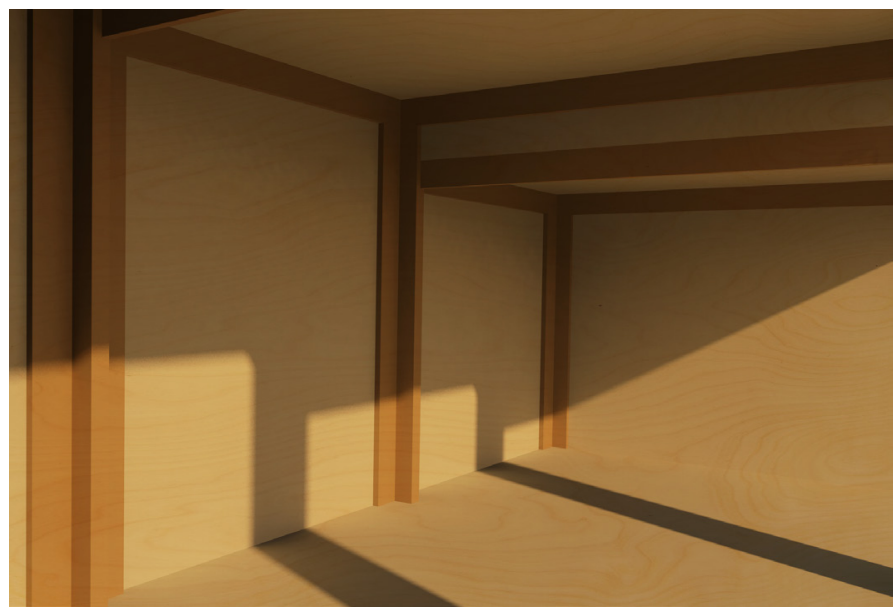




\section{Hidden Frame}

Frame sits within the wall, behind the wall lining. Plywood floor and wall sheets do not need to be cut, but a joining floor strip is needed between modules. More complex wall construction but increases usable interior space.

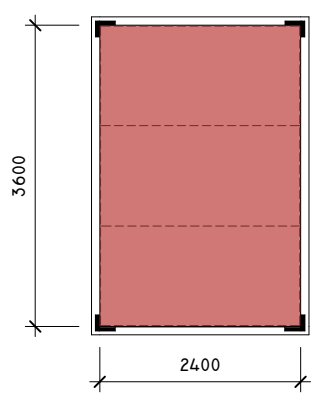

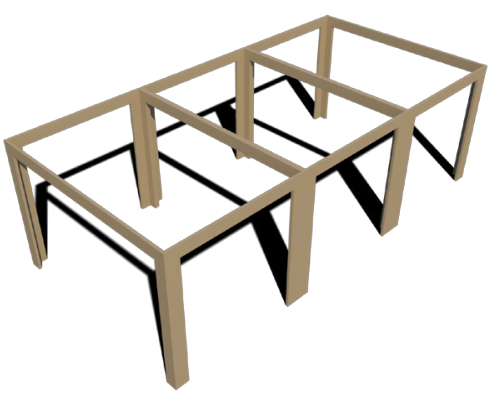

Identical frames, roof formed seperately.

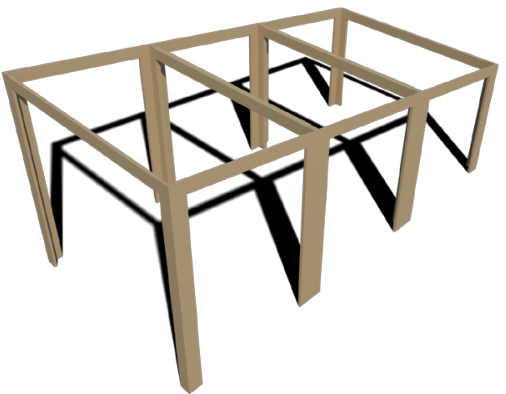

Roof slope formed by varying angled frames.

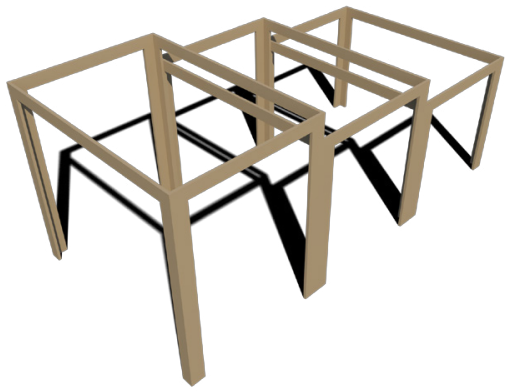

Roof slope formed by varying square frames.
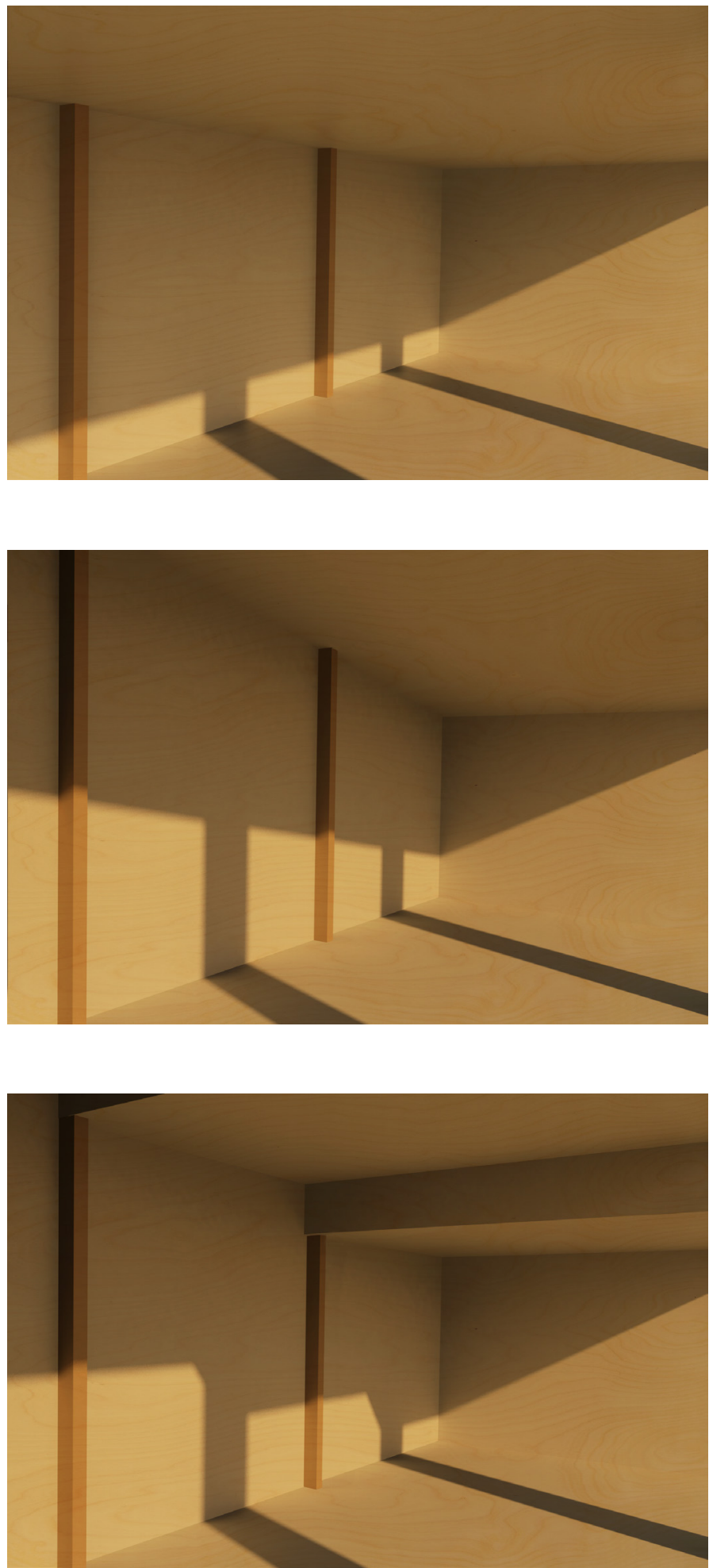


\section{MODULAR CONSTRUCTION EVALUATION}

\section{Building complexity}

While the initial concept aimed to simplify the construction of the building into standard modules and increase material efficiency by utilising a $1200 \mathrm{~mm}$ grid, explorations of the construction have highlighted many complexities to be resolved. Much of this complexity is due to the larger timber framing elements interrupting the grid, which the linings and wall cassettes must fit over or around.

The roof form has also resulted in complexity, able to be standardised only if connection elements between modules are not used. While this would simplify construction, it would greatly limit the spatial arrangements, many of which relied on connection elements within the previous explorations. A custom roof form therefore may be more appropriate and also allow for more customisation a variation of dwellings.

\section{Building aesthetics}

Due to the small $2.4 \times 3.6$ grid, the structural elements have the potential to cut up the interior visually and make the space feel small. Therefore, minimising the visual impact of the frame where possible is desirable, while still allowing for some exposure to express the timber construction within the interior. Stepping the frames to create the roof slope is the simplest for construction, however stepping the ceiling introduces complexity and may make the space feel smaller. A combination of the stepped framed and a sloped ceiling to hide the beams may therefore be a better solution (Figure 1).
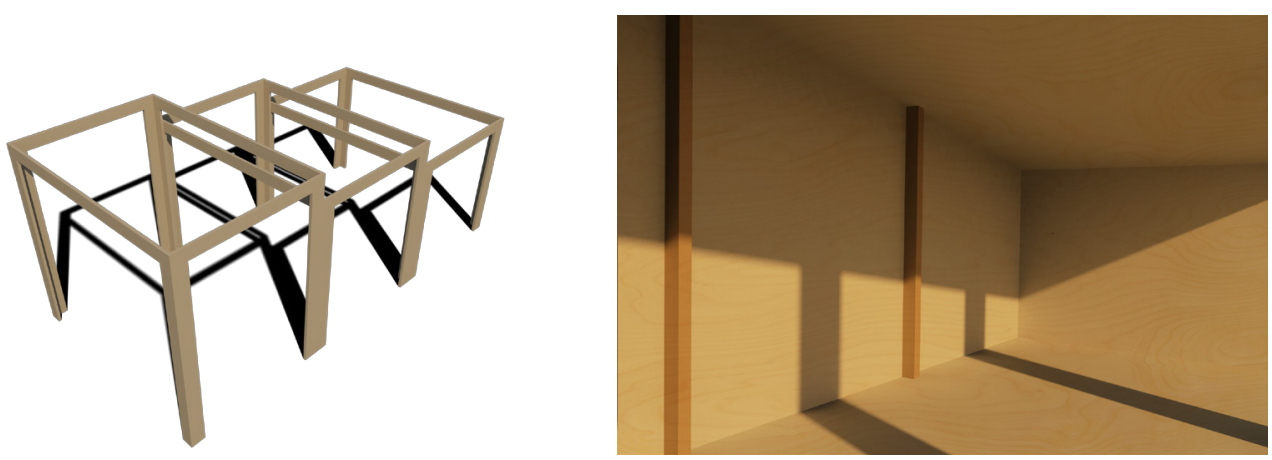

Figure 1. Stepped, hidden frames with sloped ceiling.

The use of wall cassettes will also impact the exterior aesthetics as vertical joints will be highly visible, cutting the façade visually into small $1.2 \mathrm{~m}$ strips. This would be most cost effective, allowing for maximum prefabrication, however if a higher budget project was undertaken, these cassettes could be clad onsite with a rainscreen cladding to hide the joints and create a more cohesive exterior façade.

\section{Conclusion}

Overall, standardisation of the entire building through the use of limited modules may be too limiting if variation is desired. This exploration has highlighted the need to combine standard and non-standard elements with considerations of prefabricated efficiencies carefully weighed against the overall visual and functional outcome. 
DEVELOPED CONCEPTS 
Developed concept - compact option

One possible outcome using the standard modules combined with

custom roof and deck additions.
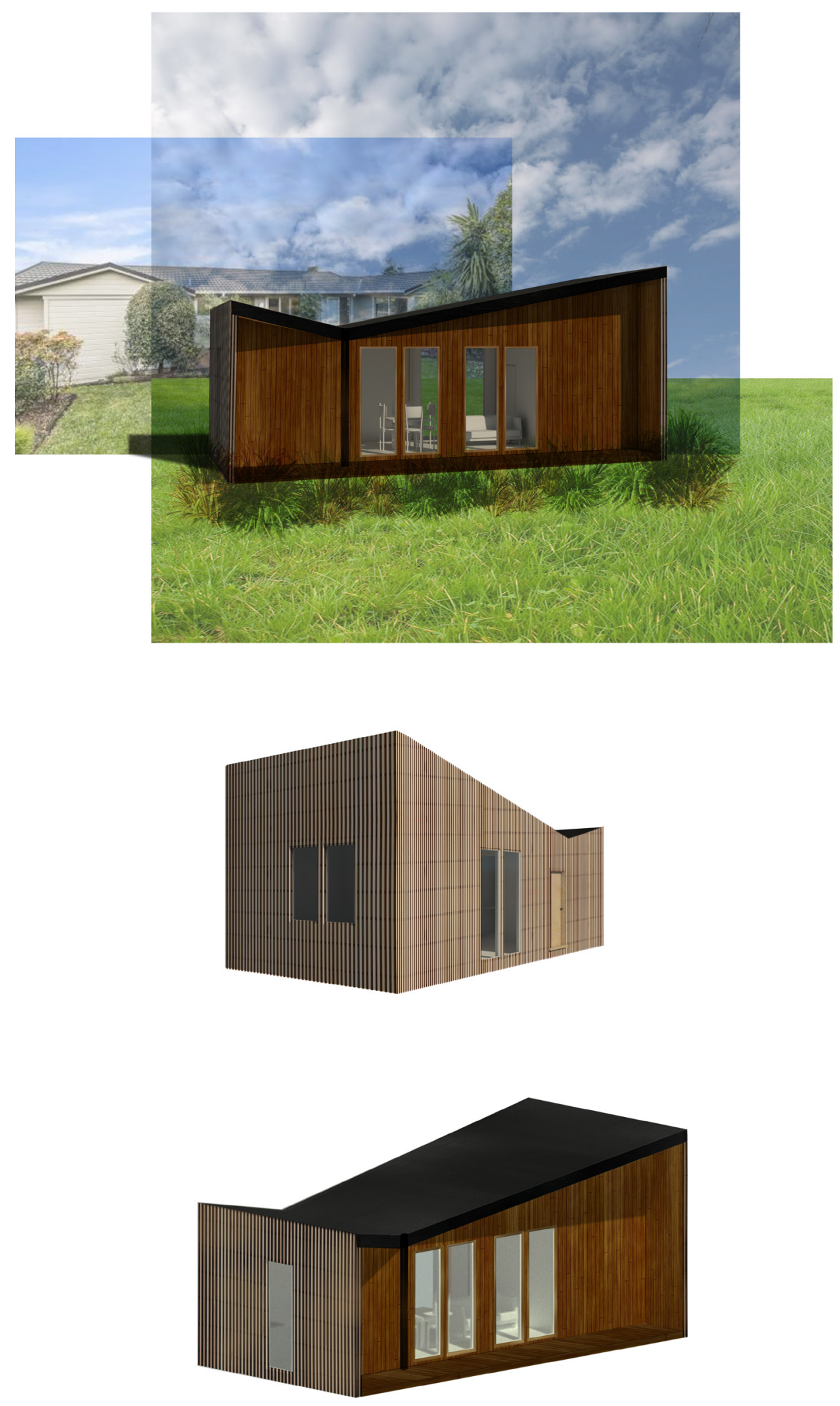

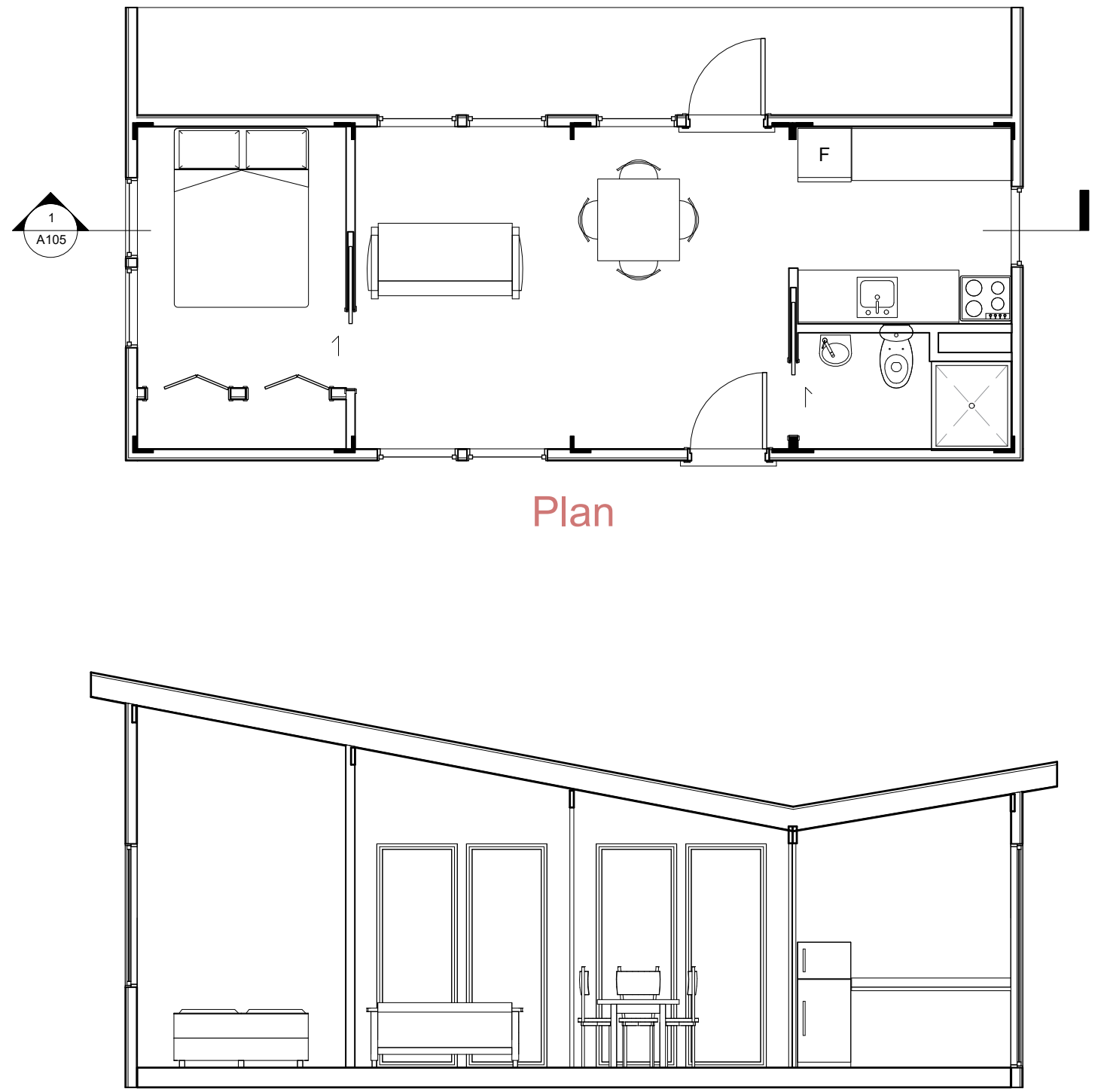

Section

The compact core has allowed for a small floor footprint overall, wasting little space for circulation. There is little separation of activities within the dwelling however, with the bathroom, bedroom and front door opening directly into the living/dining area. Due to the location of doors and circulation, the living space may also feel cramped and difficult to navigate. 
Developed concept - spacious option

One possible outcome using the standard modules combined with

custom roof and deck additions.
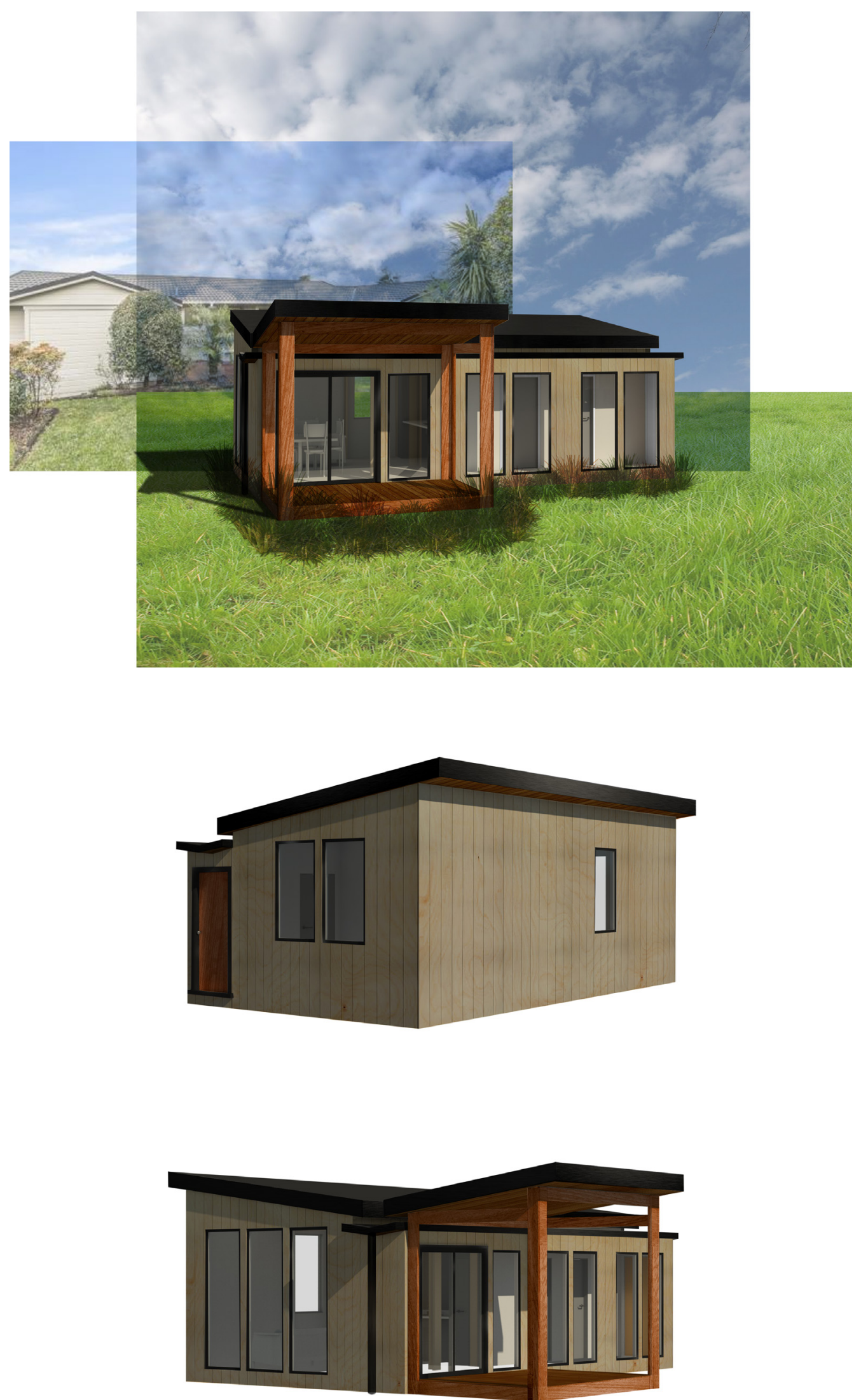

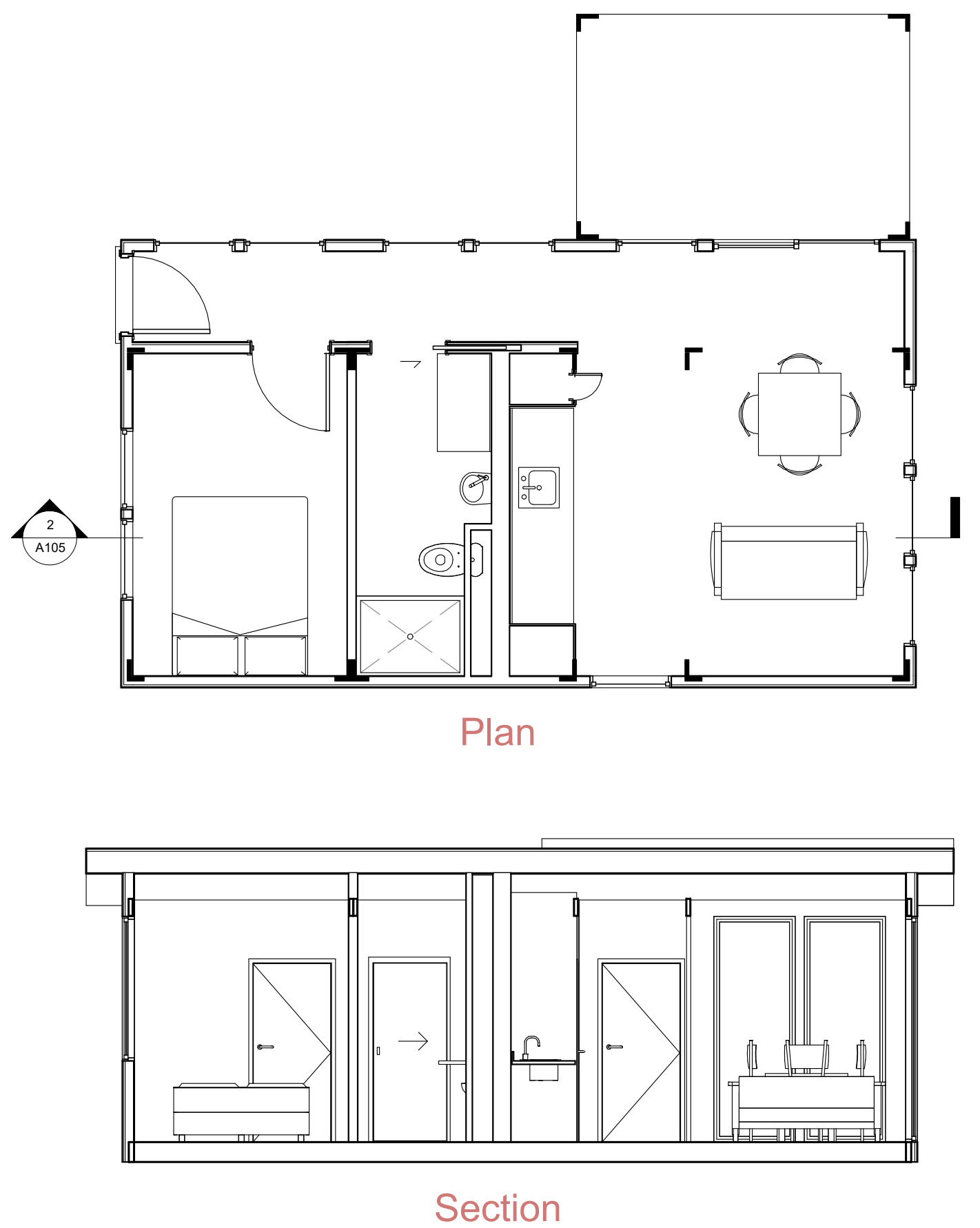

The spacious core option has allowed the kitchen amenities to connect directly to the living space, creating a more open kitchen/living/dining area than the compact option. The bedroom is then effectively separated from the living area by the bathroom, creating more privacy and separation of activities within the dwelling than the compact option. This layout has been made possible through a long hallway along one side of the dwelling which has little function beyond circulation, wasting valuable space onsite and construction budget that could be better utilised within a different layout. 


\section{CONCLUSION}

The review of literature has found that prefabrication is able to significantly reduce waste and cost within the construction of dwellings in New Zealand. Modular construction may be further able to improve cost efficiencies, but largely relies on economies of scale to be effective, meaning wide scale adoption of similar or repeated buildings is needed. This suggests that the development of single design concept that could be repeated across a wide range of sites would be ideal for the aims of this project.

The design concepts were overall successful in creating variation through the repetition of standard modules, however the design outcomes resulting in very tight and potentially undesirable living spaces. This suggests that the size of the module is ineffective. The concepts also did not consider site or outdoor space, suggesting the need for further design explorations to focus on more site responsive, rather than generic approaches. 


\section{WORKS CITED}

Atkinson, A. R. (2002). The pathology of building defects; a human error approach. Engineering Construction \& Architectural Management (Wiley-Blackwell), 9(1), 53-61. doi:10.1046/j.1365232X.2002.00224.x

Bell, P., \& Southcombe, M. (2009). Kiwi Prefab: Prefabricated Housing in New Zealand: An Historical and Contemporary Overview with Recommendations for the Future. (Master of Architecture), Victoria University of New Zealand, Wellington.

Burgess, J. C., Buckett, N. R., \& Page, I. C. (2013). Prefabrication Impacts in the New Zealand Construction Industry (SR 279). Retrieved from http://www.branz.co.nz/cms show download. php?id=2935644f1d998595f3a2d8f5e8167dd08a42a179

Fawcett, R., Allison, K., \& Corner, D. (2005). Using Modern Methods of Construction to build homes more quickly and efficiently. National Audit Office.

Kaufmann, M., \& Remick, C. (2009). prefab green: Gibbs Smith.

Kim, D. (2008). Preliminary Life Cycle Analysis of Modular and Conventioinal Housing in Benton Harbor, Michigan. University of Michigan Ann Arbor.

McGraw-Hill Construction. (2011). Prefabrication and Modularization: Increasing Productivity in the Construction Industry. Retrieved from Bedford: http://damassets.autodesk.net/content/dam/autodesk/ www/solutions/building-information-modeling/building-design/prefabrication-and-modularization-in-construction.pdf

Page, I. C., \& Norman, D. (2014). Prefabrication and standardisation potential in buildings (SR 312). Retrieved from http://www.branz.co.nz/cms show download.php?id=10b942e6e882228654fbed906d54cca424233ed7

PrefabNZ. (2014). PrefabNZ Value Case for Prefab Retrieved from http://www.prefabnz.com/Downloads/ Assets/8010/1/PrefabNZ\%20Value\%20Case\%20for\%20Prefab\%20(2014).pdf 
CHAPTER 3:

SITE SELECTION \& ANALYSIS 


\section{INTRODUCTION}

To address the issue of a lack of site responsiveness identified in the previous design explorations, this chapter aims to identify a suitable case study suburb to site further design explorations. Planning rules are reviewed to provide insight into current land use guidelines and restrictions and literature is reviewed to provide criteria for the selection of a suburb suitable for densification. The suburb is then analysed to determine existing and potential future density levels that may be achieved through the implementation of infill dwellings. 
PLANNING RULES 


\section{ANALYSIS OF EXISTING PLANNING RULES}

\section{DENSIFICATION PROVISIONS}

The problem of unmet housing demand in New Zealand has been largely addressed with respect to land prices and mortgage access, rather than through investigation and implementation of alternative housing strategies such as ADUs (Saville-Smith et al., 2017). Additionally, little consistency in planning policies exists across jurisdictions and rules are reportedly poorly articulated, lacking coherent reasoning (Saville-Smith et al., 2017). Therefore, wide scale adoption of ADUs may be hindered rather than promoted by district plans.

The addition of new builds on existing residential sites do not have title requirements, differing from site subdivision, however, they must still conform to district planning rules (Saville-Smith et al., 2017). Of New Zealand's 67 local Authorities, 44 permit the addition of a residential dwelling on an already built site, while another 7 permit the addition of a dwelling only for the purpose of housing family members (Saville-Smith et al., 2017). Within each Authority, rules relating to the addition of an ADU typically vary according to zone, often depending on the existing character and density of the area (Saville-Smith et al., 2017). Variation and implications of these rules have been examined further through the comparison of the Auckland Unitary Plan and the Wellington District Plan (Table 1).

\section{AUCKLAND UNITARY PLAN VS WELLINGTON DISTRICT PLAN}

Table 1. Comparison of the Auckland Unitary Plan and Wellington District Plan rules for ADUs.

\begin{tabular}{|c|c|c|c|c|c|}
\hline & $\begin{array}{l}\text { Number of } \\
\text { dwellings } \\
\text { permitted }\end{array}$ & $\begin{array}{l}\text { Max site } \\
\text { coverage }\end{array}$ & $\begin{array}{l}\text { Max } \\
\text { height } \\
\text { (m) }\end{array}$ & $\begin{array}{l}\text { Other dwelling size } \\
\text { restrictions }\end{array}$ & $\begin{array}{l}\text { Minimum outdoor } \\
\text { space provision per } \\
\text { dwelling }\left(\mathrm{m}^{2}\right)\end{array}$ \\
\hline \multicolumn{6}{|l|}{ Auckland } \\
\hline $\begin{array}{l}\text { Residential - } \\
\text { Single House } \\
\text { Zone }\end{array}$ & $\begin{array}{l}1+1 \text { minor } \\
\text { dwelling }\end{array}$ & $35 \%$ & 8 & $\begin{array}{l}\text { Minor dwelling must } \\
\text { not exceed } 65 \mathrm{~m} 2\end{array}$ & $\begin{array}{l}\text { Minor dwellings: } 5 \\
\text { for one bed, } 8 \text { for } \\
\text { two or more bed }\end{array}$ \\
\hline $\begin{array}{l}\text { Residential - } \\
\text { Mixed Housing } \\
\text { Suburban Zone }\end{array}$ & 2 & $40 \%$ & 8 & $\begin{array}{l}\text { Minimum dwelling size } \\
\text { of } 30 \mathrm{~m}^{2}\end{array}$ & 20 \\
\hline \multicolumn{6}{|l|}{ Wellington } \\
\hline $\begin{array}{c}\text { Outer Residential } \\
\text { Area }\end{array}$ & 2 & $35 \%$ & 8 & $\begin{array}{c}\text { Maximum height of an } \\
\text { Infill Household Unit is } \\
4.5-6 \mathrm{~m}\end{array}$ & 50 \\
\hline $\begin{array}{c}\text { Inner Residential } \\
\text { Area }\end{array}$ & 2 & $50 \%$ & 10 & none & $\begin{array}{l}35 \text { ( } 20 \text { must be } \\
\text { private) }\end{array}$ \\
\hline
\end{tabular}

Both Auckland and Wellington planning objectives are similar in their aim to achieve higher residential intensities within already developed areas that are close to existing centres, public amenities and public transport networks. However, despite these aims, both Authorities still additionally address growth through provisions for greenfield development of rezoned land for new suburbs.

Both Authorities also aim to ensure that development conforms to the existing suburban character of existing areas, respecting existing built form and current levels of property amenity. Rules are most restrictive in areas with lower existing density, aiming to maintain and enhance the values of residential neighbourhoods and their spacious lot sizes, informed by past development strategies. One exception to 
this is the Wellington District Plan provision for 'Medium Density Residential Areas' which aims to achieve comprehensive redevelopment that results in moderate to significant increases in residential density without a need to maintain the existing character of the area.

Rules for ADUs are most restrictive in Auckland's Single House Zone and Wellington's Outer Residential Area, likely due the existing lower densities of these areas. In these areas, maximum site coverages are low, restricting the footprint of dwellings and promoting underutilisation of sites. The minimum provision for outdoor space is also high in Wellington's Outer Residential Area, promoting past suburban ideals of large lot sizes. Outdoor space requirements are however minimised in Auckland for 'minor dwellings', recognising a difference in amenity provision for ADUs. In the higher density suburban zones, classified as the Mixed Housing Suburban Zone in Auckland and the Inner Residential Area in Wellington, rules are less restrictive but only marginally. 


\section{SITE SELECTION AND ANALYSIS}




\title{
SUITABILITY OF KILBIRNIE FOR DENSIFICATION
}

\author{
TRAIN STATION
}

WELLINGTON CBD

AIRPORT 

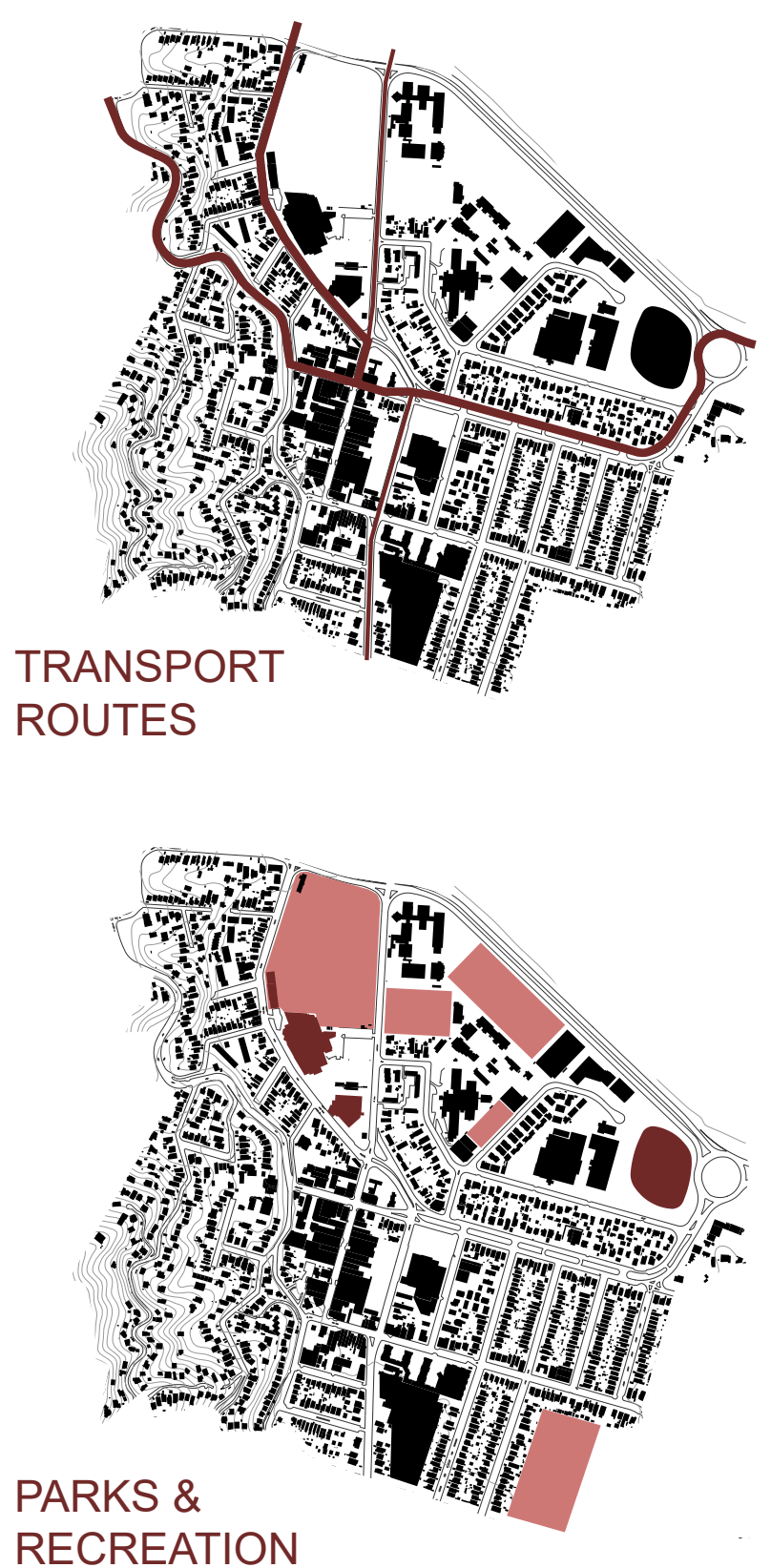
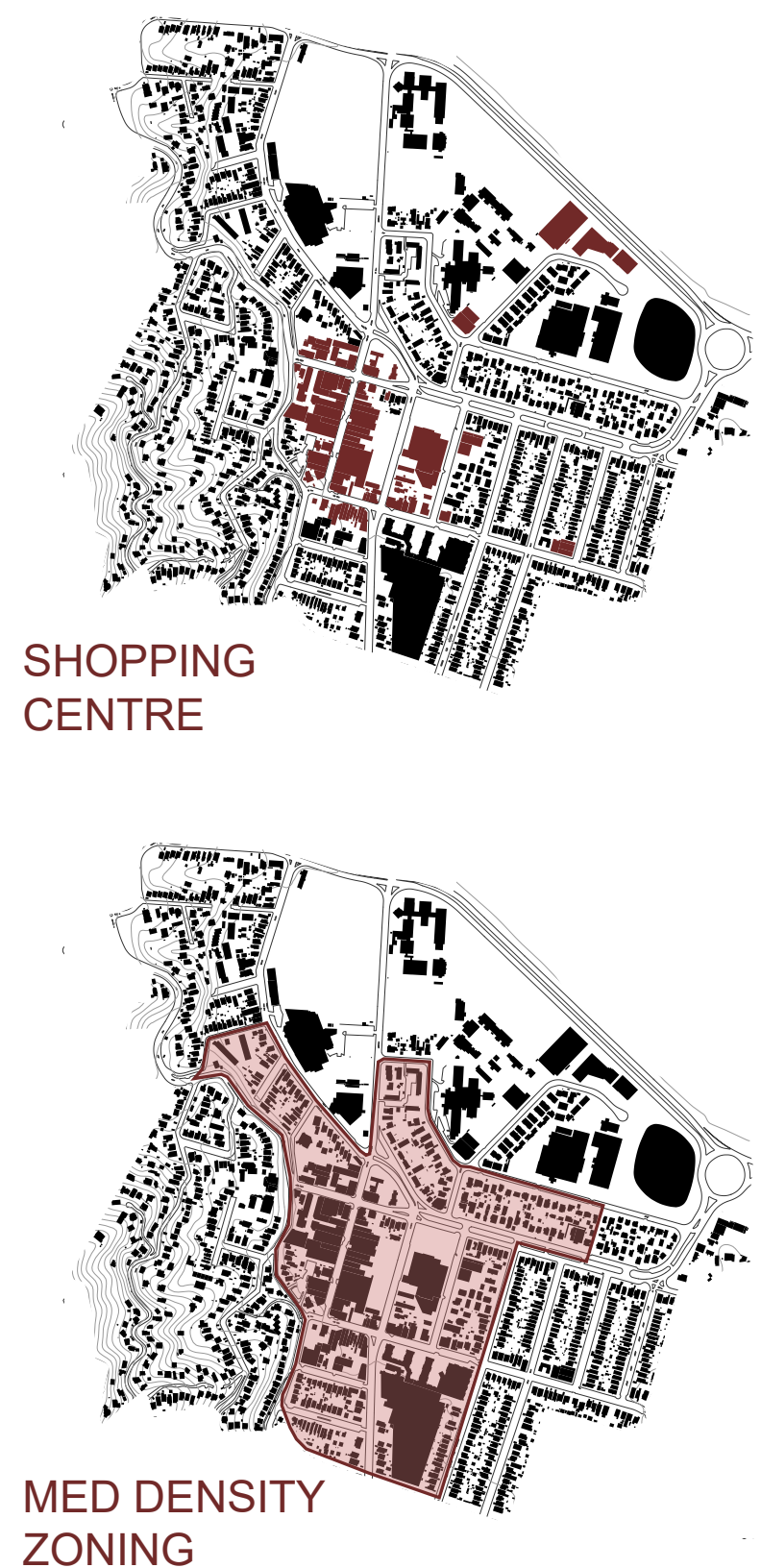

Kilbirnie, a suburb in the outer residential area of Wellington City, has been selected as a case study for this research due to the area exhibiting a range of characteristics that are likely to support densification, following recommendations by Dunham-Jones and Williamson (2008). These include:

- Public transport infrastructure; Kilbirnie is located on a key transport route from the CBD to the airport, planned for investment and upgrade of public transport and roading as part of the Wellington City Council (WCC) 10 year plan (Macleod, 2014).

- A mix of uses in walking distance; Kilbirnie contains a central shopping area, schools, a number of sports and recreational facilities, a large area of public park land and borders the town belt.

- The ability to become an economic engine and destination: Kilbirnie has a large proportion of commercially zoned land located at its centre.

Due to its location, existing infrastructure and amenity, a portion of the residential area within Kilbirnie was zoned by the WCC in 2010 for medium density housing (Gray Partners Ltd, 2014). However, despite this zoning change, very little development has taken place since then (Gray Partners Ltd, 2014). Financial feasibility studies have attributed this largely to the small scale of land parcels available, requiring developers to take a very long term stance to development, needing to acquire multiple adjoining lots as they become available for purchase to receive any substantial profit margin (Gray Partners Ltd, 2014). Due to this, the smaller scale implementation of ADUs on an individual plot scale may provide a more financially feasible solution to increasing density in the suburb. 


\section{FEASIBILITY OF AVAILABLE SITES}

\section{SITE REQUIREMENTS}

Initial concept explorations have informed minimum sized one or two bedroom dwellings, including kitchen, bathroom and living space, suitable for each site typology.

The resulting minimum site dimensions for these dwellings for each site type as follows:

- Front yards: $5300 \mathrm{~mm} \times 9300 \mathrm{~mm}$

- Side yards: $3000 \mathrm{~mm} \times 15000 \mathrm{~mm}$

- Back yards: $7000 \mathrm{~mm} \times 9100 \mathrm{~mm}$

The levels of density able to be achieved through the addition of ADUs on the identified site typologies have been estimated for a range of areas within the suburb, each with varying initial densities (Table 2). This has been done based on the available site sizes and shapes around existing dwellings, informed by the initial ADU plan and massing studies. Due to the varying configuration of sites and openings of existing dwellings for sunlight access, some of these sites are more feasible than others.

\section{AREAS ANALYSED}

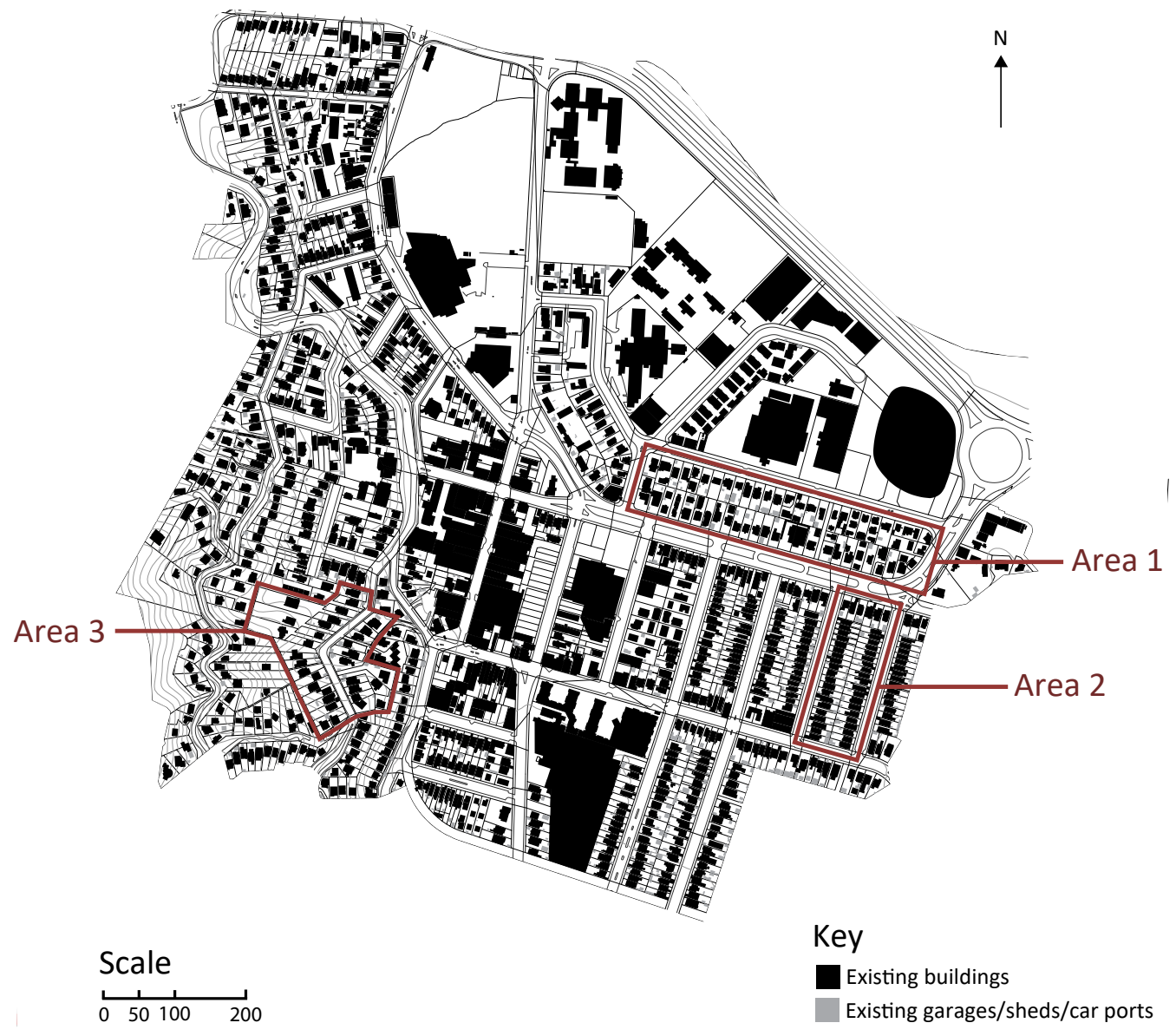


Table 2. Levels of density achieved across the sites investigated.

\begin{tabular}{|c|c|c|c|c|c|c|}
\hline & $\begin{array}{l}\text { Average } \\
\text { width }(\mathrm{m})\end{array}$ & $\begin{array}{c}\text { Average } \\
\text { length (m) }\end{array}$ & Topography & $\begin{array}{c}\text { Number of } \\
\text { suitable sites }\end{array}$ & $\begin{array}{l}\text { Density } \\
\text { (du/ha) }\end{array}$ & $\begin{array}{l}\text { Density } \\
\text { increase }\end{array}$ \\
\hline Area 1 & & & & \multicolumn{3}{|c|}{ Existing: 24.2} \\
\hline Front yards & 15.3 & 7.4 & Flat & 31 & 33.6 & $39 \%$ \\
\hline Side yards & 4.2 & 40.3 & Flat & 25 & 31.8 & $31 \%$ \\
\hline Back yards & 15.3 & 16.3 & Flat & 22 & 30.9 & $28 \%$ \\
\hline Area 2 & & & & \multicolumn{3}{|c|}{ Existing: 31.5} \\
\hline Front yards & 9.1 & 4.7 & Flat & 3 & 33.6 & $7 \%$ \\
\hline Side yards & 1.5 & 34.9 & Flat & 1 & 32.2 & $2 \%$ \\
\hline Back yards & 9.1 & 12 & Flat & 46 & 63 & $100 \%$ \\
\hline Area 3 & & & & \multicolumn{3}{|c|}{ Existing: 14.8} \\
\hline Front yards & 13.5 & 11 & Flat-sloped & 28 & 26.7 & $80 \%$ \\
\hline Side yards & 4.9 & 41.5 & Sloped-steep & 17 & 22 & $48 \%$ \\
\hline Back yards & 14.5 & 16.7 & Sloped-steep & 30 & 27.6 & $86 \%$ \\
\hline
\end{tabular}

\section{Front yards}

Front yard sites provide the most promise in terms of access, both in terms of access to the dwelling from the street and access to daylight. These benefits to the ADU however are likely in most cases to directly reduce these benefits for the existing dwelling on site, restricting their access from the street, and on smaller sites, reducing their daylight access. Despite this, a large number of the front yard sites in Kilbirnie already contain garage structures, showing acceptability for building on these sites. These negative impacts would also be limited to the immediate site, with minimal impact on neighbouring properties. Proximity to the existing road may pose issues for the ADU in terms of privacy and acoustics, however, this may be mediated through careful design of openings.

\section{Side yards}

Side yard sites provide the opportunity to minimise impact on existing urban patterns, impacting neither existing street setback patterns, nor the openness of existing back yards. Side yards are easily accessible from the street and are currently the least utilised sites, lacking the size or privacy for garden or recreational space. However, these sites are often used on one side of each property for driveway access to back yard garages which may limit building on these sites. These sites are the least available within the suburb and are typically only narrow strips, requiring close proximity to existing dwellings and restricting the possible width of ADUs. This would also limit daylight access to the ADU and the existing dwellings, although window openings are already minimal along the sides of existing dwellings. Another limitation of these sites would be a common requirement to locate the dwelling over the boundary of two existing properties to gain sufficient land width.

\section{Back yards}

Back yard sites present the most promising opportunity in terms of size and distance from existing dwellings, minimising possible negative impacts on daylight access and privacy for the ADUs and the existing dwellings. However, placing the structure close to property boundaries may cause this typology to have the greatest impact on neighbours' properties and receive objection. Back yards are also the most currently utilised areas of land, providing space for recreation, gardens, garages and storage structures. In addition to this, private back yards reportedly provide a key amenity that makes lower density suburban living desirable (Bryson, 2017). Access to these sites is also the least convenient, requiring thoroughfare past the existing dwelling, although, this may be somewhat mediated by the prevalence of existing driveways or pathways along the side yards of most properties. 


\section{CONCLUSION}

A review of district planning rules and sustainable densification literature has given insight into existing strategies for suburban densification, as well as informing the selection of the case study suburb of Kilbirnie in Wellington. Analysis of available sites in Kilbirnie has shown back and front yard sites to have the most potential for ADUs to be implemented to create significant density increases, so further development will focus on solutions for these site types. 


\section{WORKS CITED}

The Auckland Unitary Plan Operative in part, (2018).

Bryson, K. (2017). The New Zealand Housing Preferences Survey: Attitudes towards medium-density housing (SR378). Retrieved from Judgeford: https://www.branz.co.nz/cms show download. php?id=9aa2011337f7e6cebc169d4ac4c711d721b7e938

Dunham-Jones, E., \& Williamson, J. (2008). Retrofitting suburbia: urban design solutions for redesigning suburbs: John Wiley \& Sons.

Gray Partners Ltd. (2014). Commercial Drivers for Medium-Density Residential Development in Selected Wellington Suburbs Retrieved from Wellington: https://wellington.govt.nz/ /media/your-council/projects/files/housing-choice-supply/medium-density-housing/commerical-drivers-mdra-development. pdf?la=en

Macleod, A. (2014). Wellington City Housing and Residential Growth Study: Final Planning Assessment and Recommendations. Retrieved from Wellington: https://wellington.govt.nz/ /media/your-council/projects/files/housing-choice-supply/wcc-residential-study-final-report.pdf

Marriage, G. (2014). Pavlova paradise and the curse of the side yard. Building A Better New Zealand, 360365.

Saville-Smith, K., Saville-Smith, N., \& Fraser, R. (2017). ADU Potential: Have we the potential to use our existing housing stock of homes to create a bigger stock of affordable, fit for purpose homes? Retrieved from http://www.buildingbetter.nz/publications/SRA1/Saville-Smith_et_al_2017 ADU Potential.pdf

The Wellington City District Plan, (2018). 
CHAPTER 4:

SITE RESPONSIVE MASSING 


\section{INTRODUCTION}

Following the selection of a case study suburb, this chapter explores the massing of site responsive dwellings on front and backyard sites in Kilbirnie. Literature is reviewed to identify the preferences and priorities of New Zealanders in selecting a home and precedents are reviewed to determine strategies for achieving these. Massing and sunlight studies are undertaken, aiming to create dwellings that are sensitive to these preferences, as well as their sites. 
MASSING PRIORITIES 


\section{PRIVACY, OUTDOOR SPACE AND SUNLIGHT ACCESS}

\section{PRIVACY IN HOUSING DESIGN}

\section{Definitions of privacy}

Rather than regarding privacy as a state of social withdrawal, it can be considered as a process for controlling one's level of availability to others which may vary according to individual differences and changing situations (Oseland, 2009). An inability to achieve a desired level of privacy may result in discomfort and stress, with too little leading to perceptions of overcrowding, and too much leading to feelings of isolation (Oseland, 2009).

Privacy can be considered in a number of different ways, based on factors such as physical distance and control of interaction, leading to the classification of the following types (Carmona, Heath, Oc, \& Tiesdell, 2010):

1. Solitude: being alone

2. Intimacy: a small number of people by themselves and undisturbed

3. Anonymity: interacting with people without being identifiable or accountable

4. Reserve: the ability to limit communication about oneself

5. Seclusion: being out of the way and difficult to find

6. Not neighbouring: avoiding contact with neighbours

7. Isolation: being away from others

\section{Design considerations}

Privacy from the public domain is discussed as an important role of the home within western culture, impacting mental health (Lindsay, Williams, \& Dair, 2010). However, as definitions and expectations of privacy may vary greatly between individuals, cultures and situations, research suggests the built environment should allow occupants to have control over their privacy (Lindsay et al., 2010).

Design characteristics that influence privacy in the built environment can be considered as 'barriers', both physical and symbolic, which aim to deter intrusion (Abu-Ghazzeh, 2000). Physical barriers may refer to strategies involving sonic or visual 'screens' and physical distance, whereas symbolic barriers aim to manage and influence behaviour (Carmona et al., 2010). Literature on housing design often discusses both 'aural' privacy, relating to noise transference within and between dwellings, and 'visual' privacy, relating to overlooking from one property or dwelling into another (Lindsay et al., 2010; RIBA \& Ipsos MORI, 2012).

\section{SUNLIGHT ACCESS}

\section{Psychological benefits of daylight}

Numerous studies show that humans overwhelmingly prefer sitting next to windows, with reasons for this linked to access to view, as well as access to natural light (Aries, Aarts, \& van Hoof, 2015, p. 7). Reported benefits of natural light include the provision of variety and stimulation throughout the day, as well as reducing stress and increasing productivity (Aries et al., 2015). Exposure to natural light has also been found to improve mood, which is theorised to be caused by an evolutionarily developed diurnal cycle, as well as from the synthesis of vitamin D, which has been linked to the production of serotonin (Beute \& de Kort, 2014). Additionally, low lighting levels are associated with atypical depressive symptoms, such as carbohydrate craving, prolonged sleep, weight gain, and increased appetite, as well as low mood (Espiritu et al., 1994), with bright light exposure reported to improve vitality and alleviate distress (Partonen \& Lönnqvist, 2000).

\section{Passive thermal design}

Thermal comfort and energy efficiency is greatly influenced by the collection and storage of the sun's heat (Donn \& Thomas, 2001). Windows are considered the easiest way to collect heat from the sun, relying on North, East or West facing orientations to effectively capture solar energy (Donn \& Thomas, 2001). 


\section{ISSUES, EXPECTATIONS AND DESIGN CONSIDERATIONS}

\section{Urban scale}

At the urban scale, visual permeability can be regarded as enriching the public realm, however too much permeability can confuse public-private distinctions and reduce visual privacy (Carmona et al., 2010). Urban design guidelines recommend public 'fronts' should face other fronts, while more private 'backs' should face other backs, thereby reducing blank, impermeable walls facing the public realm, as well as improving the privacy of the private realm (Carmona et al., 2010). However, this may be difficult to achieve when applied to infill housing designs for front and back yards due to the current layout of 'fronts' and 'backs' created by existing dwellings and street patterns.

Current urban strategies for achieving privacy between dwellings also typically rely on the space between dwellings, causing land wastage, monotonous layouts and low density within suburbs (Carmona et al., 2010). Similarly, sunlight access is provided for within the WCC district plan through building setbacks from boundaries and relative height restrictions, again causing land use inefficiency. Infilling these spaces with additional housing therefore aims to increase density by better utilising this land, requiring the development of architectural strategies for achieving privacy and daylight access for more densely sited dwellings.

\section{Dwelling scale - privacy}

Issues of privacy relating to indoor space are affected by both the interior of the dwelling itself, as well as its relationship to the exterior environment and neighbouring dwellings (Carmona et al., 2010; Prochorskaite, Couch, Malys, \& Maliene, 2016). Inadequate privacy within the dwelling can negatively affect the wellbeing and relationships of occupants by restricting their ability to work, socialise, study and relax (Prochorskaite et al., 2016). This is commonly reported to be caused by a lack of suitable indoor space, as well as by close proximity neighbours overlooking windows (Lindsay et al., 2010; Prochorskaite et al., 2016; RIBA \& Ipsos MORI, 2012).

Designs aimed at housing multiple occupants should therefore ensure adequate space for different activities, as well as allowing separation of activities, while still meeting the limited size restrictions of infill sites. The placement of windows within the designs must also consider the issue of overlooking, ensuring interior spaces do not overlook and are not overlooked by neighbouring dwellings. Urban design theory however does suggest the ability to overlook public spaces is beneficial, improving safety through

passive surveillance (Carmona et al., 2010), so this should also be considered.

The break out of noise and separation of noise sensitive activities must also be considered within the design to achieve aural privacy. Within dwellings, this can be done through the separation of activities, through either space or time (Carmona et al., 2010). Between dwellings, where physical distance is impractical, sound transference can be reduced by offering sufficient acoustic insulation in exterior walls, while sound paths can be obstructed by providing solid screening between properties (Carmona et al., 2010). Further psychological effects of strategies such as the placement of trees and tree belts can create a sense of aural privacy, however this has little effect on actual sound transference (Carmona et al., 2010).

\section{Dwelling scale - sunlight access}

In a survey of housing preferences in Auckland, natural light was the highest rated feature within the rating of features related to dwelling characteristics and the second highest rated feature over all categories (Akehurst \& Yeoman, 2015). $77 \%$ of respondents rated access to natural light within their dwelling as very important, with an additional $21 \%$ rating it as of some importance (Akehurst \& Yeoman, 2015). The next highest rated feature was that the dwelling is easy to heat, with $73 \%$ and $25 \%$ of respondents rating it as very important and of some importance respectively (Akehurst \& Yeoman, 2015). While this feature may be related to a number of dwelling characteristics such as insulation and heating amenities, this would be greatly impacted by sunlight access. Reinforcing this, in the same survey, North facing building orientation was also rated highly within the ratings of property characteristics, with $45 \%$ and $37 \%$ of respondents rating it as very important and of some importance respectively (Akehurst \& Yeoman, 2015). In addition to the psychological and thermal benefits 
discussed earlier, these results show that sunlight and daylight access must be a key consideration within the dwelling design development.

\section{Site scale - outdoor space}

A BRANZ study of housing preferences provides evidence of New Zealanders' prevailing aspirations to live in stand-alone housing with private backyards that foster a sense of separation from neighbours (Bryson, 2017). In addition to this, a survey of Aucklanders' housing preferences also evidences stand-alone typologies and outdoor space as key considerations when choosing a place to live (Akehurst \& Yeoman, 2015). Within this survey, $90 \%$ of respondents rated the inclusion of balcony, courtyard or outdoor dining space of some or very high importance and $86 \%$ also rated having a stand-alone dwelling as of some or very high importance. Lower importance was placed on the inclusion of a lawn, or on having a large outdoor space, with $93 \%$ considering easy maintenance of the section important. This suggests that while the desire for stand-alone dwellings with outdoor space remains prevalent within New Zealand, these aspirations may be achieved with smaller, low maintenance sections or the inclusion of balcony or courtyard space.

Internationally, Australians' housing aspirations are also overwhelmingly for stand-alone housing with private outdoor living space, with such dwellings making up a reported three quarters of the Australian housing stock (Wheeler, 2010). In addition, studies of housing preferences in the UK also evidence a desire for private outdoor space, preferring it over public or shared, due to its suitability for entertaining, domestic tasks, relaxation and safe play space for children (RIBA \& Ipsos MORI, 2012), as well as being a feature ranked second in importance for housing users when choosing a home (Prochorskaite et al., 2016). Further UK studies have also reported that private outdoor spaces protected from overlooking can provide opportunity for self-expression, exercise, restoration from stress, personal satisfaction from sense of achievement, relaxation, socialising, food production and unsupervised play areas for children (Lindsay et al., 2010; Prochorskaite et al., 2016), as well as being a feature ranked second in importance for housing users when choosing a home. Additional benefits are reported for green outdoor spaces, providing views of nature which is associated with improved wellbeing and more positive neighbourhood perception (Lindsay et al., 2010; Prochorskaite et al., 2016).

This research suggests the benefits of outdoor spaces within housing design, as well as preferences for privacy within these spaces, although levels and types of privacy desired may vary between occupants and situations. Designs for infill houses should therefore aim to incorporate usable outdoor space within their small plots of land, with design measures in place to ensure visual and aural privacy from close neighbours can be achieved if desired by occupants.

\section{Detail scale - construction}

Although construction quality may be important across all building types, high density developments are reportedly much more greatly affected by the suitability and effectiveness of construction decisions due to the close proximity of dwellings (Lindsay et al., 2010). Construction of intertenancy walls must be considered carefully as while they allow efficiency in space use and higher density developments (Marriage, 2014), they may create a much more expensive construction outcome than the traditional alternative of relying on empty space between dwellings (Wheeler, 2010). However, due to their lack of external exposure these walls require less maintenance, and due to requirements for fire safety, greater acoustic privacy is achieved than the typical boundary walls of two neighbouring stand-alone homes (Marriage, 2014; Wheeler, 2010). 
KEY PRECEDENTS 


\section{SAWTOOTH HOUSE}

\section{CANBERRA - JUDD STUDIO}

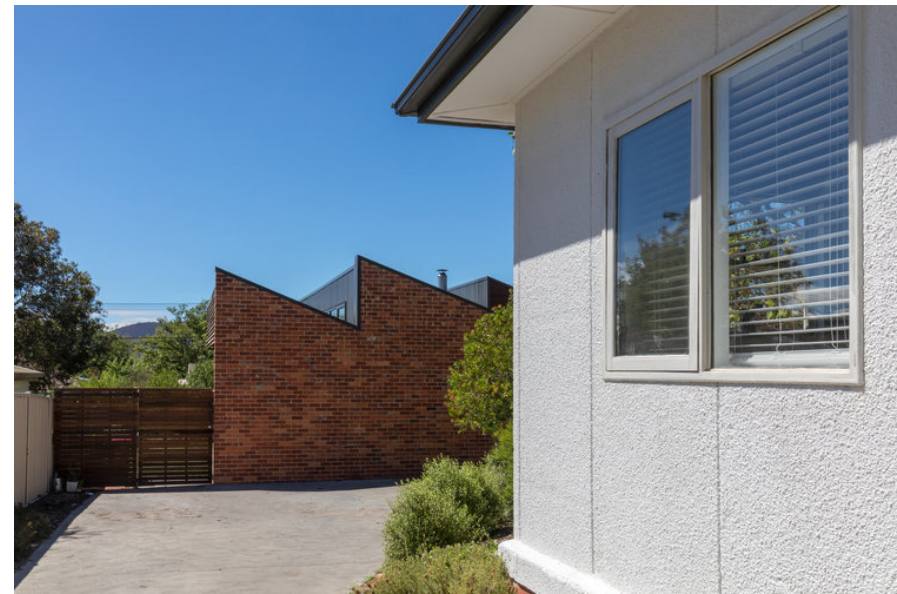

Figure 1. Existing dwelling and ADU (Judd Studio, 2016).

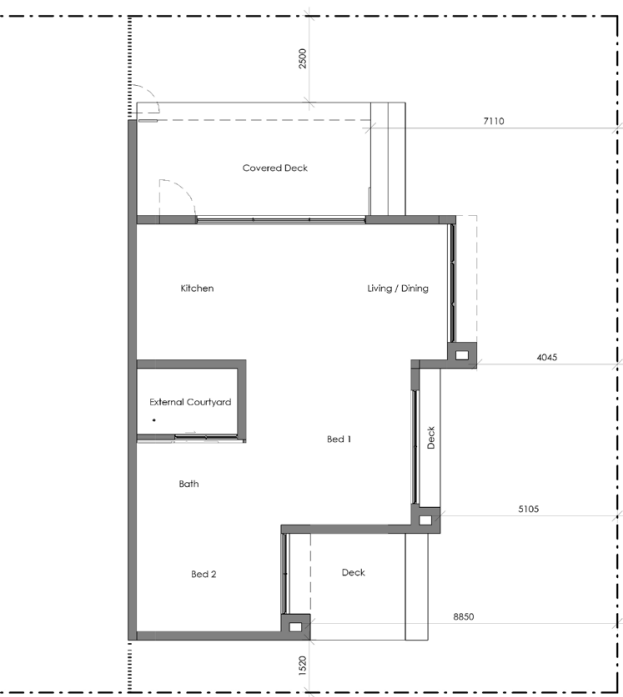

Figure 3. ADU plan (Judd Studio, 2016).

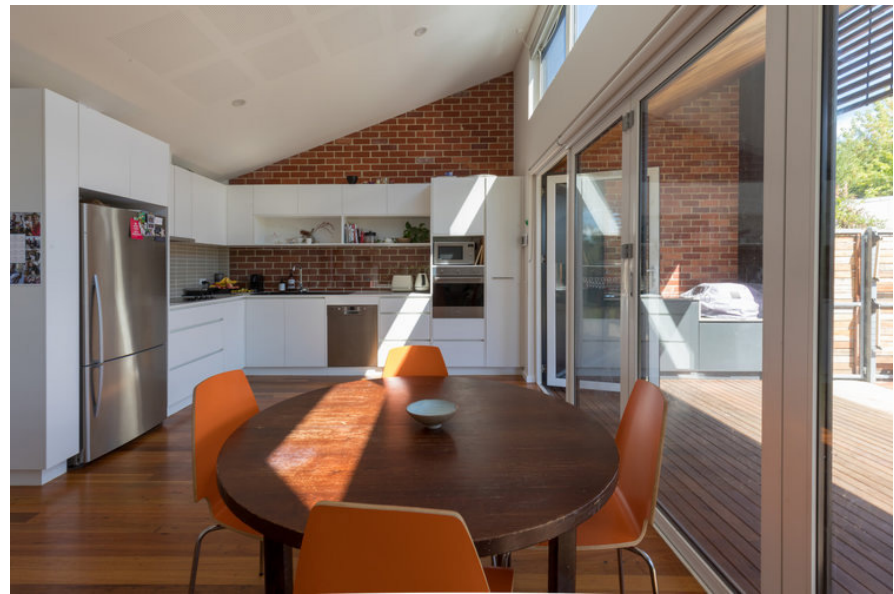

Figure 2. Living and outdoor space (Judd Studio, 2016).

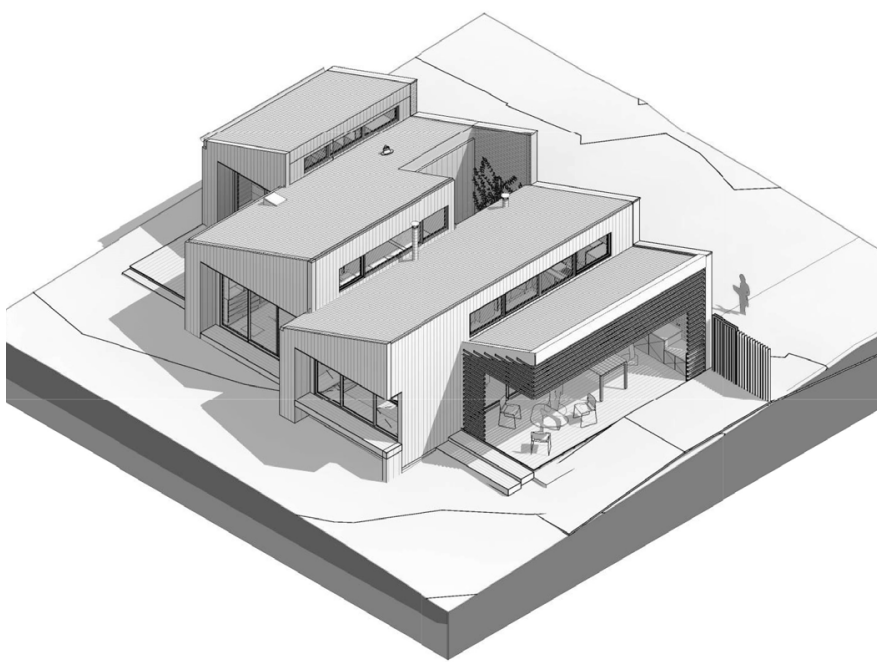

Figure 4. ADU axonometric (Judd Studio, 2016).

This strategy for an ADU is successful in the way it creates introspective views, utilising the feature brick wall (Figure 1) to create courtyards for windows to look into (Figure 2). This not only defines the individual outdoor spaces of both the existing and accessory dwelling, but also creates a visual and acoustic barrier to ensure privacy between the units.

The success of this strategy however may be somewhat due to the large scale of the site, allowing considerably more space and separation between units than is feasible within the majority of Kilbirnie. While the privacy between the existing and accessory dwelling unit within the site is created architecturally through the building form and walls, privacy between neighbouring sites relies entirely on physical separation through distance. The large windows employed in the ADU towards the back and side of the site (Figure 4) provide much needed opportunity for view out of the living and bedroom spaces, enabled by the width of outdoor space to the site boundary (Figure 3). 


\section{COURTYARD HOUSES \\ WELLINGTON - STUDIO PACIFIC ARCHITECTURE}
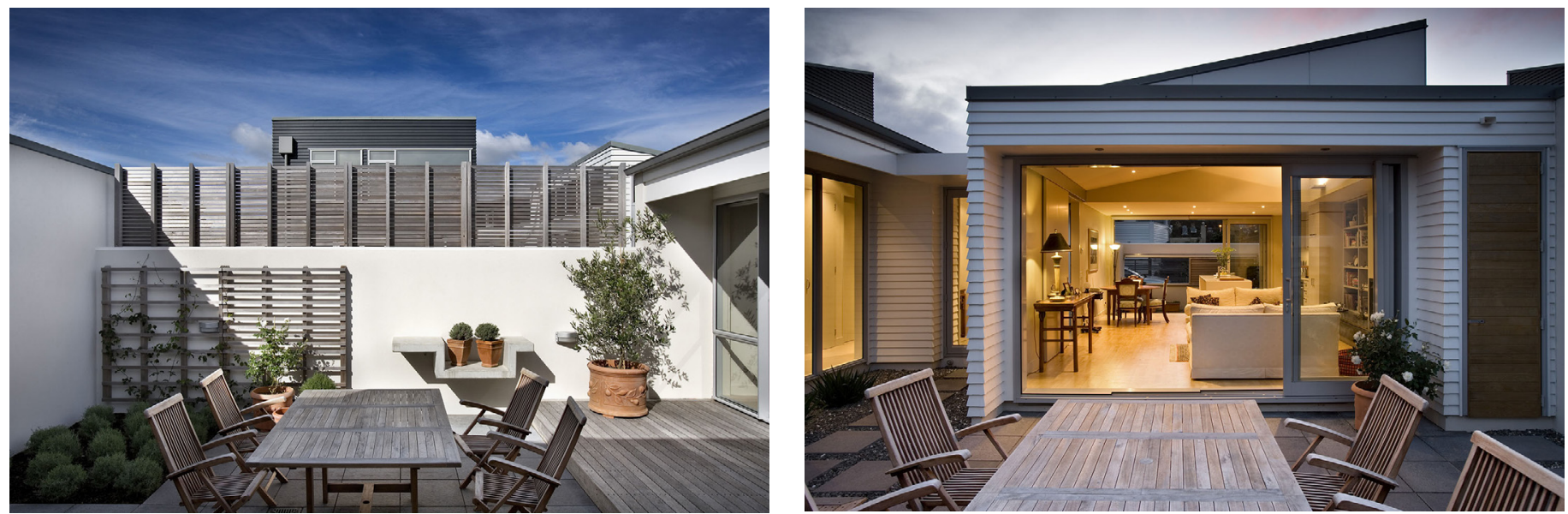

Figure 5. Private back yard space (SPA, 2003).

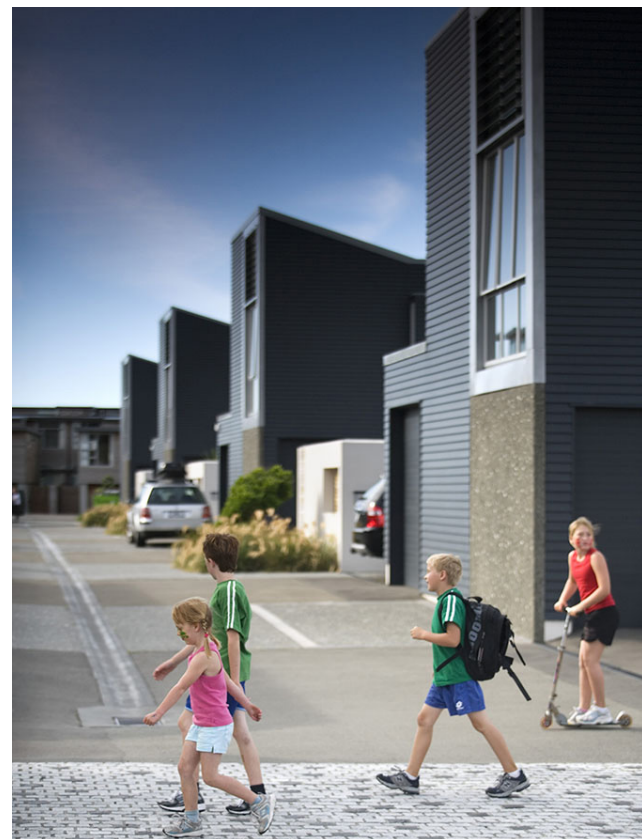

Figure 6. View from street (SPA, 2003).

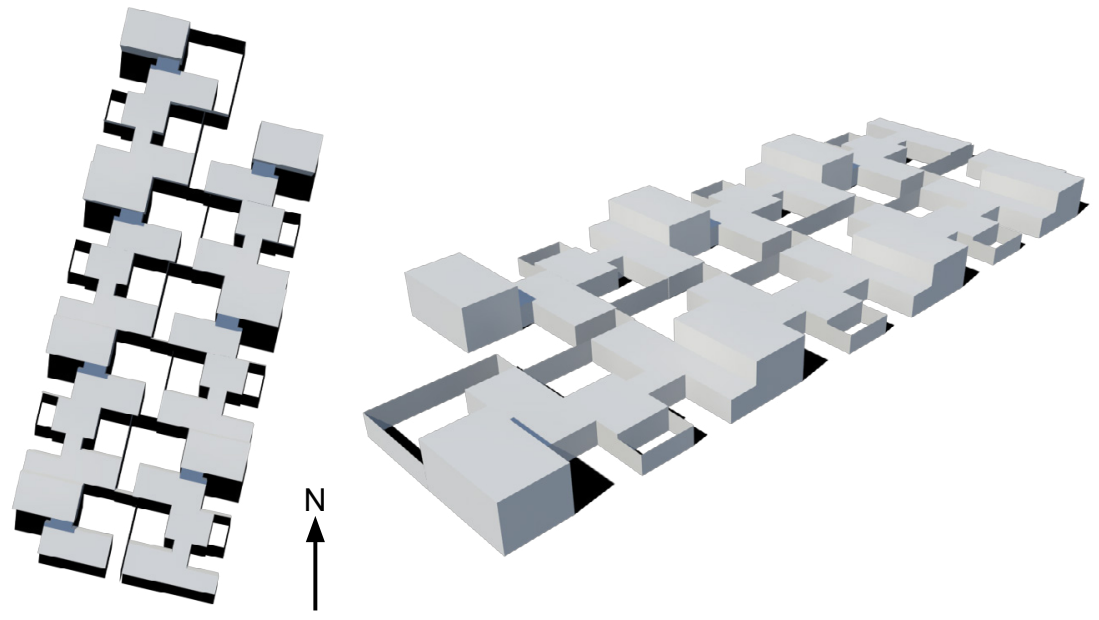

Figure 7. 3D models of building mass.

The Courtyard Houses in Seatoun provide precedence for the successful management of private outdoor space within a compact, multi-unit development. Similarly to the Sawtooth house, the building form is utilised to define outdoor space and create separation between units (Figure 7). Here, where site size constraints mean space cannot be relied upon for separation, units are built right onto the boundary lines, relying on inter-tenancy walls for visual and acoustic privacy (Marriage, 2014). This has allowed considerably more units to be placed on the site than would be possible is side and back yard setbacks had been employed (Marriage, 2014).

The mix of one and two storey volumes also provide guidance as to how upper storey windows may provide view and daylight without creating overlooking issues. Two storey volumes are placed towards the front of the site, allowing view into their own courtyards, while view into neighbouring courtyards is restricted by distance and high fencing (Figure 5). However, large bedroom windows that face the street are less successful in terms of privacy, providing little visual separation between passers-by and neighbours across the street (Figure 6). 


\section{FRONT YARD SITES}

Dwellings on front yard sites must aim to meet the identified priorities of optimising daylight, privacy and outdoor space. Additionally, due to the prevalence of garages on these sites, the dwellings should incorporate a garage to ensure existing amenity is maintained for the existing dwellings. 


\section{Garage Flats}

\section{Experimentation with spatial}

arrangements that include garages within

minimum front yard constraints.

A

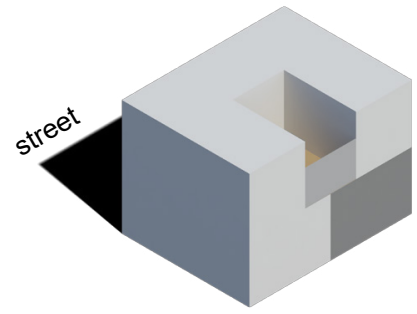

Ground Floor

Upper Floor
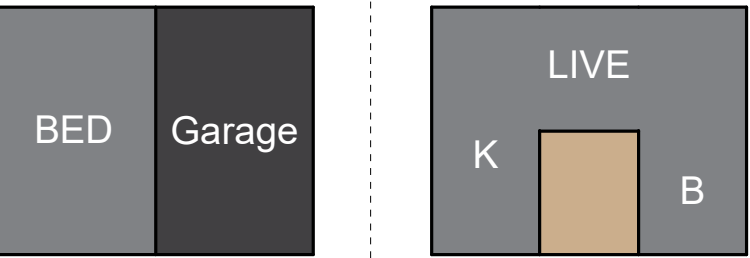

B
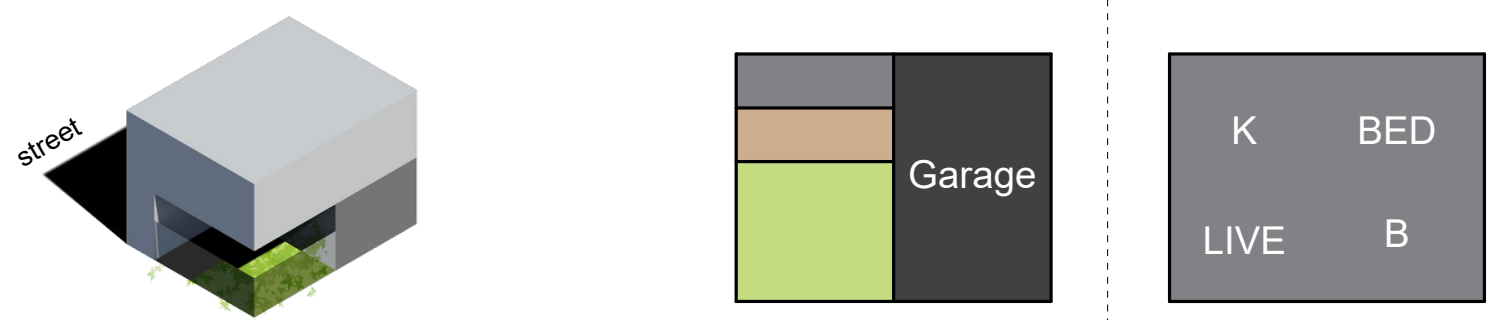

C
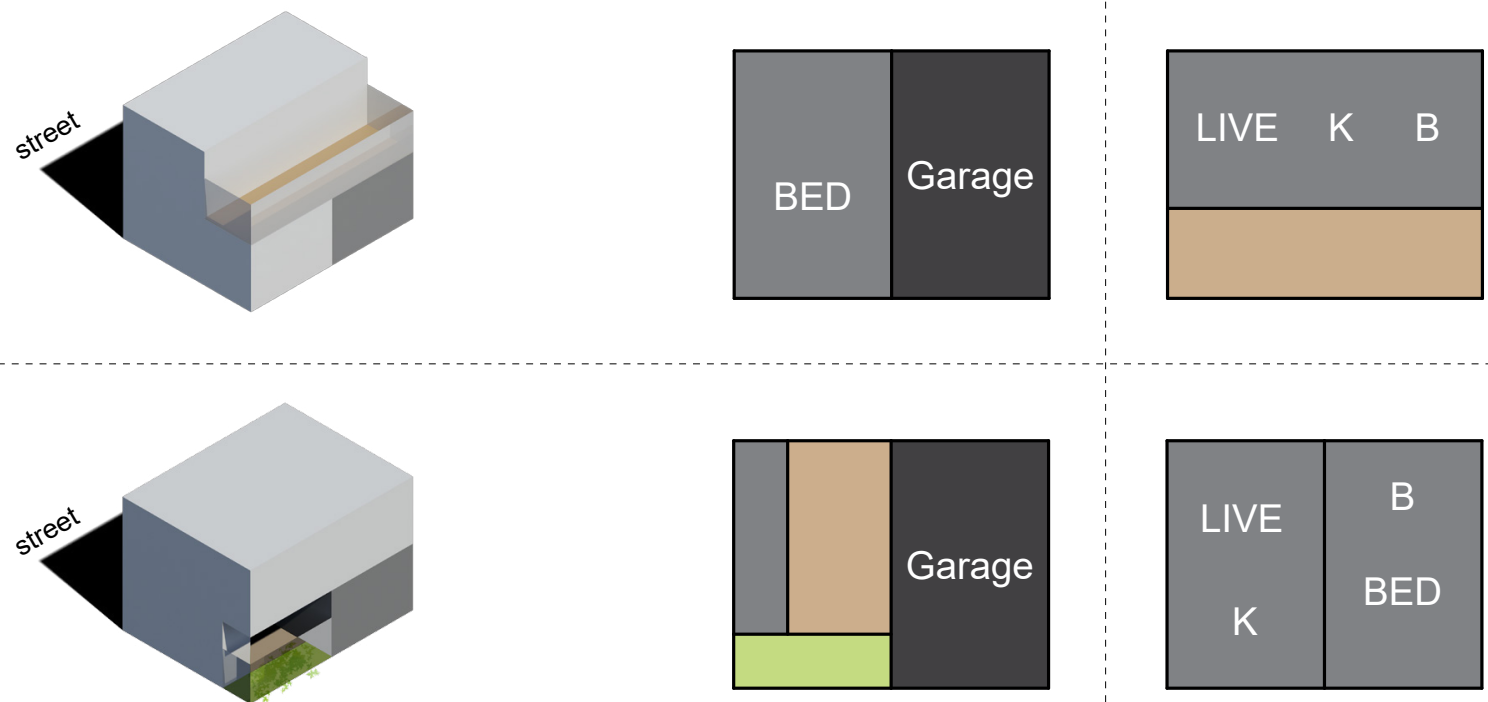

D
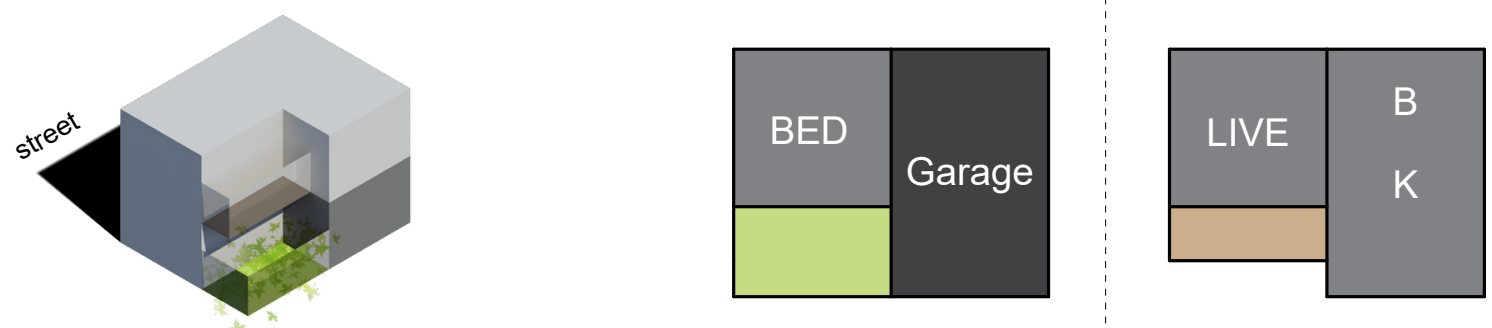

E
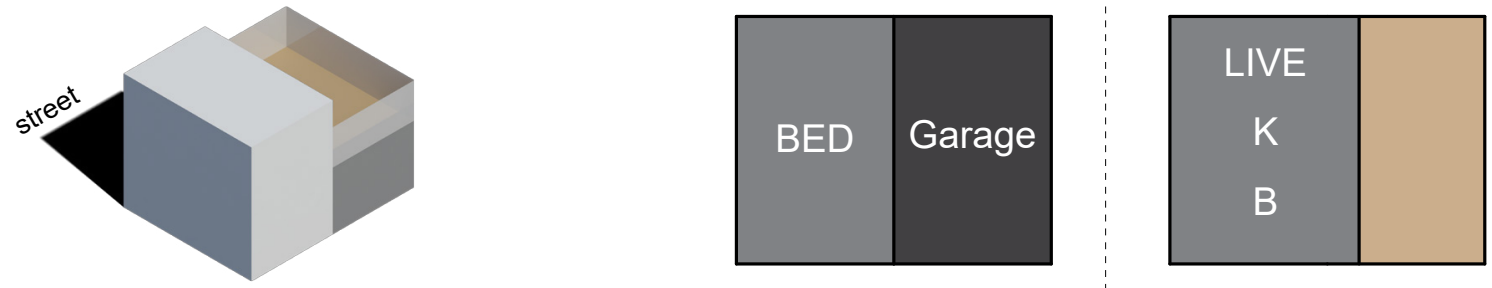
Multi Unit Layouts
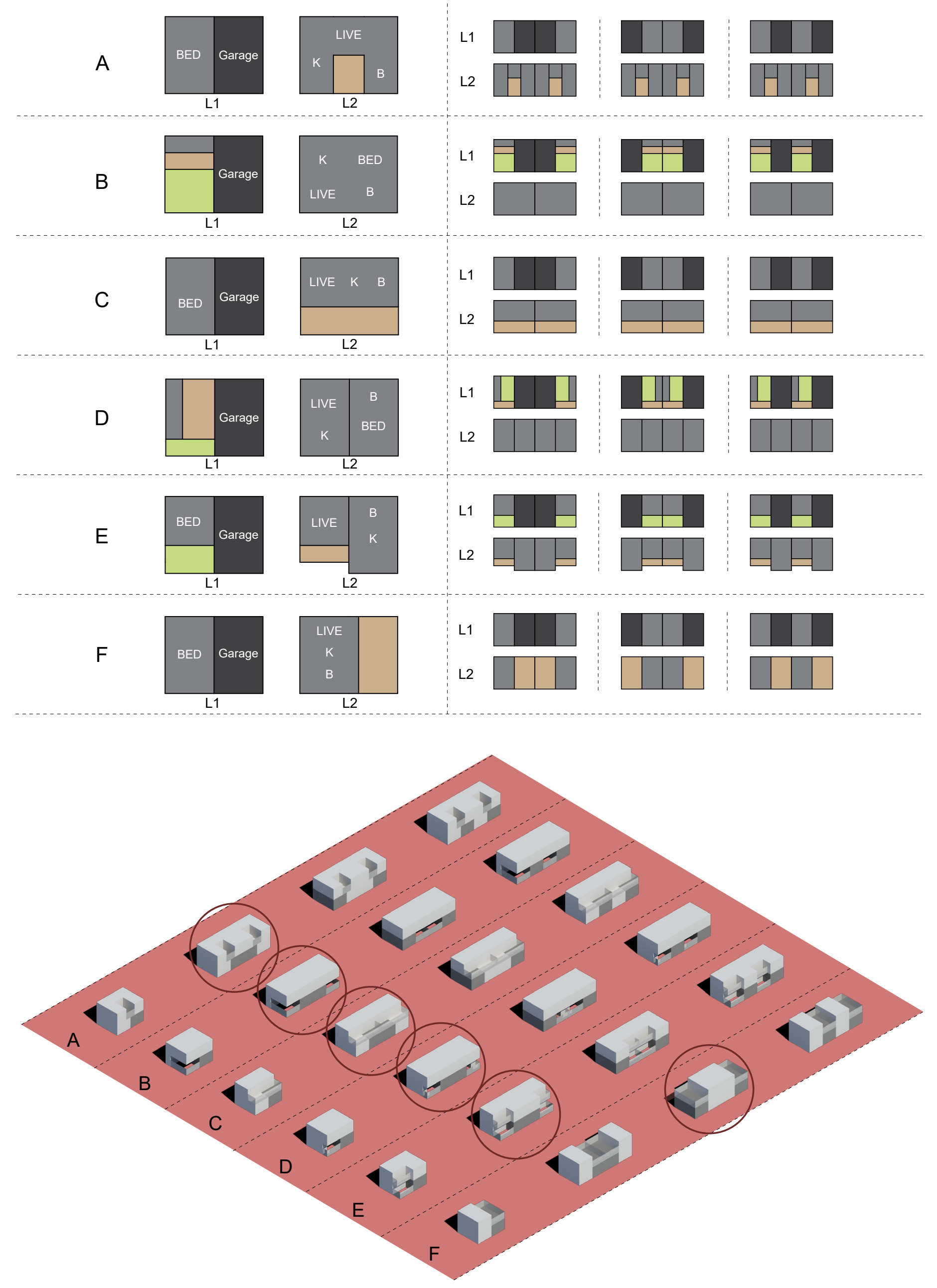


\section{FRONT YARD MASSING STUDIES}

Massing of a combined garage and ADU has been experimented with using the module of a single garage. Due to the limited size constraints of front yard sites and the need to maintain clear access to the existing dwellings behind, the units investigated are all two storeys and contain only one bedroom.

\section{Single unit}

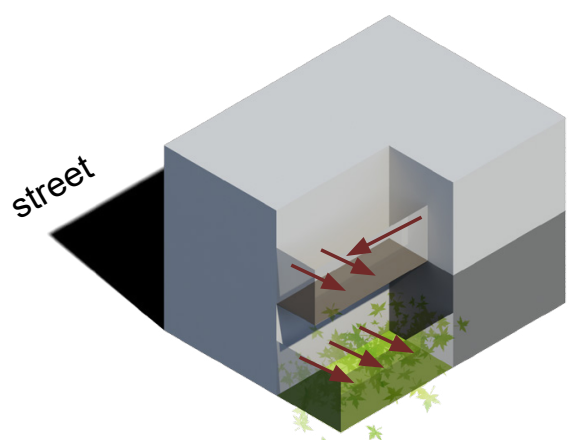

Figure 8. Most successful option (E) semi-private window outlook

Outdoor space around the dwelling was difficult to achieve while also maintaining privacy due to the proximity to the street at the front and the existing dwelling at the back. Due to this, outdoor space has been incorporated using cuts into the dwelling mass to form semi-enclosed outdoor space at the ground or upper level. Overall, the more enclosed and private the outdoor space, the less sunlight these spaces and windows into these spaces would receive. As daylight access into dwellings was identified as a higher priority, option E (Figure 8 , circled page 79) presents the most promising solution, providing some privacy to the outdoor space and somewhat introspective views from windows into these spaces while minimally impacting daylight access.

\section{Multi-unit}

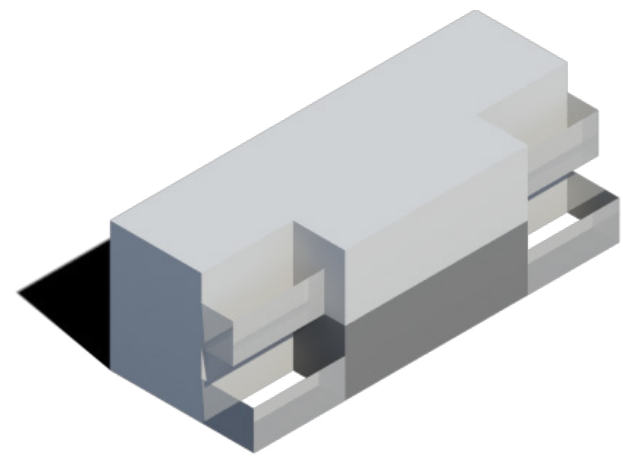

Figure 9. Garage masses in centre $(E)$

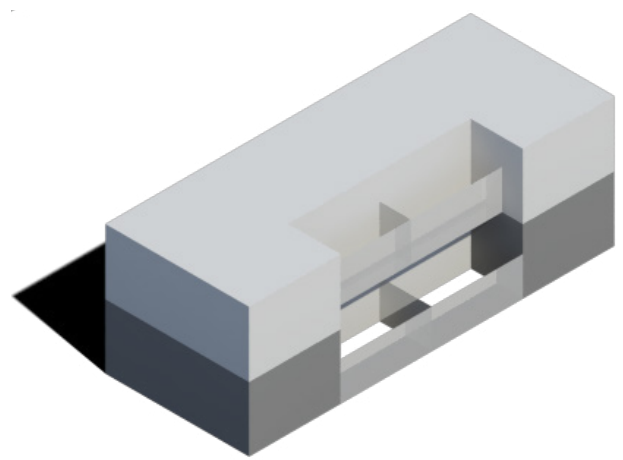

Figure 10. Garage masses on edges (E)

The possibility of combining two ADU and garage units across neighbouring boundaries has been investigated to determine if higher densities could be achieved through this strategy. Overall, mirroring the units with the garage masses in the centre has been most successful (Figure 9, circled page 80). This is due to the garage space not needing exterior windows and the separation of each unit's outdoor spaces and external windows on either side of the mass.

\section{Conclusion}

Overall, massing studies have only been somewhat successful, requiring compromise between privacy and access to daylight. The small sites allow for little outdoor space and mean the majority of windows would face outward to the street, neighbouring properties or existing dwellings, rather than into their own outdoor space. Due to privacy concerns, cuts within the mass face away from the street presenting a large blank wall to the street. The inclusion of a garage and the compactness of the sites has also created a box-like two storey mass which does not conform with the existing scale and shape of dwellings in Kilbirnie. This may pose a great visual impact on the existing streetscape and change the character of the suburb significantly which is something the WCC district plan aims to discourage. 
Sunlight Analysis - north-south site

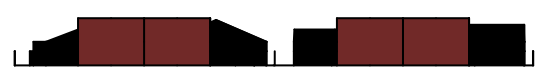

Street Elevation

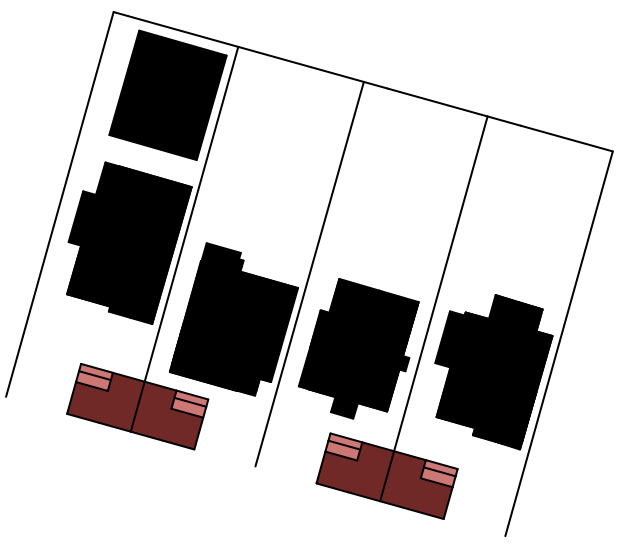

Plan

SUMMER
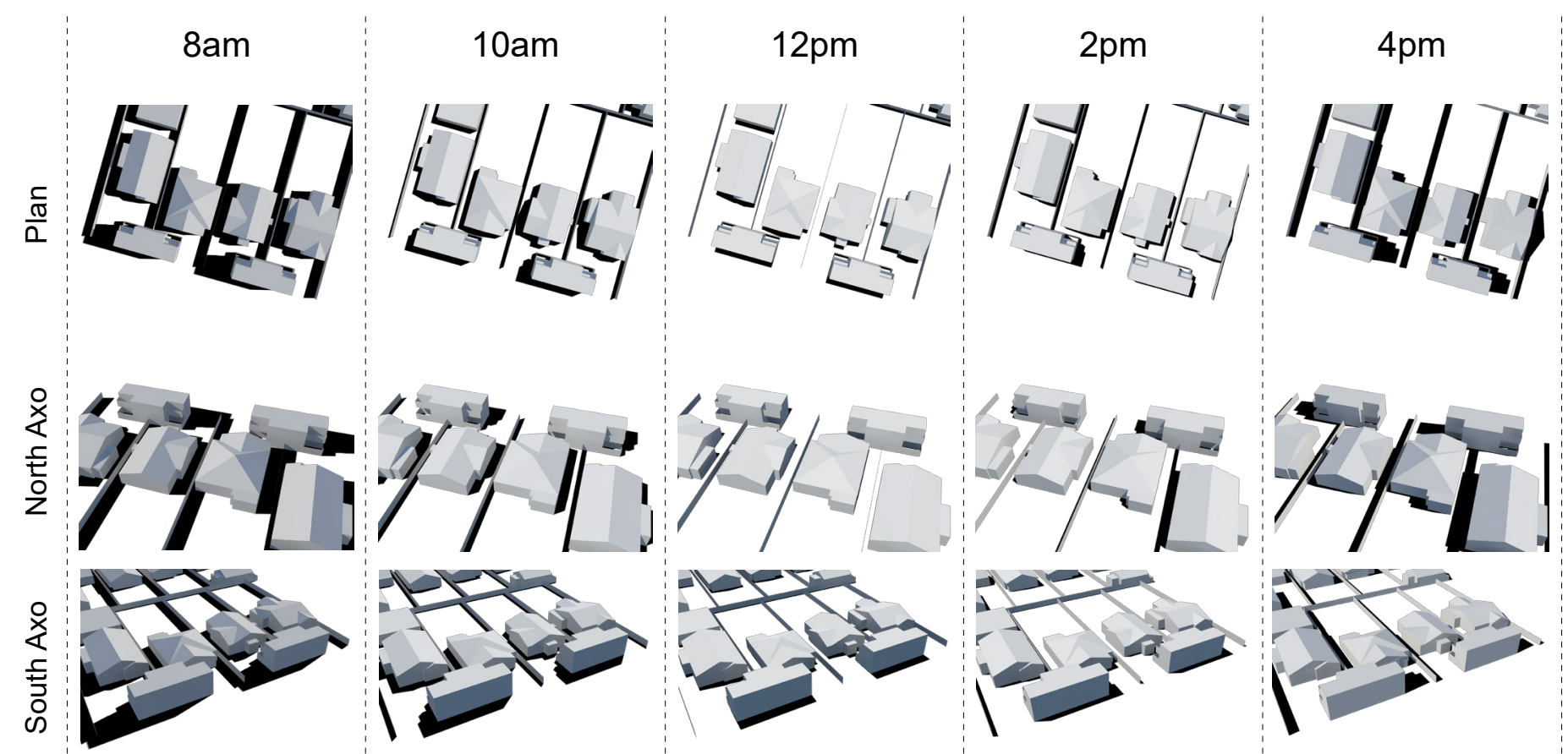

WINTER

8am

10am

$12 \mathrm{pm}$

$2 \mathrm{pm}$

$4 \mathrm{pm}$
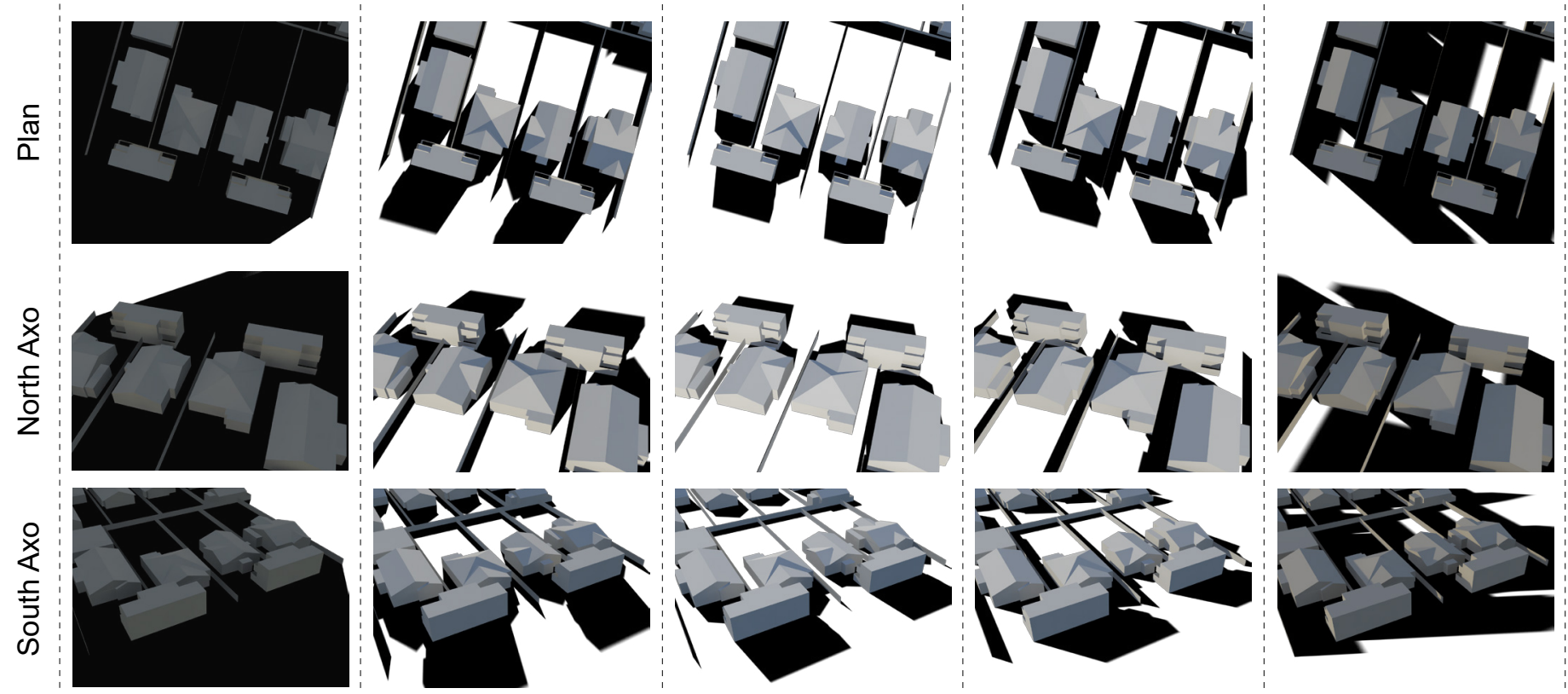
Sunlight Analysis - sloped site

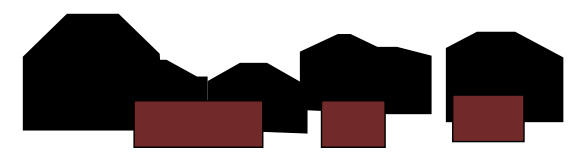

Street Elevation

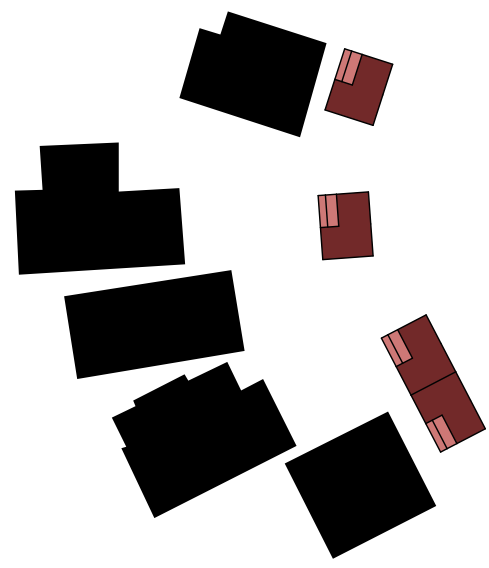

Plan

SUMMER
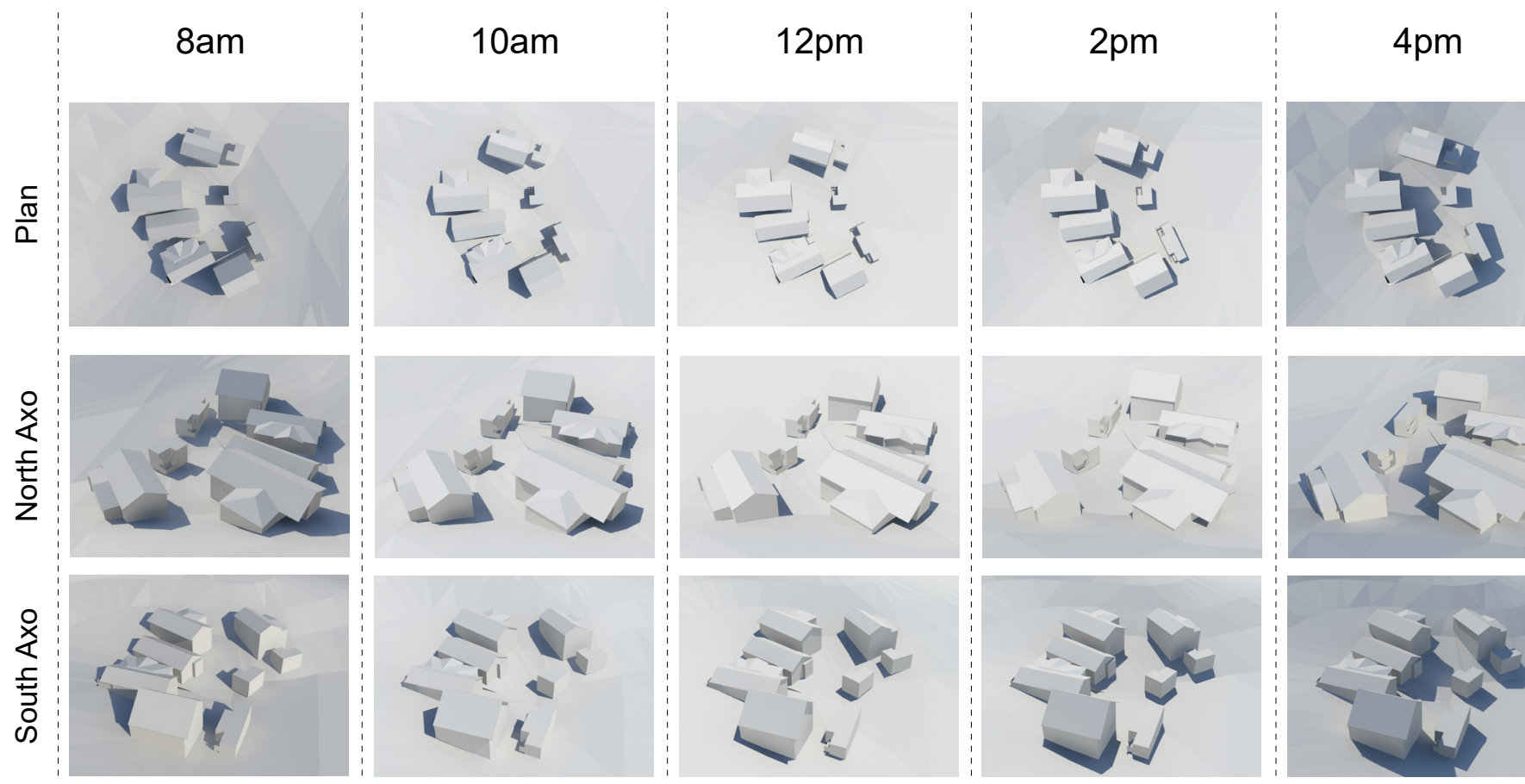

WINTER
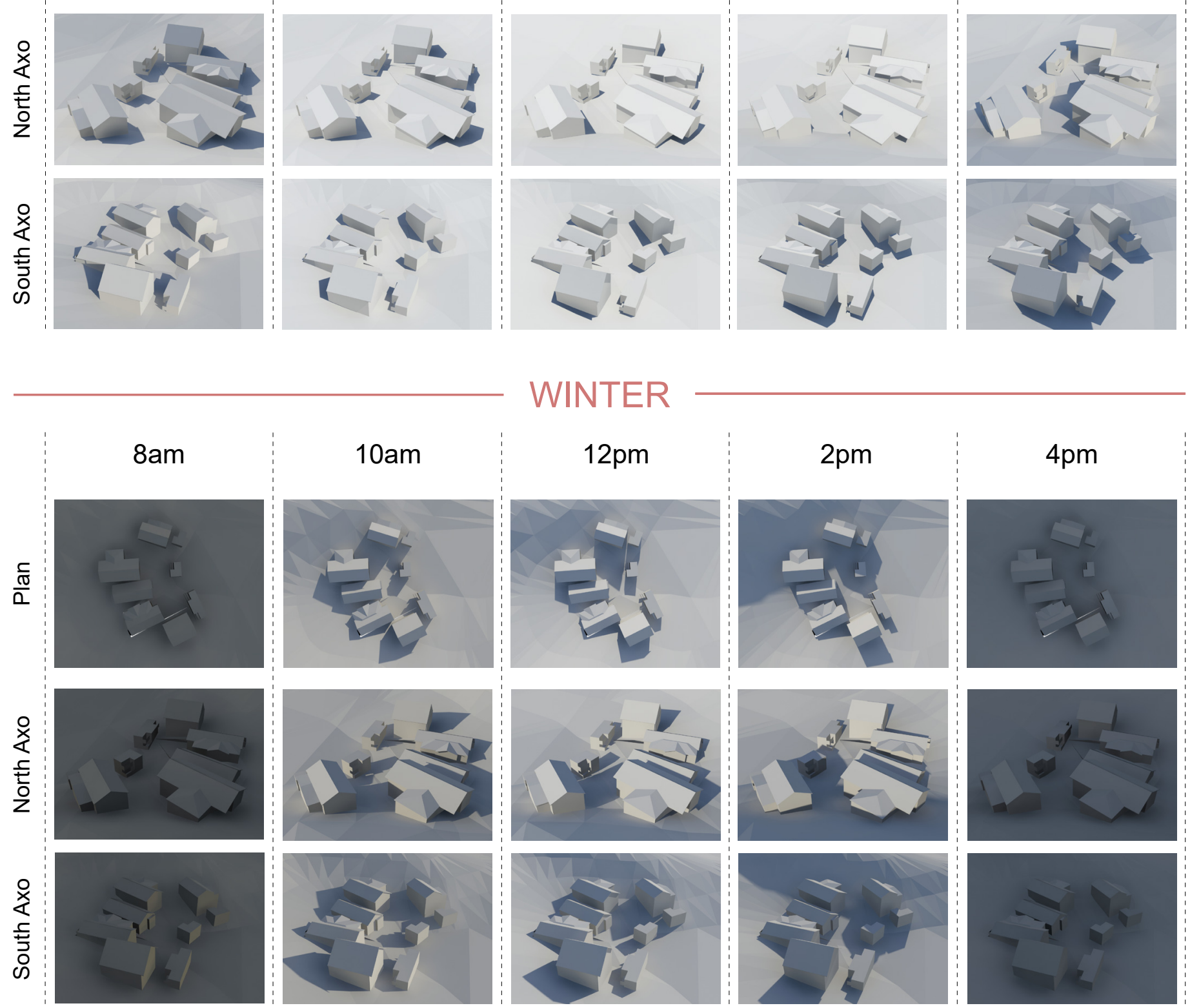


\section{SUNLIGHT STUDIES}

The feasibility and suitability of a front yard ADU has been tested further through siting the masses on four neighbouring properties within the two areas of Kilbirnie previously found to be of a suitable size for front yard ADUs. Sunlight access and the impacts of shading have been analysed using the software 3ds Max to determine the success of the design, as well as the resulting impact on the existing sites and dwellings.

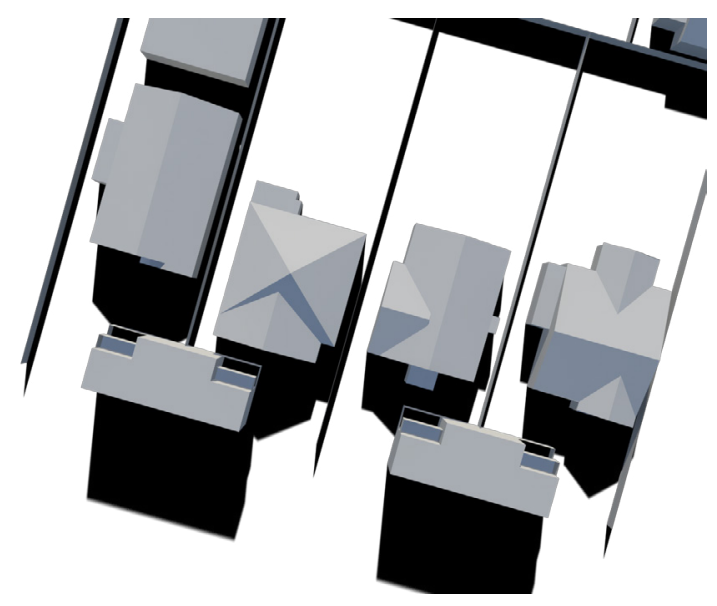

Figure 11. Shading impacts of north-south site ADUs (Winter 12pm)

On the North-South running site (Figure 11), the ADUs do not negatively impact the existing dwellings through shading as they are located to the South of them. However, if placed on the opposite side of the street a significant shading impact would be seen due to the proximity of the two storey ADUs to the front windows of the existing dwellings. Similarly, if windows are placed on the back and sides of the ADU, this would work well for solar gains only for ADUs on the North side of the street.

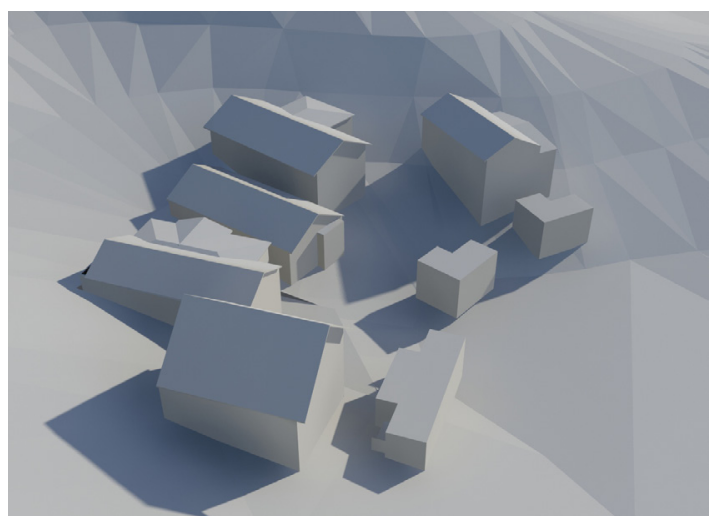

Figure 12. Shading impacts of sloped site ADUs (Winter 12pm)

The sloped site is far more successful due to the lower existing density, the East-West aspect and the topography which allows the existing dwellings to sit above the ADUs on the site. These factors have meant both the ADUs and the existing dwellings receive adequate sunlight and do not shade each other significantly (Figure 12). 

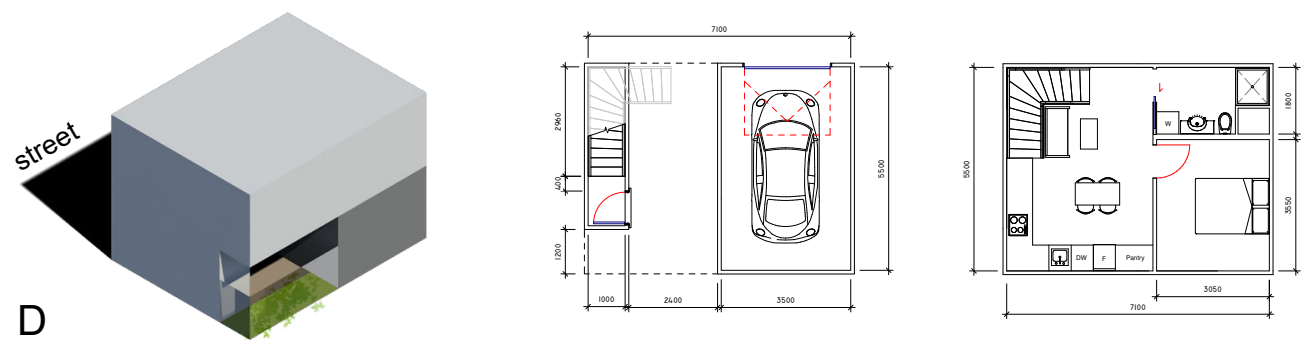

Site Area: $\mathbf{4 2} \mathrm{m}^{\mathbf{2}}$

Building Footprint: $\mathbf{2 6 \mathbf { m } ^ { 2 }}$

Floor Area: $\mathbf{4 3 m ^ { 2 }}$

Outdoor Space: $\mathbf{1 5 m ^ { 2 }}$

Bedrooms: 1
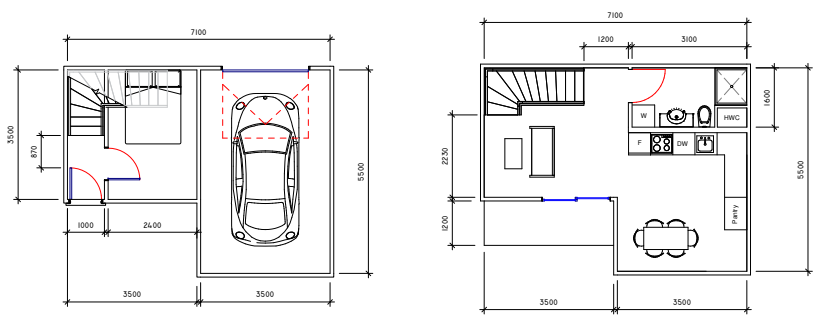

Site Area: $\mathbf{4 2} \mathrm{m}^{\mathbf{2}}$

Building Footprint: $\mathbf{3 4} \mathbf{m}^{\mathbf{2}}$

Floor Area: $44 \mathrm{~m}^{2}$

Outdoor Space: $11 \mathrm{~m}^{\mathbf{2}}$

Bedrooms: 1

E
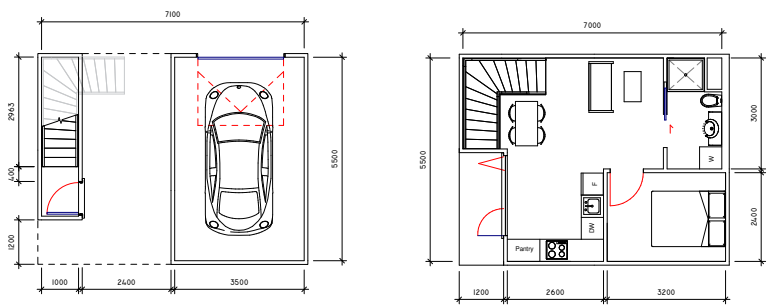

Site Area: $\mathbf{4 2} \mathrm{m}^{\mathbf{2}}$

Building Footprint: $\mathbf{2 6} \mathbf{m}^{\mathbf{2}}$

Floor Area: $\mathbf{4 0 \mathbf { m } ^ { 2 }}$

Outdoor Space: $\mathbf{1 8} \mathrm{m}^{\mathbf{2}}$

Bedrooms: 1

$D+E$

The initial planning studies done for the most successful massing iterations have not resulted in very liveable floor plan layouts. Spaces are tight and do not fit standard furniture well to create desirable living and bedroom spaces. Option $\mathrm{D}$ has no connection between the living space and the outdoor space, with option $\mathrm{E}$ achieving this best, allowing the living area to extend into the balcony.

The garage space takes up a large proportion of the floor area, meaning there is insufficient living space within the overall large building mass. Incremental development of the dwellings into the garage spaces could be explored similarly to initial incremental concepts, however this would only be feasible for option $E$ which is connected to the garage space at ground level.

Overall, the most promising plan iterations for the selected massing studies and a combination of these have not created effective living spaces, showing this massing strategy for front yard dwellings to be overall unsuccessful. 


\section{BACK YARD SITES}

Dwellings on front yard sites must aim to meet the identified priorities of optimising daylight, privacy and outdoor space. Additionally, dwellings should take into account the possible siting of multiple adjacent ADUs across neighbouring back yards. 


\section{COURTYARD DWELLINGS}

Experimentation with spatial arrangements that include private outdoor space within minimum back yard site constraints.

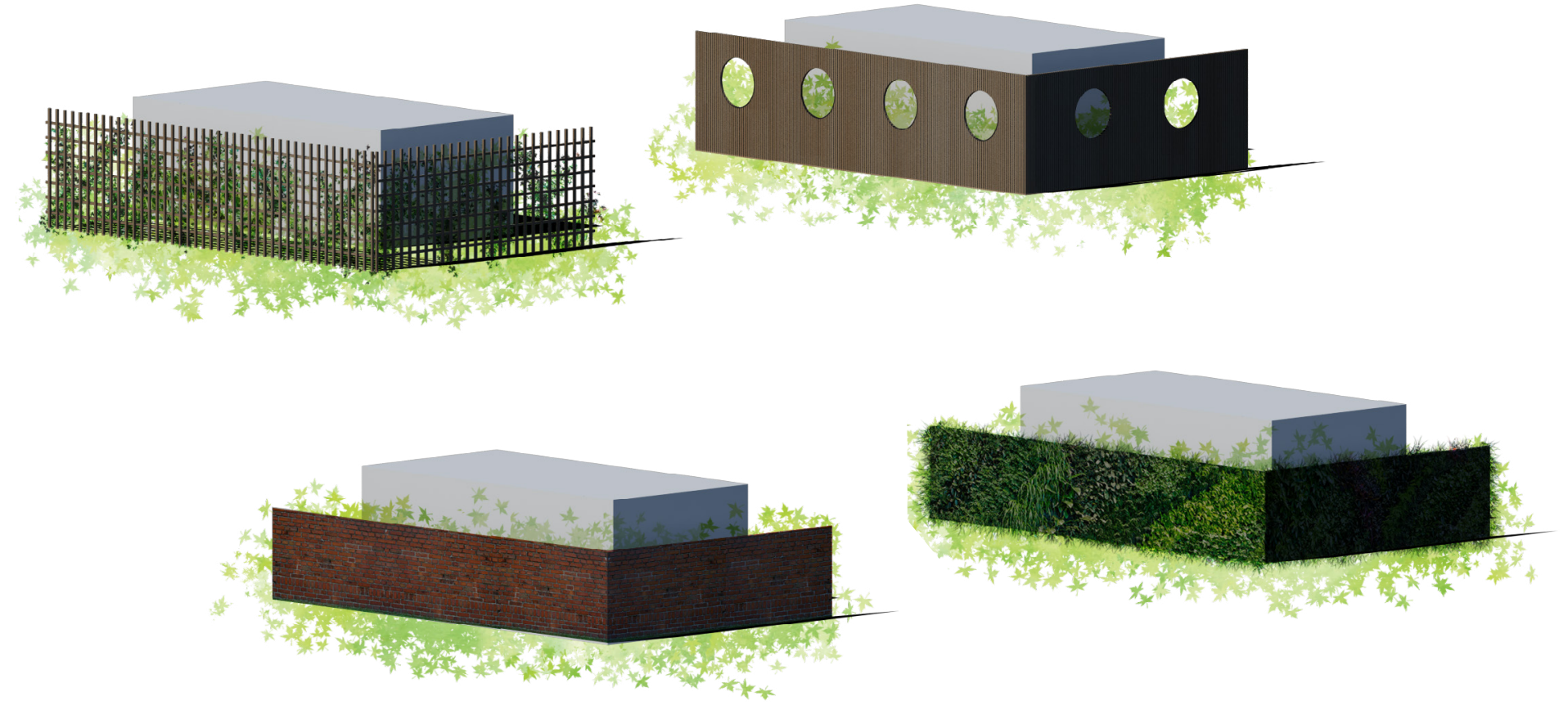

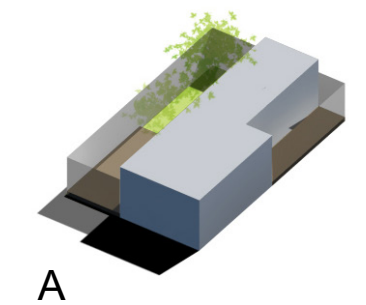

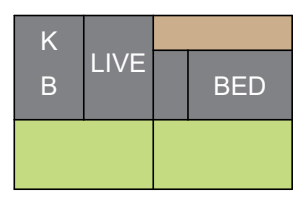

A
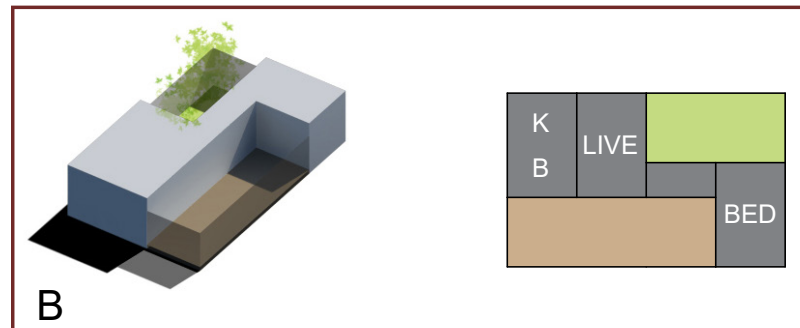

B
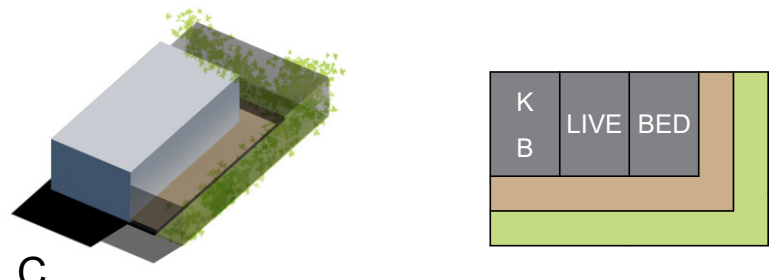
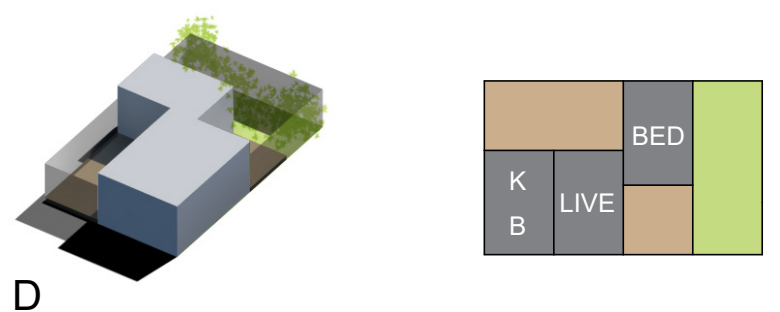

D
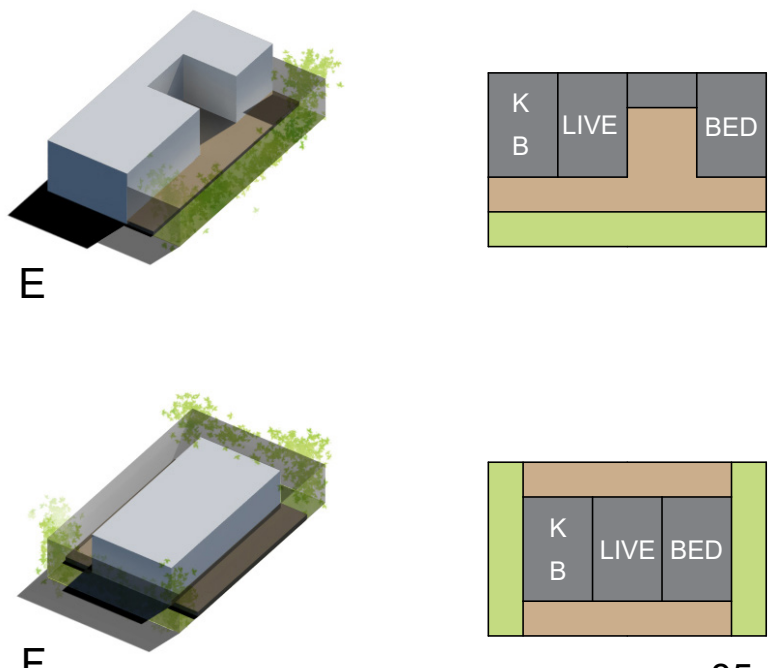
MULTI-UNIT LAYOUTS - one storey

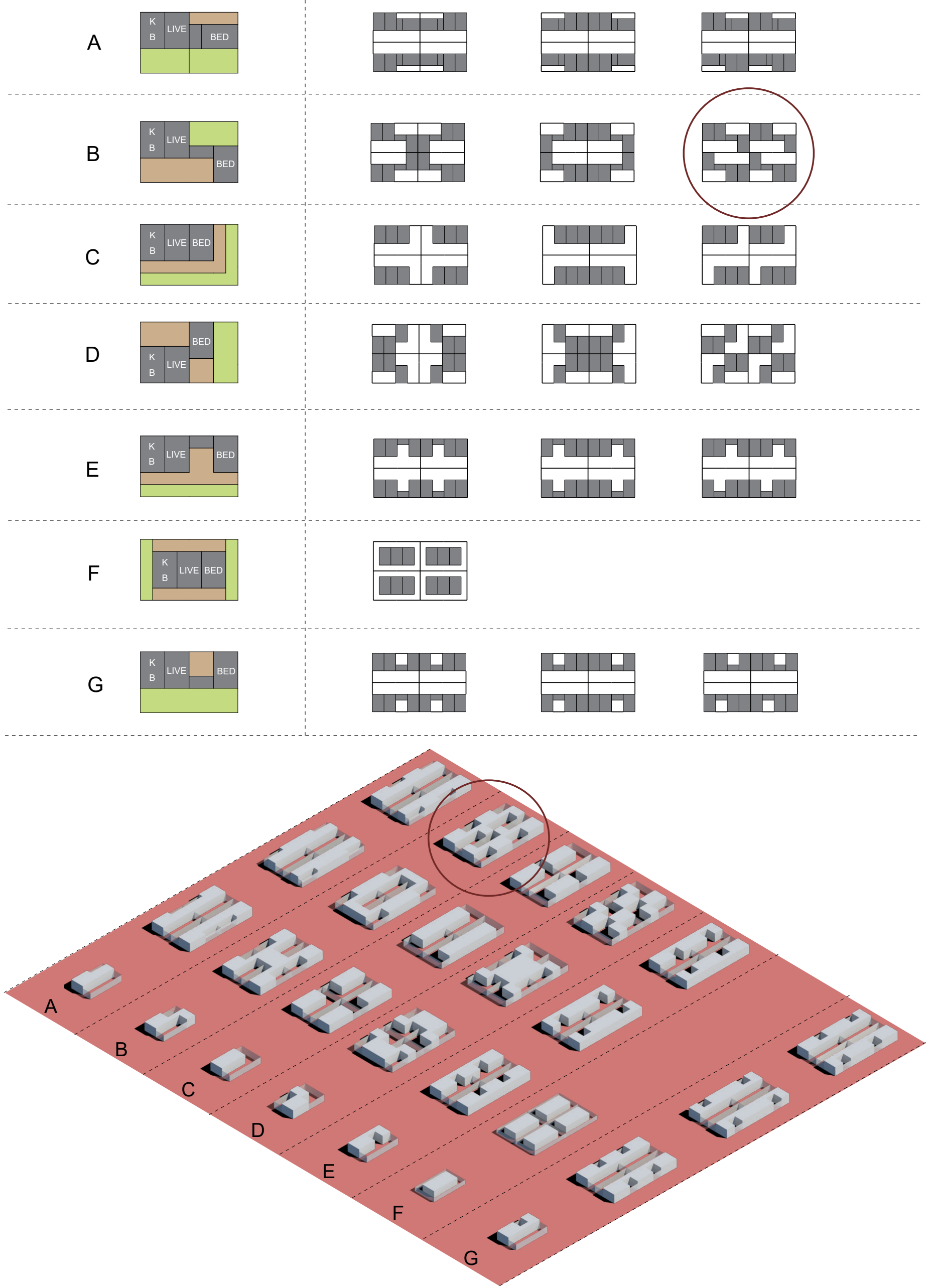




\section{SINGLE STOREY MASSING STUDIES}

Following the successful strategies identified within the precedents, the use of building form, garden walls and physical separation has been investigated to determine how ADUs can be massed to provide privacy and daylight access within backyard sites in Kilbirnie. The focus of the massing studies was to create maximum external wall area suitable for windows and maximum private outdoor space.

\section{Courtyard massing}

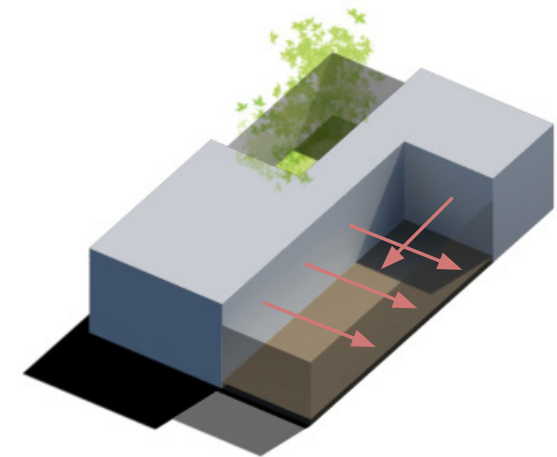

Figure 13. Most successful option window outlook (B)

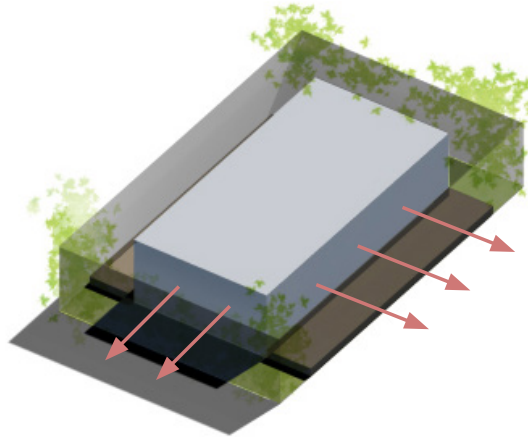

Figure 14. Least successful option window outlook $(F)$

Option F (Figure 14) is by far the least successful, relying entirely on physical separation between units through traditional front, side and back yard setbacks. This creates a 'donut' of outdoor space around the dwelling, minimising the usability and privacy of this space due to it being a thin strip, separated from neighbours only by a fence. This also means all external walls must face site boundaries and therefore neighbouring units.

Options, A, B, C, D, E and G are more successful, utilising both building form and physical separation to define outdoor spaces and direct window outlook within their own sites. The placement of building volumes right up to the boundary lines allows for more internally located outdoor space and opportunity for more introspective views. Option B (Figure 13, circled page 87) achieves this most successfully by allowing for two distinct outdoor courtyard spaces, framed by the building's mass.

\section{Multi-unit massing}

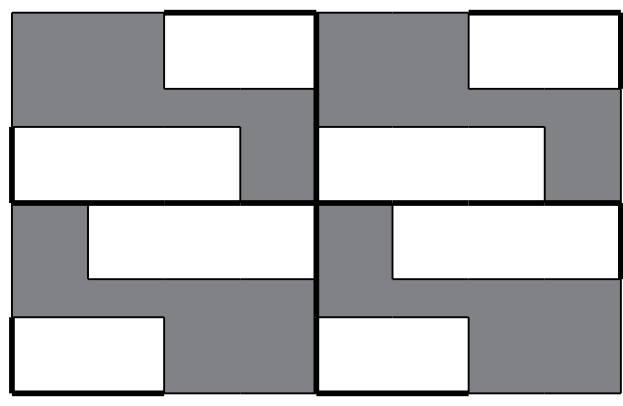

Figure 15. Plan of most successful option (B)

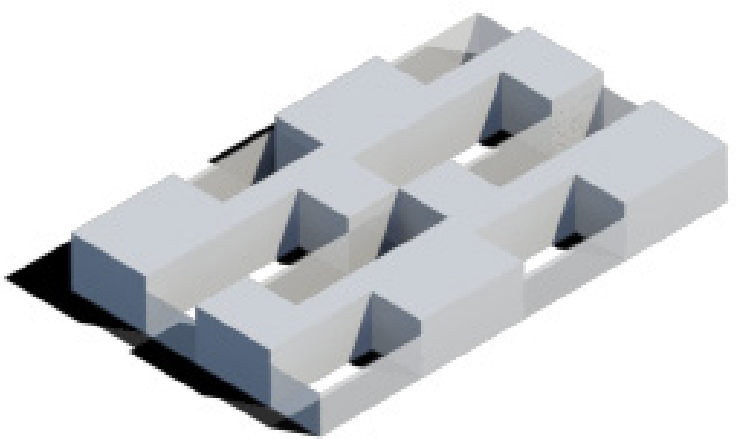

Figure 16. Axonometric of most successful option (B)

Looking at the layout of four neighbouring ADUs on adjoining backyards, further exploration has been done to determine the success of these options at higher densities. Overall, mirroring the units across boundaries is the least successful strategy for combining multiple units, creating the most adjoining outdoor space and directing window outlook into neighbouring units. Alternatively, a repeating unit layout allows for offsets in building form to better frame outdoor space and define site boundaries, ensuring windows do not look directly into one another, but rather into a courtyard or at a neighbouring blank wall. Option B (Figure 15-16, circled page 88) remains the most successful at the multi-unit stage as the plan shape of neighbouring units means outdoor spaces are further framed and separated, creating more, rather than less privacy at higher densities. 

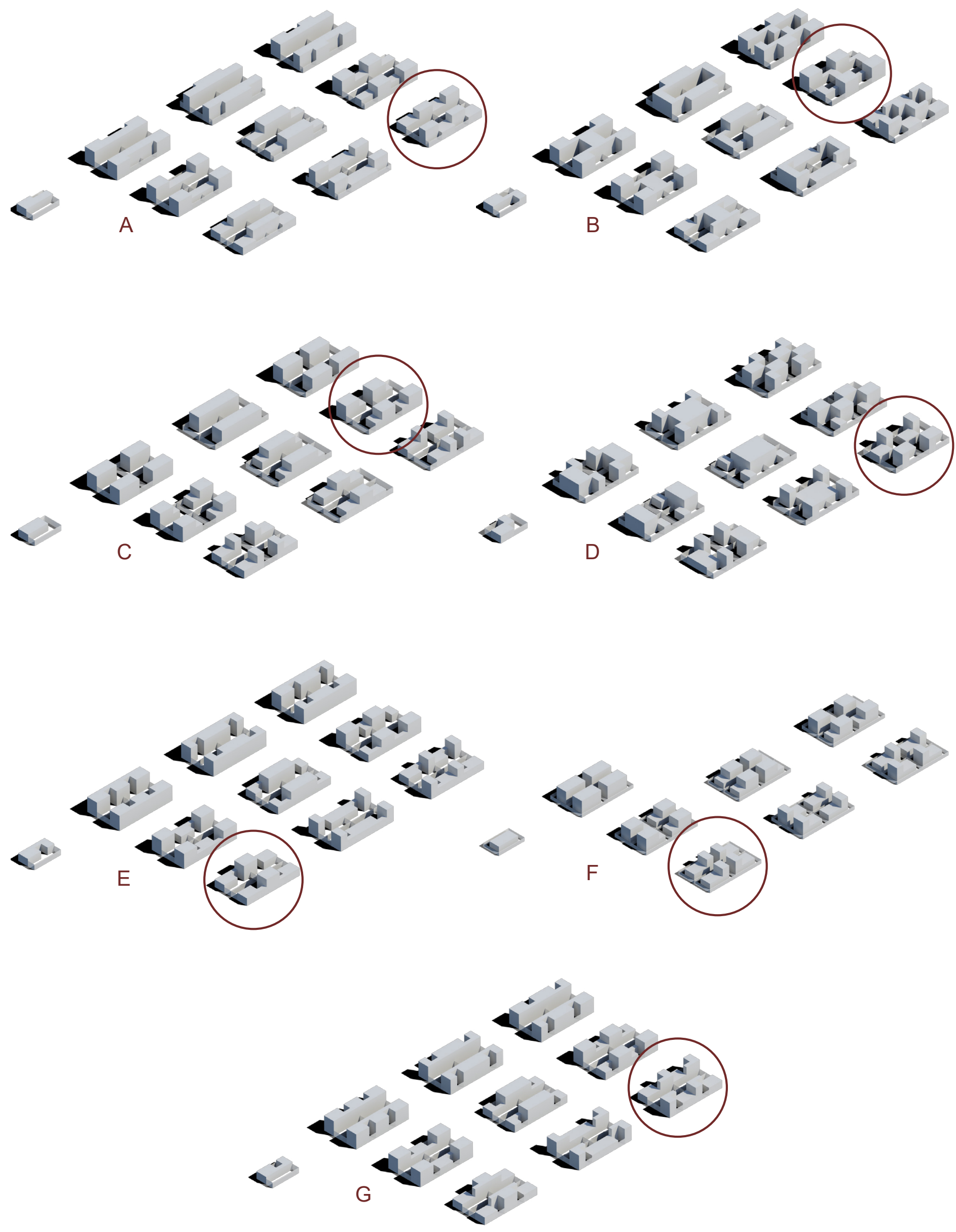
MOST SUCCESSFUL LAYOUTS - two storeys

A

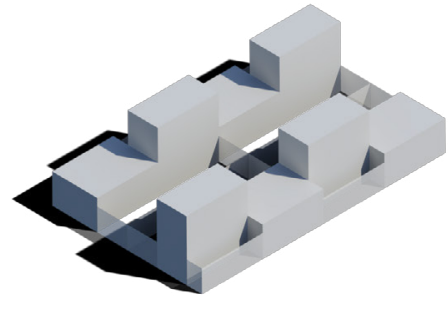

B

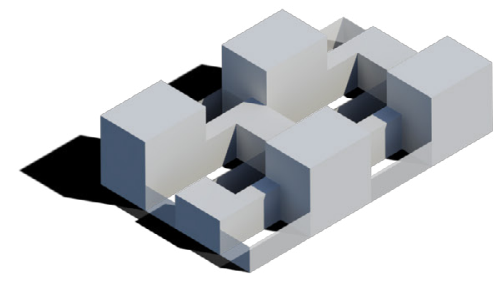

C

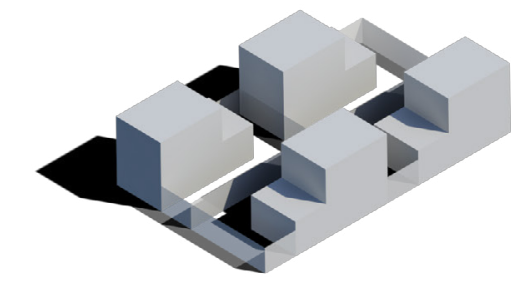

D

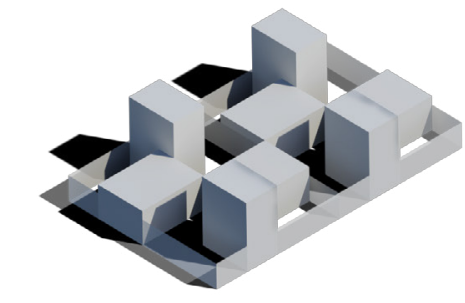

E

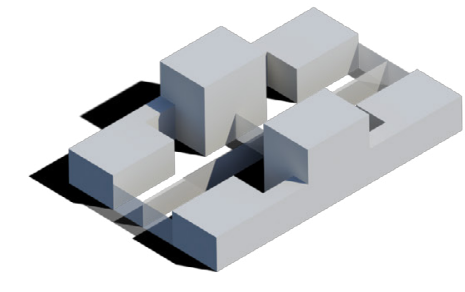

F

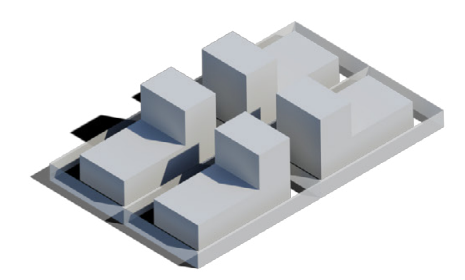

G

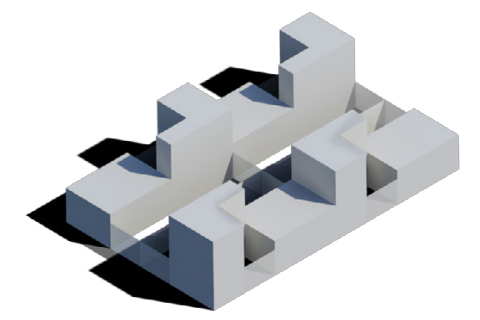

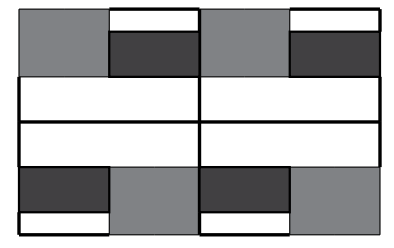
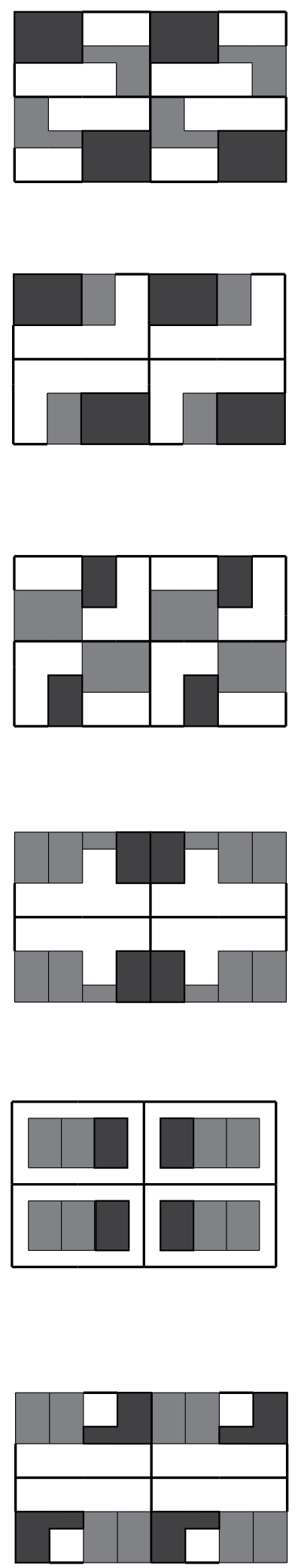
A
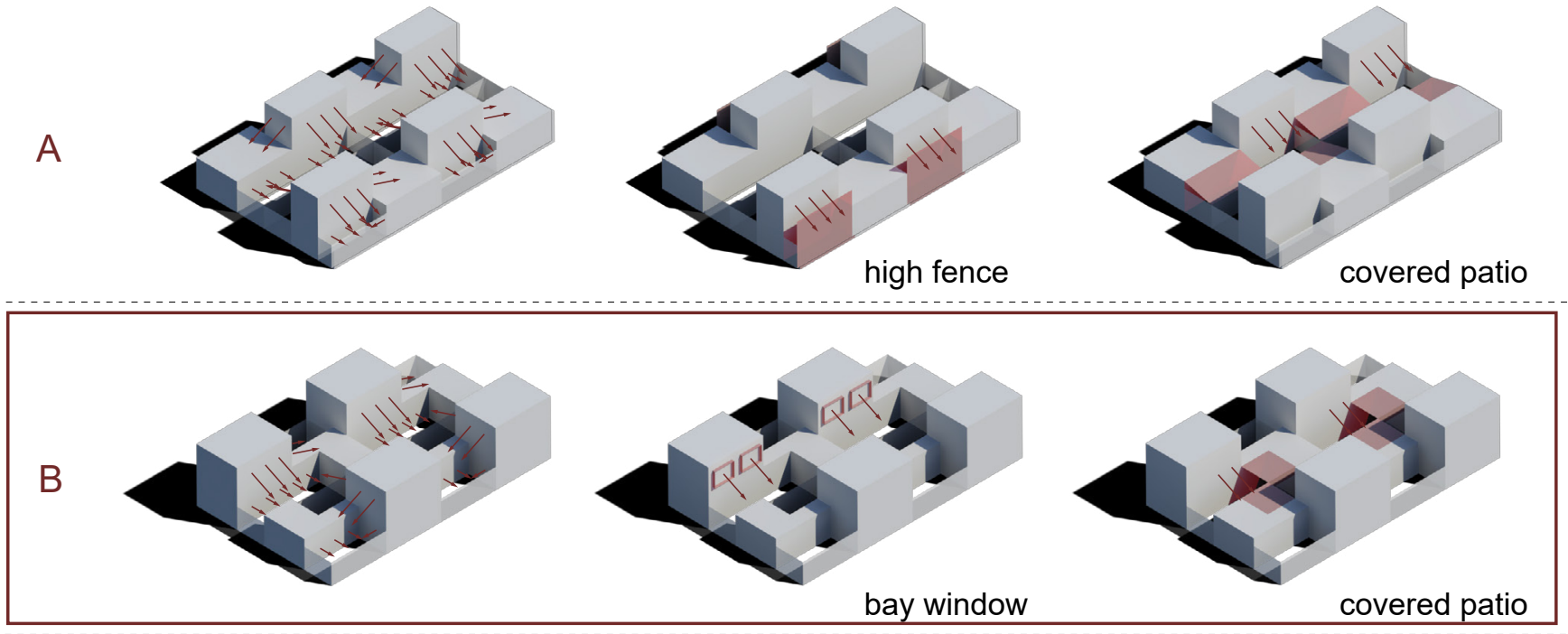

C
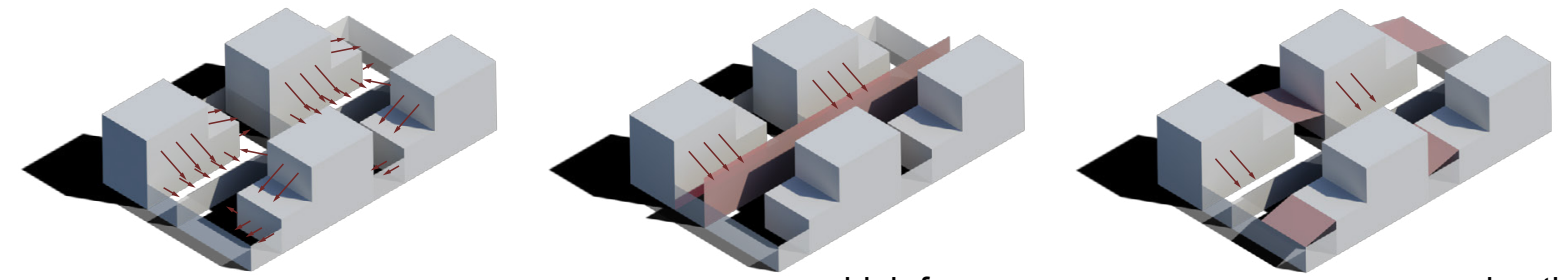

high fence

covered patio

$E$

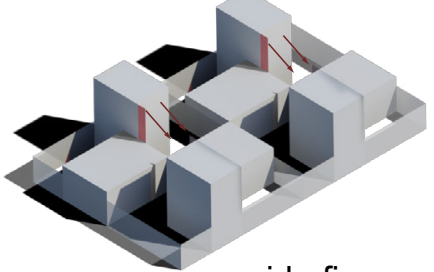

side fin
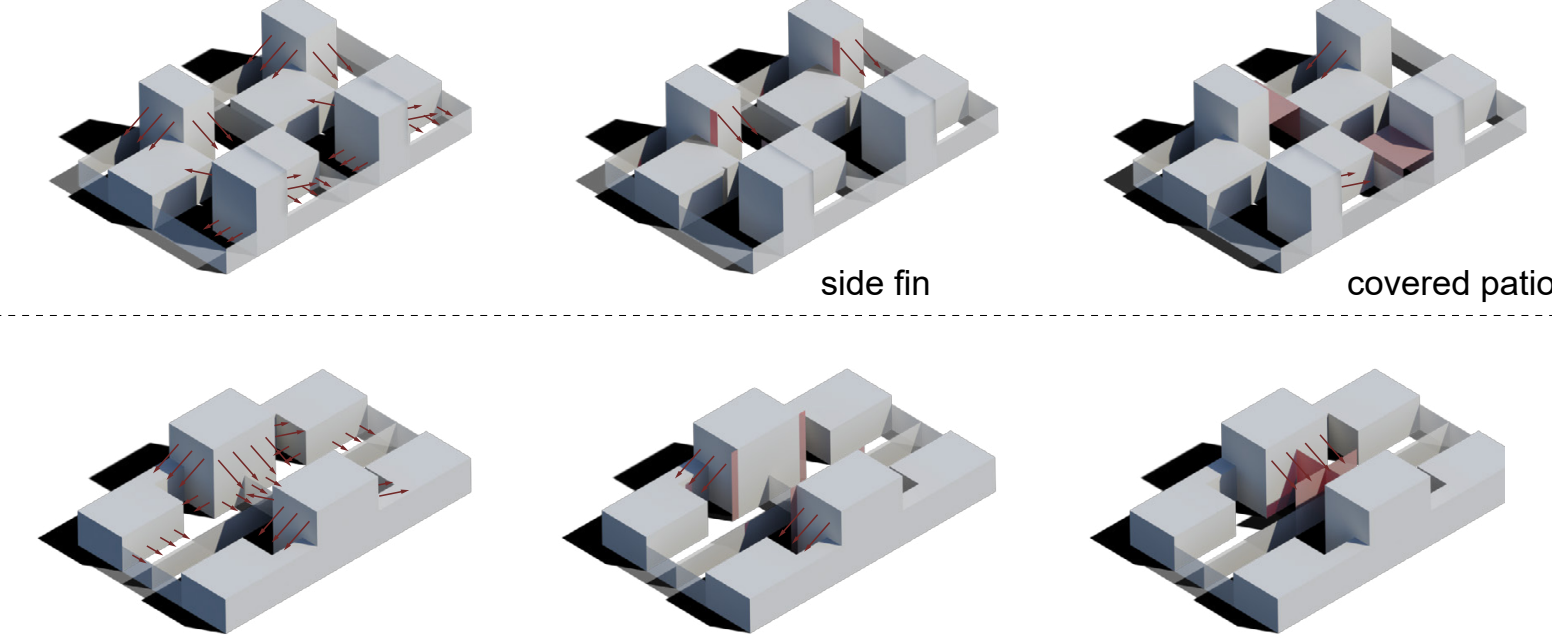

side fin

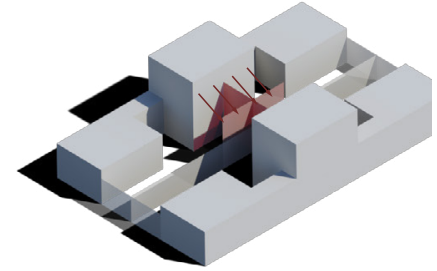

high fence

$\mathrm{F}$

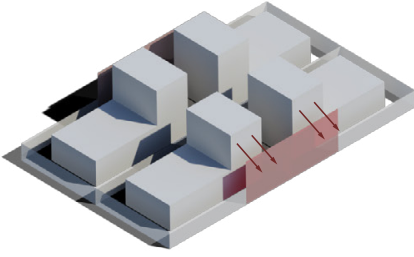

high fence

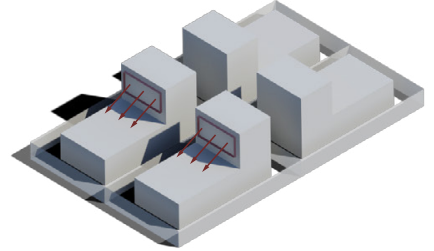

bay window

G
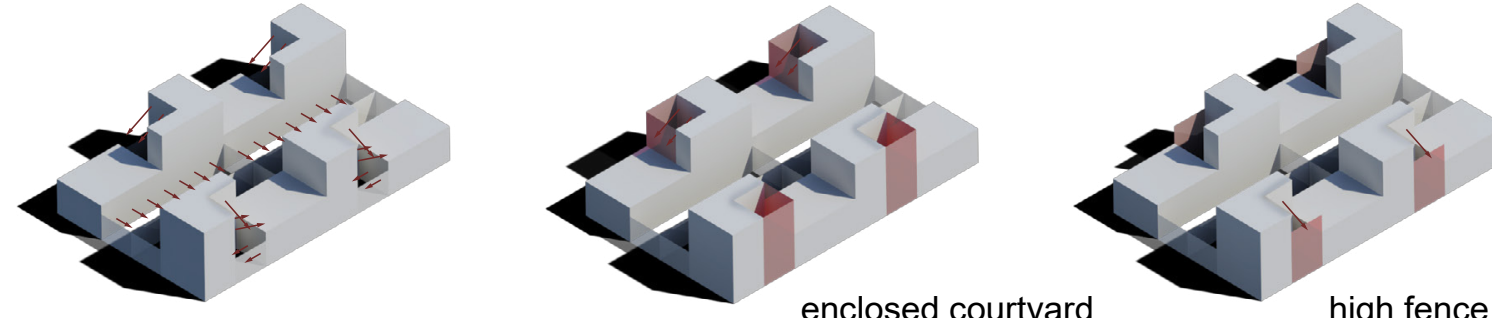


\section{Second storey mass}

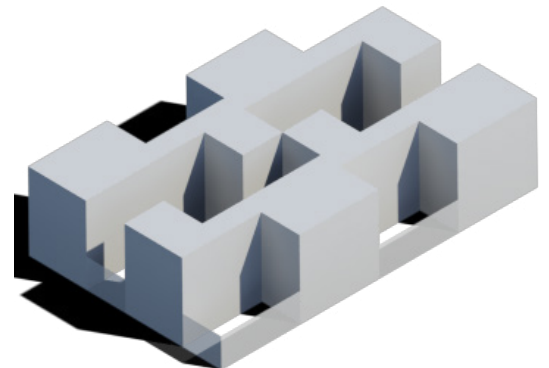

Figure 17. Fully two storey (B)

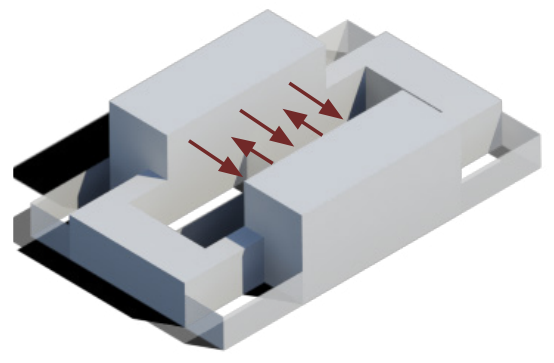

Figure 18. Mirrored mass (B)

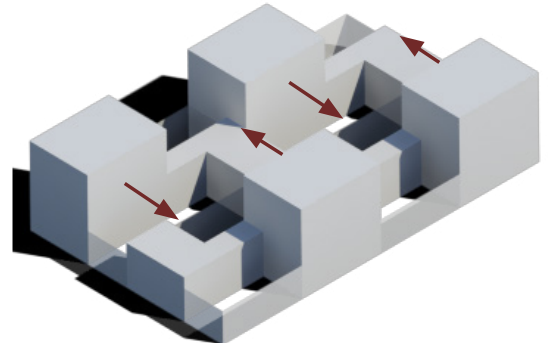

Figure 19. Offset mass (B)

Adding a second storey mass to the range of iterations previously explored at one storey has still generally shown the repeated rather than mirrored layout of units to be most successful. The placement of the second storey mass has overall been most successful when only part of the dwelling is multi-storey (circled page 90), similarly to what has been successful in the Seatoun Courtyard Houses precedent. Offsetting the double storey masses between units has also been successful, allowing views over the single storey volumes, while also working to block views into neighbouring private outdoor spaces (Figure 19). This mix of single and double storey masses, paired with the repeating layout creates less visual impact within the site and also allows better sunlight access into the buildings and outdoor space by creating a pattern of unbuilt, single height and double height masses. This is more successful compared to the mirrored layouts, or layouts with all mass built to two storeys which result in areas of bulky, concentrated mass that would be more visually imposing on existing back yards, as well reducing sunlight access and privacy.

\section{Privacy development}

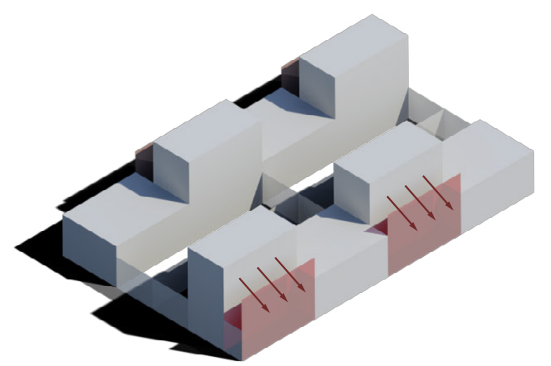

Figure 20. High fences to block view into neighbouring yard $(A)$

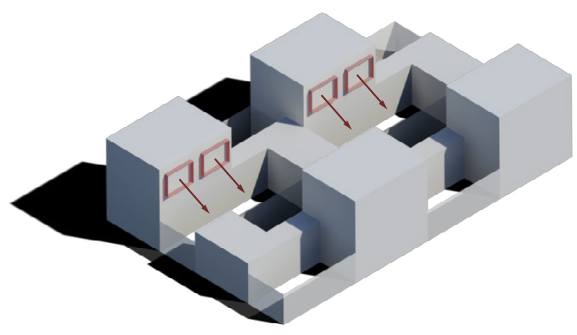

Figure 21. Bay windows to direct view away from neighbours $(B)$

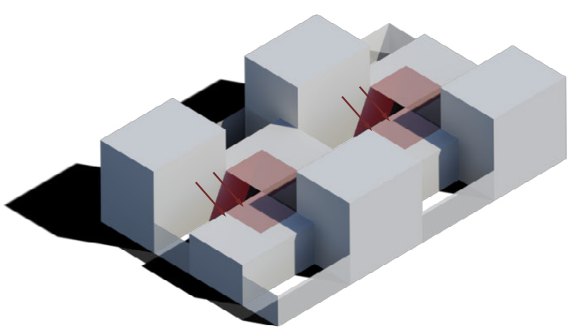

Figure 22. Awnings to create private outdoor space $(B)$

Taking the most successful multi-storey massing iterations, further development has been explored to target areas of reduced privacy and problematic overlooking (page 92). The use of screens through the employment of fencing, awnings and side fins has been found as a commonly useful strategy to block views into neighbouring outdoor spaces, however these may greatly impact sunlight access and create dark and enclosed feeling spaces so should be avoided where possible. Bay windows have also been a useful strategy to direct view away from neighbouring windows and outdoor spaces, presenting the most feasible strategy to pursue in further development.

\section{Conclusion}

Overall, option B with a repeating layout and offset two storey masses has been most successful in providing a building mass that optimises sunlight, outdoor space and privacy (circled page 92). This is largely due to its ' $Z$ ' shape that wraps around the site, extending to the site boundaries to form internal courtyards and provide introspective views. Repeating the unit shape across adjoining sites creates minimal connection of units through intertenancy walls, while maximising privacy through the building mass, rather than using fences. 
SUNLIGHT ANALYSIS - north-south site

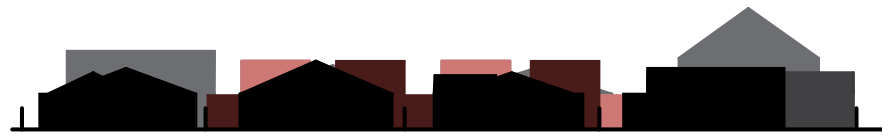

Elevation $A A^{\prime}$

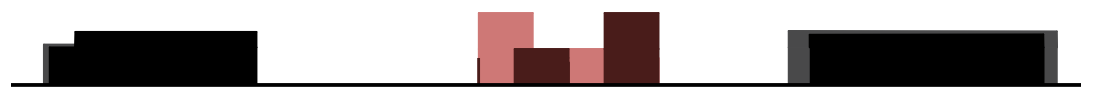

Section BB'

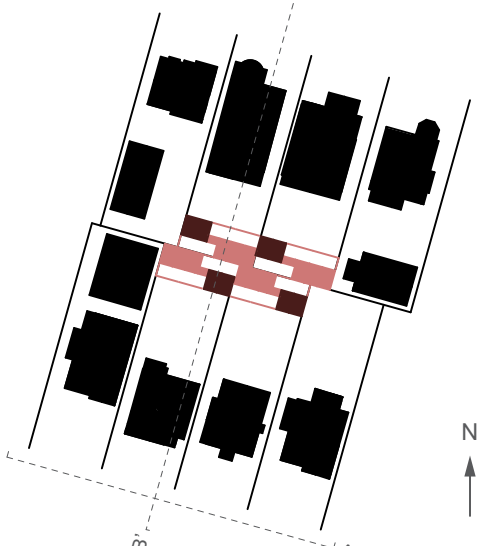

Plan

SUMMER

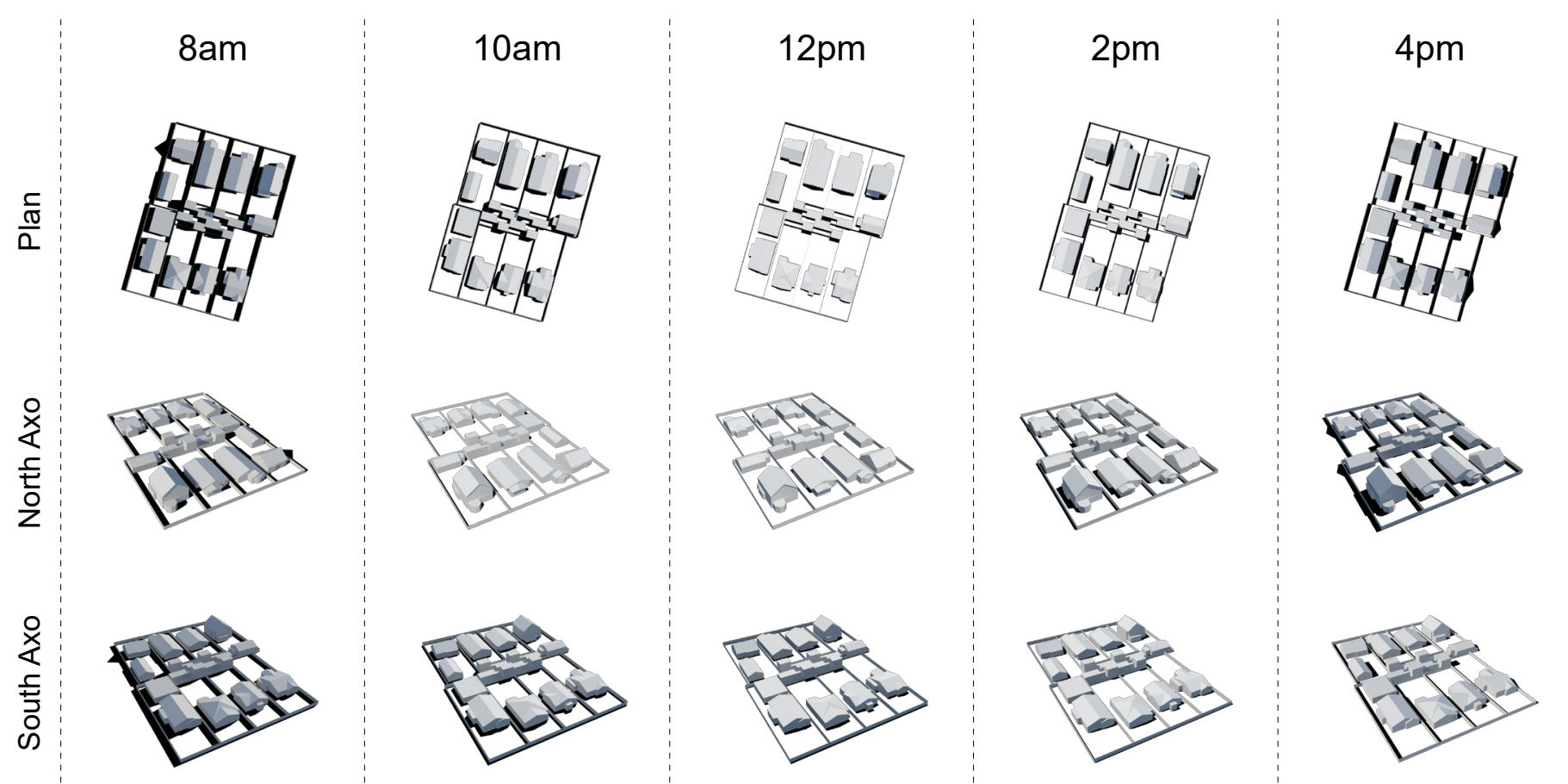

WINTER
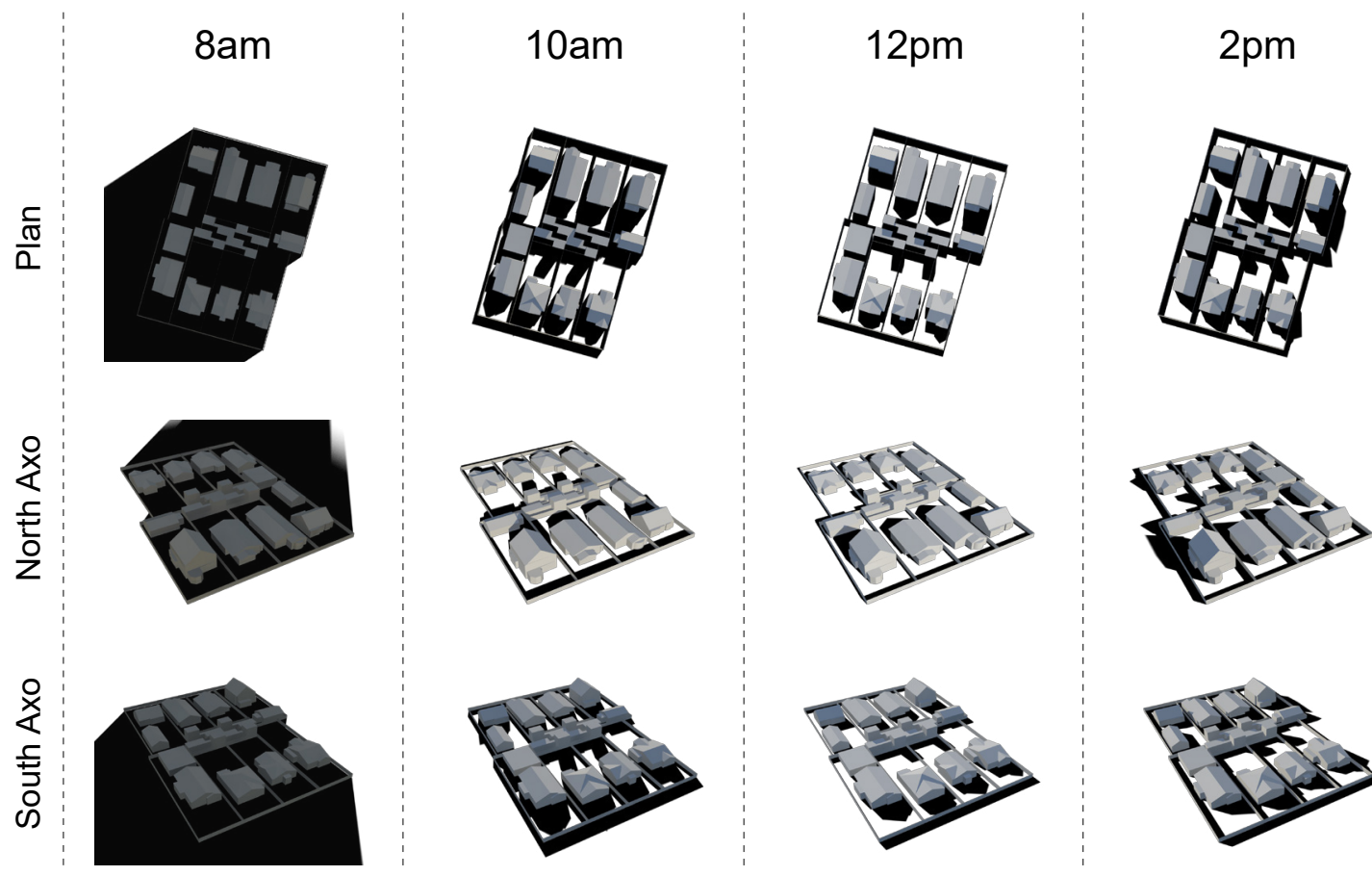

4pm
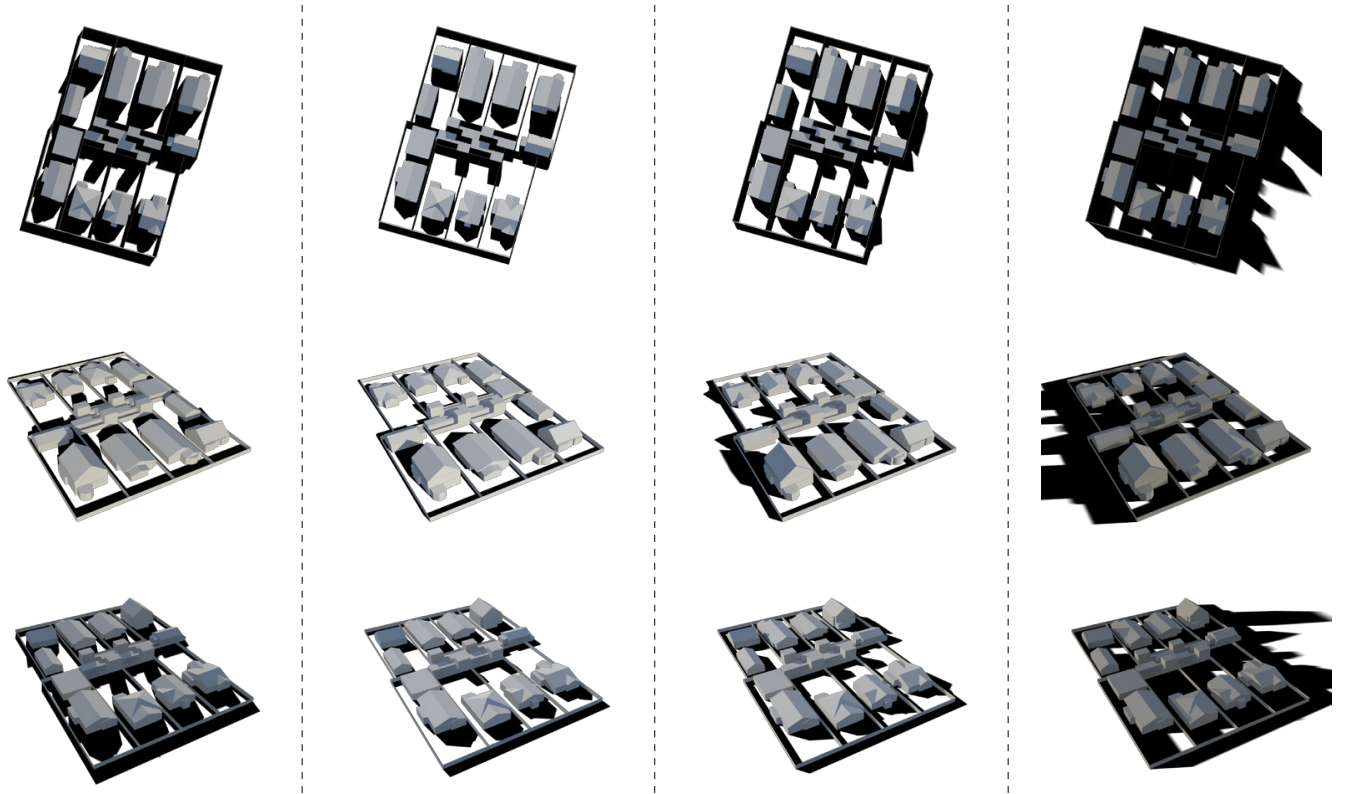


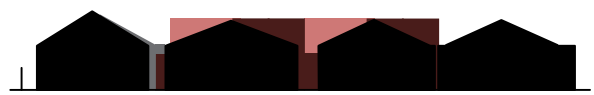

Elevation AA'

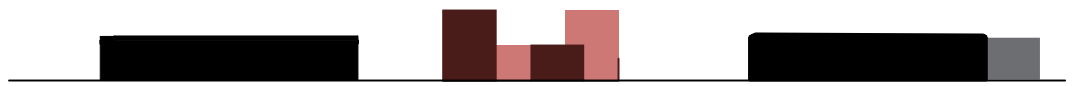

Section BB

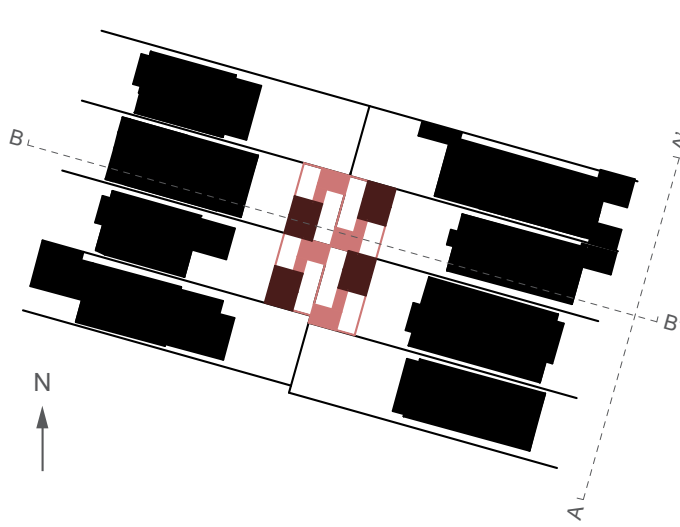

Plan

SUMMER

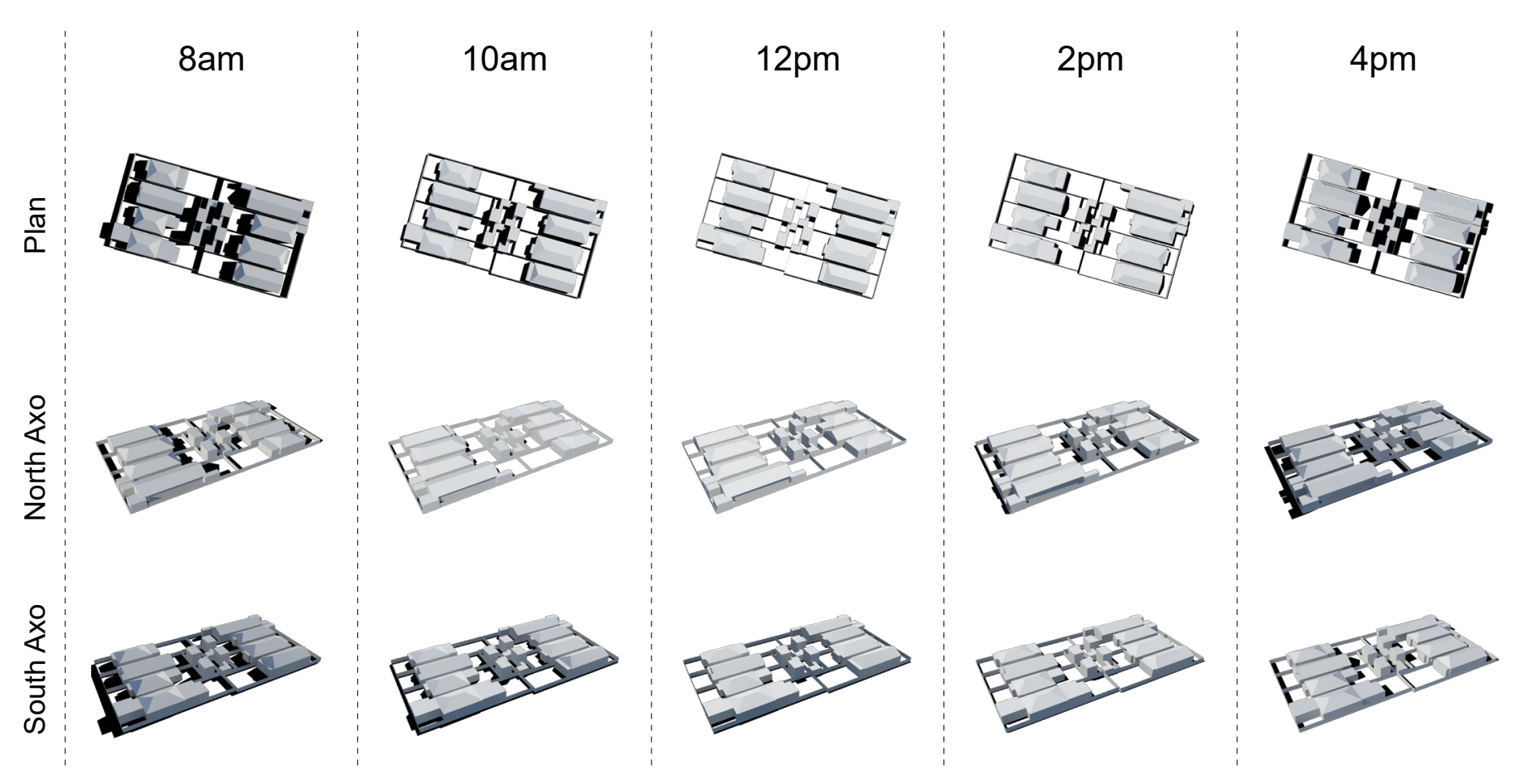

WINTER

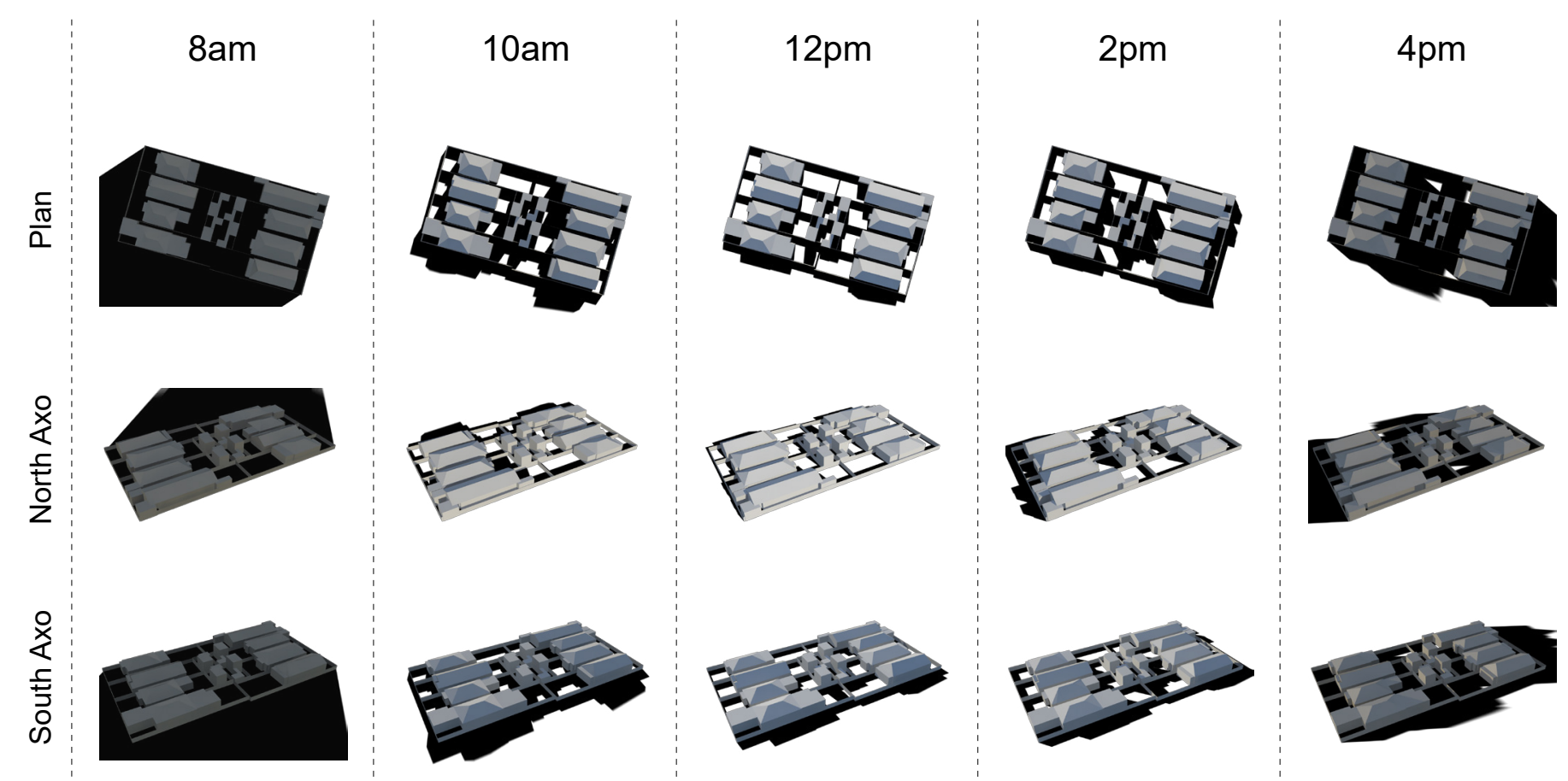




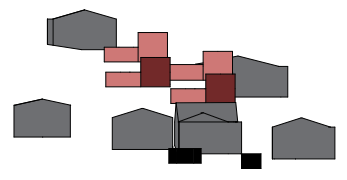

Elevation $A A^{\prime}$

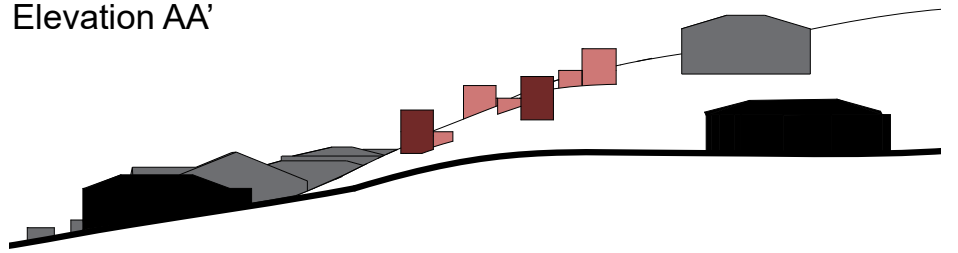

Section BB

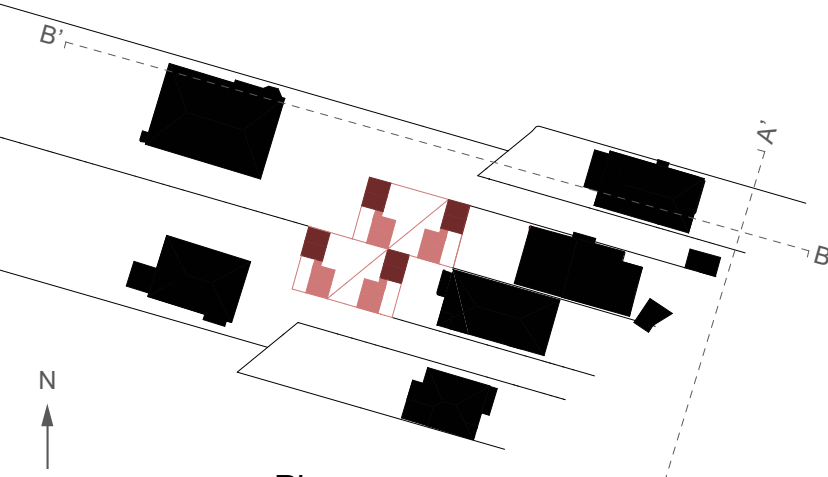

Plan

SUMMER
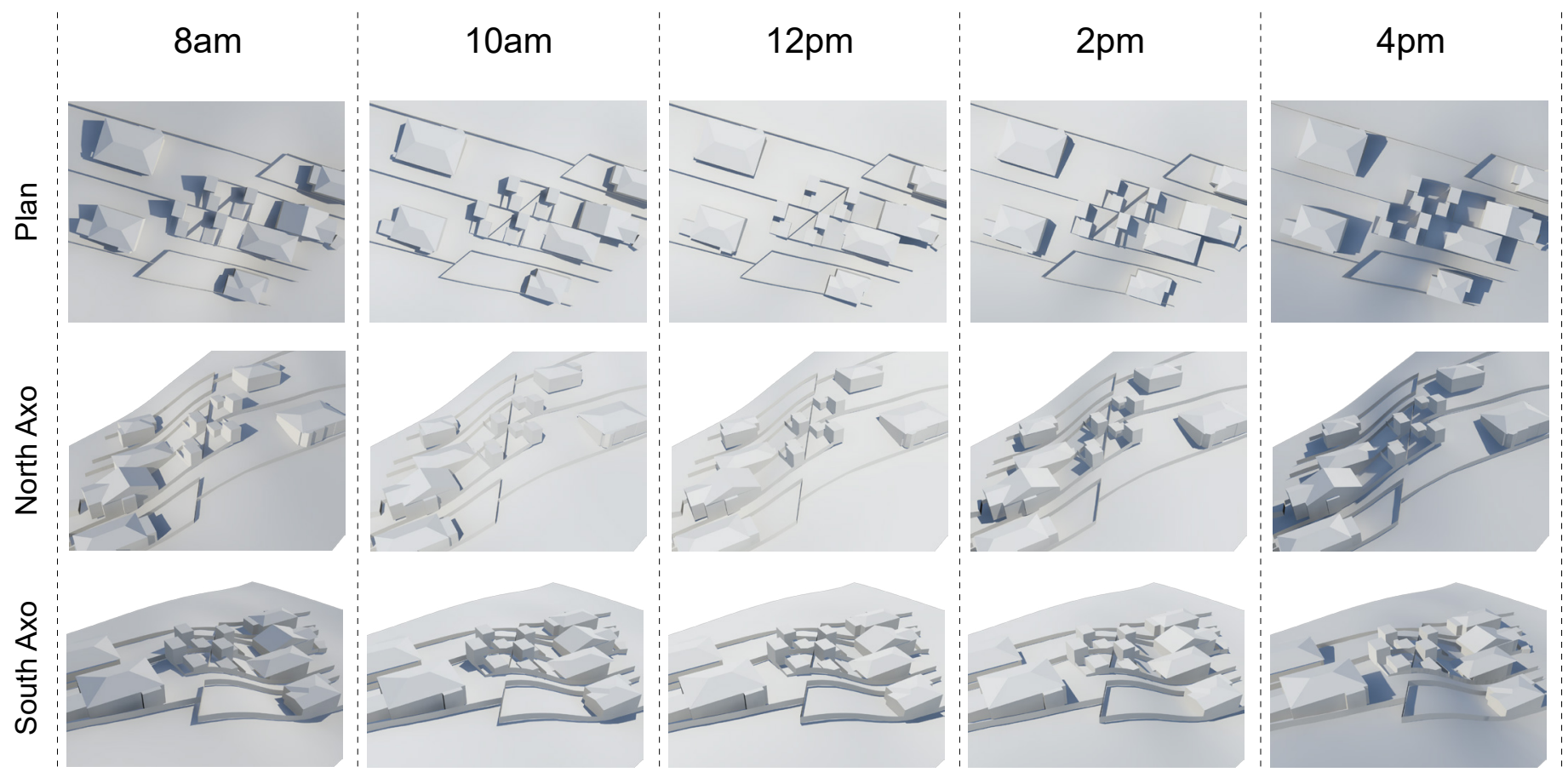

WINTER
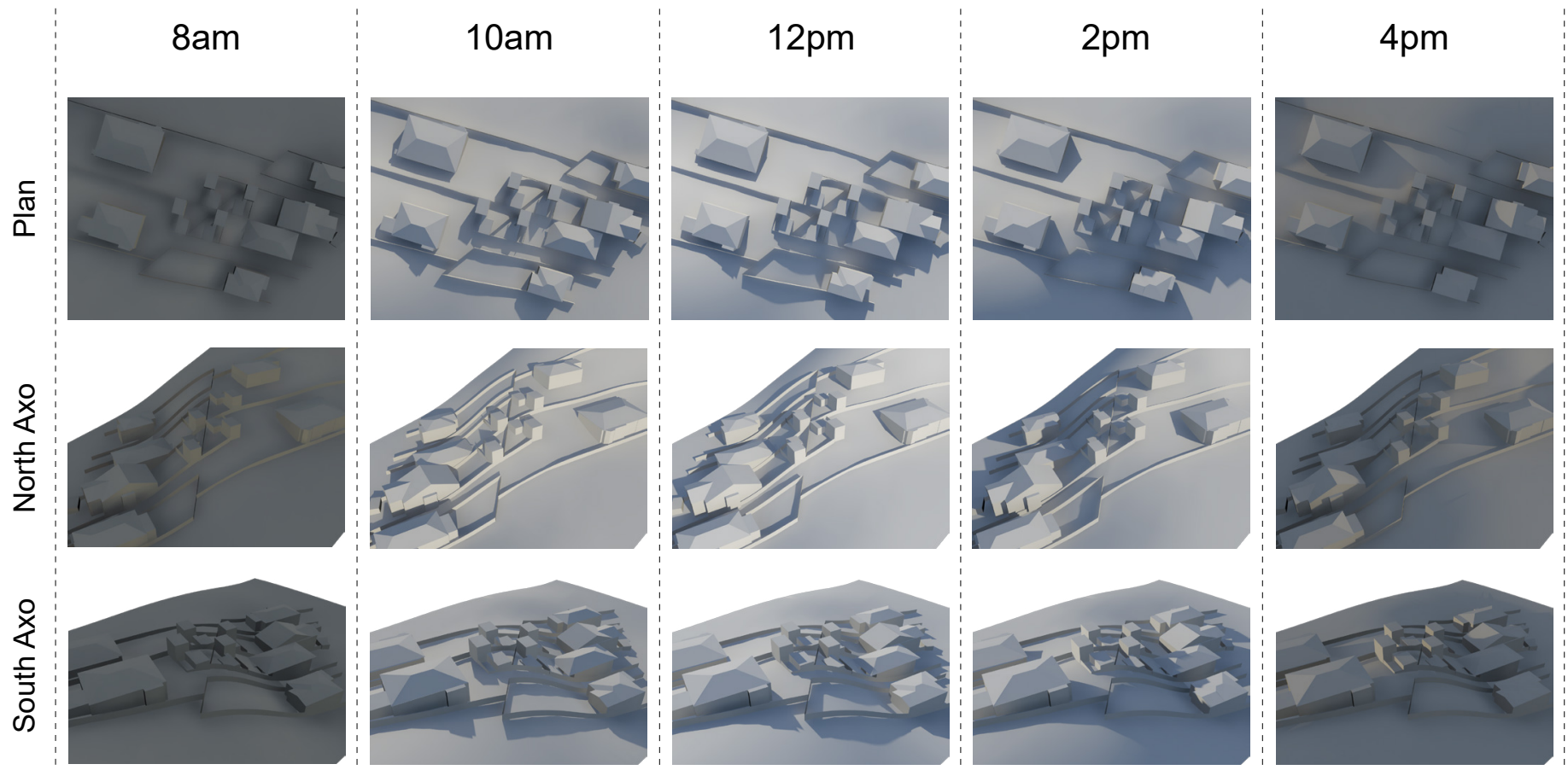


\section{SUNLIGHT STUDIES}

The feasibility and suitability of the most successful back yard ADU design, option B, has been tested and further developed through siting the dwellings on four neighbouring properties within three areas of Kilbirnie. Sunlight access and the impacts of shading have been analysed using the software $3 \mathrm{ds}$ Max to determine the success of the design, as well as the resulting impact on the existing sites and dwellings.

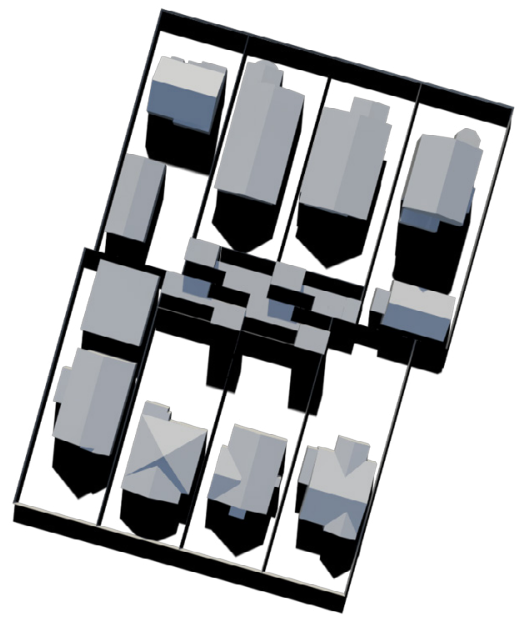

Figure 23. Shading impacts of north-south site ADUs (Winter 12pm)

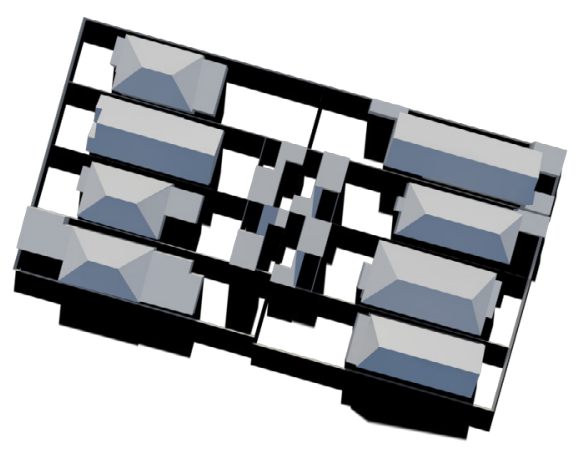

Figure 24. Shading impacts of east-west site ADUs (Winter 12pm)

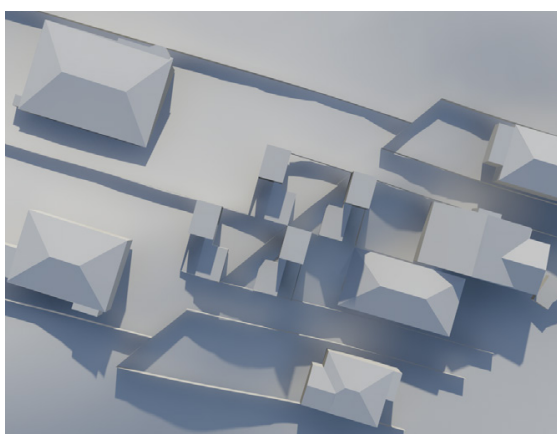

Figure 25. Shading impacts of sloped site ADUs (Winter 12pm)

Sunlight studies show the implementation of the back yard ADU design is least successful on the NorthSouth running backyards (Figure 23), as Northern sited ADUs shade the ADUs on the neighbouring back yards behind them considerably. These also have the greatest impact on shading the yards of the existing dwellings. East-West running sites are more successful (Figure 24-25), allowing sun into the courtyards of the ADUs in both summer and winter. These also have a lower impact on shading in the yards of the existing dwellings. The sloped site is the most successful (Figure 25), utilising the topography to step dwellings down the slope to allow maximum sunlight access to the ADUs and their courtyards.

Overall, the ADUs on all sites have very little impact on the sunlight access of existing dwellings, with the greatest impact seen on the back yards of neighbouring properties. While the courtyards of ADUs do not receive a large amount of direct sunlight throughout all seasons and times of day, sunlight and daylight access into the dwellings is seen throughout the year for all units on the East-West and sloped sites. This works well with the priorities identified earlier, which suggest that daylight access into dwellings is of high priority. 

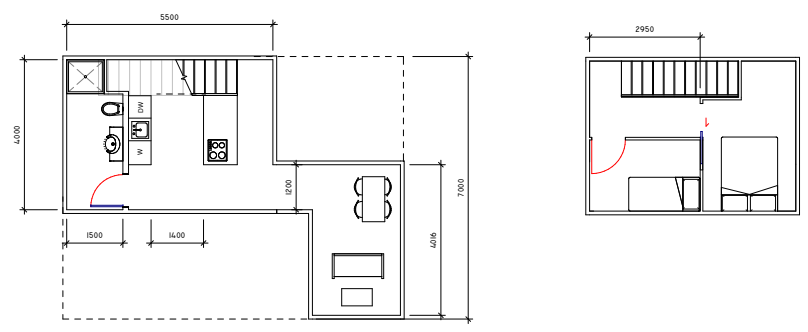

\author{
Site Area: $\mathbf{6 4 m ^ { 2 }}$ \\ Building Footprint: $\mathbf{3 6 \mathbf { m } ^ { 2 }}$ \\ Floor Area: $\mathbf{5 5 \mathbf { m } ^ { 2 }}$ \\ Outdoor Space: $\mathbf{2 8} \mathbf{m}^{\mathbf{2}}$ \\ Bedrooms: 2
}
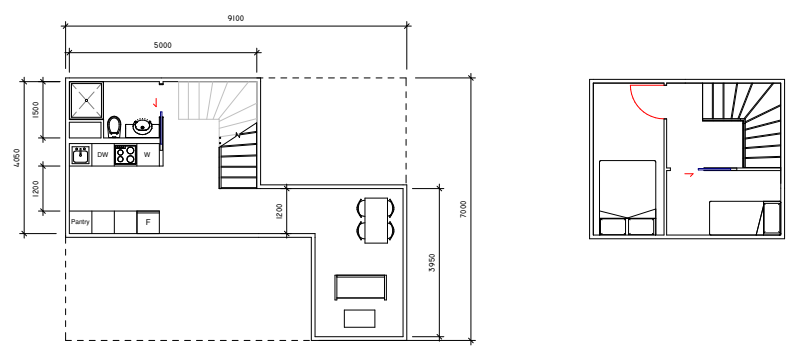

Site Area: $\mathbf{6 4 \mathbf { m } ^ { 2 }}$

Building Footprint: $\mathbf{3 4 \mathbf { m } ^ { 2 }}$

Floor Area: $\mathbf{5 1 \mathrm { m } ^ { 2 }}$

Outdoor Space: $\mathbf{3 0 \mathbf { m } ^ { 2 }}$

Bedrooms: 2
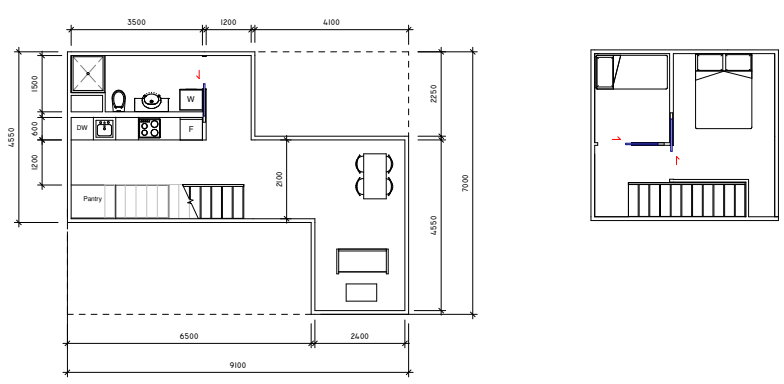

Site Area: $\mathbf{6 4 m ^ { 2 }}$

Building Footprint: $\mathbf{3 9 m ^ { 2 }}$

Floor Area: $\mathbf{5 5 m ^ { 2 }}$

Outdoor Space: $\mathbf{2 5 \mathbf { m } ^ { 2 }}$

Bedrooms: 2
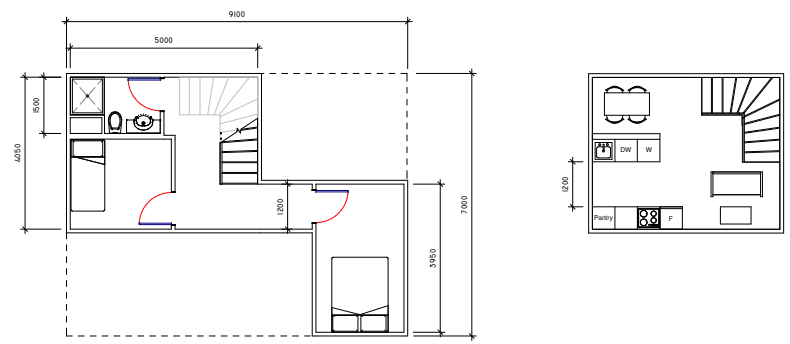

Site Area: $\mathbf{6 4 \mathrm { m } ^ { \mathbf { 2 } }}$

Building Footprint: $\mathbf{3 5 m ^ { 2 }}$

Floor Area: $\mathbf{5 1}^{\mathbf{2}}$

Outdoor Space: $\mathbf{2 9 m ^ { 2 }}$

Bedrooms: 2
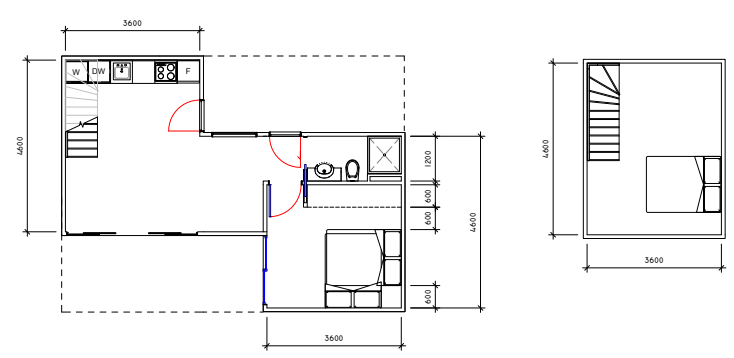

Site Area: $\mathbf{6 4 m ^ { 2 }}$

Building Footprint: $\mathbf{4 1} \mathbf{m}^{\mathbf{2}}$

Floor Area: $\mathbf{5 4 m ^ { 2 }}$

Outdoor Space: $\mathbf{2 3 \mathbf { m } ^ { 2 }}$

Bedrooms: 2 


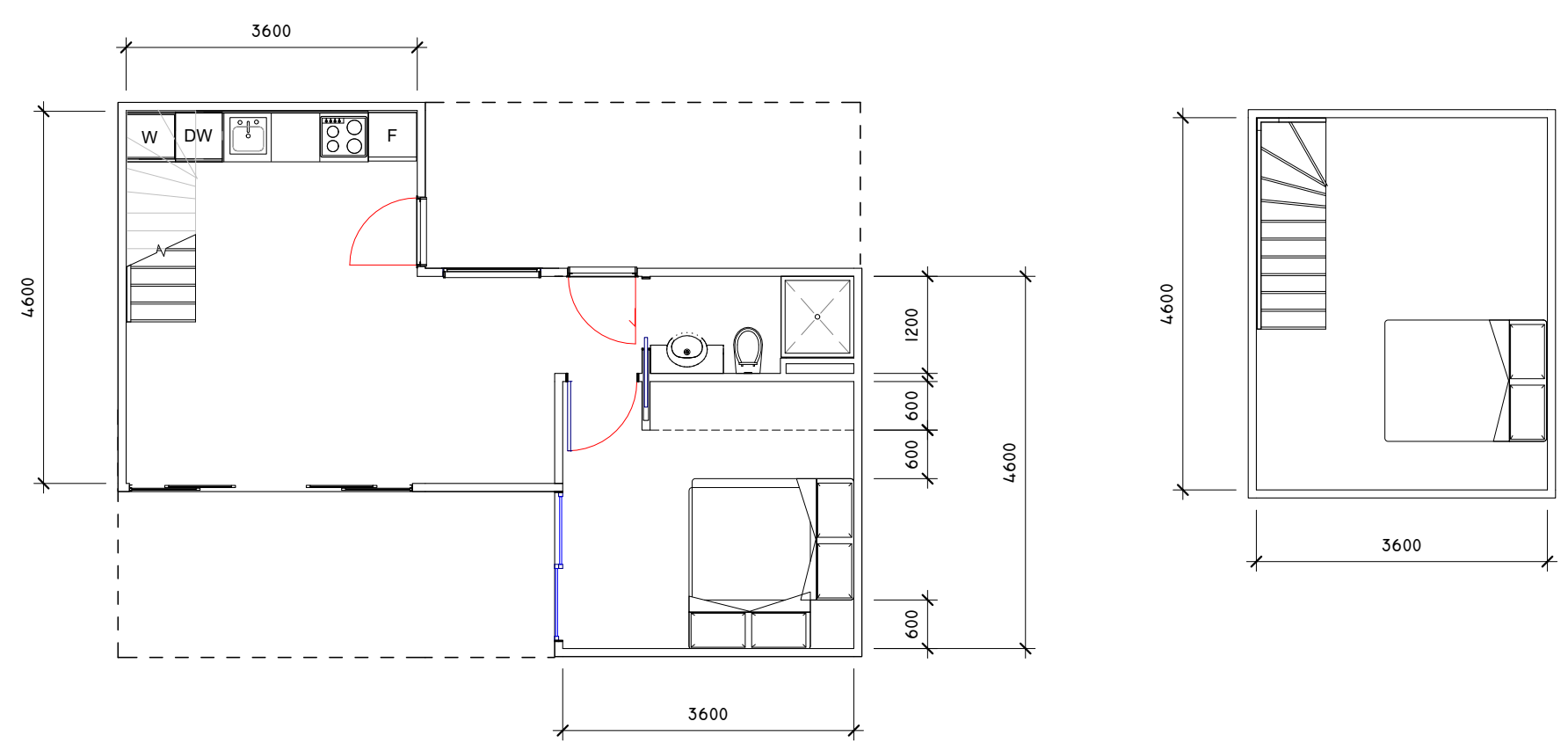

Figure 26. Most successful plan layout.

Using the massing studies as guidance for the overall building shape, as well as average site dimensions for the most successful site typology, initial planning studies have been undertaken for a fully completed dwelling.

Grouping the services around a single core wall space has been explored due to the cost and prefabrication efficiency benefits previously explored through the modular housing concept. However, this has been widely unsuccessful within this building shape, cutting the larger spaces within the dwelling into smaller, less usable spaces. Splitting the bathroom and kitchen services has allowed for more spacious kitchen and living areas, improving accessibility and creating more open spaces, essential within the small scale of the dwelling.

Although the initial massing studies utilised one large and one small volume, this has restricted the dwelling layout by creating undersized spaces. To improve this, a plan layout with identically sized volumes has been explored, maintaining the ' $Z$ ' shape which made the massing study successful. This has created the most promising initial plan layout, utilising a split service core and prioritising open spaces (Figure 26, circled page 98). 


\section{CONCLUSION}

This chapter has explored existing preferences and priorities for housing within New Zealand to develop ADUs suitable for Kilbirnie sites through massing and plan studies. Overall, the development of a back yard ADU has provided the most promising solution that best meets the identified housing priorities, while fitting within existing site constraints and context, as well as having the lowest impact on shading of existing dwellings and the existing street character of the suburb. Siting ADUs on back yards has also been found to be most successful on East-West running sites with flat access.

As the back yard ADUs have been found to be significantly more successful at this stage, front yard ADUs will not be progressed with further. Additional development is needed with the floor plan layout of the back yard $A D U$, as well as development of this finished strategy into an incremental strategy that can be built in stages. 


\section{WORKS CITED}

Abu-Ghazzeh, T. M. (2000). Environmental messages in multiple-family housing: Territory and personalization. Landscape Research, 25(1), 97.

Akehurst, G., \& Yeoman, R. (2015). The Housing We'd Choose: A Study of Housing Preferences, Choices and Trade-Offs in Auckland. Retrieved from Auckland: https://www.smartgrowthbop.org.nz/media/1631/june-the-housing-we-choose-akl.pdf

Aries, M. B. C., Aarts, M. P. J., \& van Hoof, J. (2015). Daylight and health: A review of the evidence and consequences for the built environment. Lighting Research and Technology, 47(1), 6-27. doi:http:// dx.doi.org/10.1177/1477153513509258

Beute, F., \& de Kort, Y. A. W. (2014). Salutogenic effects of the environment: review of health protective effects of nature and daylight. Applied psychology. Health and well-being, 6(1), 67-95. doi:http://dx. doi.org/10.1111/aphw.12019

Bryson, K. (2017). The New Zealand Housing Preferences Survey: Attitudes towards medium-density housing (SR378). Retrieved from Judgeford: https://www.branz.co.nz/cms show download. php?id=9aa2011337f7e6cebc169d4ac4c711d721b7e938

Carmona, M., Heath, T., Oc, T., \& Tiesdell, S. (2010). Public Places - Urban Spaces: The Dimensions of Urban Design. London: Taylor and Francis.

Donn, M., \& Thomas, G. (2001). Designing Comfortable Homes - guidelines on the use of glass, mass and insulation for energy efficiency.

Espiritu, R. C., Kripke, D. F., Ancoli-Israel, S., Mowen, M. A., Mason, W. J., Fell, R. L., . . Kaplan, O. J. (1994). Low illumination experienced by San Diego adults: Association with atypical depressive symptoms. Biological Psychiatry, 35(6), 403-407. doi:http://dx.doi.org/10.1016/0006-3223(94)90007$\underline{8}$

Judd Studio. (2016). Sawtooth House. Retrieved from http://www.juddstudio.com.au/sawtooth-house/

Lindsay, M., Williams, K., \& Dair, C. (2010). Is There Room for Privacy in the Compact City? Built Environment, 36(1), 28-46. doi:10.2148/benv.36.1.28

Marriage, G. (2014). Pavlova paradise and the curse of the side yard. Building A Better New Zealand, 360365.

Oseland, N. (2009). The impact of psychological needs on office design. Journal of Corporate Real Estate, 11(4), 244-254. doi:http://dx.doi.org/10.1108/14630010911006738

Partonen, T., \& Lönnqvist, J. (2000). Bright light improves vitality and alleviates distress in healthy people. Journal of affective disorders, 57(1-3), 55-61.

Prochorskaite, A., Couch, C., Malys, N., \& Maliene, V. (2016). Housing Stakeholder Preferences for the "Soft" Features of Sustainable and Healthy Housing Design in the UK. International Journal of Environmental Research and Public Health, 13(1), 1-15. doi:http://dx.doi.org/10.3390/ijerph13010111 
RIBA, \& Ipsos MORI. (2012). TheWayWe Live Now: What People Need and Expect from Their Homes. Retrieved from London: http://www.ekkist.co/wp-content/uploads/2018/01/ThewaywelivenowRIBAlpsosMORIMay2012.pdf

Studio Pacific Architecture. (2003). Courtyard Houses. Retrieved from https://www.studiopacific.co.nz/projects/2003/courtyard-houses/

Wheeler, T. (2010). Garden Cities of Tomorrow: Upside Down, Inside Out and Back to Front. Griffith REVIEW(29), 5-13. 


\section{CHAPTER 5: DESIGN DEVELOPMENT}




\section{INTRODUCTION}

This chapter looks at the integration of the most successful iterations that resulted from the site and massing studies with the earlier incremental and modular explorations. The site responsive massing concept is integrated into a multi-phased incremental dwelling which is then further developed by focusing on key elements, such as windows, stairs and storage, and key service areas such as the kitchen and bathroom. Other dwelling areas remain as simple as possible to reduce cost and maximise user customisation of the standardised modular design. 


\section{INCREMENTAL INTEGRATION}




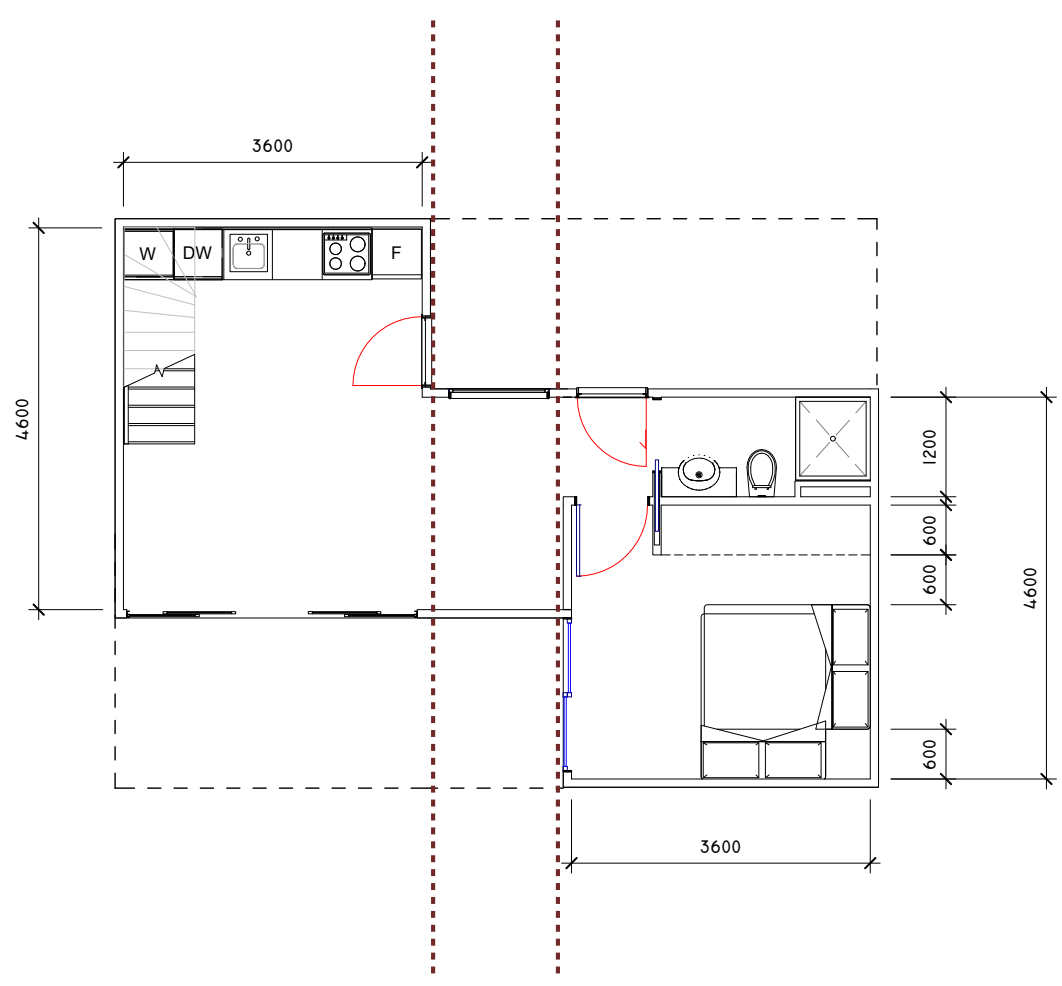

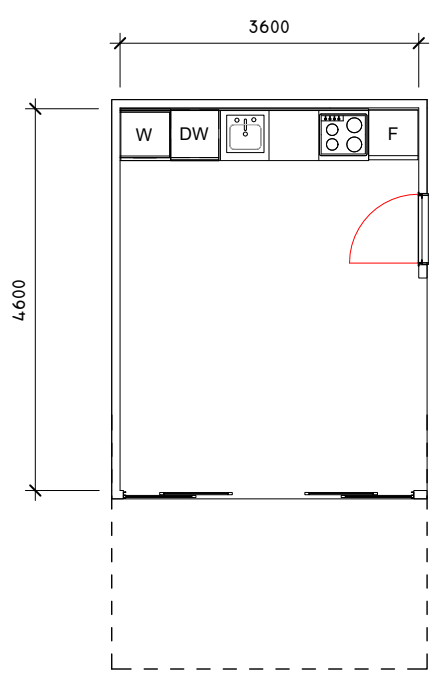

Standard module

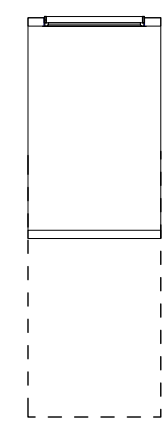

Custom connection

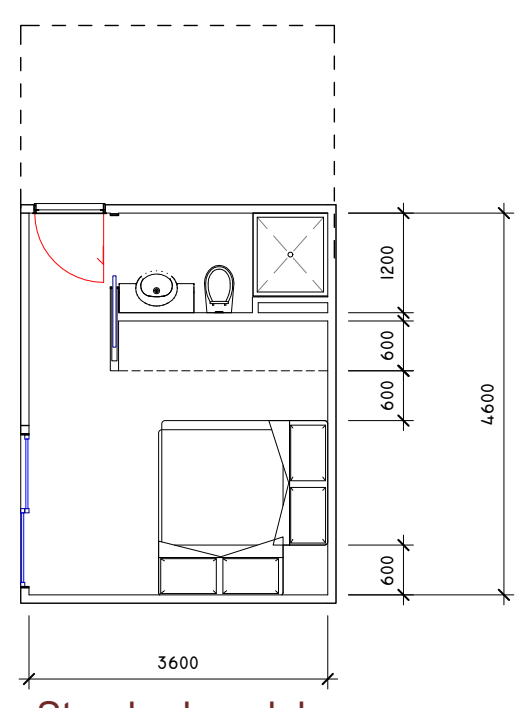

Standard module

Following the modular concept exploration, which found that a combination of standard and custom elements worked best, the plan has been split into two standard sized modules and a custom connecting element. The modules are each small enough to fit on a truck so they can be prefabricated and craned onto the suburban sites with minimal onsite construction. The division of the dwelling into modules will also facilitate additive modular incremental construction, identified earlier as the most appropriate incremental growth approach for this project. 


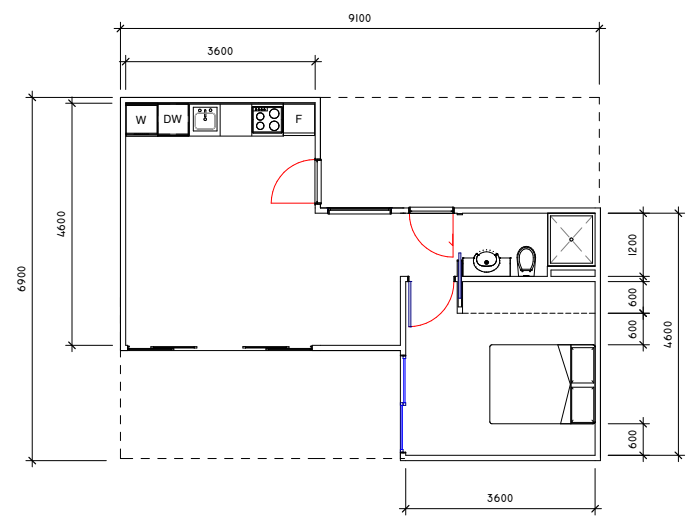

Average site

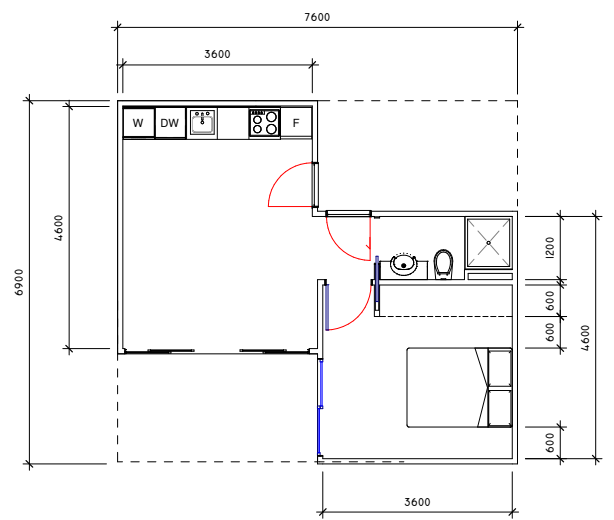

Narrow site

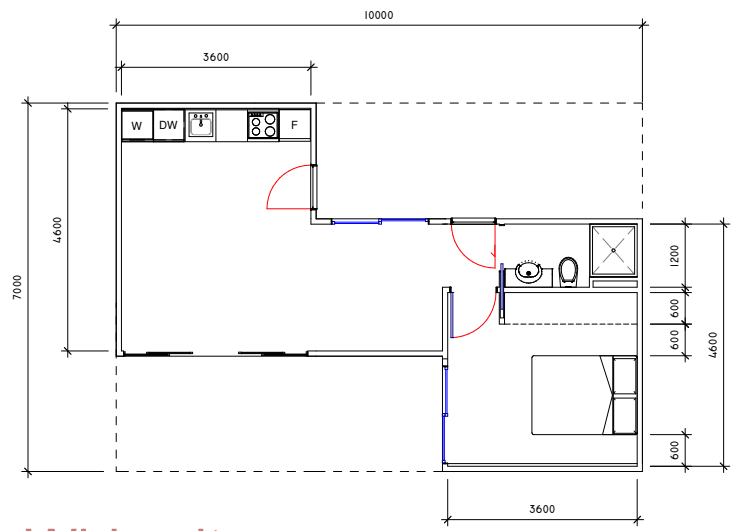

Wide site

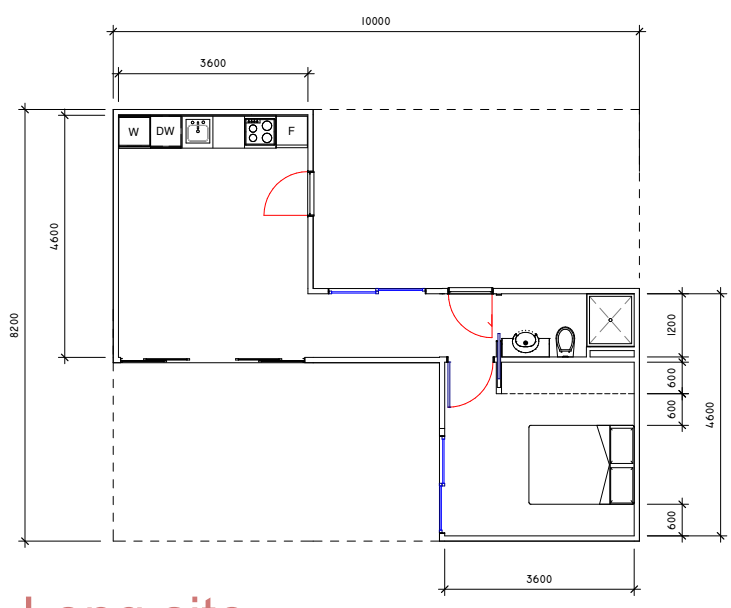

Long site

The custom connection element allows the two standard modules to fit within various site sizes, allowing for small variations in site size and shape within the selected area of Kilbirnie. This connection space has no specific function or services, allowing it to be used for a range of purposes, depending on the site size, such as a dining, entrance, storage, seating or desk space.

Further development of this connection space for other areas within Kilbirnie could facilitate different site topographies. This would allow the standard modules to remain the same as they are on flat sites, while the connection module would allow them to sit at different heights on a sloped site, creating a stepped space between. 
Plan development - incremental phases

\section{Phase 1}
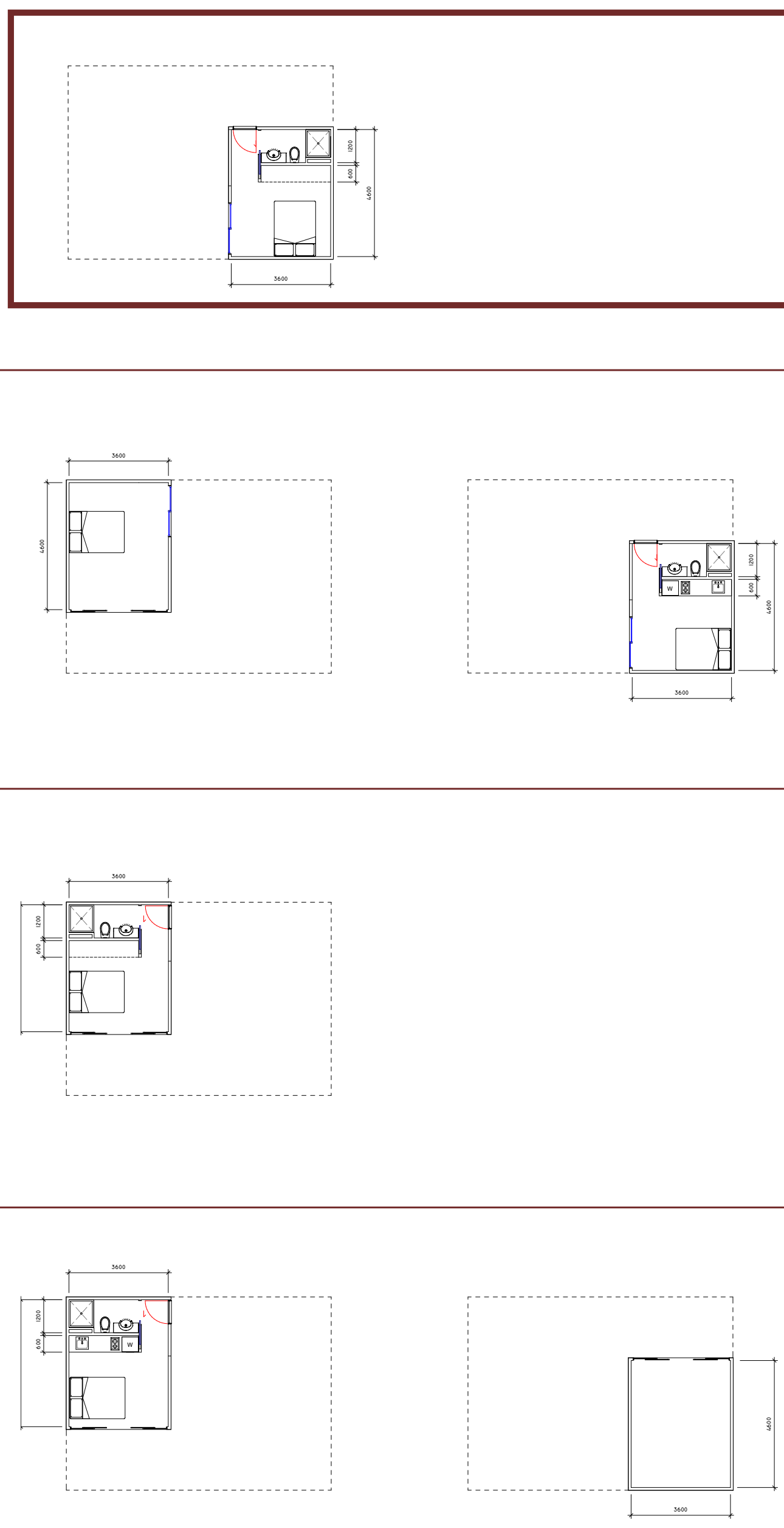
Phase 2

Phase 3
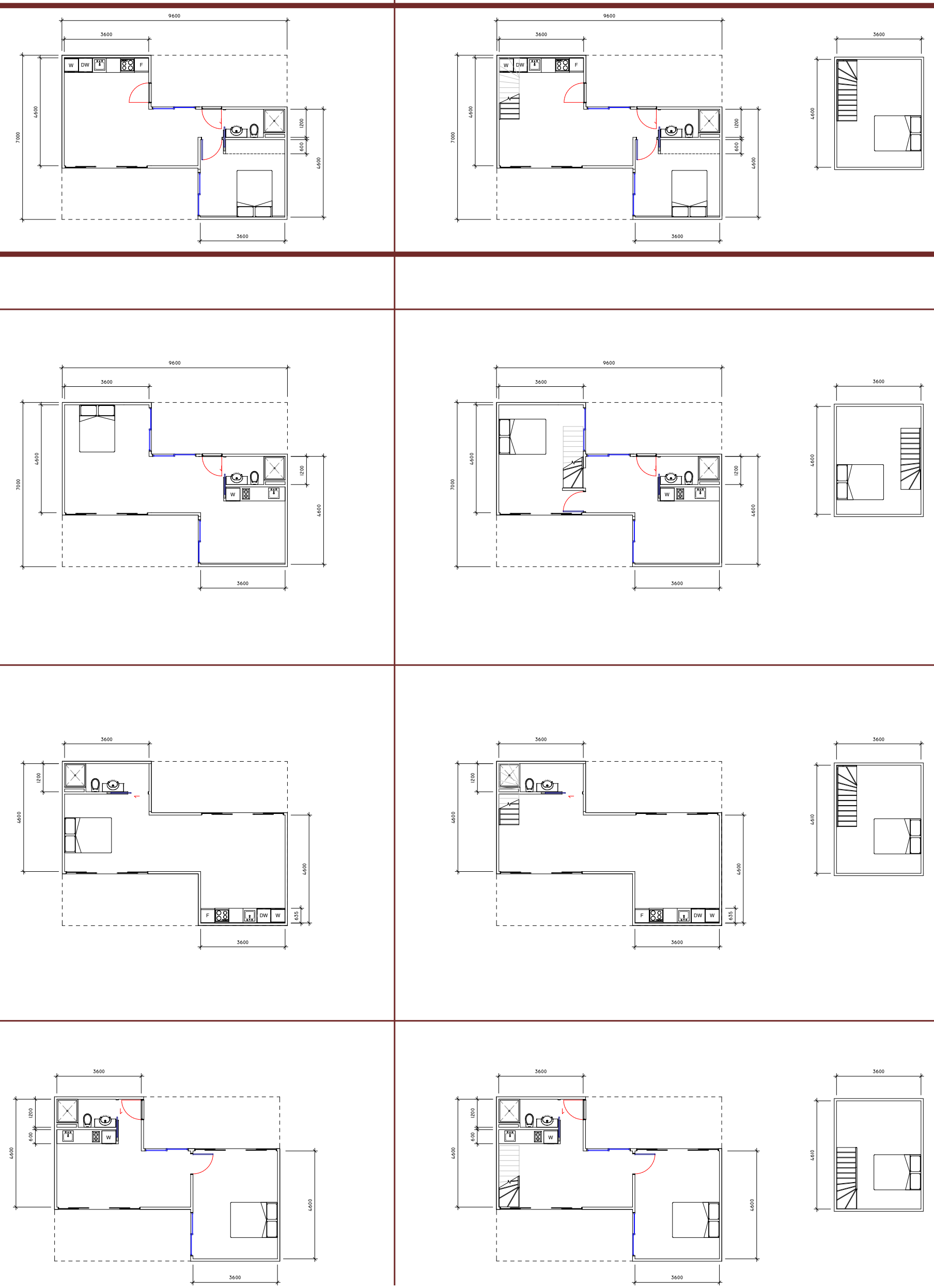


\section{INCREMENTAL CONSTRUCTION DEVELOPMENT}

Experimentation with the location and functions of the different phases has been undertaken to determine the best way, or if there are multiple ways, to achieve the desired final stage which has previously been the focus of design explorations.

\section{Phase 1}

At the first stage, the design acts as an additional bedroom unit with some independence from the existing dwelling. This may be suitable for a child of the family, needing more independence but unable to afford a place of their own, or an older family member that needs to move closer to family while still maintaining some independence. This could potentially act as a sleep-out space with no services, or include a bathroom.

\section{Phase 2}

At the second stage of growth, the dwelling is able to function independently from the existing dwelling, gaining its own kitchen and living space, as well as forming its own private outdoor courtyard space. This may again be suitable for a family member, desiring more independence, or to be rented out to someone outside of the existing family unit to provide a source of income.

\section{Phase 3}

At the third stage of growth the dwelling is able to provide an additional bedroom, making the dwelling suitable for a wider range of occupants. This may stage may take place as the occupants have children, or desire additional space for living or a home office, or may be done when can be afforded for additional rental income, able to house up to four people.

\section{Incremental layout}

In isolation, the location of phase one on the backyard site does not matter, however, when reaching phase three it has significant impact due to the location of the stairs. Following the lessons from the massing studies, the two storey volume must be located on the same side of the site for all ADUs to allow for the successful offset layout of the building mass. This means the successful layout of the final phase can only be achieved if the first phase is the single height mass on the right side of the backyard. This allows for the most efficient spatial layout which includes two bedrooms and a full sized kitchen at the final phase (circled page 108-109). Additionally, to achieve this, the first phase must also include both the bathroom and bedroom space. 


\section{WINDOWS}


View and light requirements - single dwelling

Phase 1

EXISTING DWELLING
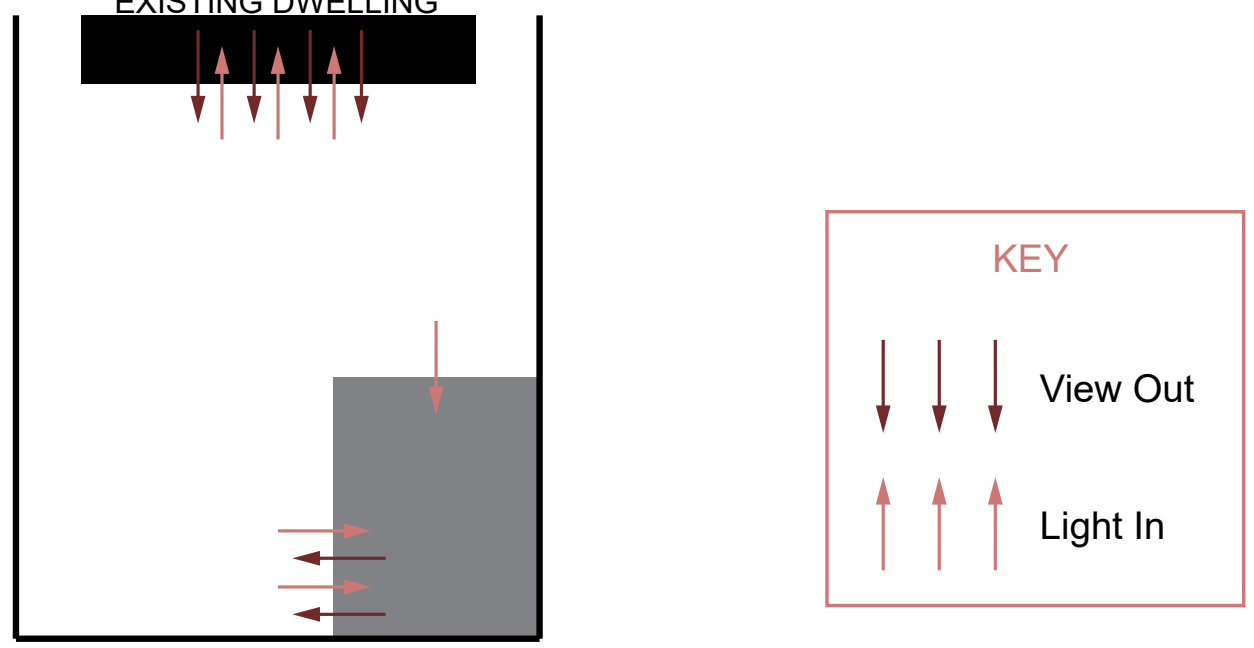

Phase 2

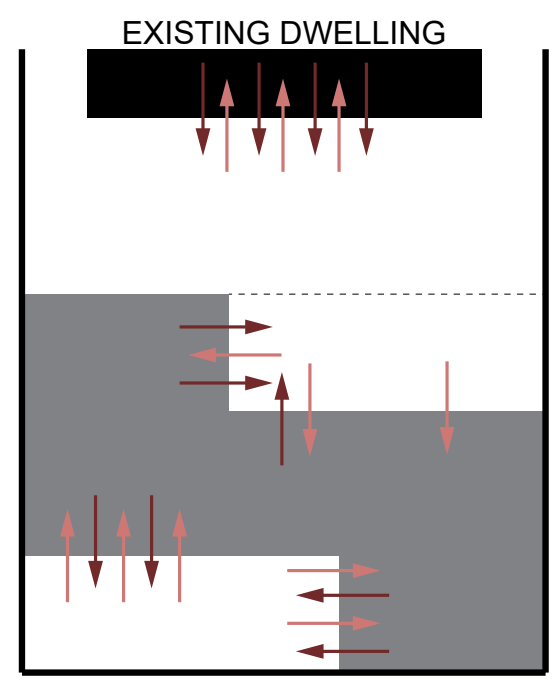

Phase 3
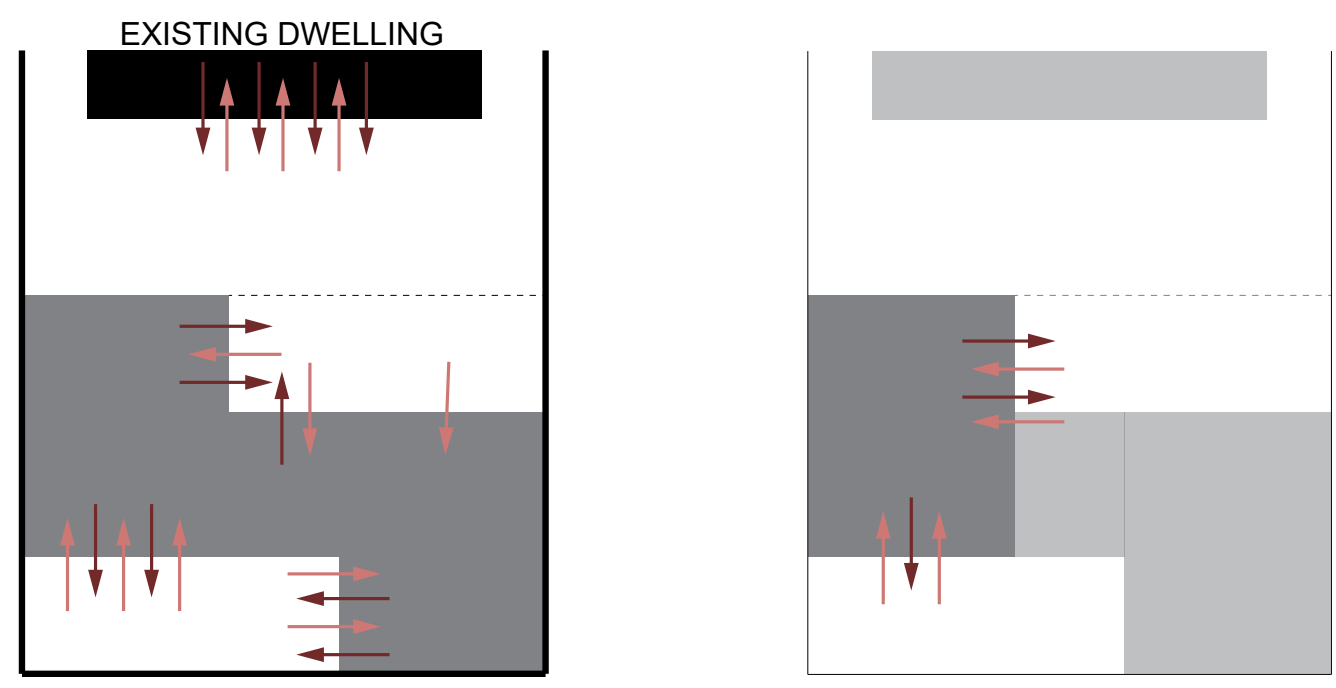

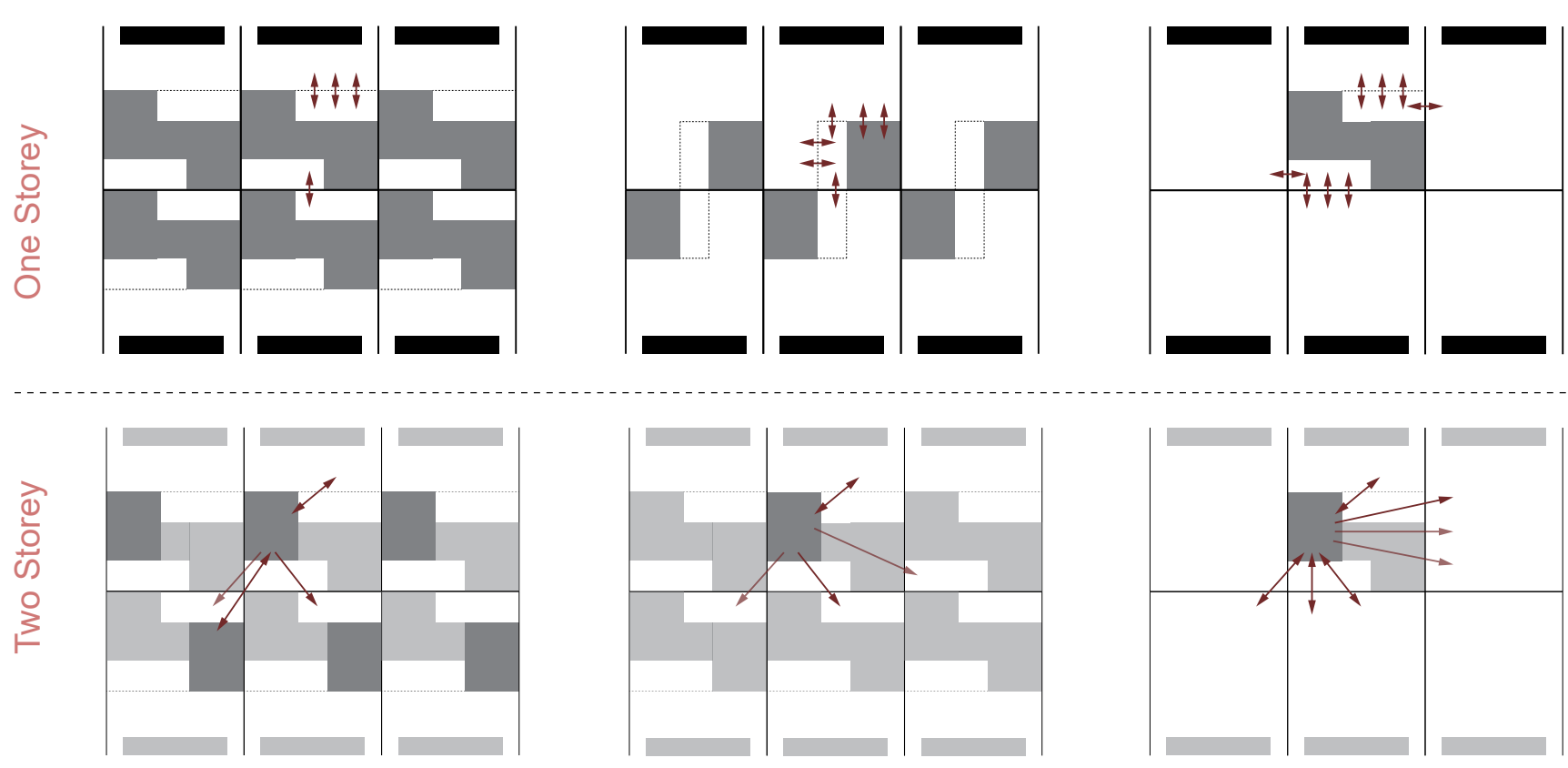

At different stages of the ADU and neighbouring ADU development, various privacy issues occur. Much of this can be solved through screens or fences across site boundaries, which may vary in height depending on user requirements and desired levels of privacy. Key privacy issues relating to the dwelling itself are largely due to upper storey windows ( $B, C$ below) that may overlook neighbouring backyards, or look into the upper storey windows of neighbouring ADUs. Additionally, the bathroom window (A below) should be made as private as possible as it faces into the existing dwelling's back yard at phase one and is located near the front entrance of the ADU.

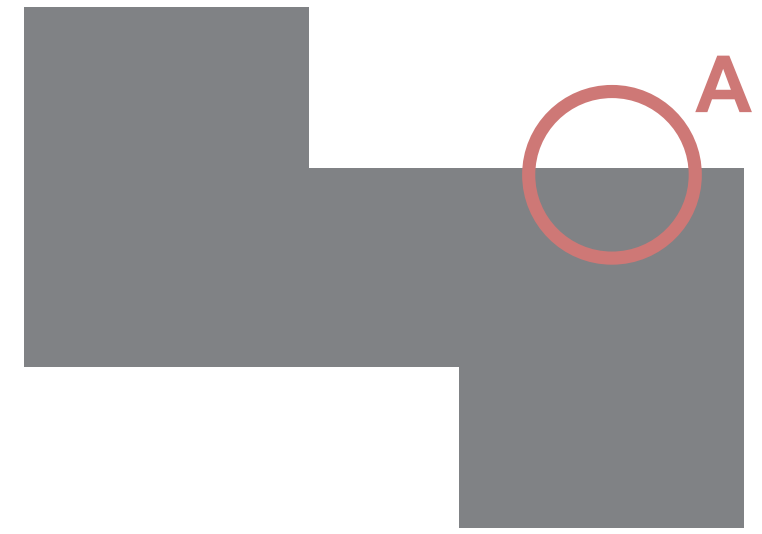

Ground Floor

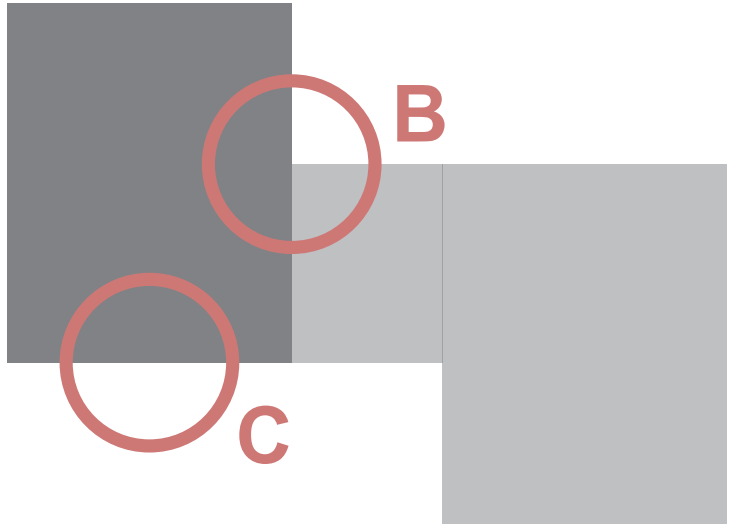

First Floor 


\section{Window concepts - extra space}
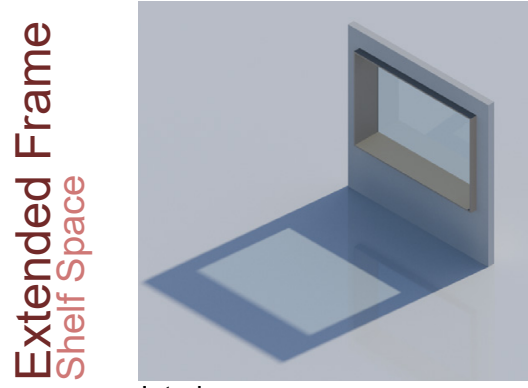

Interior

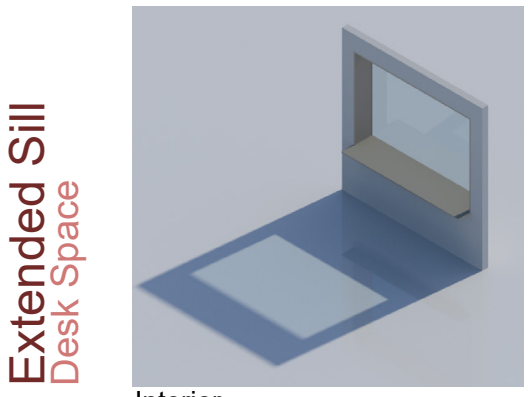

Interior
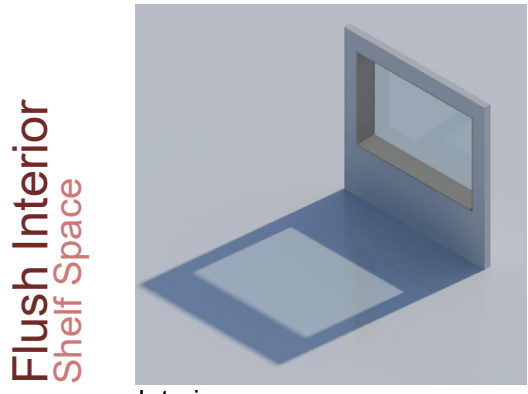

Interior

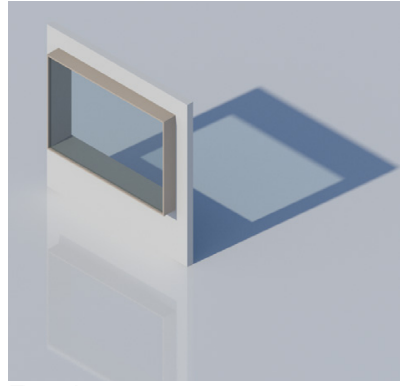

Exterior

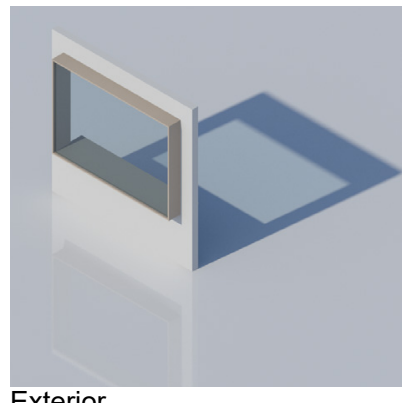

Exterior

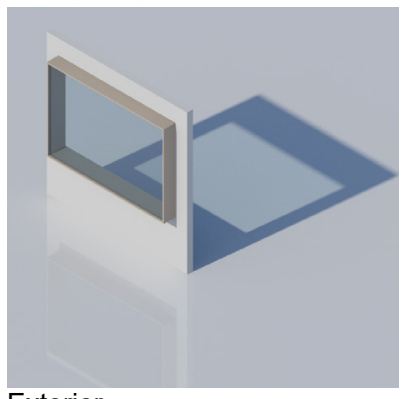

Exterior

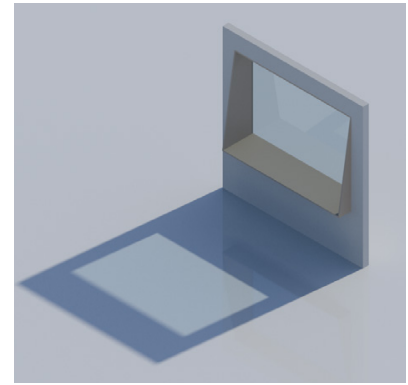

Interior

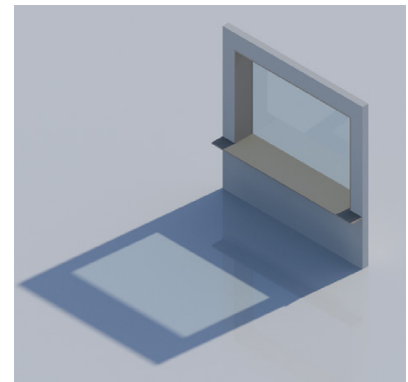

Interior

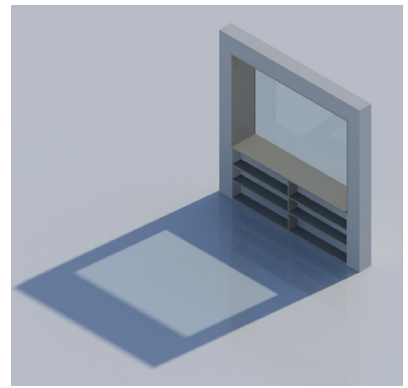

Interior

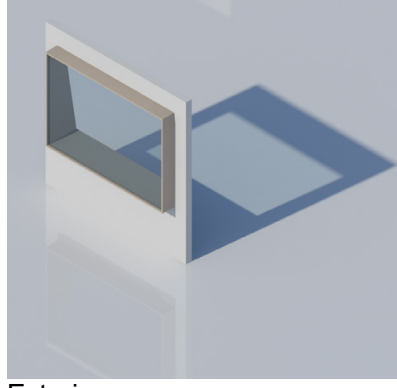

Exterior

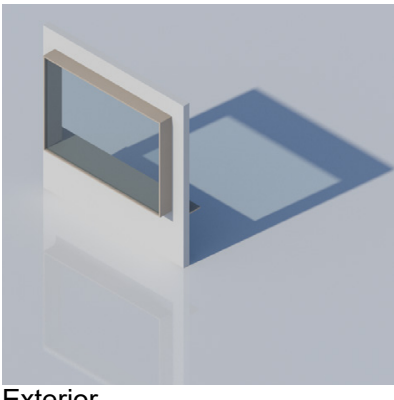

Exterior

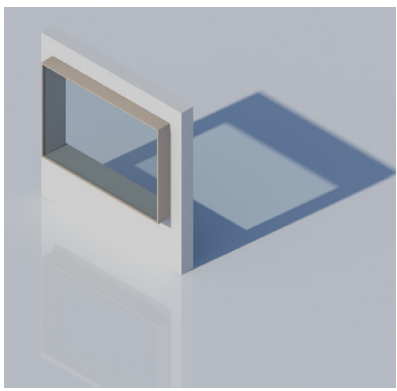

Exterior

The small scale of the dwellings may create a challenge for liveability, requiring the optimisation of all spaces within the dwelling. The windows present an opportunity to be better utilised as a three dimensional object, rather than a flat plane, to provide storage, shelf or desk space. 


\section{Window concepts - privacy}

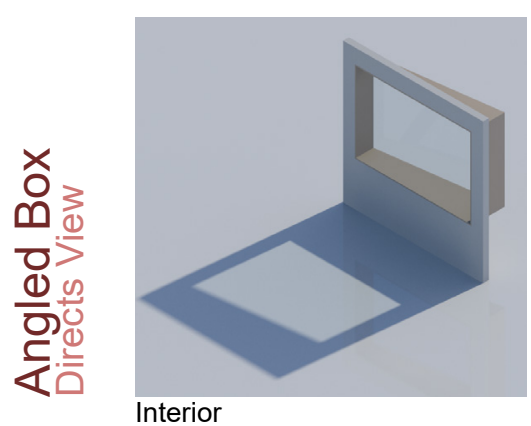

Interior

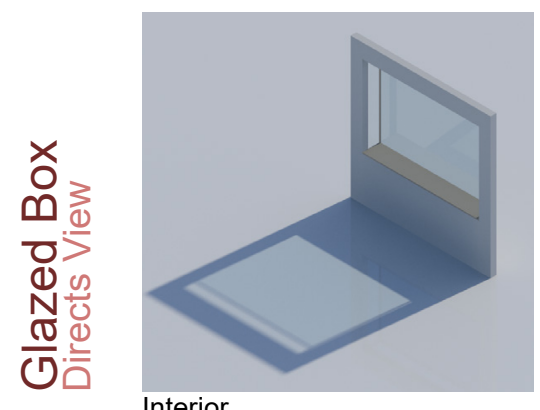

Interior

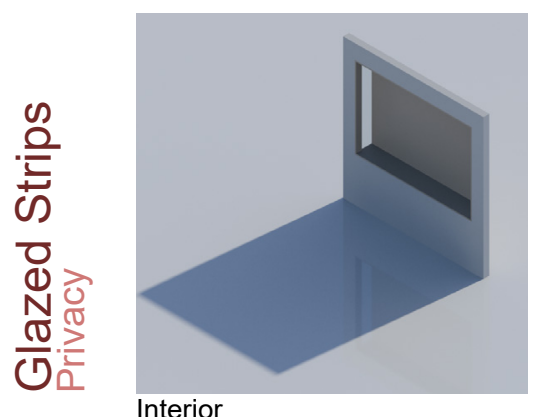

Interior

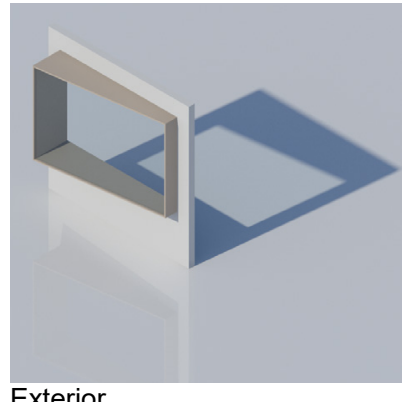

Exterior

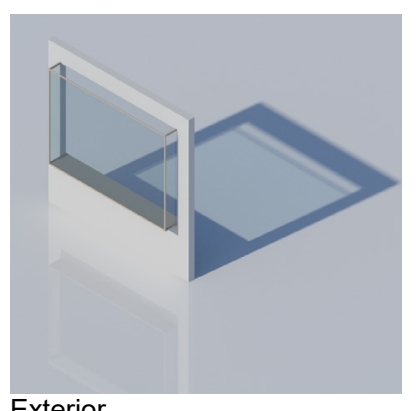

Exterior

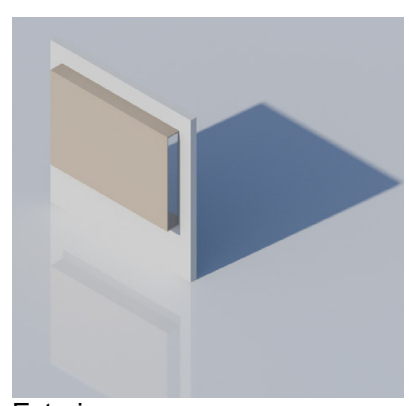

Exterior

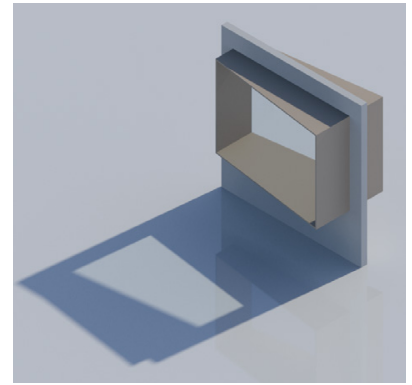

Interior

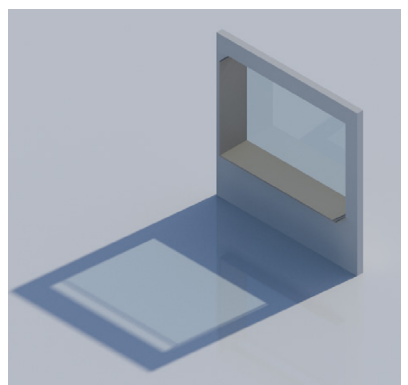

Interior

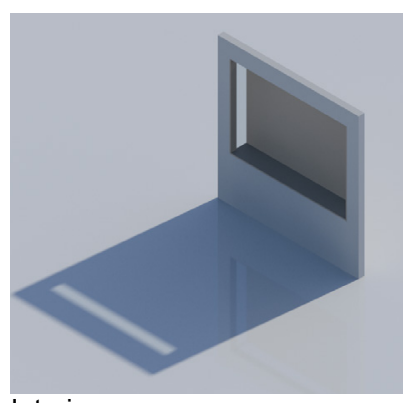

Interior

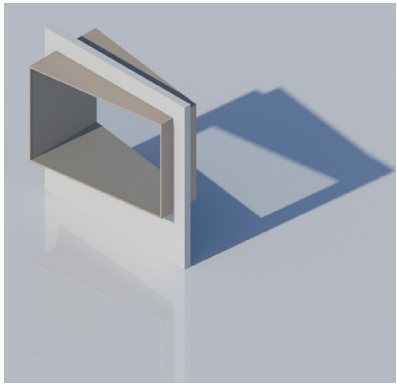

Exterior

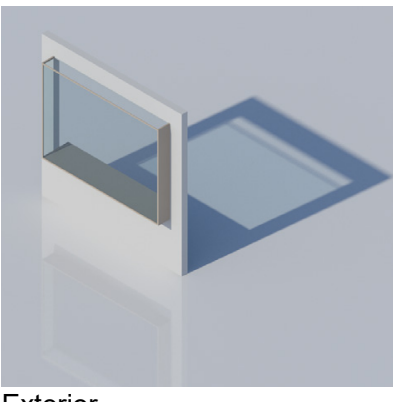

Exterior

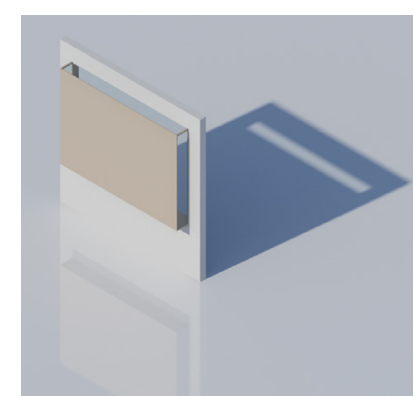

Exterior

The shape of the windows also presents an opportunity to direct or block views in or out of the dwelling. Experimentation with bay window shapes has shown that this can be effective to block views downward to neighbouring yards and direct views forwards or sideways, away from neighbouring dwellings. 


\section{Window development}
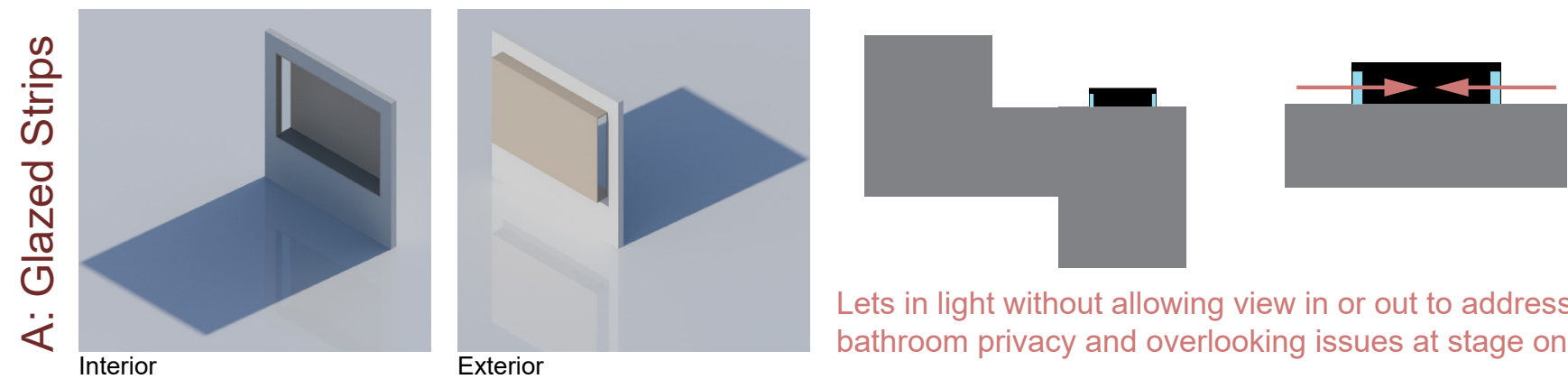

Lets in light without allowing view in or out to address bathroom privacy and overlooking issues at stage one.
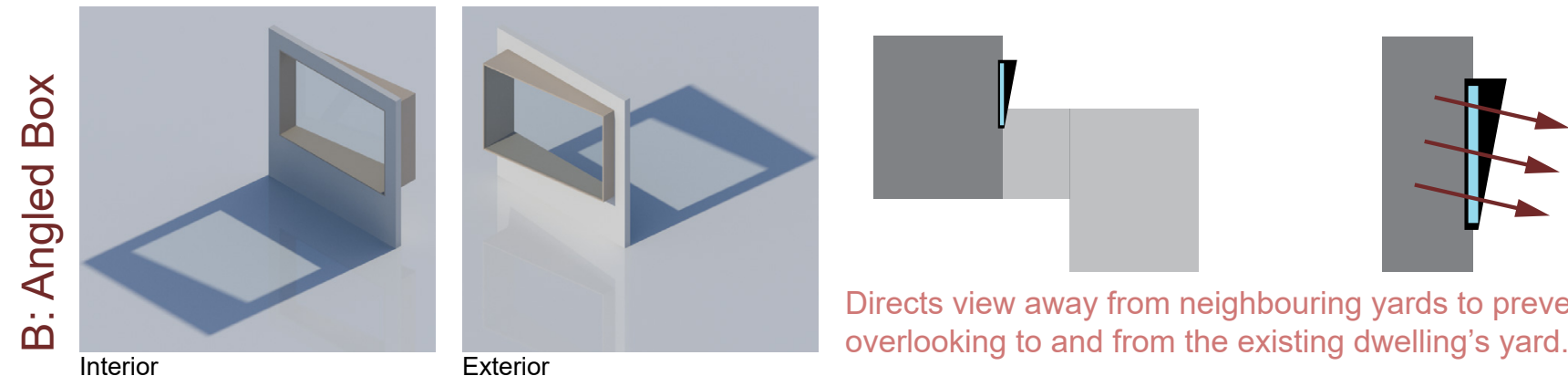

Directs view away from neighbouring yards to prevent overlooking to and from the existing dwelling's yard.
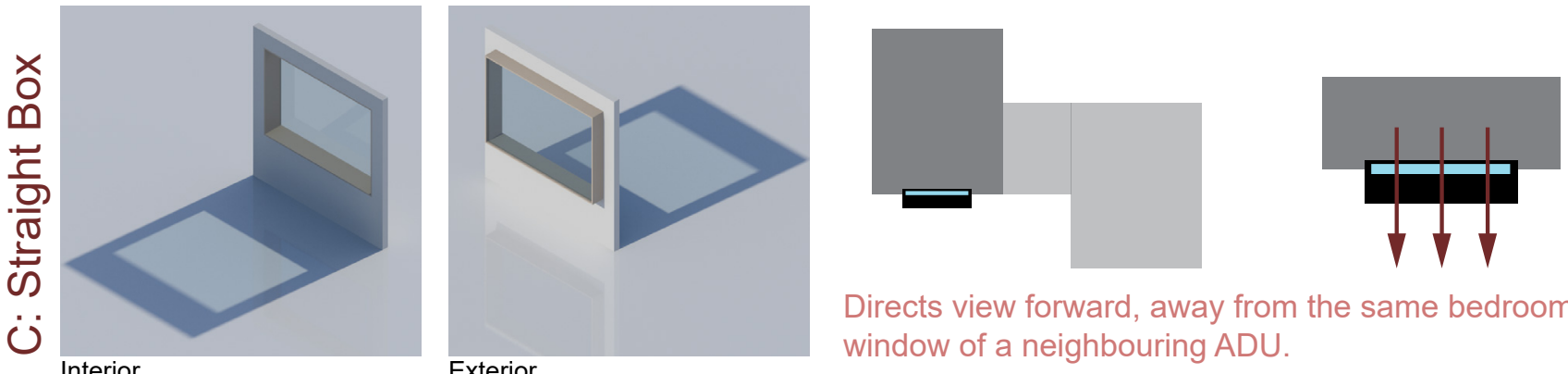

Directs view forward, away from the same bedroom window of a neighbouring ADU.

Useful concepts resulting from the window experimentation have been applied to the windows identified earlier with key privacy issues. While these deeper windows may reduce direct solar gains into the dwelling, the privacy gained from the bay window shapes will allow the windows to be bigger, allowing more daylight into the dwelling. 


\section{KITCHEN / LIVING}




\section{Kitchen and stair layout - stage three}

Optimising kitchen and living space while incorporating stairs for the second storey volume added in stage 3 .
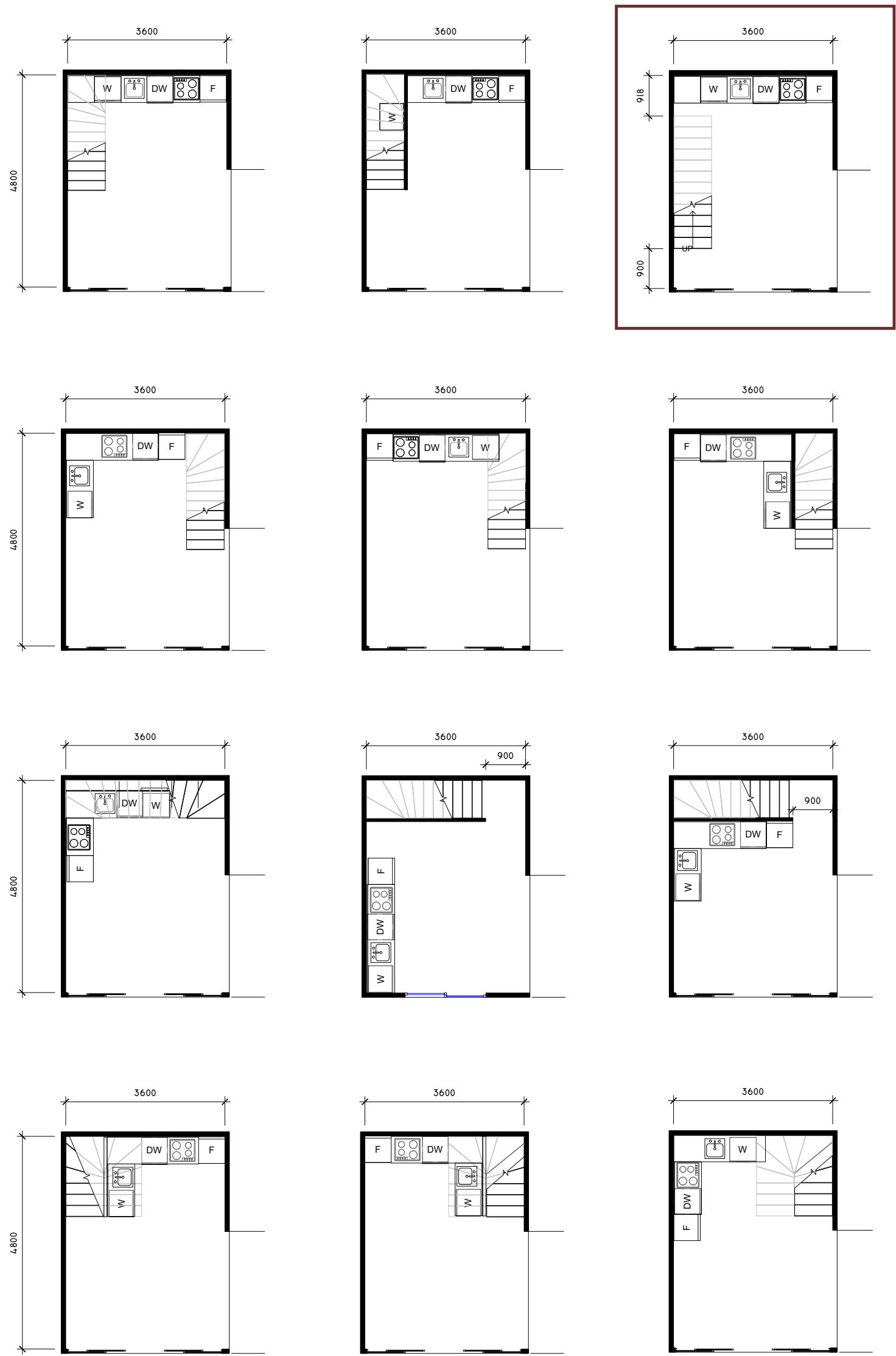

Due to the small scale of the dwelling, the addition of a stair at phase 3 of the development has a large impact on the useable space of the kitchen/living area making layout key. The length of the dwelling has been extending to $4800 \mathrm{~mm}$, increasing useable space and allowing for a $1200 \mathrm{~mm}$ construction grid. 

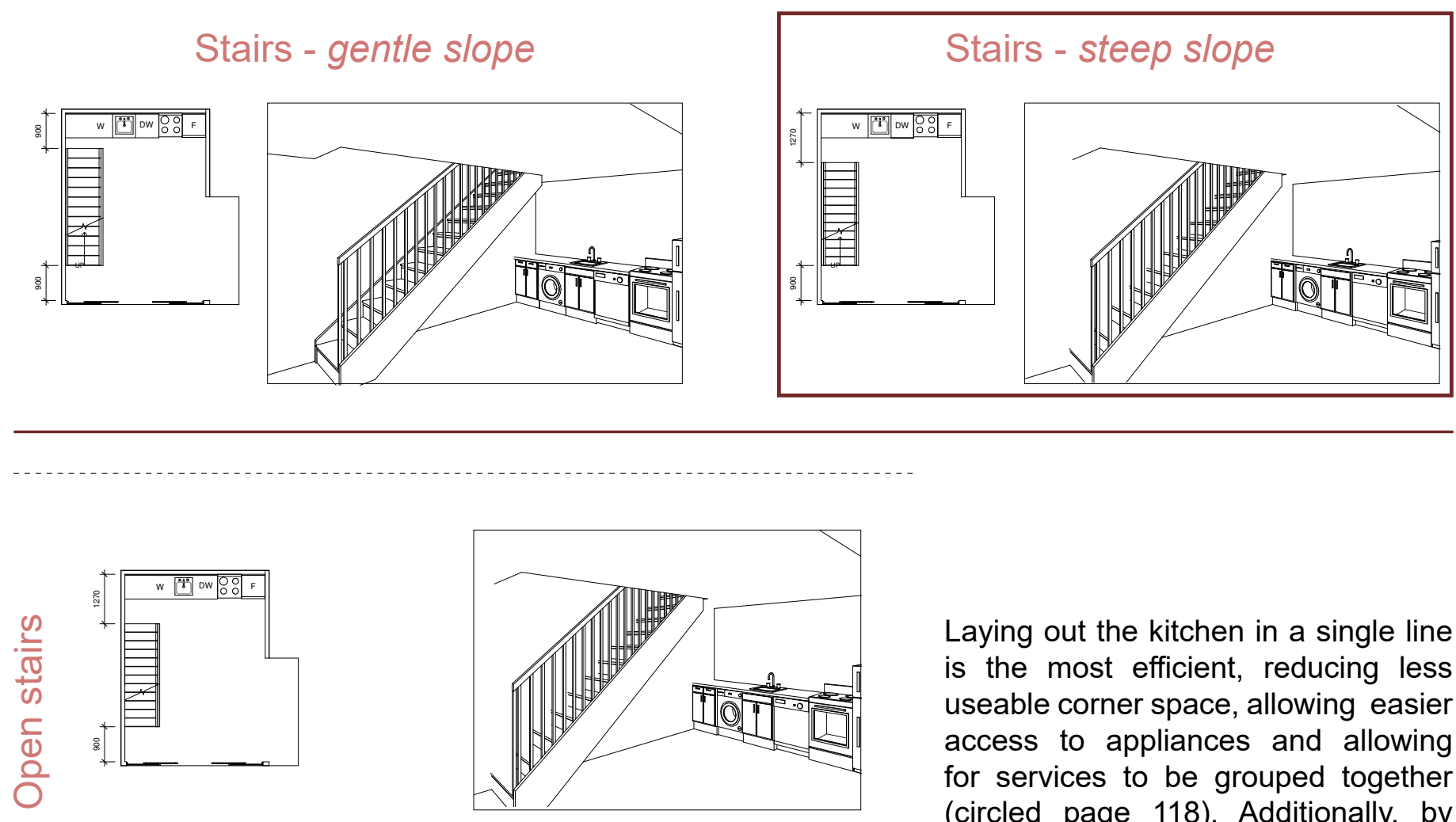

Laying out the kitchen in a single line is the most efficient, reducing less useable corner space, allowing easier access to appliances and allowing for services to be grouped together (circled page 118). Additionally, by restricting the appliances and stairs to walls adjacent to neighbouring properties, the remaining walls are free for doors and large windows to maximise light and view into the courtyard spaces for both the living space and the upper storey bedroom space.

As the upper storey is not intended for a main living space or highly trafficked area, accessible stairs are not required and the spaces can be much better utilised by providing a steeper stair (circled page 119). The space behind the stair can then be utilised for a large storage cupboard, allowing for storage of household items, such as cleaning equipment, outside of the bedrooms (circled page 119).

Partitioning the stairs from the space also helps to define the living space and reduce visual clutter that could make the space feel small or crowded. This also improves privacy between the living space and the bedroom above while maintaining an open layout. 
Kitchen and stair layout - stage two \& three

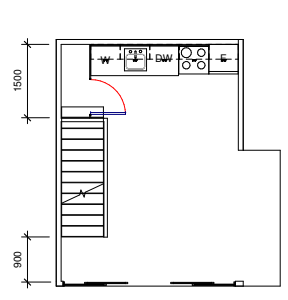

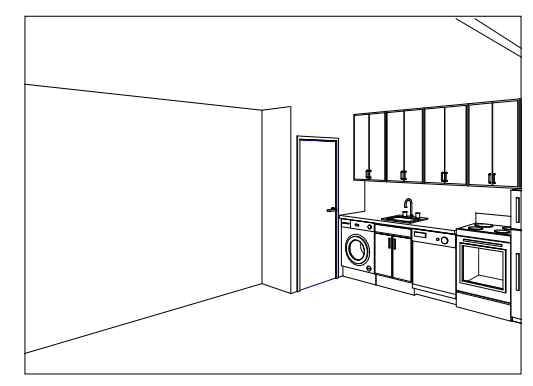

Stage 2 - single storey
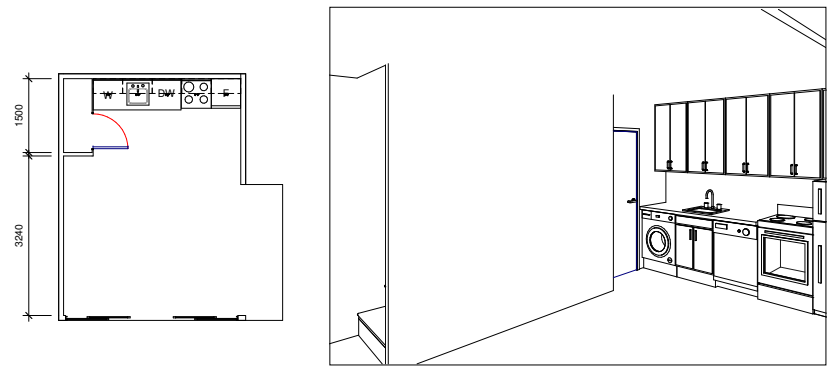

Stage 3 - double storey
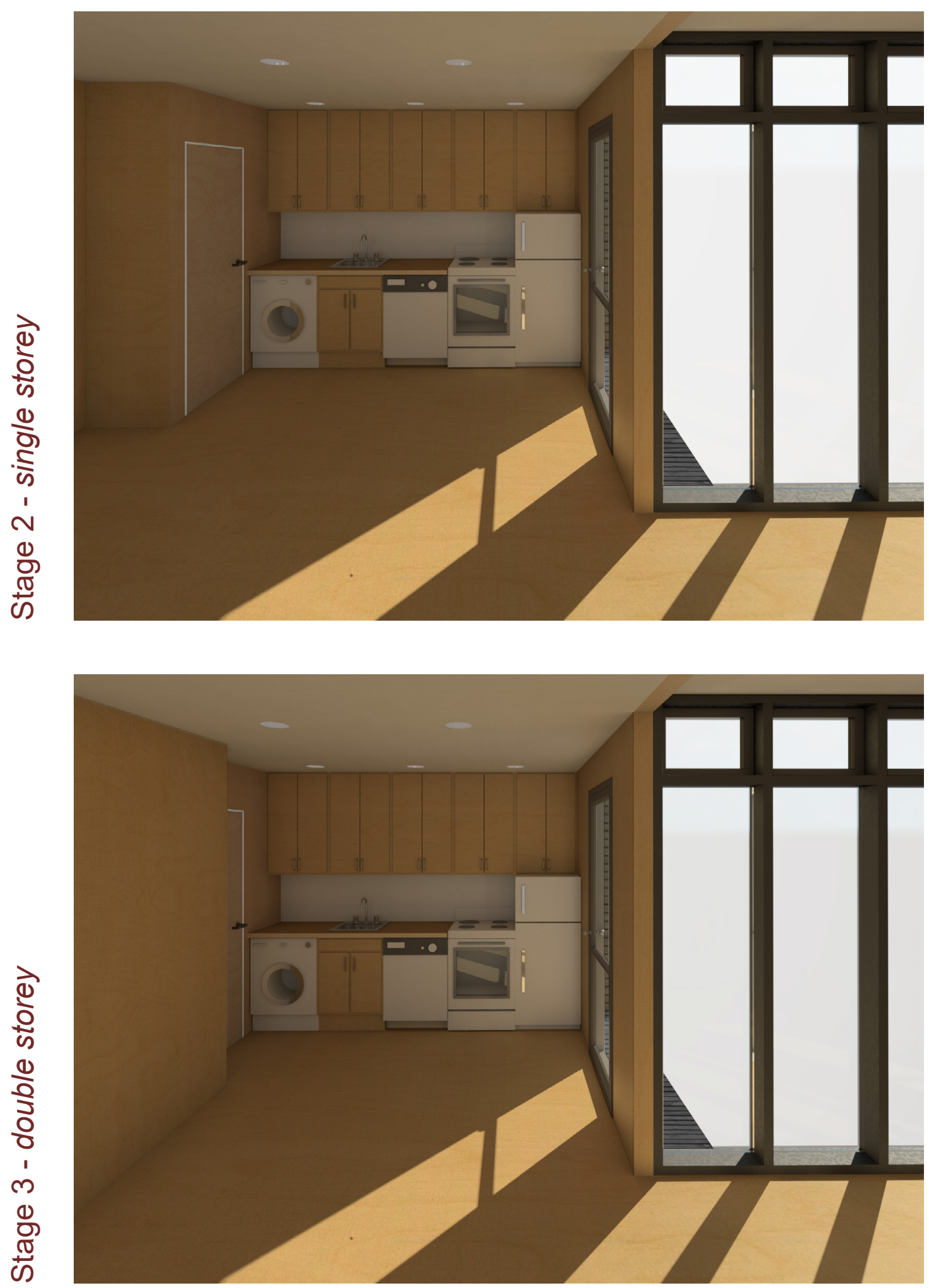
BATHROOM 


\section{Bathroom development}
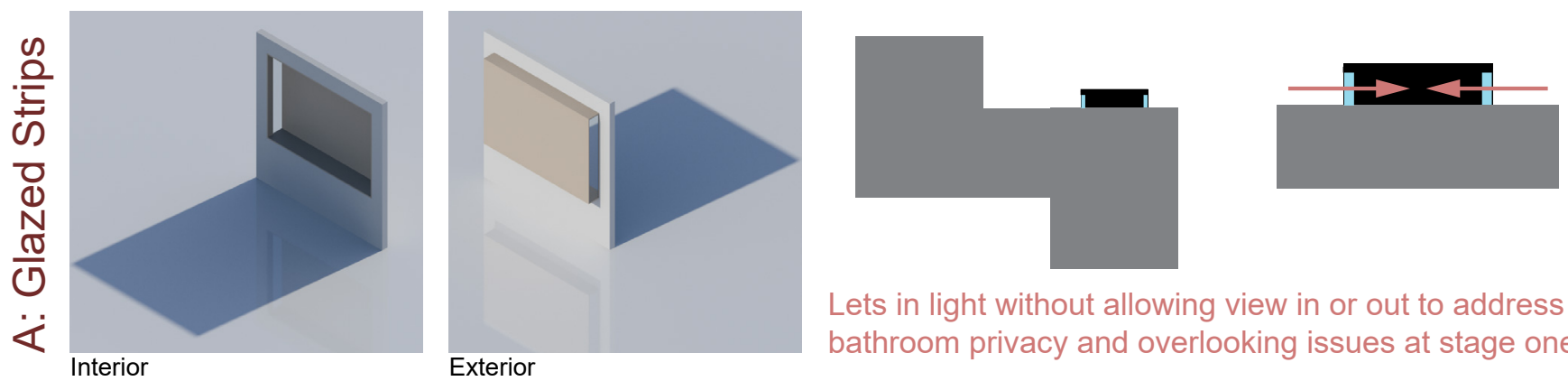

Lets in light without allowing view in or out to address bathroom privacy and overlooking issues at stage one.

The box window concept with glazed side strips has been developed further for the bathroom to let light in, while maintaining privacy, as well as to provide space for the vanity. Placing windows on either side of the mirror maximises natural light where it is needed most, while also maximising feelings of privacy in other areas of the bathroom. This has also allowed for more circulation space in the bathroom, making it feel more spacious and improving accessibility.
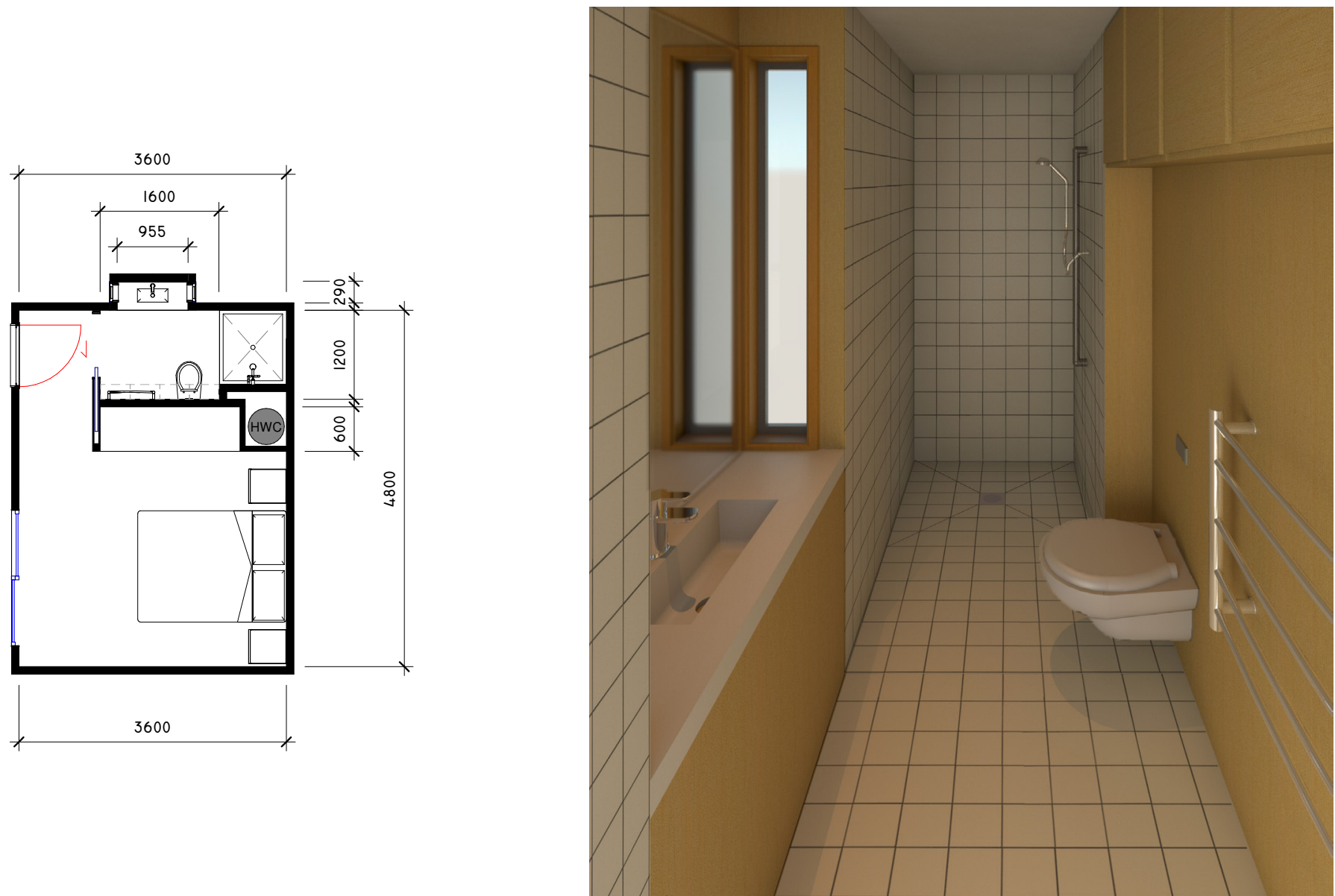

Using a sliding door has maximised usable space in the bathroom, making entering and exiting easier in the compact space. This has required an extension of the wall into the bedroom which has been utilised to define a wardrobe space, while also reducing view directly into the bedroom from the entrance. Space for a hot water cylinder has been recessed into the shower, requiring less width than the rest of the bathroom, further defining the wardrobe space in the bedroom without significantly impacting usable space. Storage cupboards are placed above the toilet and towel rail to minimise impact on circulation and maintain feelings of spaciousness in the narrow room that would be compromised with low or full height cupboards. 


\section{CONCLUSION}

This chapter has developed the most successful massing concept into an incremental housing strategy that can be applied to the most appropriate area of Kilbirnie, identified earlier. Explorations have found that a single growth strategy is most effective when considering the relationship between ADUs on neighbouring sites to ensure optimal building function and to maintain the successful multi-unit massing strategies identified earlier. The building dimensions, layout and windows have also been further developed to achieve this incremental strategy, aiming to maximise building function, daylight and privacy. 
CHAPTER 6:

\section{FINAL DESIGN PROPOSAL}


SITE SCALE 


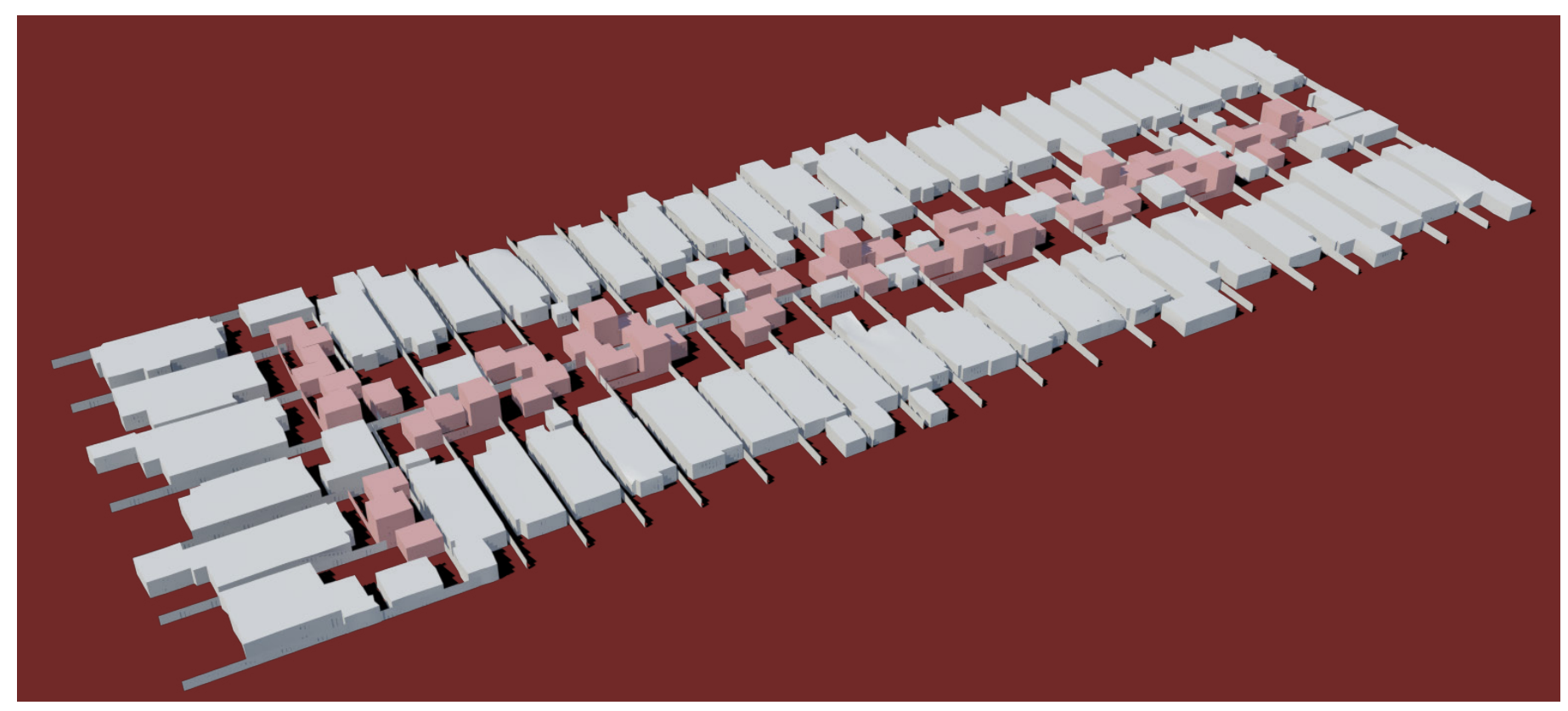

Site Axonometric

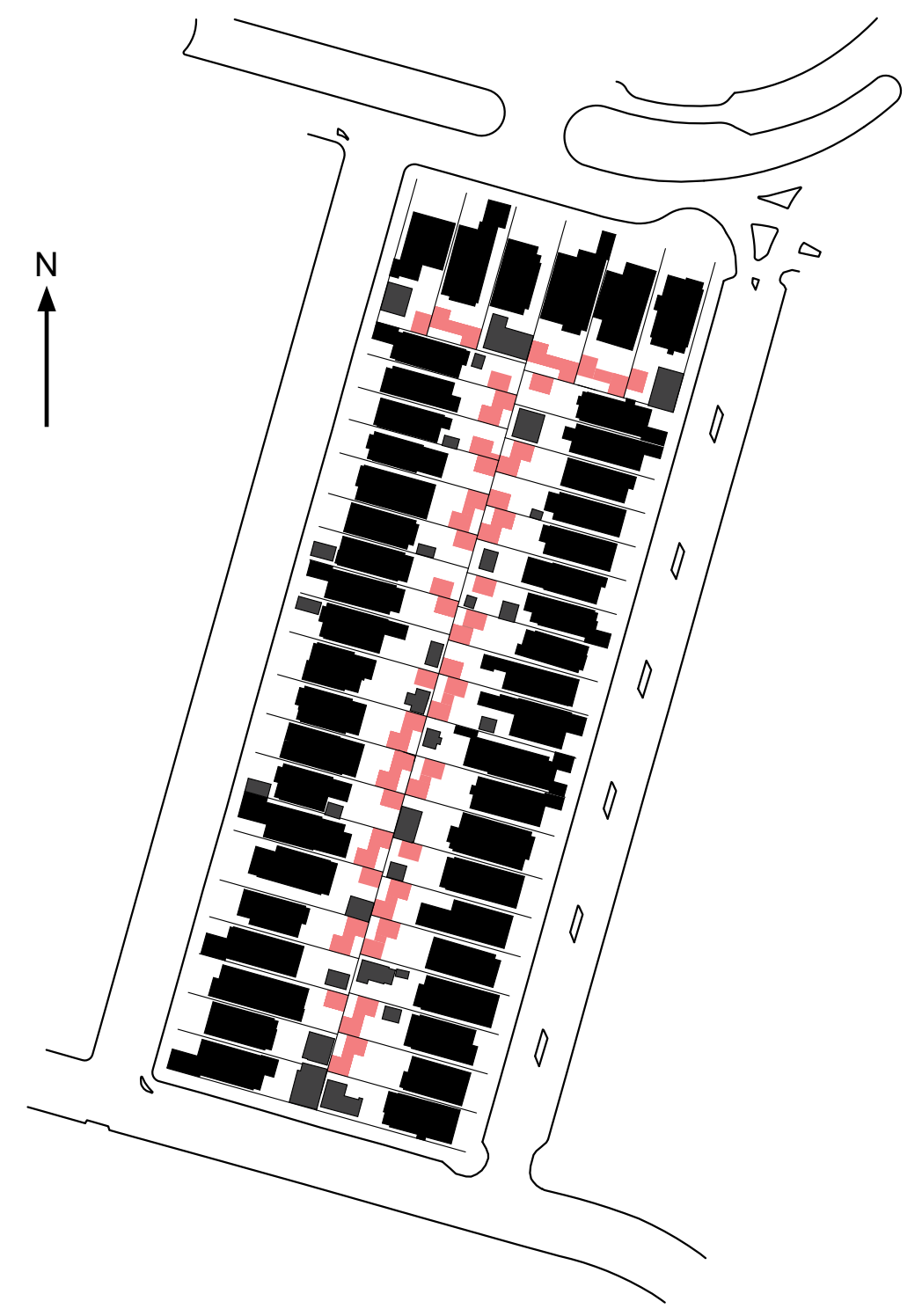

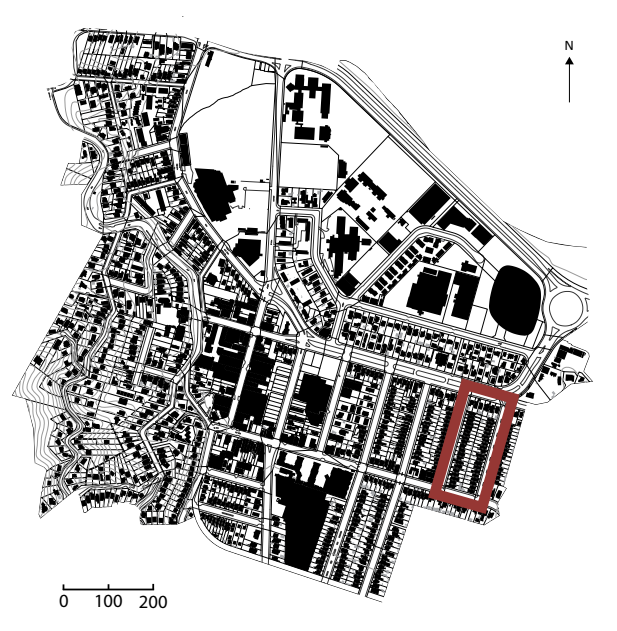

Area in Kilbirnie

\section{Key} ADU

Existing garage/shed

Existing dwelling 
Neighbouring property scale - fully developed ADUs

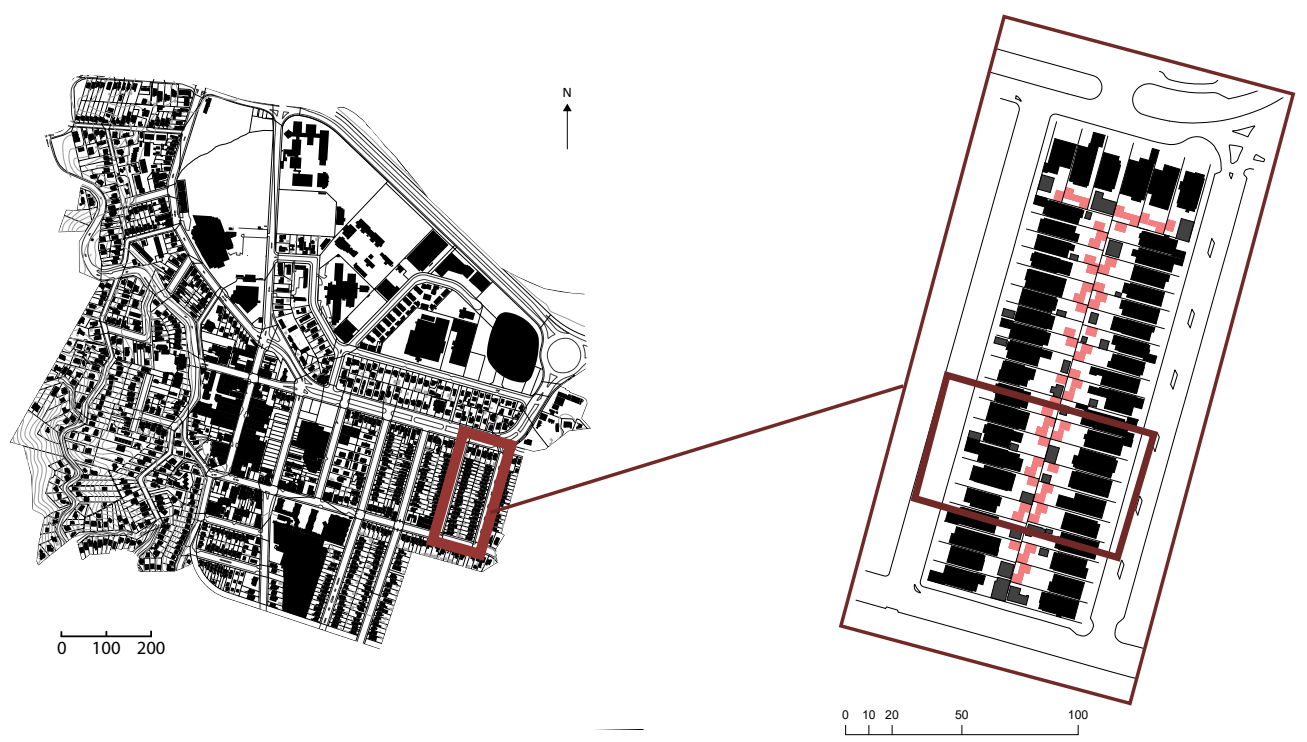

Site Location
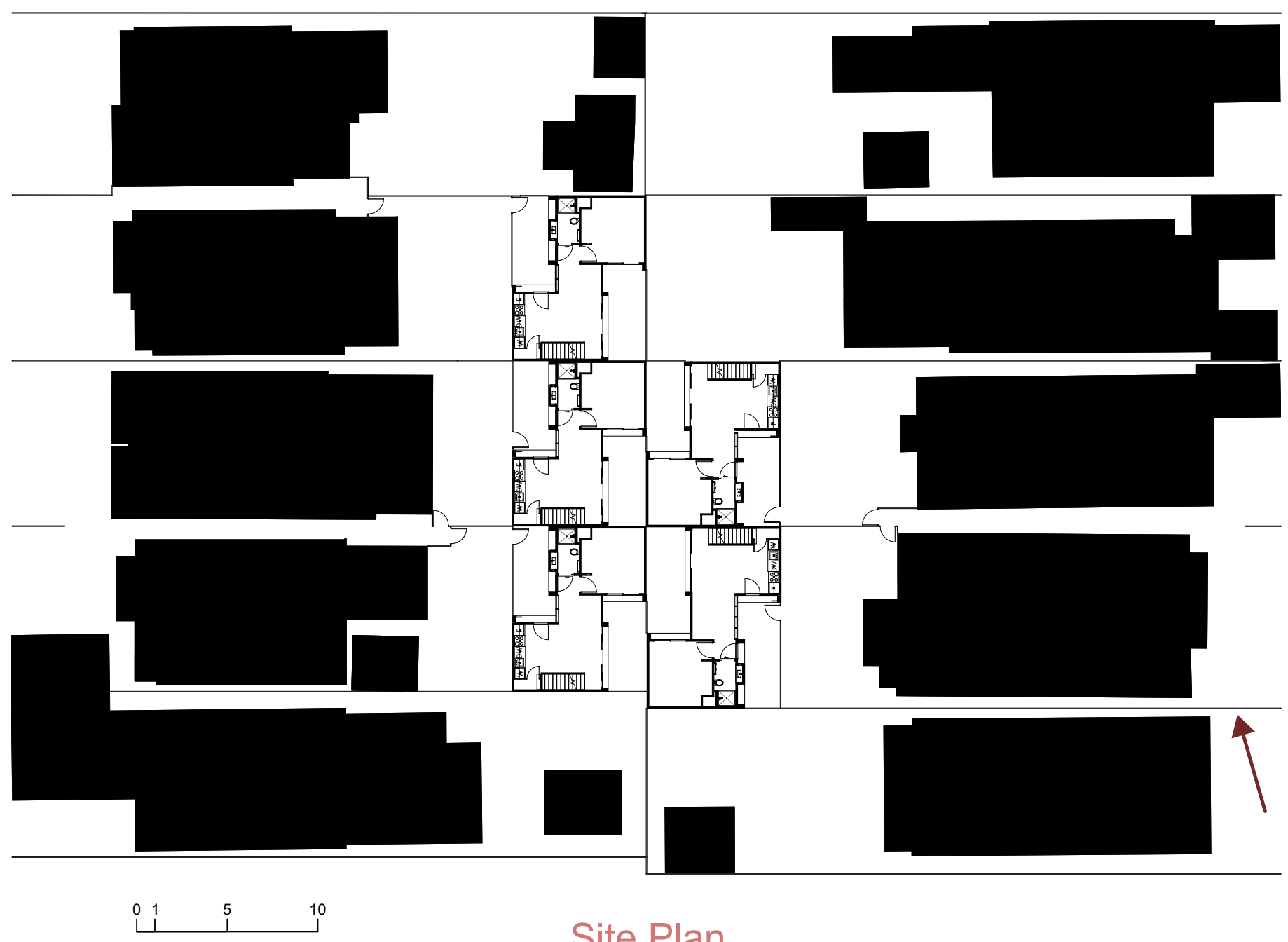

\section{Site Plan}




\section{Street Perspective over time}
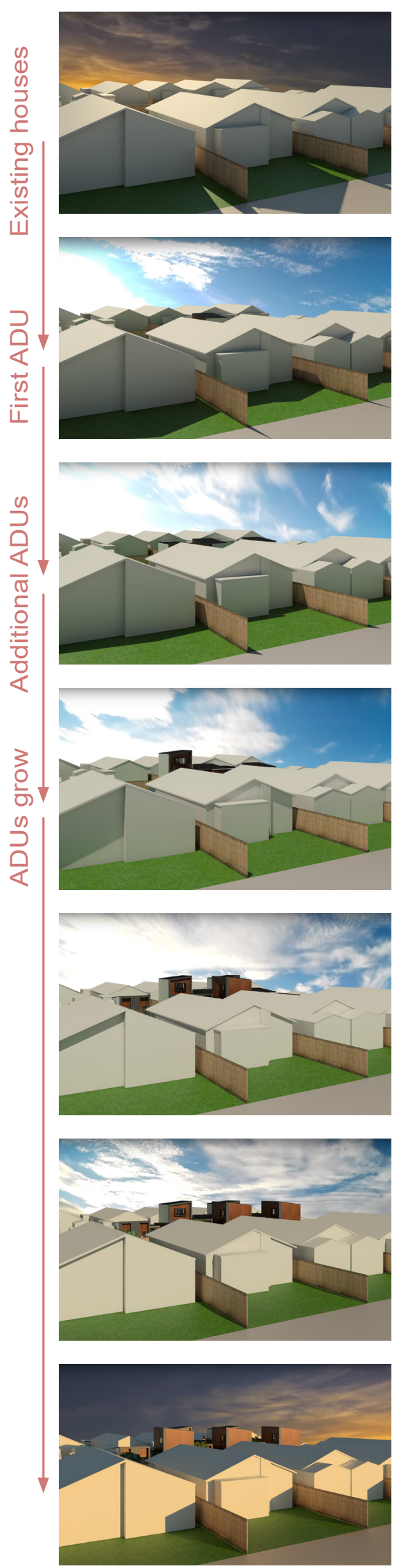

Axonometric over time
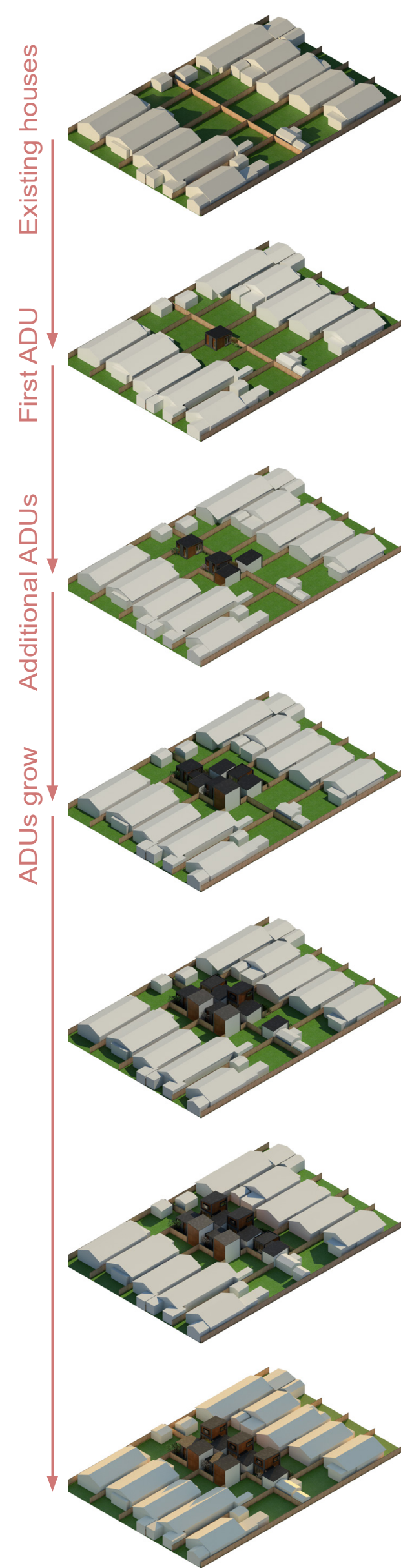

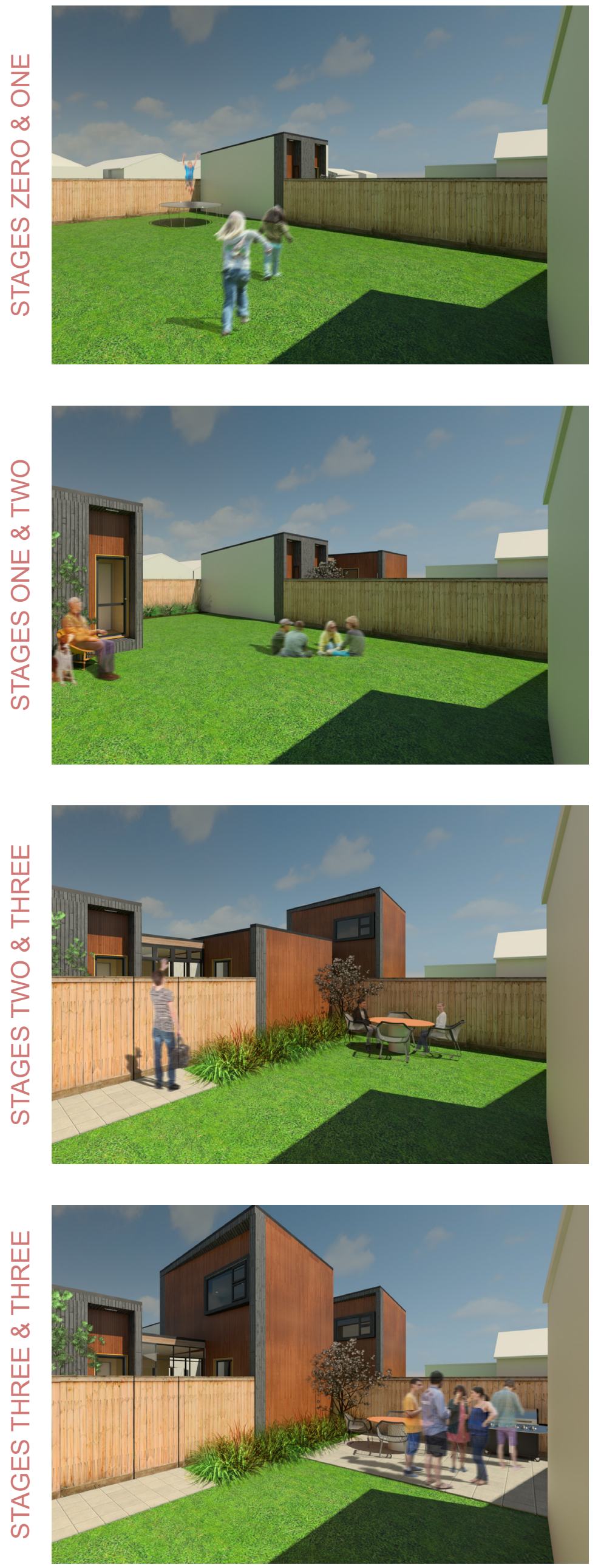

A neighbouring ADU is constructed having minimal visual impact on the existing backyard.

A new ADU is constructed while the neighbouring ADU expands. At this stage the yard can be shared between occupants of the existing dwelling and the ADU.

The ADU expands, now clearly defining separate space for the ADU and the existing dwelling. Windows are directed into private courtyards minimising overlooking.

Both neighbouring ADUs are now at full expansion with the addition of a second storey. Windows angle away from the existing yards and face a blank wall of the neighbouring ADU. 
New and existing dwelling relationships - site sections
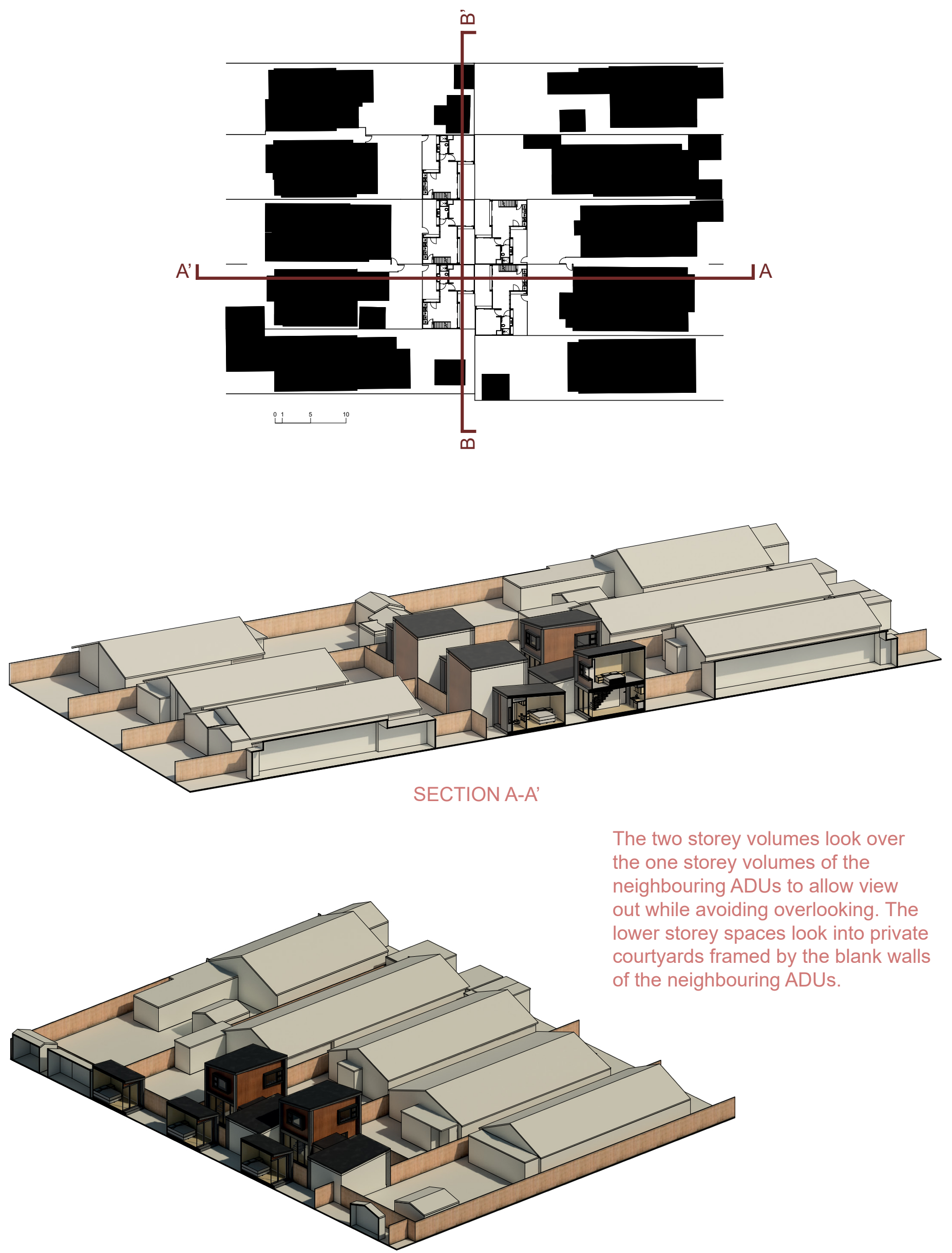

The two storey volumes look over the one storey volumes of the neighbouring ADUs to allow view out while avoiding overlooking. The lower storey spaces look into private courtyards framed by the blank walls of the neighbouring ADUs.

SECTION B-B' 
Window views - ground floor courtyards

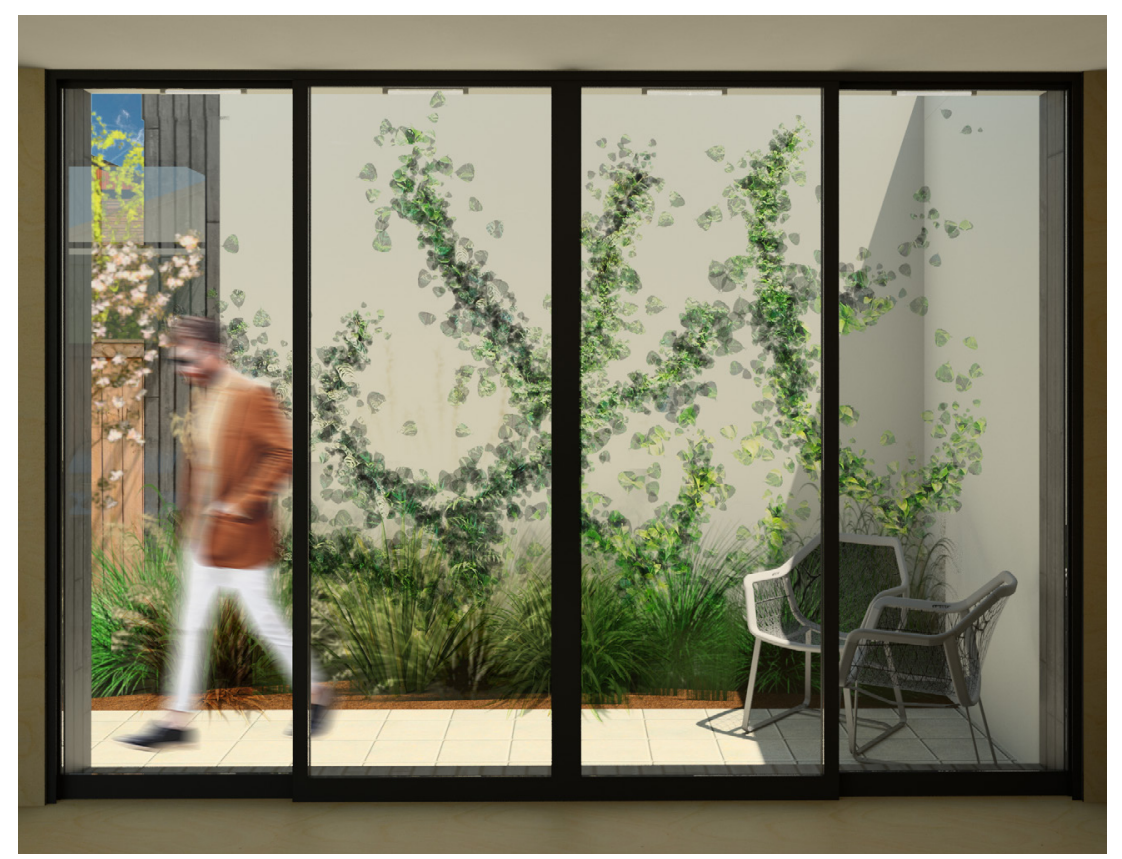

VIEW FROM KITCHEN / LIVING SPACE - private back courtyard framed by neighbouring ADU

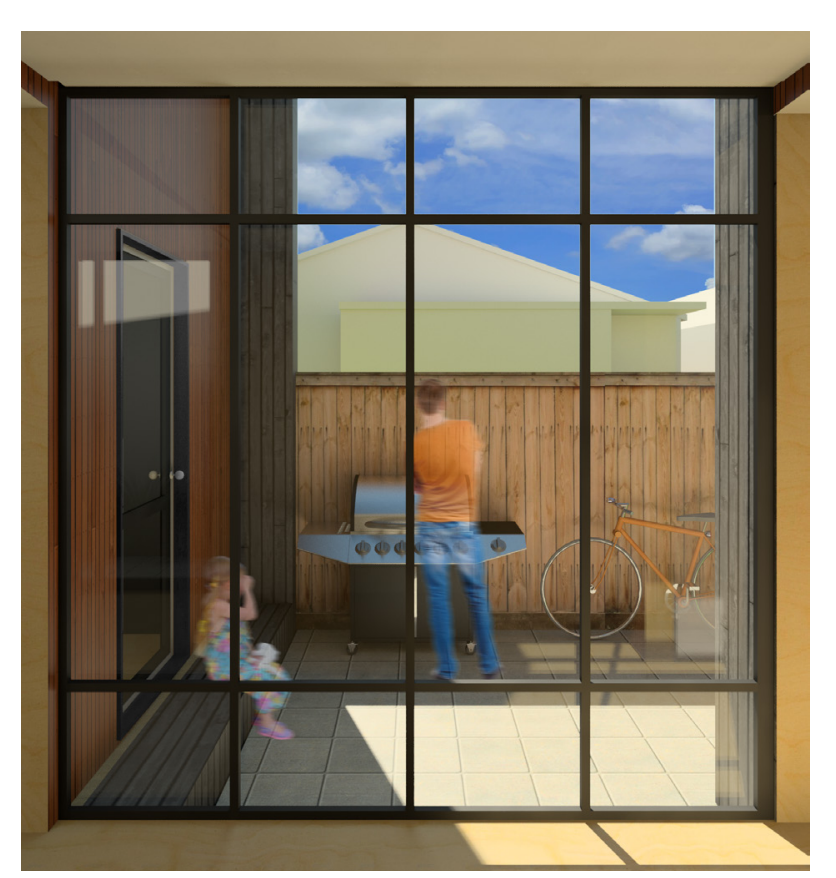

VIEW FROM CONNECTION SPACE - semiprivate front courtyard enclosed by fence

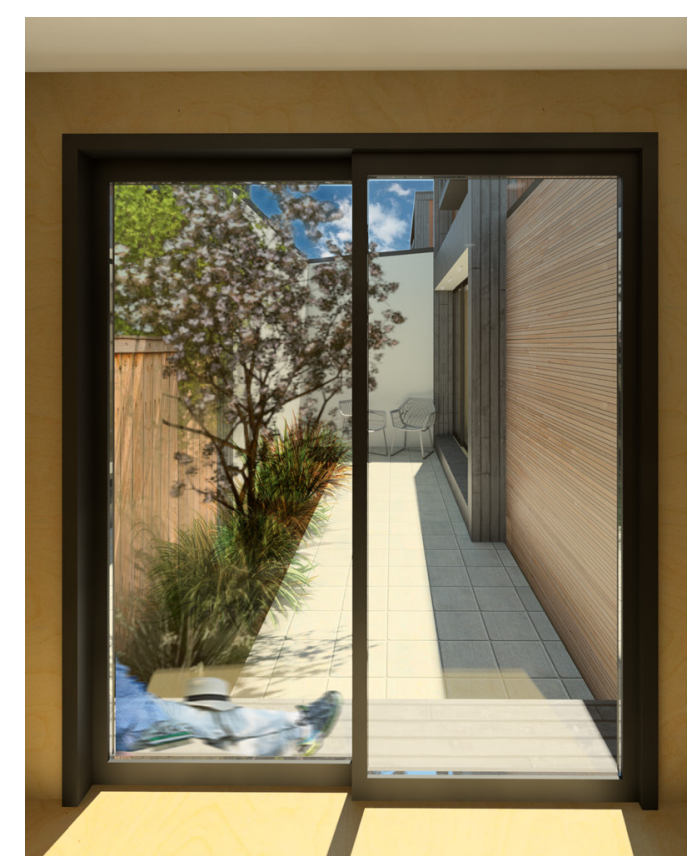

VIEW FROM BEDROOM - private back courtyard framed by neighbouring ADU

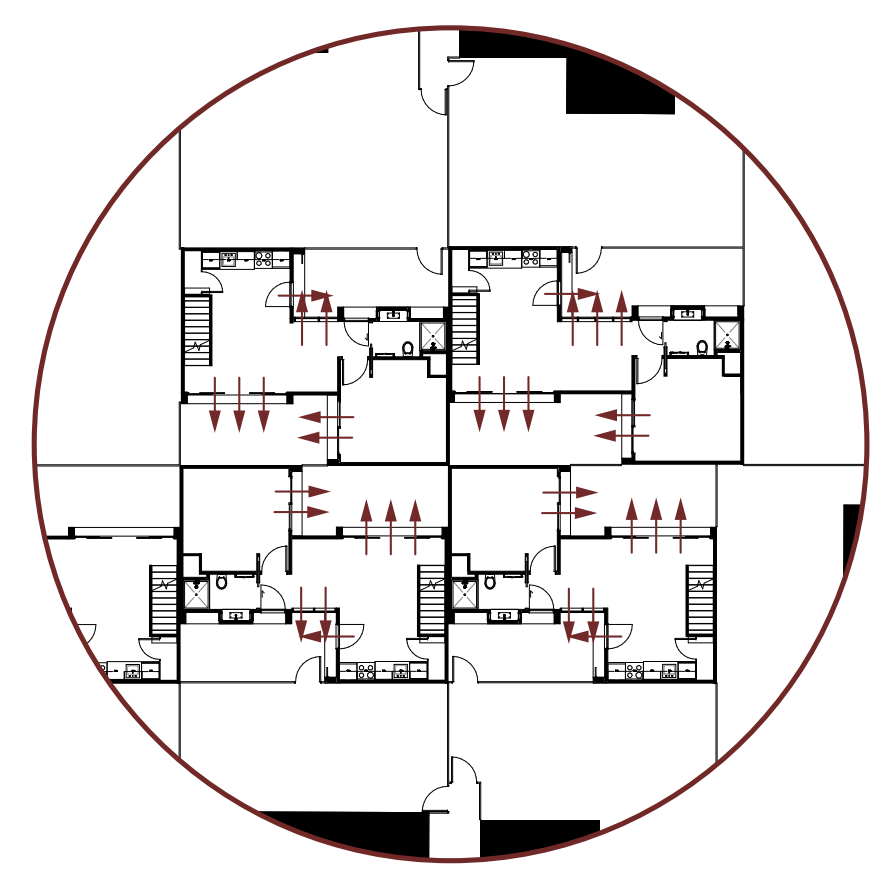




\section{Window views - upper storey}

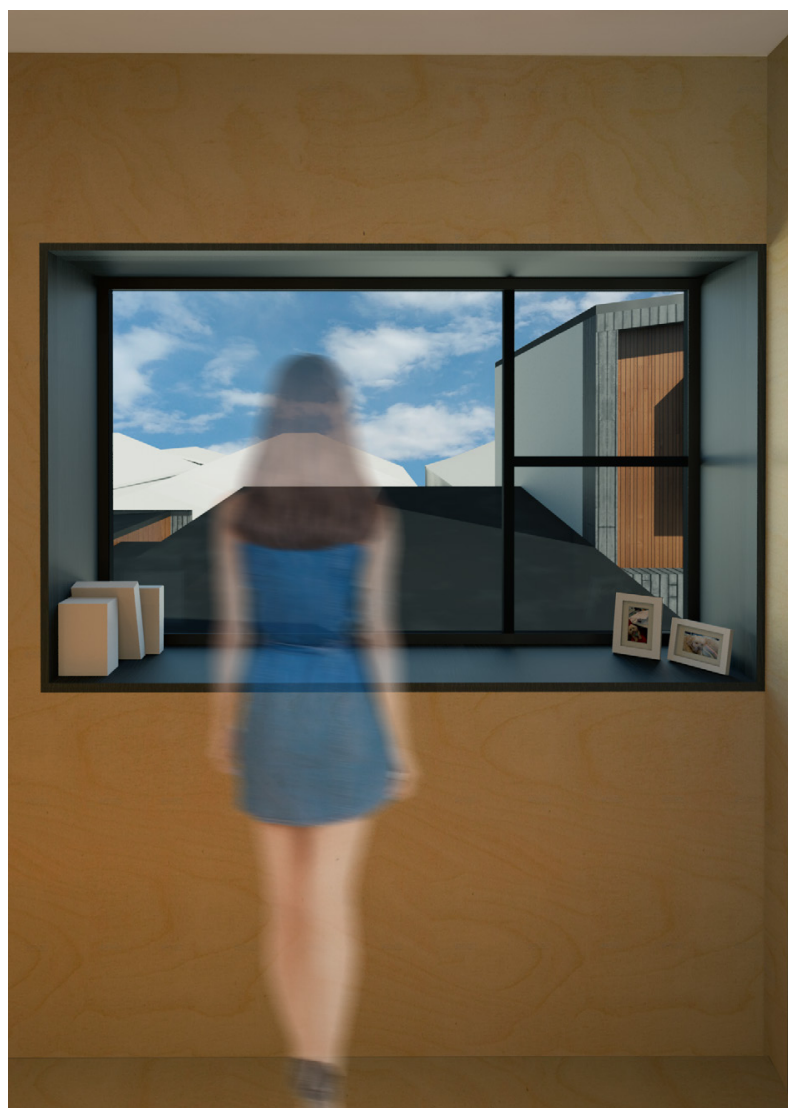

VIEW FROM BEDROOM - looks over single storey volume of neighbouring ADU. Bay window shape directs view straight forward, away from the double storey volume and window of neighbouring $A D U$.

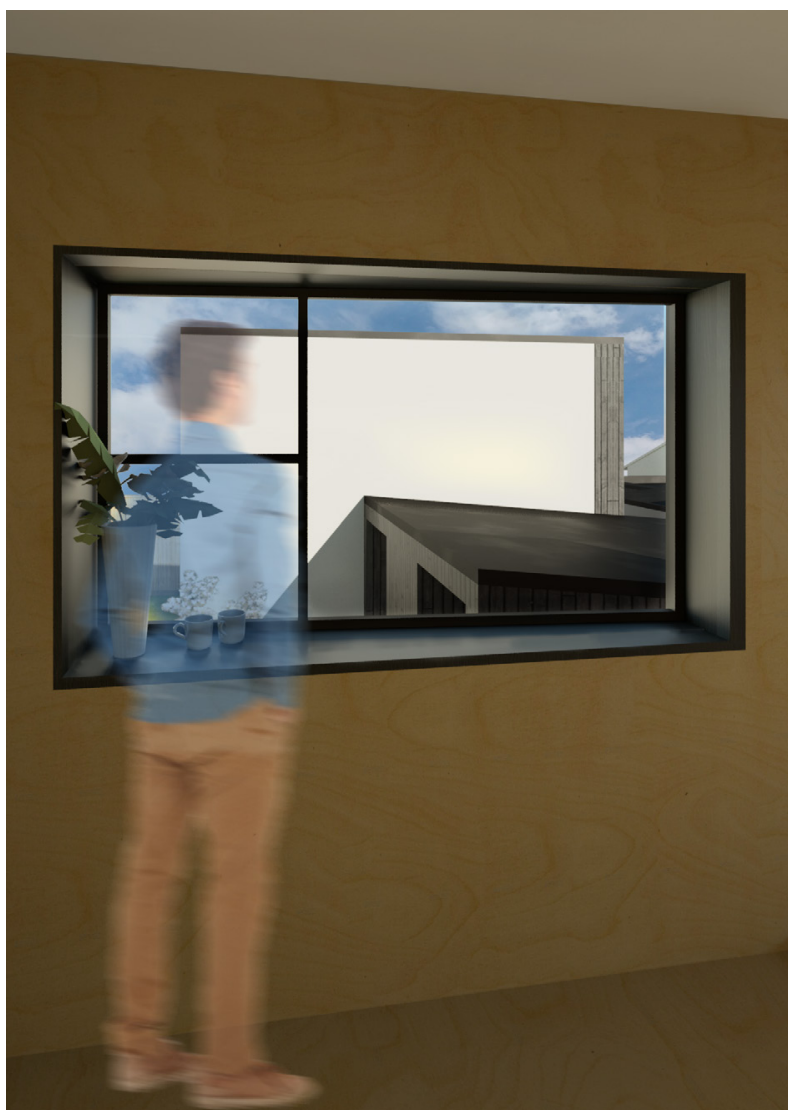

VIEW FROM BEDROOM - looks into the ADU's own private courtyard. View of neighbouring $A D U$ is blocked by the blank wall of it's two storey volume. Bay window shape directs view away from existing dwelling's yard.

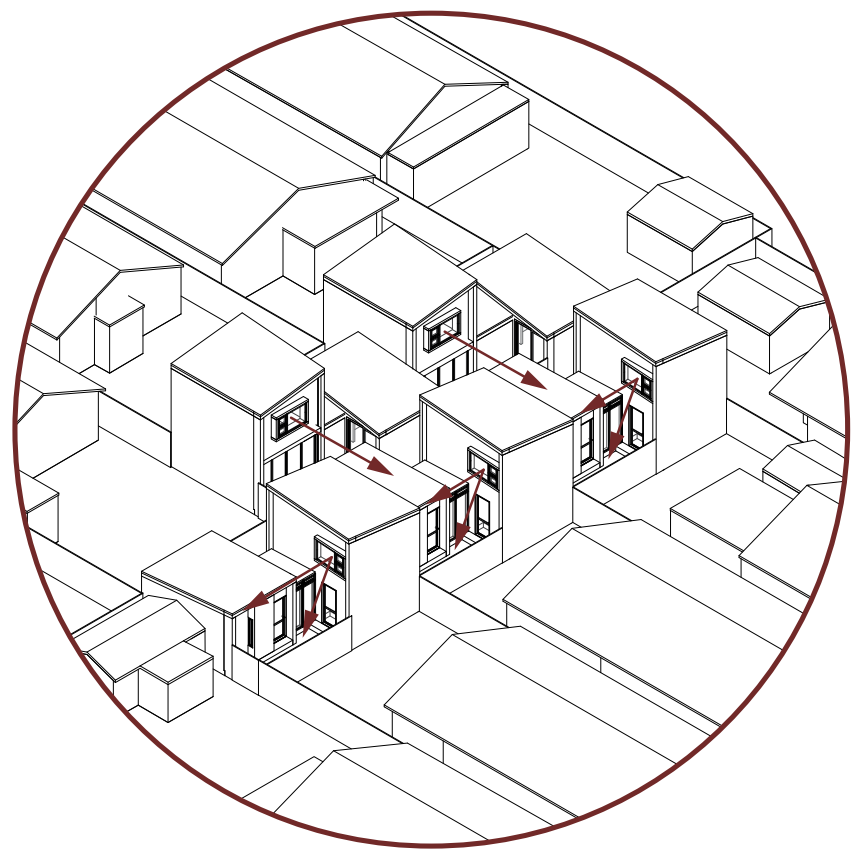




\section{DWELLING SCALE}


Floor plan - phase one

$$
\begin{gathered}
\text { level } 1 \\
\text { + bedroom + bathroom } \\
\left(\mathbf{1 8 m ^ { 2 }} / \$ \mathbf{5 4 , 0 0 0 )}\right.
\end{gathered}
$$

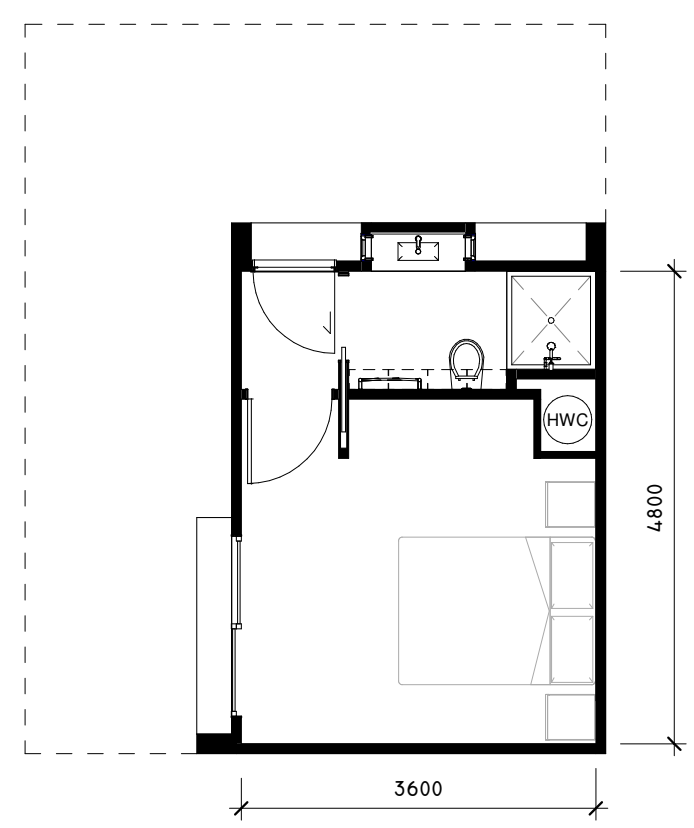

\section{KEY STATS}

Floor Area:

$18 \mathrm{~m}^{2}$

Outdoor Space:

$23 \mathrm{~m}^{2}$

Total Cost:

$\$ 54,000$

Amenities:

Double Bedroom

Bathroom

Outdoor Space 
Floor plan - phase two

level 1

+ kitchen + living

$\left(24 \mathrm{~m}^{2} / \$ 72,000\right)$

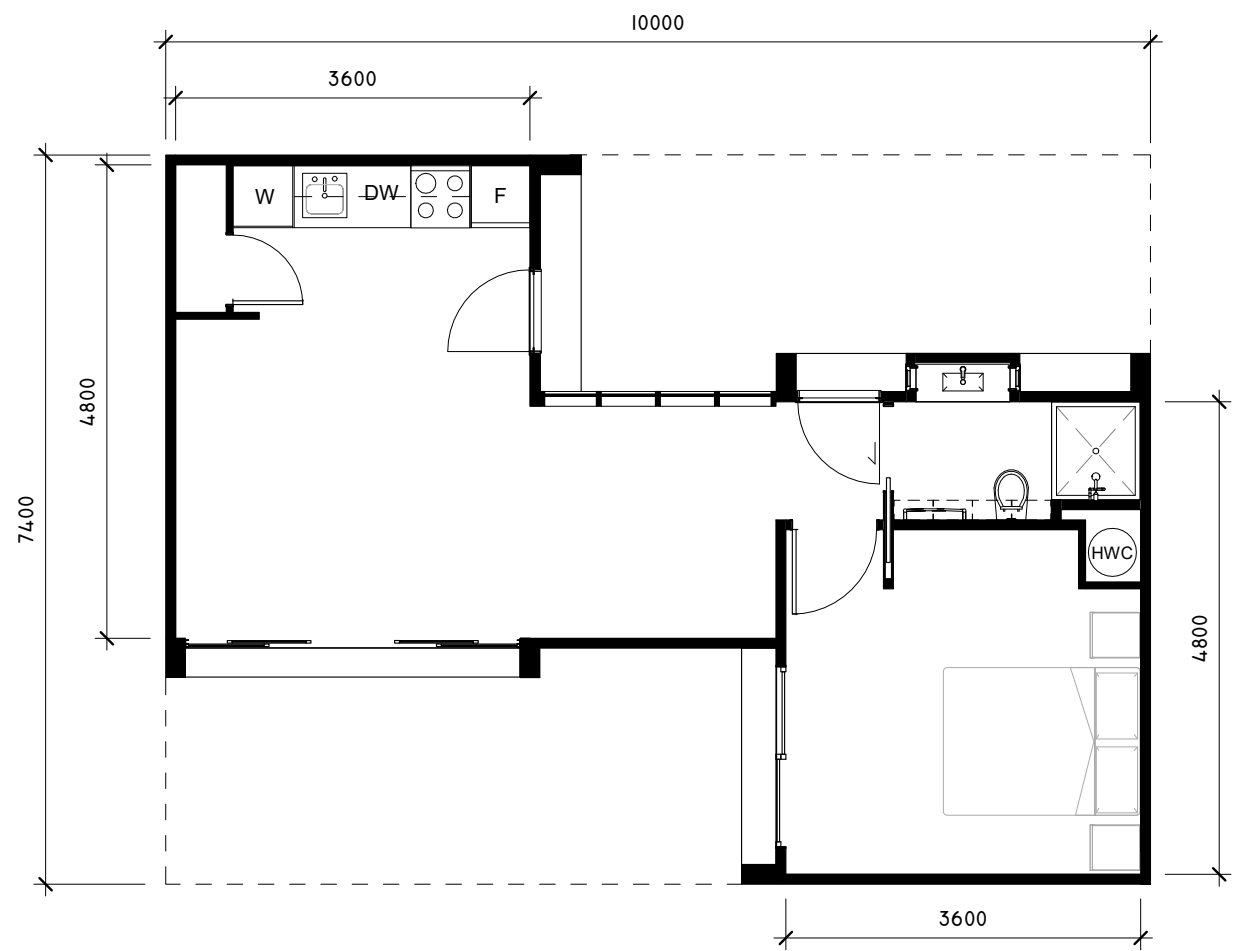

\section{KEY STATS}

Floor Area:

$42 m^{2}$

Outdoor Space:

$30 \mathrm{~m}^{2}$

Total Cost:

$\$ 126,000$

Amenities:

Double Bedroom

Bathroom

Kitchen/Living

Private Courtyards 
Floor plan - phase three

level 1

+ stairs

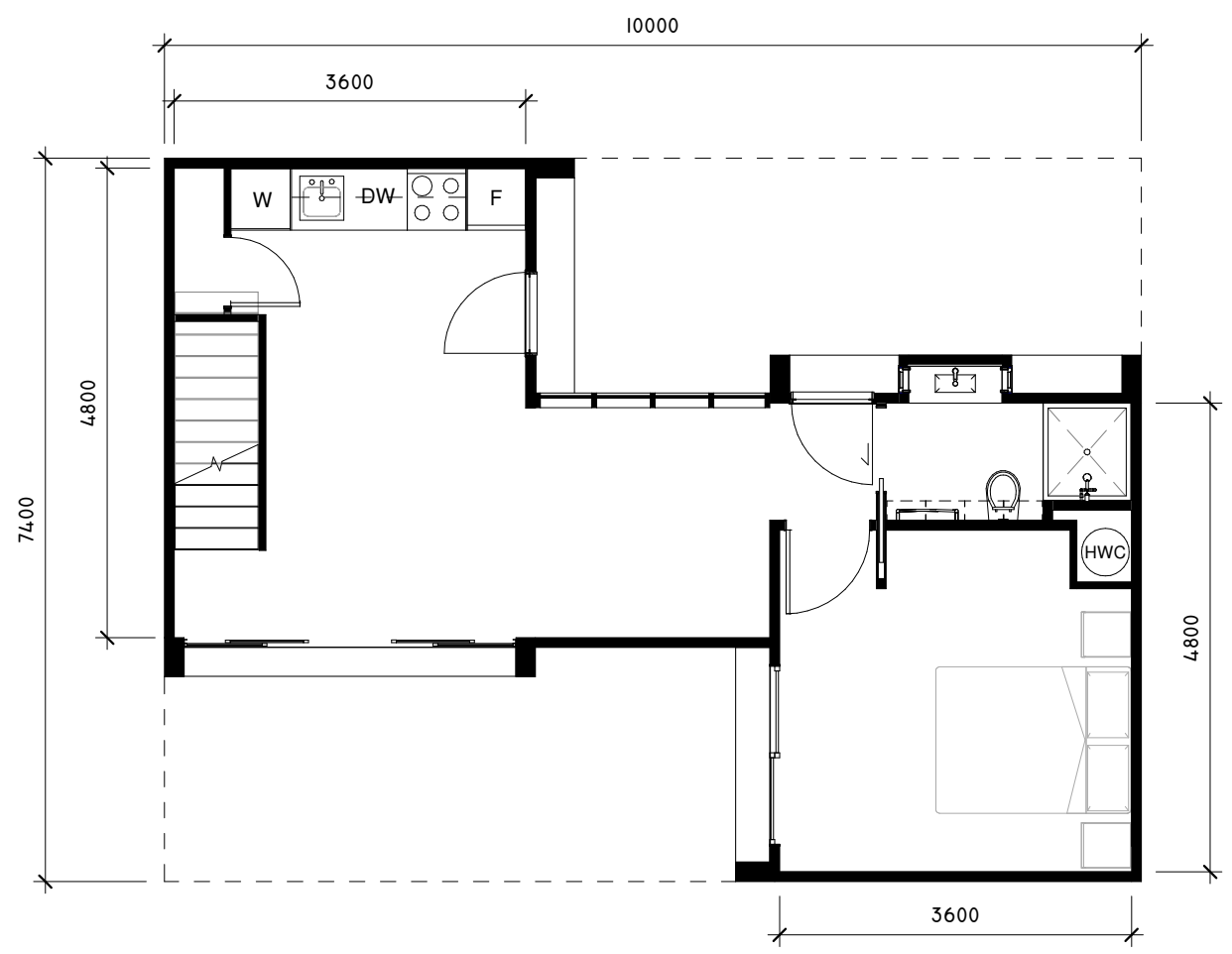

level 2

+ bedroom $\left(18 \mathrm{~m}^{2} / \$ 54,000\right)$

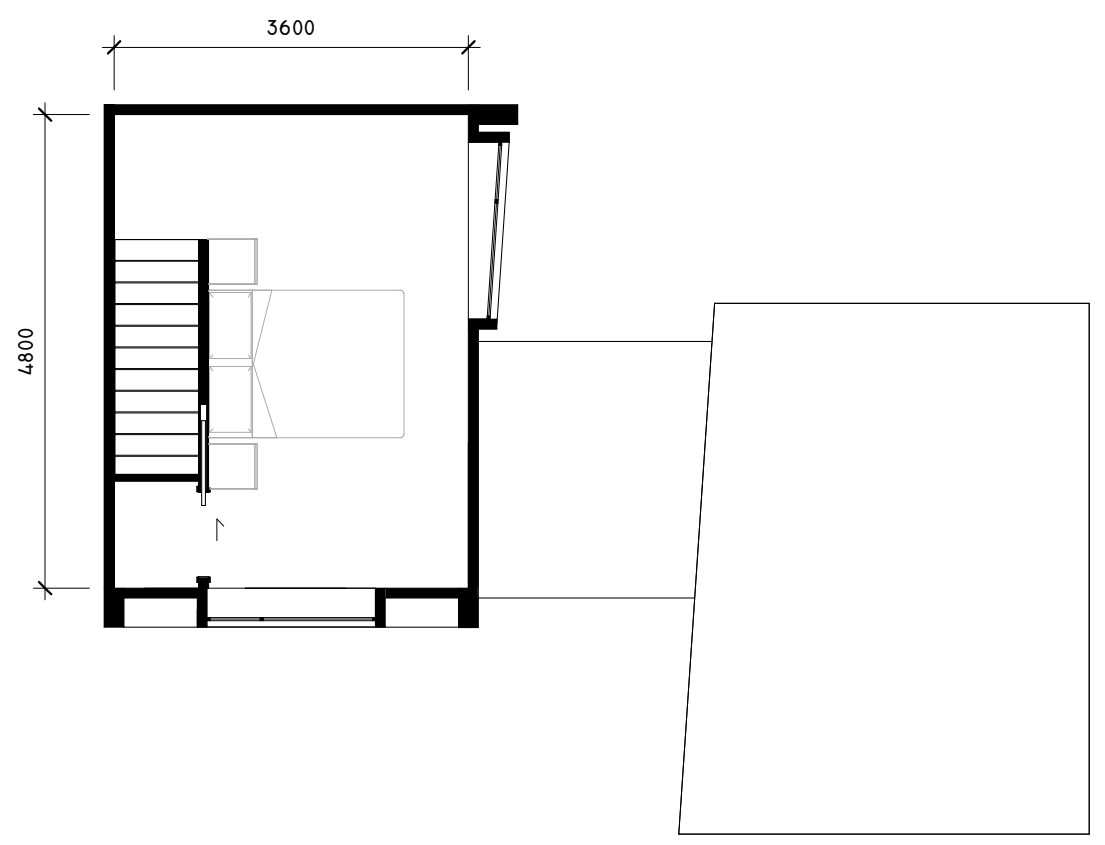

\section{KEY STATS}

Floor Area:

$60 \mathrm{~m}^{2}$

Outdoor Space:

$30 \mathrm{~m}^{2}$

\section{Total Cost:}

$\$ 180,000$

Amenities:

Double Bedroom

Bathroom

Kitchen/Living

Private Courtyards

Extra Bedroom/Living/Office 


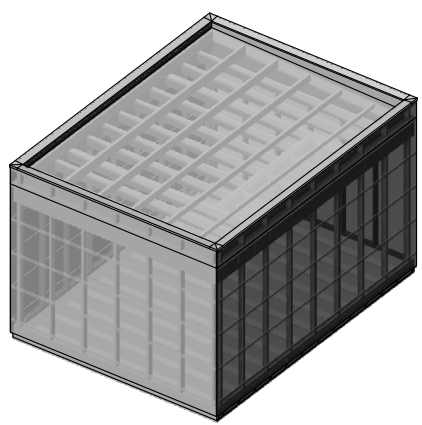

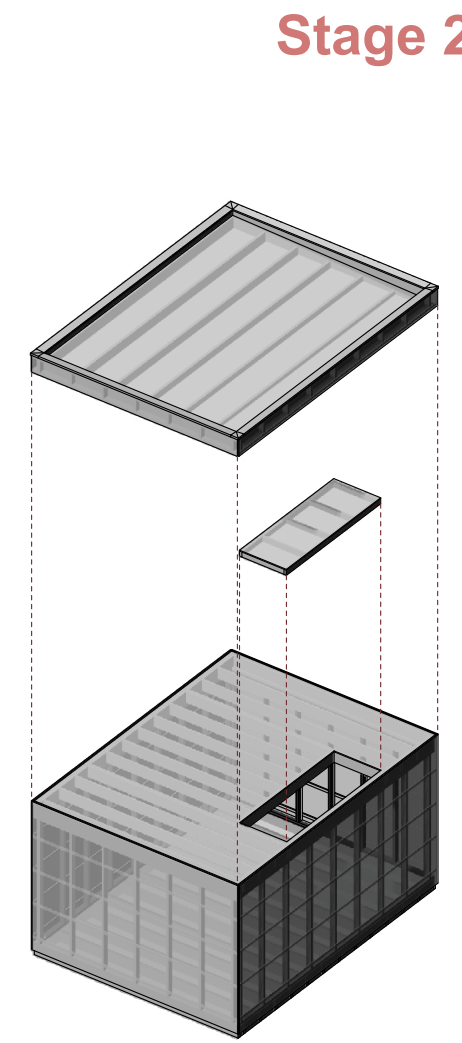

remove roof and parapet

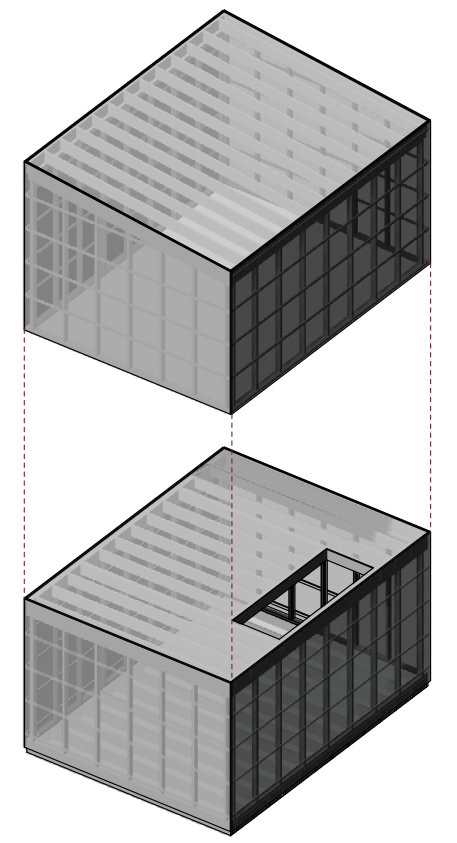

crane on second storey

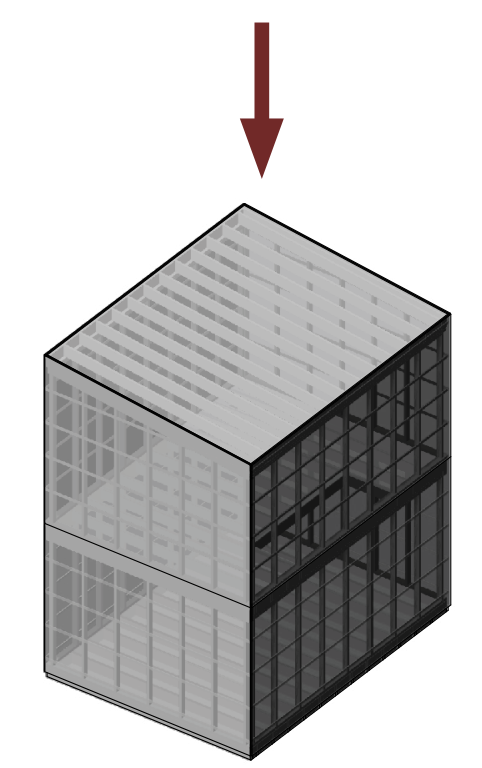

Stage 3 - two storeys 


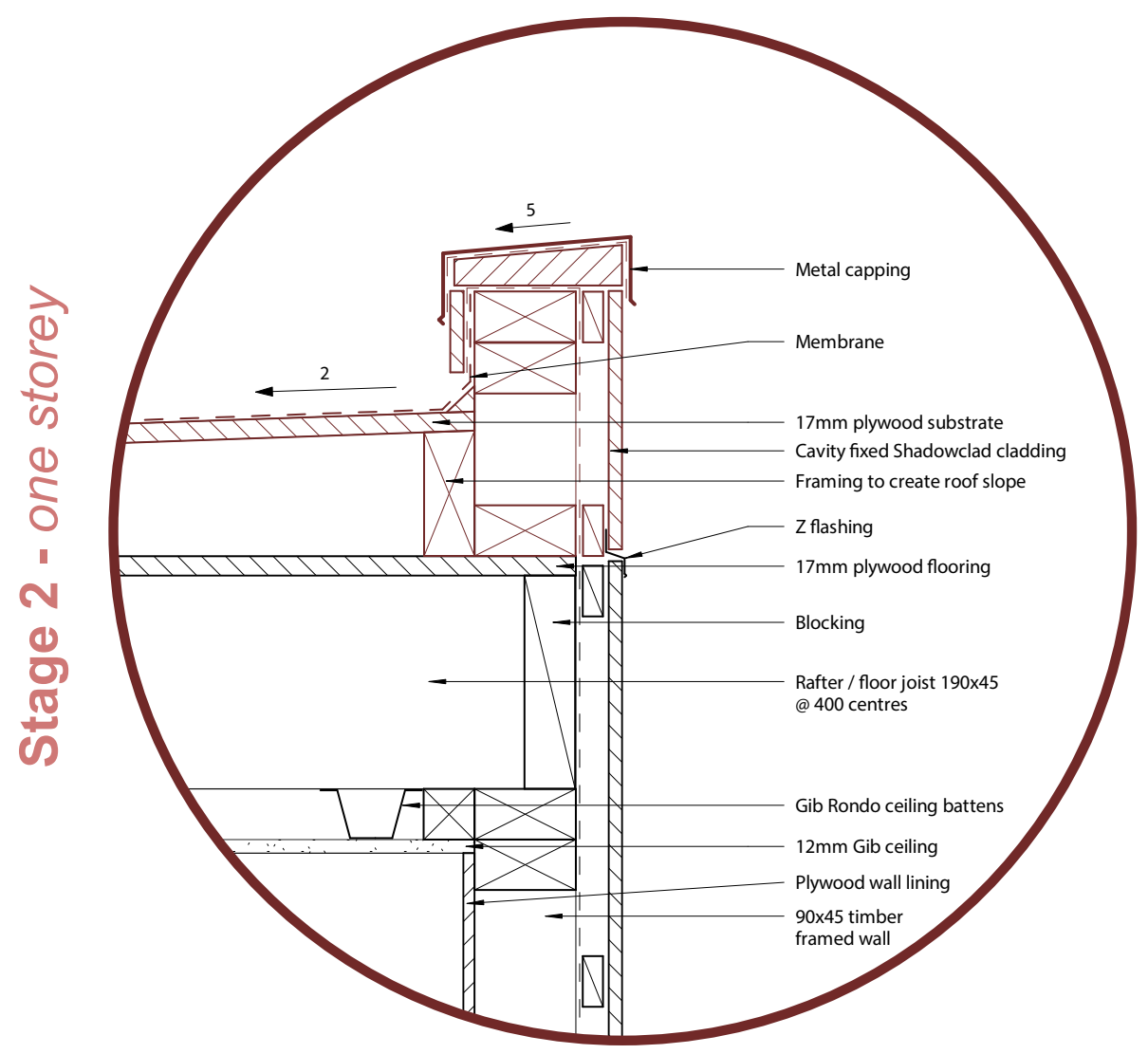

The existing roof and and parapet are removed and the second storey module sits directly on top of the existing rafters. A 'Z' flashing is utilised to allow the existing cladding to be easily removed and replaced.

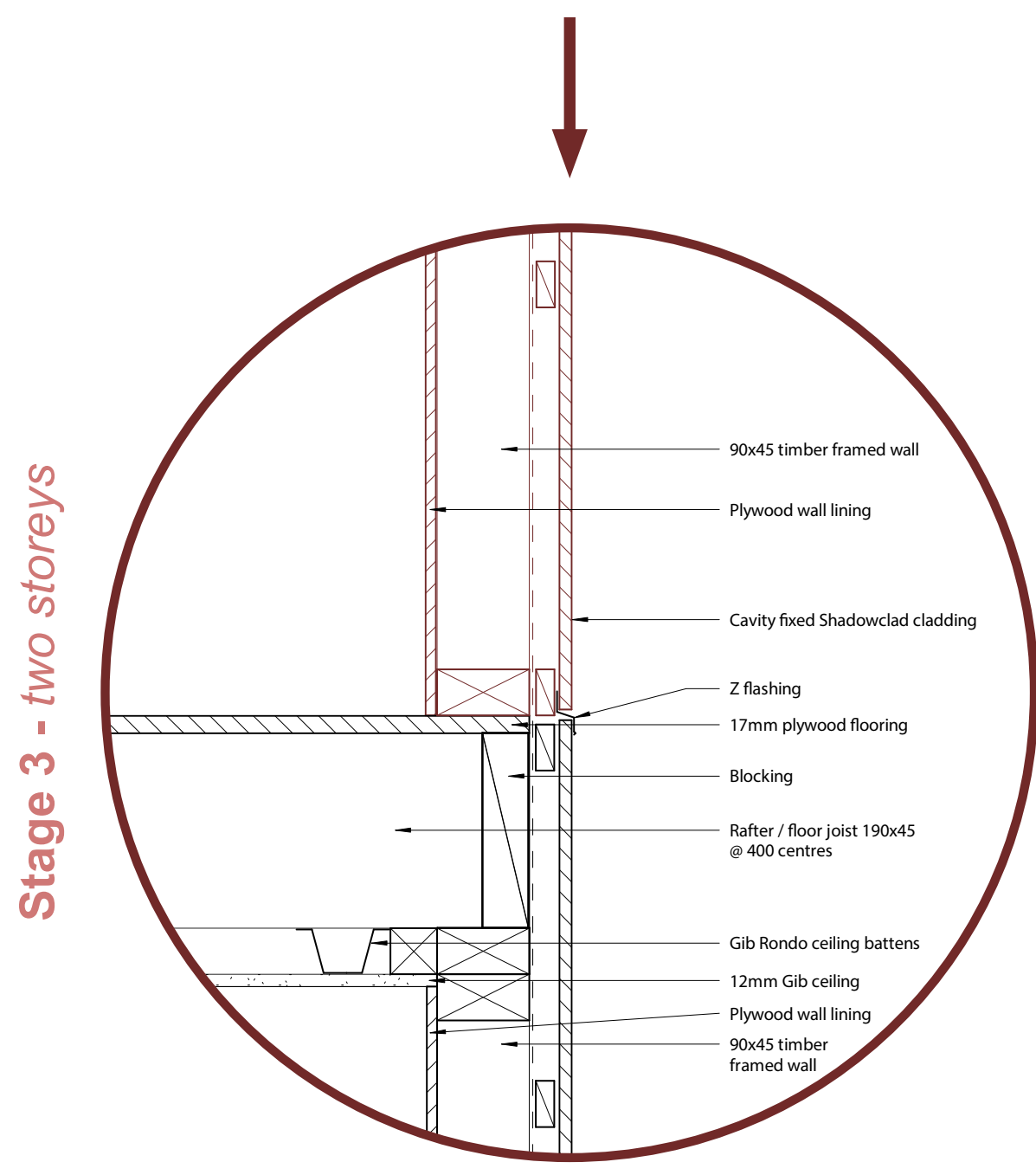

Rafters are over sized to later be used as the floor joists for the second storey. The roof slope is then formed separately on top of the rafters to later be removed to allow for the second storey module to be craned in place. 

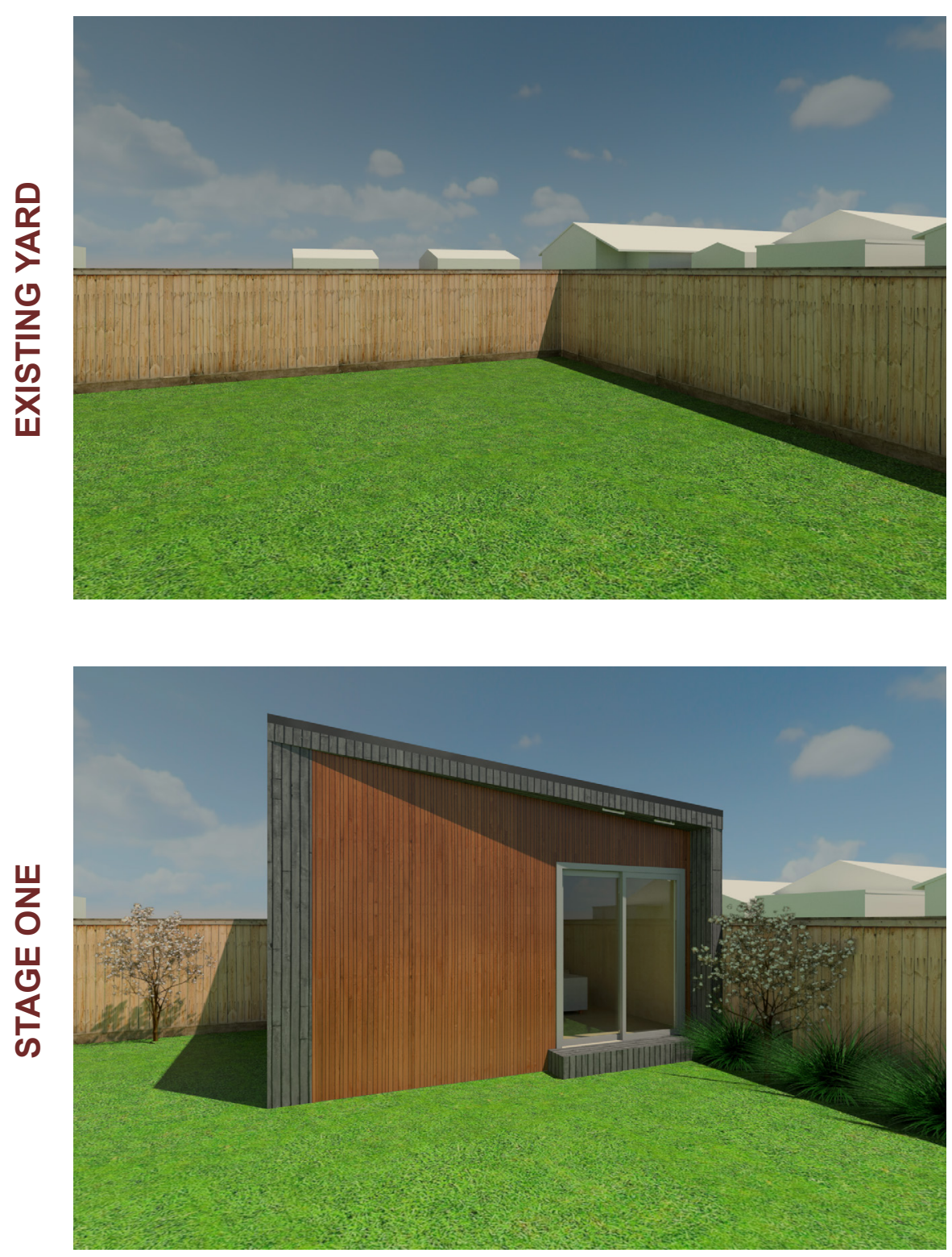

Initial ADU sited in the back corner of the yard taking minimal back yard space. Bedroom/ living space opens to the side of the site, minimising visual connection existing dwellings.

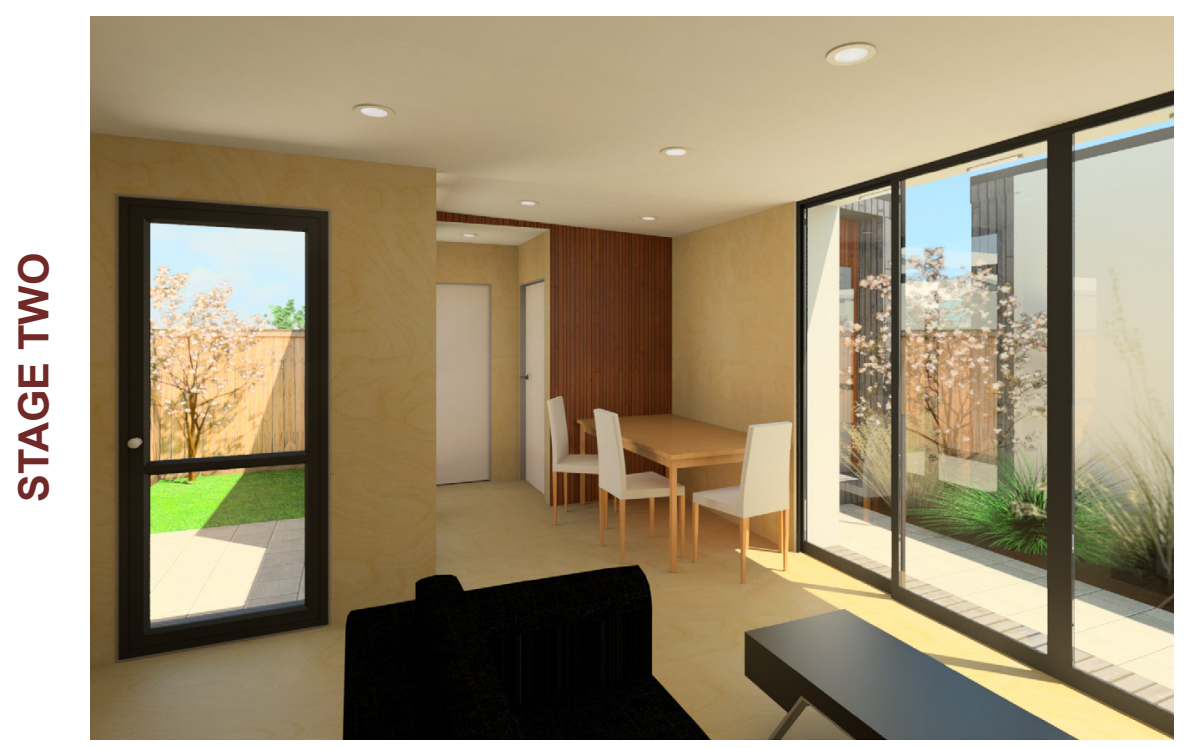

Stage 2 of the ADU encloses more of the back yard and wraps around the site to enclose private courtyards. Implementation of a neighbouring ADU further encloses the back courtyard. 


\section{Bathroom - phase 1}

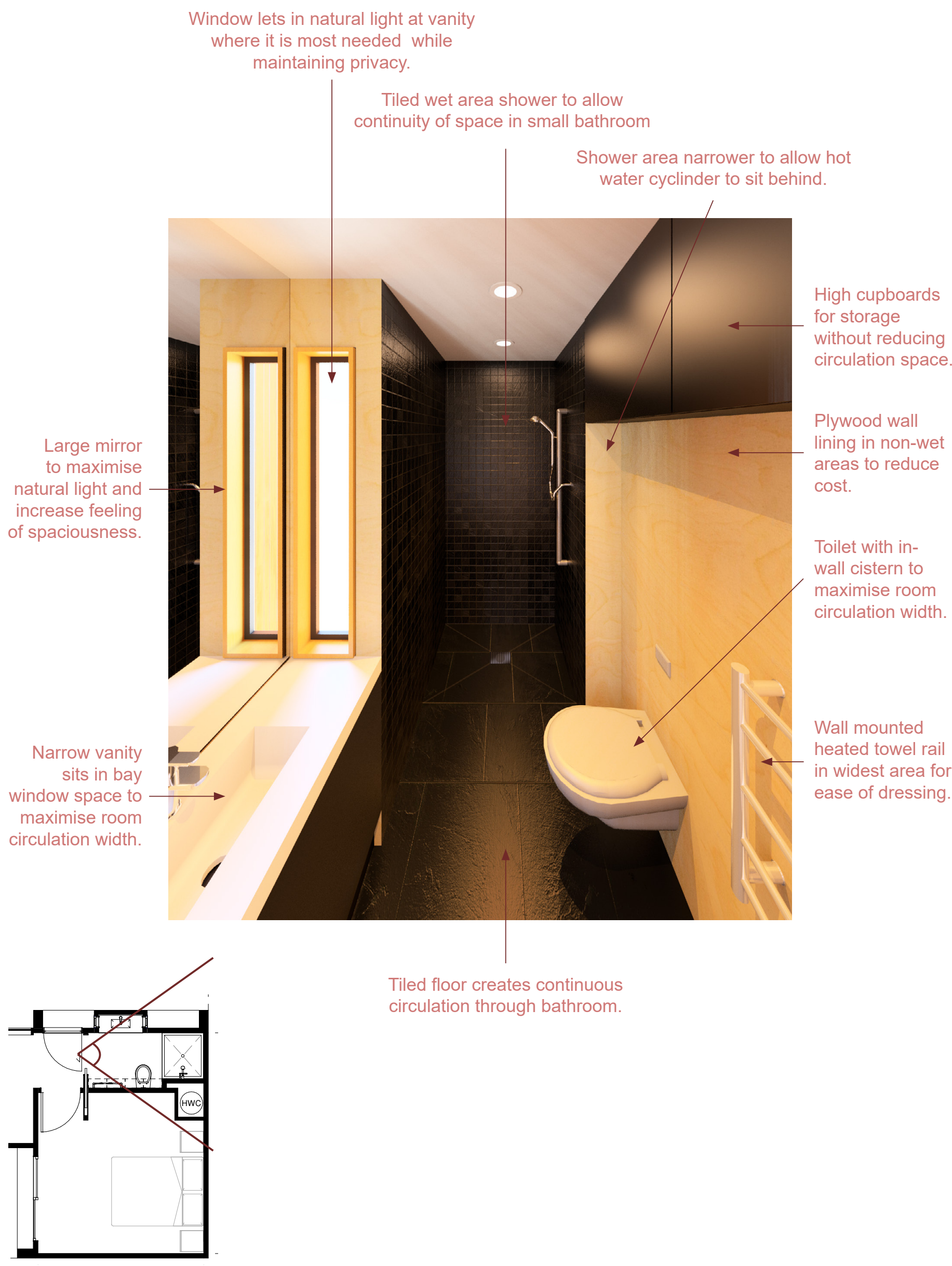


Kitchen / living transformation - phases 2-3
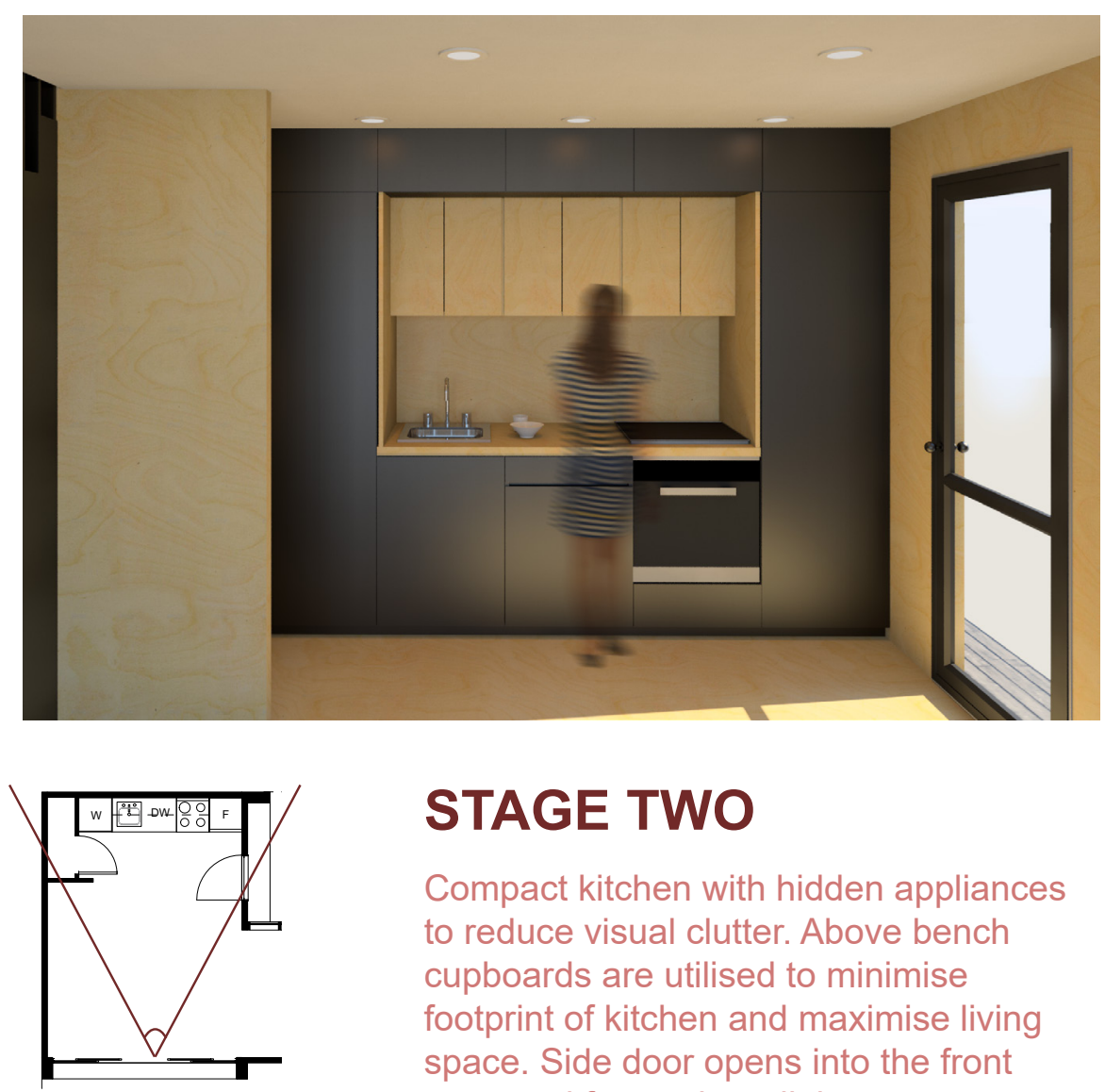

\section{STAGE TWO}

Compact kitchen with hidden appliances to reduce visual clutter. Above bench cupboards are utilised to minimise footprint of kitchen and maximise living space. Side door opens into the front courtyard for outdoor dining.
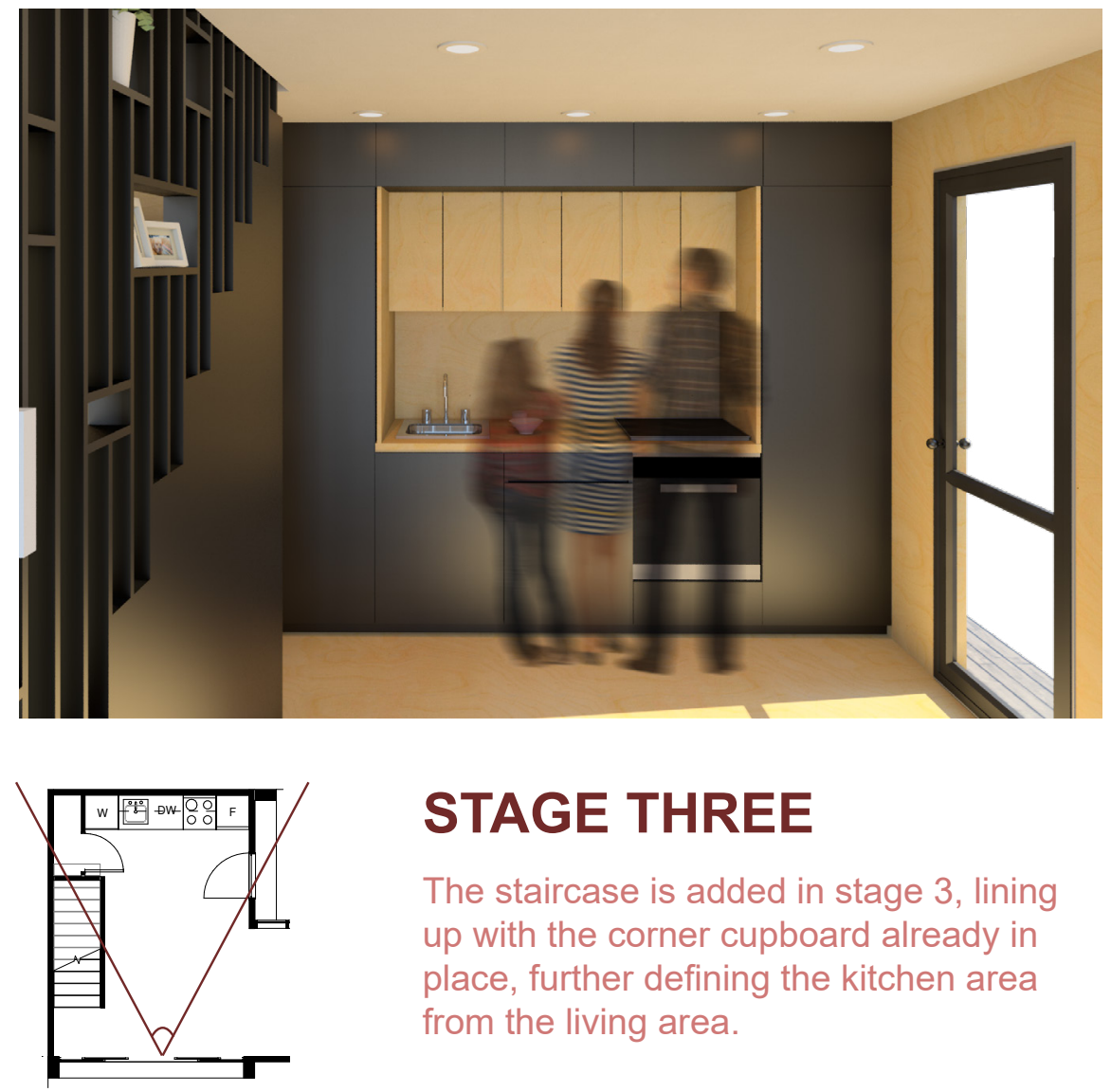

\section{STAGE THREE}

The staircase is added in stage 3 , lining up with the corner cupboard already in place, further defining the kitchen area from the living area. 
Interior transformation - phases 2-3
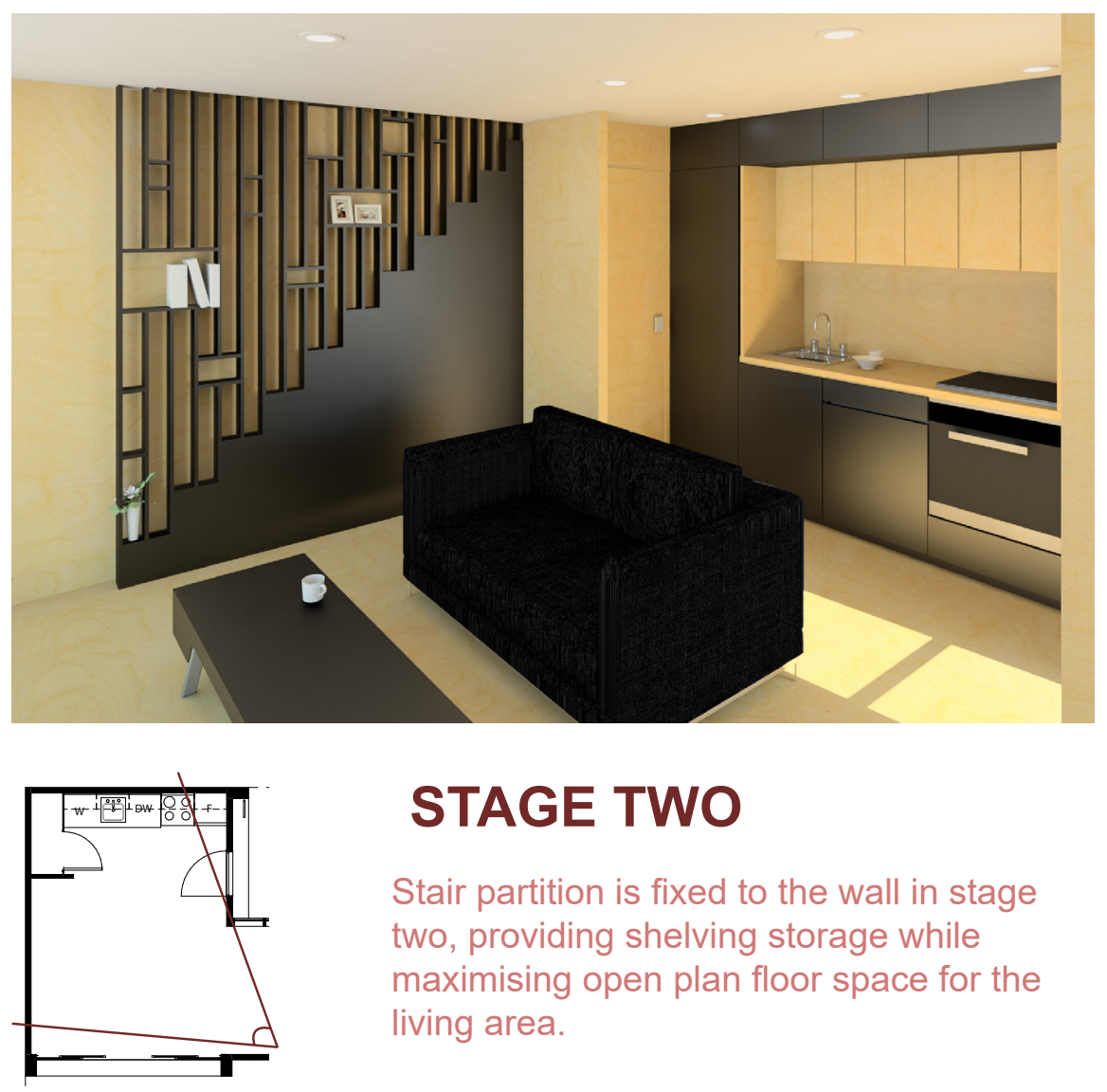

\section{STAGE TWO}

Stair partition is fixed to the wall in stage two, providing shelving storage while maximising open plan floor space for the living area.
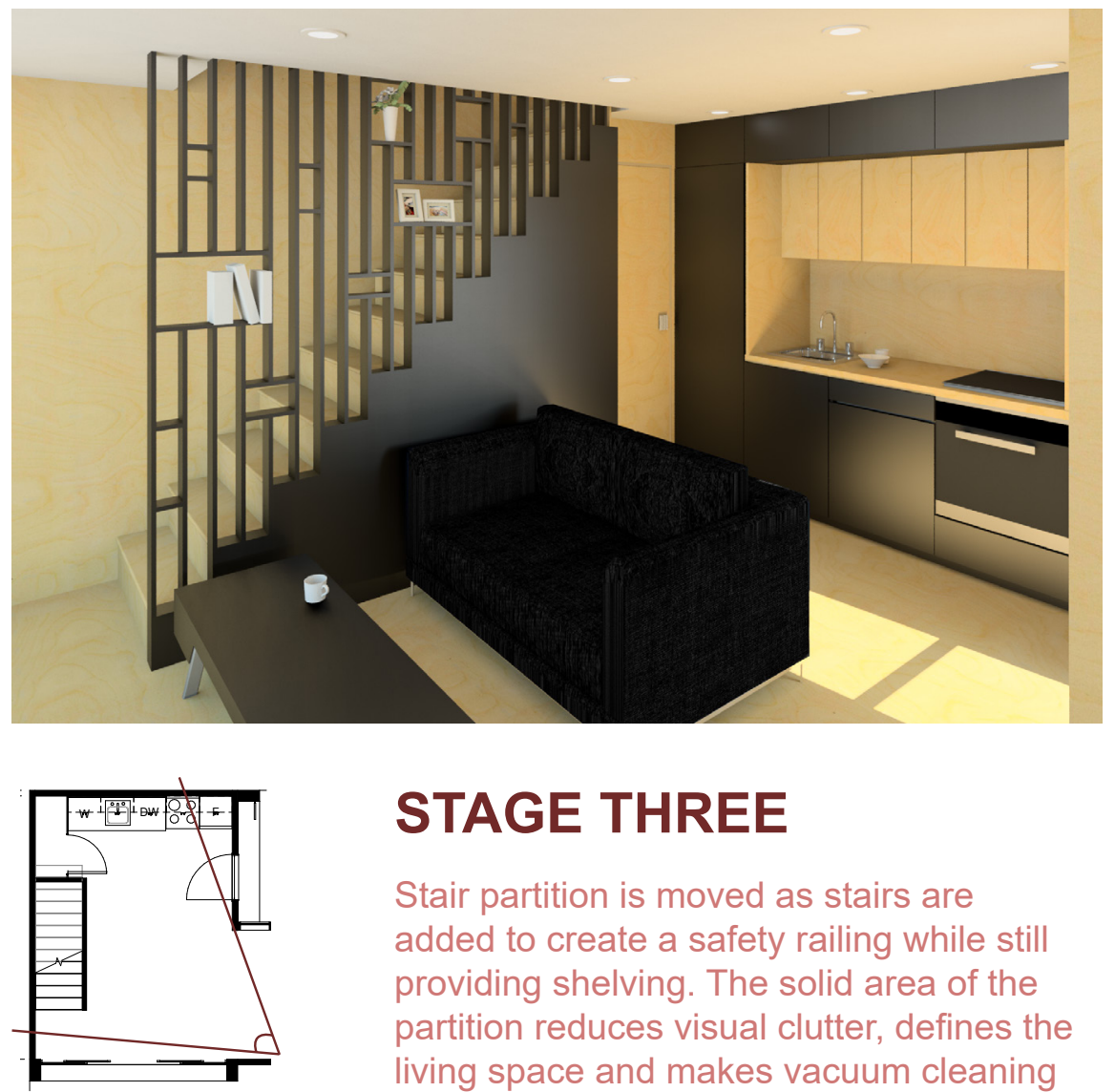

\section{STAGE THREE}

Stair partition is moved as stairs are added to create a safety railing while still providing shelving. The solid area of the partition reduces visual clutter, defines the living space and makes vacuum cleaning easier. 
CHAPTER 7:

CONCLUSION 


\section{CONCLUSION}

\section{AIMS AND OBJECTIVES}

The research has met the aim to address housing shortages and suburban sprawl through the development of a proposal for back yard ADUs in Kilbirnie, Wellington that increase the utilisation of existing residential sites in the suburb. These ADUs work around the existing dwellings, fitting within the boundaries of existing residential sites, increasing density without the need for demolition and redevelopment. Additionally, the research has met the aim of developing this as an incremental strategy, with the final design proposal demonstrating how the ADUs can be added to back yards within the suburb gradually over time, each able to expand incrementally in three phases. More specifically, these aims have been addressed by meeting the following objectives.

\section{Objective 1: To determine appropriate incremental growth strategies for ADUs within the Wellington suburban context}

A review of incremental dwelling precedents and initial concept explorations based on the various strategies identified demonstrated that a modular, additive approach to incremental growth is the most appropriate for the aims of this research. This was due to the ability to start with a small initial dwelling with minimal impact on site, reducing initial cost and creating slower paced change within suburbs.

The modular strategy was then refined further, determining through literature review and construction explorations that a combined approach of standard modules and custom connections was the most effective. This type of prefabricated modular strategy was found to provide the best construction efficiencies and cost, while also allowing for variation between different dwellings on different sites.

This strategy was then later applied to the final incremental dwelling proposal, allowing the dwelling to be constructed of standard sized $3.6 \times 4.8$ m modules. This allowed the dwelling to be built in three distinct phases as additional modules could be craned onto site to expand the building over time. A custom connection space was also developed to allow these standard modules to react and fit within different site shapes and sizes.

\section{Objective 2: To identify suitable sites in Wellington for sustainable densification through the implementation of ADUs}

Kilbirnie was identified as a suitable case study suburb for sustainable densification through the implementation of ADUs as it met a range of criteria identified within the literature. This included existing public transport infrastructure, a mix of uses in walking distance and the ability to become an economic engine and destination. Additionally, Kilbirnie was found to be more suited to densification through the use of ADUs, rather than more comprehensive redevelopment, due to the small scale of land parcels available, making it difficult for developers to acquire enough land to receive any substantial profit margin.

Analysis of available underutilised land within Kilbirnie found that front and back yard sites were the most suitable, in terms of size and shape, for siting ADUs. Massing, planning and daylight studies for dwellings on these sites further tested their suitability, finding that back yard sites were the most promising to provide sites for liveable dwellings that met user preferences. Daylight studies also identified that East-West running sites were far more successful than North-South running sites due to a minimisation of overshadowing on neighbouring sites.

\section{Objective 3: To develop ADU designs that meet current preferences and priorities for housing in New Zealand}

Based on recent surveys of New Zealanders, as well as additional supporting literature, privacy, outdoor space and sunlight access were identified as the three most important considerations for dwellings to meet current housing preferences. Access to sunlight was found to be most important, ranked highly by New Zealanders for its ability to provide natural light, as well as passively heat dwellings. Privacy and outdoor 
space were also considered high priorities within multiple studies, showing New Zealanders to have prevailing aspirations to live in stand-alone housing with private outdoor space.

Massing studies were then undertaken using these identified preferences and priorities to test the success of different concepts and to select and further develop the most promising options. This process allowed the overall form of the final ADU design to be developed to create a dwelling that balanced privacy and daylight access, while also incorporating private outdoor space. The relationship between neighbouring ADUs, back yards and existing dwellings was of key consideration in this development due to the close proximity of dwellings having significant impact on privacy and sunlight access. Further development of the dwelling also worked to meet current preferences, balancing the priorities of sunlight access and privacy through the careful design of windows.

\section{Objective 4: To develop spatial strategies for the ADUs to be incrementally built and expanded to densify Wellington suburbs gradually}

The final design development of the ADUs allowed for the incorporation of the earlier construction, site and massing findings into a coherent spatial strategy. The final design utilised the modular, incremental growth strategies found to be most appropriate to create a spatial strategy to achieve the most successful massing concept in three distinct and liveable dwelling phases. Phase one created a dependent bedroom and bathroom space to add to the existing dwelling; phase two added and kitchen and living space to allow the ADU to become an independent dwelling; and phase three added an additional storey to allow for an additional bedroom.

At the urban scale the strategy of adding ADUs to back yard sites allows the density of the suburb to increase incrementally over time to a maximum of double the initial density. Within the case study block this could allow the initial density of $31.5 \mathrm{du} / \mathrm{ha}$ to increase to $63 \mathrm{du} / \mathrm{ha}$, as existing dwelling owners decide to add ADUs to their properties for family members or for additional income.

\section{FURTHER RESEARCH}

\section{Application to different sites}

Although it became necessary in the development process to move from a general approach to a site responsive approach, the research would benefit from testing of the design concepts across further sites and in other suburbs.

Testing the ADU concept on sites within other Wellington suburbs would give insight into the aspects of the design that are effective only in Kilbirnie, as well as the aspects of the design that may be effective anywhere. This could lead to the development of more general design principles for densification through the addition of ADUs, rather than a single architectural response. For example, the finding that East-West sites are more successful for siting ADUs than North-South sites is likely to be applicable to all suburbs. Alternatively, the module size developed for sites in Kilbirnie may not be widely appropriate, depending on the suburb's existing density or site shapes.

Similarly, site topography could be further explored. Steep sites in Kilbirnie were deemed less suitable than flat sites due to their poor access, meaning the developed design phase focused on a response to the flat sites. The connection element between the modules could be developed to connect standard modules on various site slopes. Exploration of this may give further insight into site parameters that allow for densification through the addition of ADUs, such as maximum slope.

\section{Site access}

Access to ADUs on back yard sites could be further explored, addressing this aspect of the design from multiple perspectives.

Most importantly would be from a fire safety perspective, to determine whether side yard access provides sufficient escape routes, or how these could be modified to do so. Additionally, access in terms of construction 
would be important to consider further, to determine in more detail how the modules could be craned onto site and implications of this in terms of cost and site disturbance. This analysis may further refine the site selection process, potentially reducing the number of suitable sites, or increase the cost of construction on some sites.

Finally, this access may be considered from a social perspective, looking into the possible interactions or disturbances that may arise from occupants of the ADU using a portion of the existing dwelling's land to access their dwelling. This could lead to the design of communal spaces, or alternatively the need to design for separation of space to further define the domains of each distinct dwelling. This may be most appropriately explored in the realm of landscape architecture. 


\section{Availability and Deposit of Thesis Form - Open Research Archive}

\begin{tabular}{|c|c|}
\hline Author's Name & Tegan Wardle \\
\hline Thesis Title & $\begin{array}{l}\text { URBAN COMPRESSION: Incremental Strategies for Achieving } \\
\text { Suburban Densification }\end{array}$ \\
\hline Degree Name & MARCHP - Master of Architecture (Prof) \\
\hline Discipline & Architecture \\
\hline School & School of Architecture \\
\hline Supervisor(s) & Guy Marriage \\
\hline Year & 2019 \\
\hline Keywords (3) & Architecture, housing, incremental \\
\hline Research Code & 120101 Architectural Design \\
\hline $\begin{array}{l}\text { Availability } \\
\text { Statement }\end{array}$ & $\begin{array}{l}\text { I hereby consent to the above thesis being consulted, borrowed, copied or } \\
\text { reproduced in accordance with the provisions of the Library Regulations from } \\
\text { time to time made by the Academic Board. }\end{array}$ \\
\hline Signature & Tegan Wouther \\
\hline Date & $21 / 09 / 19$ \\
\hline Deposit Declaration & 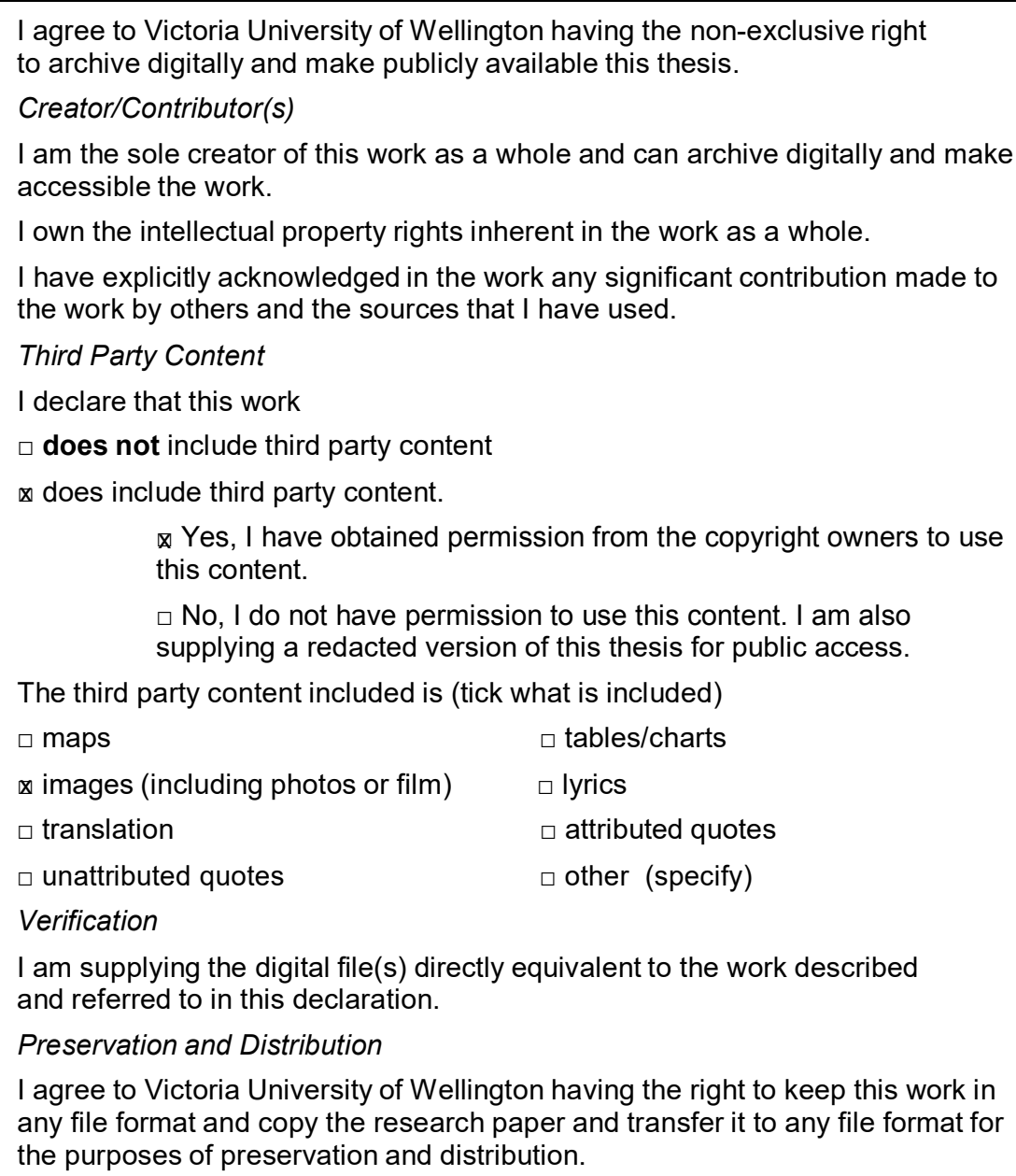 \\
\hline Signature & Tegm Wouthe \\
\hline Date & $21 / 09 / 19$ \\
\hline
\end{tabular}


